\title{
Andreone Teles Medrado
}

\section{AN AtLAS OF the CATFISH BRAIN}

Steindachneridion parahybae

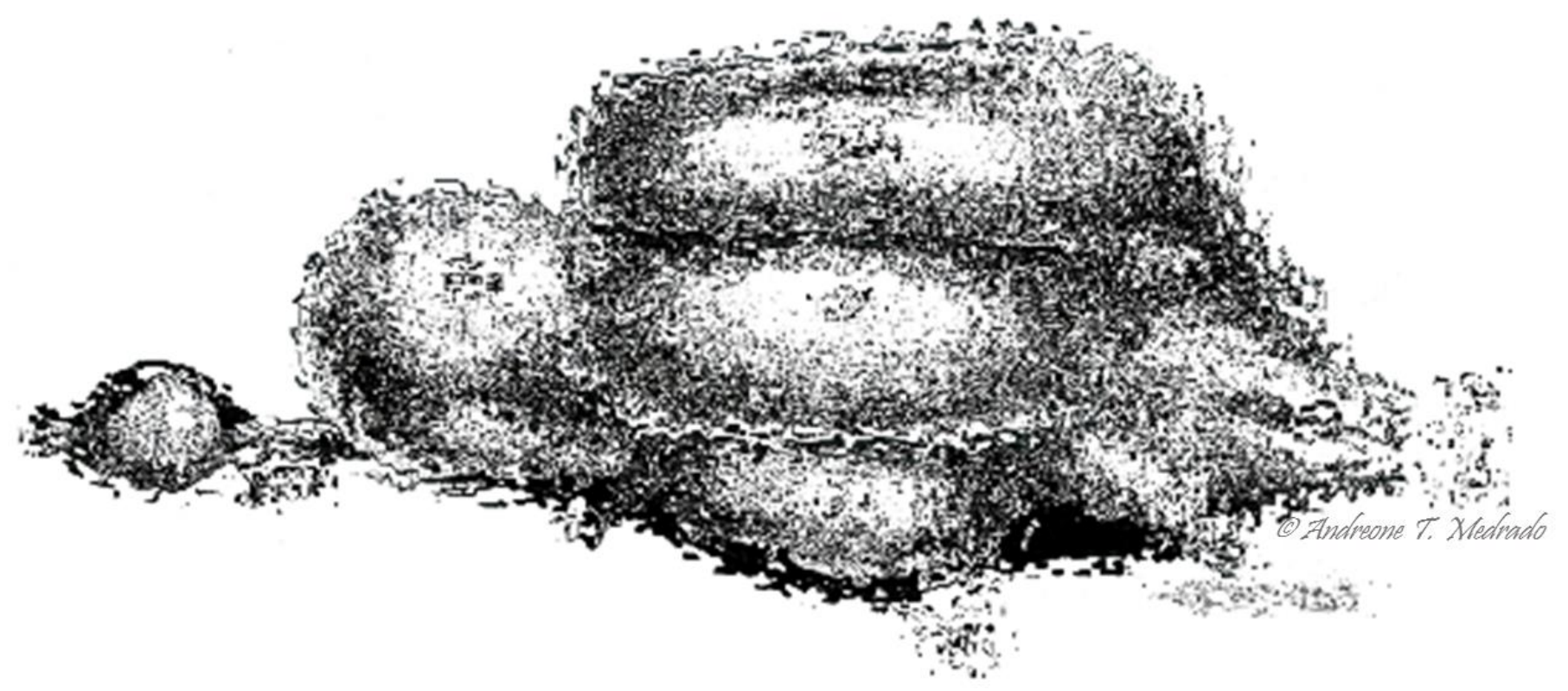

A detailed cytoarchitectonic study of the different brain areas and nuclei as a basis for further morphological and functional studies

Instituto de Biociências da Universidade de São Paulo 2015 


\section{Andreone Teles Medrado}

Um Atlas do encéfalo do catfish - Steindachneridion parahybae (TELEOSTEI: SILURIFORMES): um estudo citoarquitetônico detalhado das diferentes áreas e núcleos do cérebro, como base para futuros estudos morfológicos e funcionais

An Atlas of catfish brain - Steindachneridion parahybae (TELEOSTEI: SILURIFORMES): a detailed cytoarchitectonic study of the different brain areas and nuclei as a basis for further morphological and functional studies

\section{VERSÃo CORRIGIIDA}

$O$ original encontra-se disponível no Instituto de Biociências da Universidade de São Paulo

São Paulo 



\section{Andreone Teles Medrado}

Um Atlas do encéfalo do catfish - Steindachneridion parahybae (TELEOSTEI: SILURIFORMES): um estudo citoarquitetônico detalhado das diferentes áreas e núcleos do cérebro, como base para futuros estudos morfológicos e funcionais

An Atlas of catfish brain - Steindachneridion parahybae (TELEOSTEI: SILURIFORMES): a detailed cytoarchitectonic study of the different brain areas and nuclei as a basis for further morphological and functional studies

Dissertação apresentada ao Instituto de Biociências da Universidade de São Paulo, para obtenção do Título de Mestre em Ciências, na Área de Fisiologia Geral.

Dissertation Advisor: Dra. Renata Guimarães Moreira Whitton

Dissertation Collaborator: Dr. José Antonio Muñoz-Cueto

São Paulo 


\section{Cataloguing Data}

MEDRADO, Andreone Teles (MEDRADO, A. T.) - 2015.

An Atlas of catfish brain - Steindachneridion parahybae (TELEOSTEI: SILURIFORMES): a detailed cytoarchitectonic study of the different brain areas and nuclei as a basis for further morphological and functional studies. 210p.

Master's Dissertation - Instituto de Biociências da Universidade de São Paulo (IB/USP). Universidade de São Paulo.

1. Brain; 2. Neurons; 3. Central Nervous System; 4. Neuroanatomy; 5. Neuroendocrinology; 6. Histology; 7. Physiology; 8. Immunohistochemistry; 9. Steindachneridion parahybae.

I. Universidade de São Paulo. Instituto de Biociências. Departamento de Fisiologia.

\section{JUdding Committee}

Prof. Dr. Mari Inês Borella

Prof. Dr. André Frazão Helene

Professor Dr. Renata Guimarães Moreira Whitton ADVISOR 


\section{DEDICATÓRIA}

Dedico este Atlas a todos que estudam neuroanatomia de peixes, bem como aqueles(as) que estudam a neuroanatomia comparativa. Desejo que este trabalho sirva como ferramenta de estudos, assim como muitos outros estudos anteriores serviram para que este fosse feito.

(Andreone Teles Medrado) 


\section{Epígrafe}

\section{O Amanhã em Três Palavras}

O Destino é apenas uma palavra que representa aquilo já escrito nas entrelinhas da vida, mas que não se consegue ler. O Futuro é apenas uma palavra que suprime a obrigação de se fazer tudo hoje, supondo que haja tempo e tempos. A Ansiedade, por sua vez, não existe; o que existe é a inquietação de fazer o amanhã chegar hoje, e se fazer de hoje o passado. Nem sempre de forma clara, todavia infalivelmente, o que estas palavras têm em comum é o simples fato de colocar nas mãos de seus possuidores o achismo do direito da transformação. Quando na verdade, sem saber, se transforma em incerto o chamado destino, querendo mudar o intitulado futuro, enquanto esse é devorado pela própria inquietude. Sofrese então, por não se desapegar daquilo que ao menos se possui-o amanhã. 


\section{EPÍGRAFE}

AYER POR LA TARDE MURIÓ OBLOMOV, nuestro último pez rojo. Lo intuí hace varios días en los que apenas lo vi moverse dentro de su pecera redonda. Tampoco saltaba como antes para recibir la comida o para perseguir los rayos del sol que alegraban su hábitat. Parecía víctima de una depresión o el equivalente en su vida de pez en su cautiverio. Llegué a saber muy pocas cosas acerca de este animal. Muy pocas veces me asomé al cristal de su pecera y o miré a los ojos y, cuando eso sucedió, no me quedé mucho tiempo. Me daba pena verlo ahí, solo, en su recipiente de vidrio. Dudo mucho que haya sido feliz. Eso fue lo que más tristeza me dio al verlo ayer por la tarde, flotando como un pétalo de amapola en la superficie de un estanque. Él, en cambio, tuvo más tiempo, más serenidad para observarnos a Vicent y a mí. Y estoy segura de que, a su manera, también sintió pena por nosotros. En general, se aprende mucho de los animales con los que convivimos, incluidos los peces. Son como un espejo que refleja emociones o comportamientos subterráneos que no nos atrevemos a ver.

(Fragment of "El Matrimonio de los peces rojos" - by 


\section{CONTENT}

PREFACE 013

ABSTRACT 017

GENERAL INTRODUCTION 019

CHAPTER I

An atlas of catfish brain - Steindachneridion parahybae (TELEOSTEI: SILURIFORMES): a detailed cytoarchitectonic study of the different brain areas and nuclei as a basis for further morphological and functional studies

ABSTRACT 031

INTRODUCTION 032

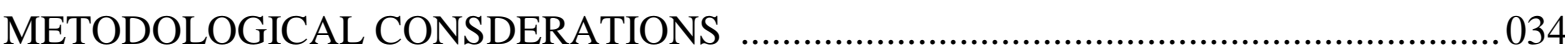

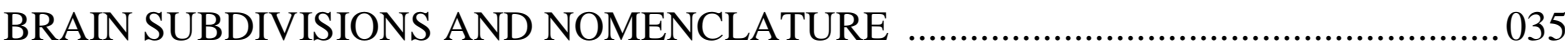

TABLE I - ORGANIZATION OF THE BRAINS AREAS OF CATFISH ……………..... 039

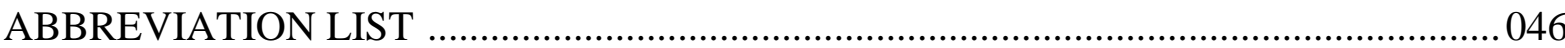

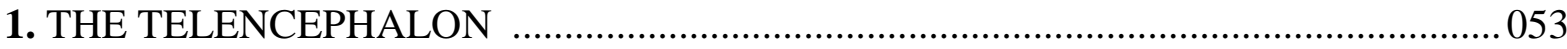

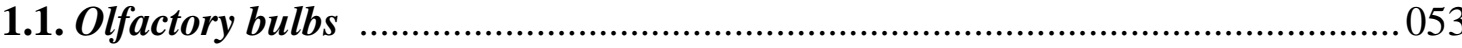

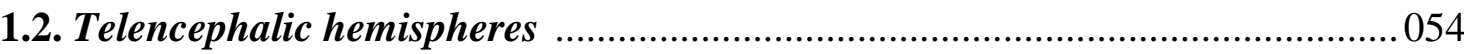

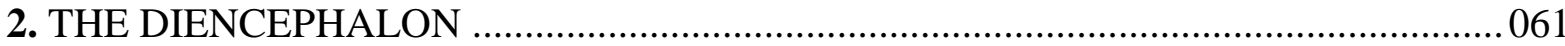

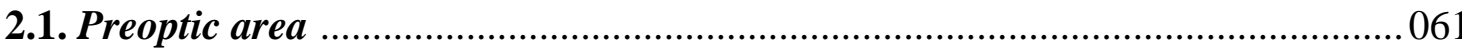

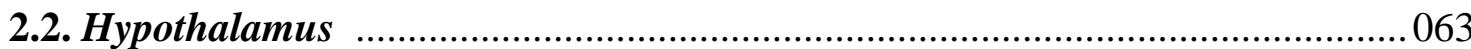

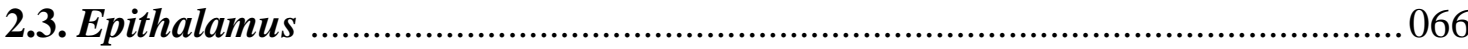

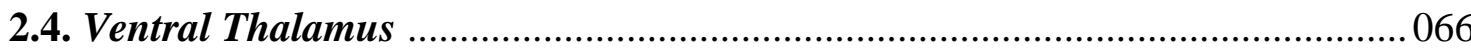

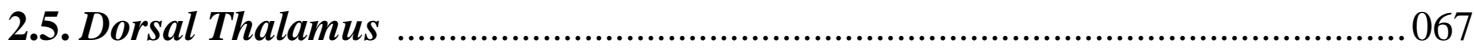

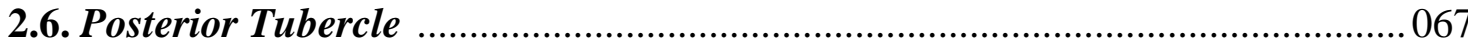

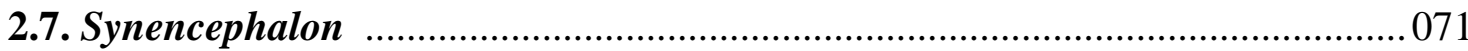

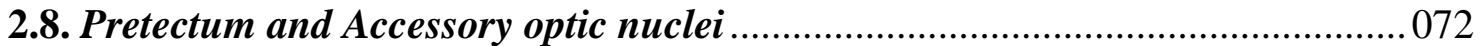




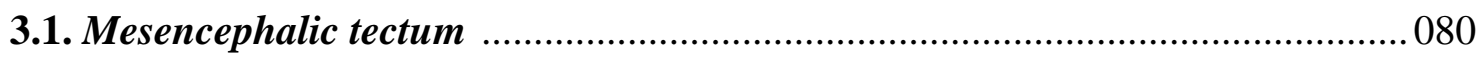

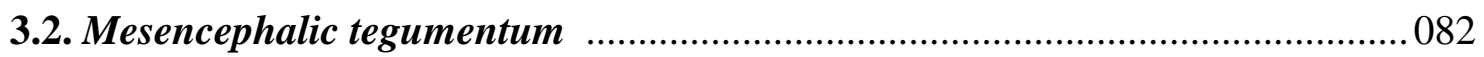

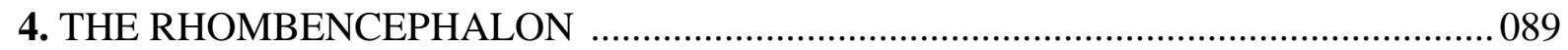

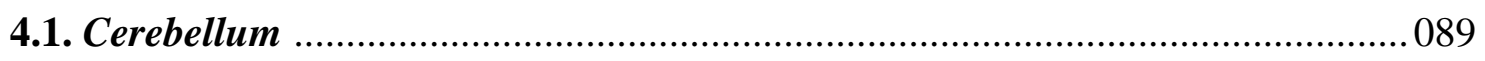

The rest of Rhombencephalon .................................................................................. 094

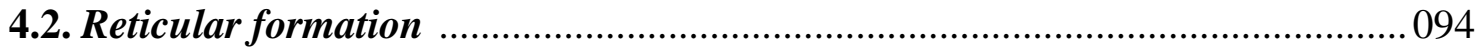

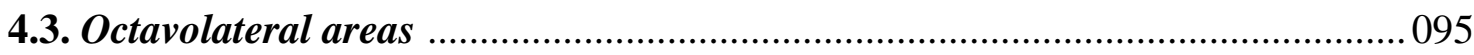

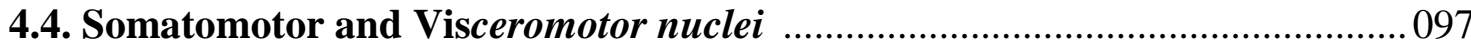

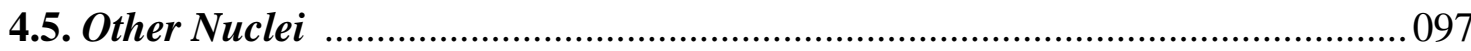

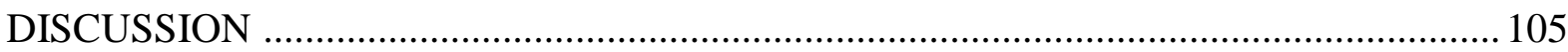

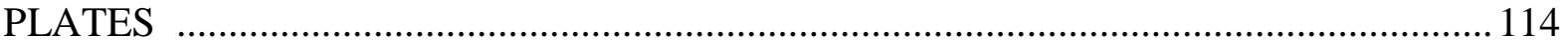

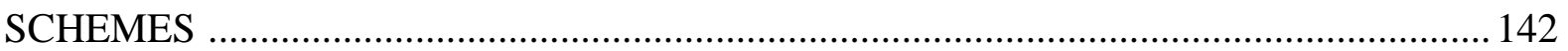

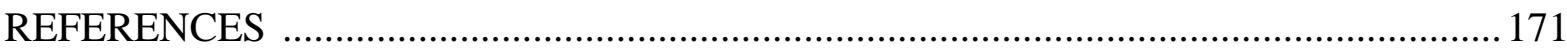

CHAPTER II ......................................................................................................... 181

First insights into the localization of GnRH-1 neurons in Steindachneridion parahybae juveniles

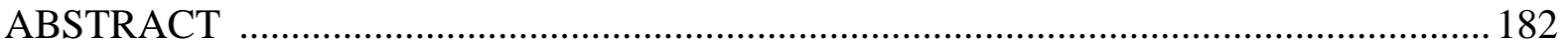

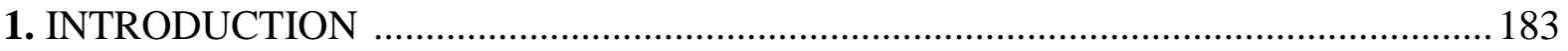

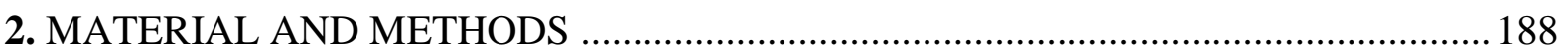

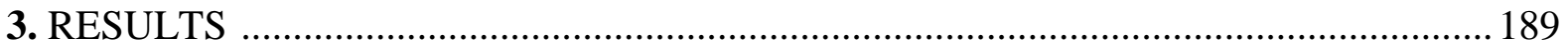

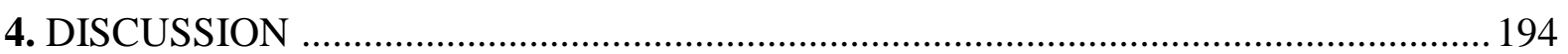

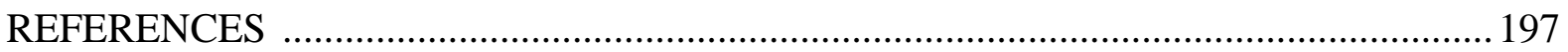

FINAL CONSIDERATIONS ............................................................................................... 201

ACKNOWLEDGMENTS .................................................................................................... 203 

Preface 
The present Master's Dissertation shows a layout that may be different of the commonly presented so far. It is due to the fact that the study conducted here is a complete Atlas of Brain of a fish. Generally, the main feature of a Brain Atlas is its complexity and the detailed description of different brain areas and nuclei, which is the case of the present study. Thus, the study performed was organized strategically in different chapters to provide a better illustration of the work developed. Moreover, in the presentation of the Atlas of catfish brain we have assumed the structure of traditional publications in this field, as observed for the last studies published. Besides, we have considered that could be useful to write it in English to make easy future publications of these data in an international scientific Journal, i.e. Journal of Morphology; Brain, Behavior and Evolution; Acta Histochemica, another.

Therefore, three main chapters for this Master's Dissertation have been adopted. Firstly, in the CHAPTER I, a detailed cytoarchitectonic analysis of the brain of the catfish Steindachneridion parahybae has been carried out. In this chapter we present a complete and detailed description of all encephalic areas and nuclei of the catfish, illustrated with several microphotographs and plates that combine images and schemes as a graphical complement in the description of all the brain cell masses. We have also presented several schemes that are not cited throughout this chapter, but serves as a practice tool for futures studies focused in the brain of catfish. Additionally, a discussion of the results obtained compared with that reported in other teleost fishes is 
presented for concluding this part. In the second section, the CHAPTER II, previous immunohistochemical analyses of GonadotropinReleasing Hormone 1 (GnRH-I) system in the brain of catfish are presented. These analyses were performed in a few animals due to the difficulty that we had for implementing this technique in juvenile catfish. Nonetheless, the Atlas of the catfish brain developed in the previous chapter was revealed as a valuable tool to approach the present study. An important illustration of this application is revealed in the last scheme used in the Chapter II, where the precise localization of the cfGAP-immunoreactive neurons and its projections is showed along the brain. The third, and last, chapter represents the concluding section of this Master's Dissertation, and is presented as FINAL CONSIDERATIONS, which serves to expose the main achievements reached in the present studies.

I would like to make special mention to the section "Acknowledgments". Firstly, this section is presented in Portuguese and Spanish, but not in English. It was made in this way to show my closeness and appreciation to people that in some cases do not speak English as a first language. Surprisingly, this section was gradually increasing in length and, for this reason, it has been placed in the last part of this Master's Dissertation. So, I (Medrado), kindly invite you to read this Acknowledgments section at the end of this Dissertation, specifically in the page 203. 
Images from Preface:

Both images represent coronal (transverse) sections (5 $\mu$ m-thick) of the catfish brain, stained with cresyl-violet. The first image represents the vagal lobe (above) and large neurons of the vagal nerve motor nucleus (below). The second image represents the granular cells associated to the medial auditory nucleus, medially (left) by the ependymal periventricular cells, and laterally (right) by fibers of the brachium conjunctivum. 
Esta Dissertação de Mestrado, apresenta-se estruturalmente como um Atlas, em que é apresentado um detalhado estudo citoarquitetônico do encéfalo de catfish - Steindachneridion parahybae. Para a realização deste, foram utilizados 7 juvenis de 100 dias após a eclosão, analisados por técnicas rotineiras de histologia, cujas secções coronais (transversais) - $5 \mu \mathrm{m}$ de espessura - foram obtidas utilizando-se de um micrótomo rotativo, coradas com violeta de cresil e examinadas a partir de sistema digital de análise. Alguns critérios foram utilizados para classificar as diferentes massas de células do cérebro catfish, tais como: (i) o tamanho característico, forma e intensidade da coloração do corpo celular do neurônio; (ii) padrão de densidade de agrupamento e distribuição dos corpos celulares; (iii) a presença de neurópilos ao redor dos desses agrupamentos celulares e (iv) a consistência/coerência destes agrupamentos em ambos os hemisférios dos diferentes encéfalos, então analisados. Dessa forma, são descritas aproximadamente 130 massas celulares para o encéfalo de S. parahybae, as quais estão distribuídas em quatro principais regiões que, da parte rostral para caudal, são: telencéfalo, diencéfalo, mesencéfalo e rombencéfalo. Embora sejam observadas semelhanças entre o encéfalo de $S$. parahybae e de outros teleósteos, nota-se, também, certas diferenças quanto às características e/ou localização das massas celulares em relação ao encéfalo de outros teleósteos, ou mesmo quando comparado com espécies da mesma Ordem, Siluriformes. Algumas destas diferenças podem estar relacionadas com a idade dos animais estudados, no entanto, também podem representar diferenças espécie-específicas, uma vez que o encéfalo de indivíduos adultos de $S$. parahybae apresentam grande similaridade citoarquitetônica, além da organização geral do encéfalo, previamente observadas em animais acima dos 100 dias após a eclosão. Portanto, como resultado deste estudo tem-se a disponibilidade de um Atlas completo do encéfalo de $S$. parahybae, o qual representa uma ferramenta valiosa para o estudo das conexões neurais entre diferentes áreas do encéfalo, bem como para futuras análises endócrinas, permitindo o mapeamento preciso de neuro-hormônios nesta espécie, como demonstrado ao longo deste estudo, para o hormônio liberador de gonadotropinas. 
Palavras-chave: Encéfalo, Neurônios, Sistema Nervoso Central, Neuroanatomia, Neuroendocrinologia, Histologia, Fisiologia, Imuno-histoquímica, Steindachneridion parahybae.

GENERAL ABSTRACT

In the present Master's Dissertation, a detailed cytoarchtectonic study of the brain of the juvenile catfish - Steindachneridion parahybae, has been performed. The animals used for this Atlas were juvenile specimens of one hundred days post-fertilization. The coronal (transverse) sections (5 $\mu$ m-thick) were obtained by using a rotary microtome, stained with cresyl-violet and examined under a photomicroscopy with the help of a digital system of analysis. Some criteria have been used to classify the different cell masses of the catfish brain: (i) characteristic size, shape and intensity of the staining from the perykarya; (ii) packing density and distribution pattern of the cell bodies; (iii) neuropil surrounding the cell groups and (iv) consistency of cell groups in both hemispheres and different brains of catfish. Thus, around one hundred and thirty nuclei have been described in the catfish brain, which are distributed in four main region that are from rostral to caudal: telencephalon, diencephalon, mesencephalon and rhombencephalon. Although we have observed important similarities between the brain of catfish and other teleosts, we have also noticed some differences in the characteristics and placement of several nuclei in relation to other teleosts, or even when compared to the brain of species of the same Order, the Siluriformes. Some of these differences could be related with the age of the animals studied here, but probably represent species-specific differences because the brain of adult catfish specimens has a great similarity in cytoarchitecture and overall organization compared to younger animals. The main outcome of this study has been the availability of a complete Atlas of the brain of catfish, which has been used to localize precisely the distribution of cells and fibers of the Gonadotropin-releasing hormone in the brain. This Atlas will also represent a valuable tool for future endocrine analyses, allowing the precise mapping of the different neurohormones in the brain of catfish, as well as for the study of neural connections among different brain areas.

Key-words: Brain, Neurons, Central Nervous System, Neuroanatomy, Neuroendocrinology, Histology, Physiology, Immunohistochemistry, Steindachneridion parahybae. 


\section{GENERAL}

INTRODUCTION 


\section{ATLAS OF THE BRAIN, A TOOL FOR THE STUDY OF THE NEUROENDOCRINOLOGY OF FISHES}

As for any class of vertebrates, the development of neuroendocrinology in fish has been tightly dependent on anatomo-functional studies aiming at identifying brain regions potentially implicated in neuroendocrine regulation of pituitary functions and at tracing the neuronal systems participating in those regulations. For a given species, such studies require the availability of an atlas of the brain of this particular or a closely related species. The best example of this requirement is illustrated by the tremendous impact that the publication of the atlas of the goldfish brain by Peter and Gill (1975) had on fish neuroendocrinology.

Teleosts represent the largest group of vertebrates with over 25.000 species, 58 orders and 468 families (Nelson, 2006), with a long evolutionary history and a dramatic diversity. Although the overall pattern of organization of the brain is similar in all fish, there is a considerable variation in the topology of many brain regions from one species to another and the amplitude of this variation increases with the evolutionary distance separating these species. Thus, a complete brain atlas for the electric fish Apteronotus leptorhynchus (Gymnotiformes) (Maler et al., 1991), a recently developed atlas for the zebrafish (Wullimann et al., 1996) and a number of brain partial atlases have already been published in the goldfish, Carassius auratus (Cypriniformes) (Peter \& Gill, 1975), the killifish, Fundulus heteroclitus (Cyprinodontiformes) (Peter et al., 1975), and two salmonids, the rainbow trout, Oncorhynchus mykiss (Billard \& Peter, 1982) and the Atlantic salmon, Salmo salar (Peter et al., 1991).

\section{THE GONADOTROPIN-RELEASING HORMONE IN FISHES: BRIEF HISTORIC AND DISTRIBUTION IN THE BRAIN}

The existence of vascular contact between the hypothalamus and the pituitary was demonstrated in the 1930's, but it was not until the 1940's and 1950's that Geoffrey Harris, one of the pioneers of neuroendocrinology, began to consolidate the concept of neurohormonal regulation of adenohypophysary functions. This concept was at first in conflict with the existing lines of research, whereby it was held that neurons only communicated with each other by means of electrical signals, and that the anterior lobe of the adenohypophysis of mammals was not innervated. The experiments of Geoffrey Harris 
provided a confirmation that sectioning the pituitary stalk interrupted ovarian cyclicity in the rat, and that the restitution of the hypothalamus-hypophysary portal system restored this cyclicity. These studies opened the way to the discovery of the brain factors that are transported by this vascular system to the pituitary to regulate the secretion of gonadotropins and development of the gonads (Donovan \& Harris, 1954). Then the 1970's saw the discovery by the research groups of Dr. Roger Guillemin (France) and Dr. Andrew Schally (United States) of a decapeptide of the mammalian hypothalamus that was called LH-RH (Luteinizing-Hormone Releasing Hormone) because of its capacity to stimulate the secretion of luteinizing hormone (Burgus et al., 1971; Matsuo et al., 1971). Subsequently it was observed that it was also capable of stimulating the secretion of follicle-stimulating hormone (FSH), and for this reason it was given its generic name: gonadotropin-releasing hormone or GnRH.

But in reality, GnRH is a family of peptides with a multiplicity of isoforms ( 24 different isoforms) that are present in vertebrates, protochordates and invertebrates (Matsuo et al., 1971; King \& Millar, 1982a; King \& Millar, 1982b; Sherwood et al., 1983; Ngamvongchon et al., 1992; Lovejoy et al., 1992; Sower et al., 1993; Powell et al., 1994; Powell et al., 1996a; Powell et al., 1996b; Jimenez-Liñan et al., 1997; Carolsfeld et al., 2000; Okubo et al., 2000; Yoo et al., 2000; Zhang et al., 2000; Montaner et al., 2001; Iwakoshi et al., 2002; Adams et al., 2002). These forms of GnRH have traditionally received the name of the species in which they were discovered for the first time, although they can be present in other different species. Within the vertebrates, teleosts represent the phylogenetic group that expresses the largest number of variants of $\mathrm{GnRH}$.

Regarding the distribution of the GnRH cells, its basic pattern in teleost fishes suggested the existence of two principal systems: one GnRH system distributed along the ventral portion of the forebrain (terminal nerve, ventral telencephalon, preoptic area and hypothalamus), that expresses different forms of GnRH according to the species; and another GnRH system in the transition between the diencephalon and the mesencephalon (synencephalon), that expresses GnRH-2 in a conserved form (Goos et al., 1985; Kah et al., 1986; Batten et al., 1990; Kah et al., 1991; Rodríguez-Gómez et al., 1999; Kah et al., 2007). Subsequently, studies conducted in species of perciforms demonstrated that these evolved teleosts express three different forms of GnRH in the brain: sGnRH (GnRH-3), sbGnRH (GnRH-1) and cGnRH-II (GnRH-2) (Powell et al., 1994; White et al., 1995; Gothilf et al., 1996; Senthilkumaran et al., 1999). These three forms of GnRH have a clear stimulatory action on the release of pituitary gonadotropins, with the GnRH-2 and GnRH-3 
forms having more potent effects compared with the GnRH-1 form (Zohar et al., 1995). However, the GnRH-1 form presents much higher levels in the pituitary of perciforms, indicating that this is the isoform that carries out the physiological hypophysiotrophic functions (Powell et al., 1994; Holland et al., 1998; Rodríguez et al., 2000; GonzálezMartínez et al., 2002). The GnRH-3 and GnRH-2 forms seem to perform neurotransmitter, neuromodulatory and/or behavioural actions, although their functions have still not been fully clarified (Zohar et al., 2001; Fernald \& White, 1999).

Morphofunctional studies appeared to demonstrate a clear neuroanatomical segregation of the cellular systems that express these three forms of $\mathrm{GnRH}$ in the brain of perciforms (Gothilf et al. 1996; White \& Fernald, 1998). Thus, the expression of the GnRH-3 form takes place in cells of the olfactory bulbs and the terminal nerve; the cells of the preoptic area express the GnRH-1 form; and lastly, the GnRH-2 form is expressed in cells of the dorsal synencephalon, in the transition between the diencephalon and the mesencephalon (Gothilf $\boldsymbol{e t}$ al., 1996; Parhar, 1997). Based on this neuroanatomical and functional segregation, and on observations obtained during ontogenic development, several authors proposed that the three GnRH systems expressed in the brain of perciforms originated from different embryonic primordia (Parhar, 1997). Thus, the neurons that express GnRH-3 would have developed from the olfactory placode, while the GnRH-1 and GnRH-2 cells would have developed from primordia of the basal preoptic area and of the mesencephalon, respectively. However, in vertebrates such as the amphibians, birds and mammals, all the GnRH cells of the forebrain developed from the same primordium in the olfactory placode, while the GnRH cells of the midbrain originate from another primordium in the germinal zone of the third ventricle (Schwanzel-Fukuda \& Pfaff, 1989; Schwanzel-Fukuda, 1999).

But evidences have been accumulated to show that the expression of three different forms of $\mathrm{GnRH}$ in the brain of teleosts is not restricted to perciforms, but is a fairly extensive characteristic of teleosts, since three different isoforms of GnRH have also been detected in clupeiforms (Carolsfeld et al., 2000), characiforms (Powell et al., 1997), salmoniforms (Adams et al., 2002), atheriniforms (Montaner et al., 2001; Guilgur et al., 2007), synbranchiforms (Somoza et al., 2002), beloniforms (Okubo et al., 2000), cyprinodontiforms (Somoza et al., 2002), scorpaeniforms (Powell et al., 1996a), pleuronectiforms (Andersson et al., 2001; Amano et al., 2002) and tetraodontiforms (Aparicio et al., 2002; Lethimonier et al., 2004). The presence of three GnRH genes has also been described in other species of salmonids, cyprinids and silurids, although in these cases this seems to be due to phenomena of tetraploidization that have determined subsequent duplications of the GnRH-1 gene 
(catfish), the GnRH-2 gene (goldfish) and the GnRH-3 gene (trout and salmon) (Kah et al., 2007). Although the occurrence of a third form of GnRH has also been suggested in other vertebrates, including humans (Sherwood et al., 1986; Montaner et al., 1998; Yahalom et al., 1999), its presence has not been demonstrated yet. 
ADAMS, B.A., E.D. VICKERS, C. WARBY, M. PARK, W.H. FISCHER, A.G. CRAIG, J.E. RIVIER, AND N.M. SHERWOOD, 2002. Three forms of gonadotropin-releasing hormone, including a novel form, in a basal salmonid, Coregonus clupeaformis. Biol. Reprod. 67: 232-239.

AMANO, M., Y. OKA, T. YAMANOME, K. OKUZAWA, AND K. YAMAMORI, 2002. Three GnRH systems in the brain and pituitary of a pleuronectiform fish, the barfin flounder Verasper moseri. Cell. Tissue Res. 309: 323-329.

ANDERSSON, E., P.G. FJELLDAL, U. KLENKE, E. VIKINGSTAD, G.L. TARANGER, Y. ZOHAR, AND S.O. STEFANSSON, 2001. Three forms of GnRH in the brain and pituitary of the turbot, Scophthalmus maximus: immunological characterization and seasonal variation. Comp Biochem. Physiol. B. Biochem. Mol. Biol. 129: 551-558.

APARICIO, S., J. CHAPMAN, E. STUPKA, N. PUTNAM, J.M. CHIA, P. DEHAL, A. CHRISTOFFELS, S. RASH, S. HOON, A. SMIT, M.D. GELPKE, J. ROACH, T. OH, I.Y. HO, M. WONG, C. DETTER, F. VERHOEF, P. PREDKI, A. TAY, S. LUCAS, P. RICHARDSON, S.F. SMITH, M.S. CLARK, Y.J. EDWARDS, N. DOGGETT, A. ZHARKIKH, S.V. TAVTIGIAN, D. PRUSS, M. BARNSTEAD, C. EVANS, H. BADEN, J., POWELL, G. GLUSMAN, L., ROWEN,L. HOOD, Y.H.TAN, G. ELGAR, T. HAWKINS, B. VENKATESH, D. ROKHSAR, S. BRENNER, 2002 Whole-genome shotgun assembly and analysis of the genome of Fugu rubripes. Science 297:13011310.

BATTEN, T.F.C., M.L. CAMBRE, L. MOONS, AND F. VANDESANDE, 1990. Comparative distribution of neuropeptide-immunoreactive systems in the brain of the green molly, Poecilia latipinna. J. Comp. Neurol. 302: 893-919.

BILLARD, R., PETER, R. E. 1982. A stereotaxic atlas and technique for nuclei of the diencephalon of rainbow trout (Salmo gardineri). Reprod. Nutr. Dev. 22: 1-25.

BURGUS, R., M. BUTCHER, N. LING, M. MONAHAN, J. RIVIER, R. FELLOWS, M. AMOSS, R. BLACKWELL, W. VALE, R. GUILLEMIN, 1971. Molecular structure of the hypothalamic factor (LRF) of ovine origin monitoring the secretion of pituitary gonadotropic hormone of luteinization (LH). C. R. Acad. Sci. Hebd. Seances Acad. Sci. D. 273: 1611-1613.

CAROLSFELD, J., J.F.F. POWELL, M. PARK, W.H. FISCHER, A.G. CRAIG, J.P. CHANG, J.E. RIVIER, AND N.M. SHERWOOD, 2000. Primary structure and function 
of three gonadotropin-releasing hormones, including a novel form, from an ancient teleost, herring. Endocrinology 141:505-512.

DONOVAN, B.T., AND G.W. HARRIS, 1954. Effect of pituitary stalk section light-induced oestrus in the ferret. Nature 174: 503-504.

FERNALD, R.D., AND R.B. WHITE, 1999. Gonadotropin-releasing hormone genes: phylogeny, structure, and functions. Front Neuroendocrinol. 20: 224-240.

GUILGUR, L.G., G. ORTÍ, P.H. STROBL-MAZZULLA, J.I. FERNANDINO, L.A. MIRANDA, AND G.M. SOMOZA, 2007. Characterization of the cDNAs encoding three GnRH forms in the pejerrey fish Odontesthes bonariensis (Atheriniformes) and the evolution of GnRH precursors. J. Mol. Evol. 64:614-627.

GONZÁLEZ-MARTÍNEZ, D., N. ZMORA, E. MAÑANOS, D. SALIGAUT, S. ZANUY, Y. ZOHAR, A. ELIZUR, O. KAH, AND J.A. MUÑOZ-CUETO, 2002. Immunohistochemical localization of three different prepro-GnRHs (Gonadotrophinreleasing hormones) in the brain and pituitary of the European sea bass (Dicentrarchus labrax) using antibodies against recombinant GAPs. J. Comp. Neurol. 446: 95-113.

GOOS, H.J.TH., R. DE LEEUW, C. DE ZOETEN-KAMP, J. PEUTE, AND S. BLASER, 1985. Gonadotropin-releasing hormone -immunoreactive neuronal structures in the brain and pituitary of the African catfish, Clarias gariepinus (Burchell). Cell Tissue Res. 241: 593-596.

GOTHILF, Y., J.A. MUÑOZ-CUETO, C.A. SAGRILLO, M. SELMANOFF, T.T. CHEN, A. ELIZUR, O. KAH, AND Y. ZOHAR, 1996. Three forms of gonadotrophin-releasing hormone in a teleost fish: cDNA characterization and brain localization. Biol. Reprod. 55:636-645.

HOLLAND, M.C.H., Y. GOTHILF, I. MEIRI, J.A. KING, K. OKUZAWA, A. ELIZUR, AND Y. ZOHAR, 1998. Levels of the native forms of GnRH in the pituitary of the gilthead seabream, Sparus aurata, at several characteristic stages of the gonadal cycle. Gen. Comp. Endocrinol. 112: 394-405.

IWAKOSHI, E., K. TAKUWA-KURODA, Y. FUJISAWA, M. HISADA, K. UKENA, K., TSUTSUI, H. MINAKATA, 2002. Isolation and characterization of a GnRH-like peptide from Octopus vulgaris. Biochem. Biophys. Res. Commun 291: 1187-1193.

JIMENEZ-LIÑÁN, M., B.S. RUBIN, AND J.C. KING, 1997. Examination of guinea pig luteinizing hormone-releasing hormone gene reveals a unique decapeptide and existence of two transcripts in the brain. Endocrinology 138: 4123-4130. 
KAH, O., B. BRETON, J. G. DULKA, J. NUÑEZ-RODRIGUEZ, R.E. PETER, A. CORIGAN, J. J. RIVIER, AND W. W. VALE, 1986. A reinvestigation of the Gn-RH (Gonadotropin-releasing hormone) systems in the goldfish brain using antibodies to salmon Gn-RH. Cell Tissue Res. 244: 327-337.

KAH, O., S. ZANUY, E. MAÑANOS, I. ANGLADE, AND M. CARRILLO, 1991. Distribution of salmon gonadotrophin-releasing hormone in the brain and pituitary of the sea bass (Dicentarchus labrax). Cell Tissue Res. 266: 129-136.

KAH, O., C. LETHIMONIER, G. SOMOZA, L.G. GUILGUR, C. VAILLANT, J.J. LAREYRE, 2007. GnRH and GnRH receptors in metazoa: A historical, comparative, and evolutive perspective. Gen. Comp. Endocrinol. 153: 346-364.

KING, J.A., AND R.P. MILLAR, 1982a. Structure of chicken hypothalamic luteinizing hormone-releasing hormone I. Structural determination on partially purified material. J. Biol. Chem. 257: 10722-10728.

KING, J.A, AND R.P. MILLAR, 1982b. Structure of chicken hypothalamic luteinizing hormone-releasing hormone II. Isolation and characterization. J. Biol. Chem. 257:10729-10732.

LETHIMONIER, C., T. MADIGOU, J.A. MUÑOZ-CUETO, J.J. LAREYRE, AND O. KAH, 2004. Evolutionary aspects of GnRHs, GnRH neuronal systems and GnRH receptors in teleost fish. Gen. Comp. Endocrinol. 135: 1-16.

LOVEJOY, D.A., W.H. FISCHER, S. NGAMVONGCHON, A.G. CRAIG, C.S. NAHORNIAK, R.E. PETER, J.E. RIVIER, AND N.M. SHERWOOD, 1992. Distinct sequence of gonadotropin-releasing hormone $(\mathrm{GnRH})$ in dogfish brain provides insight into GnRH evolution. Proc. Natl. Acad. Sci. USA 89: 6373-6377.

MALER, L., SAS, E., JOHNSTON, S., ELLIS, W. 1991. An atlas of the brain of the electric fish Apteronotus leptorhynchus. J. Chem. Neuroanat. 4: 1-38.

MATSUO, H., Y. BABA, R.M.G. NAIR, A. ARIMURA, AND A.V. SCHALLY 1971. Structure of the porcine LH- and FSH-releasing hormone. I. The proposed amino acid sequence. Biochem. Biophys. Res. Comm. 43: 1334-1339.

MONTANER, A.D., G.M. SOMOZA, J.A. KING, J.J. BIANCHINI, C.G. BOLIS, AND J.M. AFFANNI, 1998. Chromatographic and immunological identification of GnRH (gonadotropin-releasing hormone) variants. Occurrence of mammalian and a salmonlike $\mathrm{GnRH}$ in the forebrain of an eutherian mammal: Hydrochaeris hydrochaeris (Mammalia, Rodentia). Regul. Pept. 73:197-204. 
MONTANER, A.D., M.K. PARK, W.H. FISCHER, A.G. CRAIG, J.P. CHANG, G.M. SOMOZA, J.E. RIVIER, AND N.M. SHERWOOD, 2001. Primary structure of a novel gonadotropin-releasing hormone in the brain of a teleost, pejerrey. Endocrinology 142:1453-1460.

NELSON, J.S. Fishes of the world, 3 ed. John Wiley \& Sons, New York. 2006. 600p.

NGAMVONGCHON, S., D.A. LOVEJOY, W.H. FISCHER, A.G. CRAIG, C.S. NAHORNIAK, AND N.M. SHERWOOD, 1992. Primary structure of two forms of gonadotropin-releasing hormone, one distinct and one conserved, from catfish brain. Mol. Cell Neurosci. 3: 17-22.

OKUBO, K., M. AMANO, Y. YOSHIURA, H. SUETAKE, AND K. AIDA, 2000. A novel form of gonadotropin-releasing hormone in the medaka, Oryzias latipes. Biochem Biophys. Res. Commun. 276: 298-303.

PARHAR, I.S., 1997. GnRH in tilapia: three genes, three origins and their roles, pp. 99-122 in GnRH Neurons: Gene to Behavior, edited by I.S. Parhar and Y. Sakuma. Brain Shuppan, Tokyo.

PETER, R.E. AND GILL, V.E. 1975. A stereotaxic atlas and technique for forebrain nuclei in the goldfish, Carassius auratus. J. Comp. Neurol., 159: 69-102.

PETER, R.E., CRIM, L.W. AND BILLARD, R. 1991. A stereotaxic atlas and implantation technique for nuclei of the diencephalon of Atlantic salmon (Salmo salar) parr. Reprod. Nutr. Dev., 31: 167-186.

POWELL, J.F.F., Y. ZOHAR, A. ELIZUR, M. PARK, W.H. FISCHER, A.G. CRAIG, J.E. RIVIER, D.A. LOVEJOY, AND N.M. SHERWOOD, 1994. Three forms of gonadotropin-releasing hormone characterized from brains of one species. Proc. Natl. Acad. Sci. USA 91:12081-12085.

POWELL, J.F.F., S.L. KRUECKL, P.M. COLLINS, AND N.M. SHERWOOD, 1996a. Molecular forms of GnRH in three model fishes: rockfish, medaka and zebrafish. J. Endocrinol. 150:17-23.

POWELL, J.F.F., S. RESKA-SKINNER, M.O. PRAKASH, W.H. FISHER, M. PARK, J.E. RIVIER, A.G. CRAIG, G.O. MACKIE, AND N.M. SHERWOOD, 1996b. Two new forms of gonadotropin-releasing hormone in a protochordate and the evolutionary implications. Proc. Natl. Acad. Sci. USA 93: 10461-10464.

POWELL, J.F.F., E.M. STANDEN, J. CAROLSFELD, M.I. BORELLA, R. GAZOLA, W.H. FISCHER, M. PARK, A.G. CRAIG, C.M. WARBY, J.E. RIVIER, M.V. VAL-SELLA, 
AND N.M. SHERWOOD, 1997. Primary structure of three forms of gonadotropinreleasing hormone (GnRH) from the pacu brain. Regul. Pept. 68: 189-195.

RODRÍGUEZ-GÓMEZ, F.J., M.C. RENDÓN, C. SARASQUETE, AND J.A. MUÑOZCUETO, 1999. Distribution of gonadotropin-releasing hormone immunoreactive systems in the brain of the Senegalese sole, Solea senegalensis. Histochem. J. 31: 695703.

RODRÍGUEZ, L., M. CARRILlO, L.A. SORBERA, M.A. SOUBRIER, E. MAÑANÓS, M.C. HOLLAND, Y. ZOHAR, AND S. ZANUY, 2000. Pituitary levels of three forms of $\mathrm{GnRH}$ in the male European sea bass (Dicentrarchus labrax, L.) during sex differentiation and first spawning season. Gen. Comp. Endocrinol. 120: 67-74.

SCHWANZEL-FUKUDA, M., AND D.W.PFAFF, 1989. Origin of luteinizing hormonereleasing hormone neurons. Nature 338:161-164.

SCHWANZEL-FUKUDA, M. 1999. Origin and migration of luteinizing hormone-releasing hormone neurons in mammals. Microsc. Res. Tech. 44: 2-10.

SENTHILKUMARAN, B., K. OKUZAWA, K. GEN, T. OOKURA, AND H. KAGAWA, 1999. Distribution and seasonal variation in levels of three native GnRHs in the brain and pituitary of perciform fish. J. Neuroendocrinol. 11: 181-186.

SHERWOOD, N., L. EIDEN, M. BROWNSTEIN, J. SPIESS, J. RIVIER, AND W. VALE, 1983. Characterization of a teleost gonadotropin-releasing hormone. Proc. Natl. Acad. Sci. USA 80: 2794-2798.

SHERWOOD, N.M., R.T. ZOELLER, AND F.L. MOORE, 1986. Multiple forms of gonadotropin-releasing hormone in amphibian brains. Gen. Comp. Endocrinol. 61:313-322.

SOMOZA, G.M., D.W. LESCHEID, L.A. MIRANDA, F.L. LO NOSTRO, L., MAGLIULOCEPRIANO A.D. MONTANER, M.P. SCHREIBMAN, J.E. RIVIER, AND N.M. SHERWOOD, 2002. Expression of pejerrey gonadotropin releasing hormone (pjGnRH) in three orders of fish. Biol. Reprod. 67:1864-1871.

SOWER, S.A., Y.C. CHIANG, S. LOVAS, AND J.M. CONLON, 1993. Primary structure and biological activity of a third gonadotropin-releasing hormone from lamprey brain. Endocrinology 132: 1125-1131.

WHITE, S.A., T.L. KASTEN, C.T. BOND, J.P. ADELMAN, AND R.D. FERNALD, 1995. Three gonadotropin-releasing hormone genes in one organism suggest novel role for an ancient peptide. Proc. Natl. Acad. Sci. USA 92: 8363-8367. 
WHITE, R.B., AND R.D. FERNALD, 1998. Ontogeny of gonadotropin-releasing hormone $(\mathrm{GnRH})$ gene expression reveals a distinct origin for GnRH containing neurons in the midbrain. Gen. Comp. Endocrinol. 112: 322-329.

WULLIMANN, M. F., RUPP, B., REICHERT, H. 1996. Neuroanatomy of the zebrafish brain: a topological atlas. Birkhauser Verlag, Switzerland.

YAHALOM, D., A. CHEN, N. BEN-AROYA, S. RAHIMIPOUR, E. KAGANOVSKY, E. OKON, M. FRIDKIN, AND Y. KOCH, 1999. The gonadotropin-releasing hormone family of neuropeptides in the brain of human, bovine and rat: identification of a third isoform. FEBS Lett. 463: 289-294.

YOO, M.S., H.M. KANG, H.S. CHOI, J.W. KIM, B.E. TROSKIE, R.P. MILLAR, AND H.B. KWON, 2000. Molecular cloning, distribution and pharmacological characterization of a novel gonadotropin-releasing hormone $\left(\left[\operatorname{Trp}^{8}\right] \mathrm{GnRH}\right)$ in frog brain. Mol. Cell. Endocrinol. 164:197-204.

ZHANG, L., N.L. WAYNE, N.M. SHERWOOD, H.R. POSTIGO, AND P.S.TSAI, 2000. Biological and immunological characterization of multiple GnRH in an opisthobranch mollusk, Aplysia californica. Gen. Comp. Endocrinol. 118: 77-89.

ZOHAR, Y., A. ELIZUR, N.M. SHERWOOD, J.F. POWELL, J.E. RIVIER, AND N. ZMORA. 1995. Gonadotropin-releasing activities of the three native forms of gonadotropin-releasing hormone present in the brain of gilthead seabream, Sparus aurata. Gen. Comp. Endocrinol. 97: 289-299. 
CHAPTER I 


\title{
An atlas of catfish brain - Steindachneridion parahybae: a detailed cytoarchitectonic study of the different brain areas and nuclei as a basis for further morphological and functional studies
}

\author{
Andreone T. Medrado', Renata G. Moreira'1, and José A. Muñoz-Cueto2* \\ ${ }^{1}$ Departamento de Fisiologia, Instituto de Biociências da Universidade de São Paulo, São Paulo, Brazil \\ ${ }^{2}$ Departamento de Biología, Faculdad de Ciências del Mar y Ambientales, Campus de Excelencia Internacional \\ del Mar (CEI·MAR). Universidad de Cádiz, Campu Río San Pedro, Puerto Real (Cádiz), Spain
}

\begin{abstract}
Key words:

Fish Brain;

Cytoarchitecture;

Teleosts comprise approximately 50 per cent of all vertebrates' species Neurons;

Teleost fish; Morphology. and, due to the large variety and different adaptive features found in this group, many studies have been conducted to better understand important events in life from these animals. Among the various studies, we highlight those related to reproductive physiology and neuroendocrinology, which are directed to obtain in-depth knowledge of different neurohormones that trigger most relevant processes involved in reproduction. Accordingly, there is a great interest in knowing the different brain areas where neurohormones acting on the endocrine control of reproduction are produced and where these neurohormones are released. It should be noted that although the overall pattern of organization of the brain is similar in all fish, there is a considerable variation in the topology of many brain regions from one species to another and the amplitude of this variation increases with the evolutionary distance separating these species. Thus, around one

Contact Author: Dr. José Antonio MuñozCueto, Department of telencephalon, diencephalon, mesencephalon and rhombencephalon. Biology and Ecology, Although we have observed important similarities between the brain of
Faculty of Marine Sciences, University of catfish and other teleosts, we have also noticed some differences in the Cádiz, Polígono Río San Pedro, 11510, Puerto Real, Cádiz, Spain. Email: characteristics and placement of several nuclei in relation to other teleosts, or even when compared to the brain of species of the same Order, the munoz.cueto@uca.es Siluriformes.
\end{abstract}




\section{INTRODUCTION}

TELEOSTS represent a large group within the vertebrates, being the oldest within the subphylum Vertebrata, which is included in the Phylum Chordata (Hieckman, et al., 2004). In fact, with approximately 28,000 species currently recognized, they account for around 50\% of species of Vertebrates (Nelson, 2006). This large group can be divided into three extant Classes Agnatha (jawless fish), Chondrichthyes (cartilaginous fishes), and Osteichthyes (bony fish). Currently, bony fishes are divided into two other subclasses: the Sarcopterygii (fleshy finned fishes, ancestors of tetrapods) and Actinopterygii (ray finned fishes). The latter one, represents the majority of finfish and has been the largest and most predominant group since the Paleozoic era. Within this group, the most representative are the teleosts (Teleostei), with over 23,000 living species (Nelson, 2006).

As for any class of vertebrates, the development of neuroendocrinology in fish has been tightly dependent on anatomo-functional studies aiming at identifying brain regions potentially implicated in neuroendocrine regulation of pituitary functions and at tracing the neuronal systems participating in those regulations. However, despite the high diversity in teleost group, detailed and complete cytoarchitectonic studies of the brain have been accomplished only in a few species. Among the studies providing detailed cytoarchitectonic analysis of different brain regions, many of them have been focused in the telencephalon. The distribution and location of the different telencephalic nuclei were studied in several species such as Anguilla japonica (Mukuda \& Ando, 2003), Dicentrarchus labrax (CerdáReverter, 2001a), Sparus aurata (Muñoz-Cueto et al., 2001), Carassius auratus (Morita \& Finger, 1987; Rupp, B. et al, 1996), Oncorhynchus mykiss (Nieuwenhyus et al., 1998), Danio rerio (Wullimann et al., 1996) and Ictalurus punctatus (Bass, 1981) (for review see Northcutt \& Davis, 1983; Northcutt, 2008). Apart from the telencephalon, the cytoarchitecture of the diencephalon has also been investigated in osteoglossoform (Butler $\boldsymbol{\&}$ Saidel, 1991), clupeomorph (Butler \& Northcutt, 1993) and perciform (Muñoz-Cueto et al., 2001, Cerdá-Reverter, 2001b; Fernald \& Shelton, 1985) species. Additionally, detailed cytoarchitectonic studies for several species of fish have already been published, providing complete brain atlases for the electric fish, Apteronotus leptorhynchus (Gymnodontiformes; Maler et al, 1991), the swordtail fish, Xiphophorus helleri (Cyprinodontiformes; Anken \& Rahmann, 1994), zebra fish, Danio rerio (Cypriniformes Wullimann et al, 1996) and 


\section{CHAPTER I - A Atlas of the Catfish Brain - Introduction}

gilthead seabream, Sparus aurata (Perciformes; Muñoz-Cueto et al, 2001), as well as a great number of partial brains atlases, as those of goldfish, Carassius auratus (Cypriniformes; Peter \& Gill, 1975), the killifish, Fundulus heteroclitus (Cyprinodontiformes; Peter et al, 1975), and two salmonids, the rainbow trout, Oncorhynchus mykiss (Bilard \& Peter, 1982) and the Atlantic salmon, Salmo salar (Peter et al, 1991).

Another reason to approach these cytoarchitectonic studies is that the brain of fish can vary considerably between groups and/or species depending upon several factors, including the environment and the ecological niche occupied by the species, among others. During evolution, these factors have exerted a selective pressure, favoring individuals better adapted to different environmental conditions (Ito et al., 2007, Kotrschal et al, 1998; Eastman \& Lanoo, 1995; Northcutt, 2008; Trajano, 1994). As a result, and compared with other vertebrates, fish have a greater diversification in the brain morphology (Kotrschal et al., 1998). This diversity might be, at least in part, related to the high sensory modality that fish need in their aquatic habitat, due to the physicochemical properties of water (Atema $\boldsymbol{e t}$ al., 1988). Interestingly, in addition to sight, hearing and olfaction, fish exhibit a sensory diversity because the existence of mechanoreceptors (lateral line and barbels), chemoreceptors (taste buds) and electroreceptors (e.g. in Gymnodontiformes) (Brandstätter \& Kotrschal, 1989, 1990). Moreover, neurogenesis in fish continues throughout life, being this allometry a putative factor that would cause morphological changes in the fish brain (Brandstätter \& Kotrschal, 1989, 1990), and therefore, that would be on the basis for such variety in brain morphology. 


\section{Methodological Considerations}

\section{Animals}

The specimens used in this study $(n=7)$ were obtained from induced artificial reproduction (Caneppele, 2009) at the Hydrobiology and Aquaculture Station of the Energy Company of São Paulo (CESP). The animals were acclimated in rectangular tanks (72L, at a temperature of $29^{\circ} \mathrm{C}$ ) from hatching to the 100 day post-hatching (dph). During the sampling, it were desensitized with benzocaine (ethyl p-aminobenzoate) $\left(1 \mathrm{~g} / 10 \mathrm{~L} \mathrm{H}_{2} 0\right)$ and placed in a fixing solution (acetic Bouin) for 24 hours. It should be emphasized here that the procedures followed in this study were according to the protocol 072/2008 of the Animal Ethics Committee from the Institute of Biosciences of the University of São Paulo.

\section{Histology}

According to routine histological techniques, animals were transferred to ethanol $70^{\circ}$ GL after 24 hours of fixation. The samples were dehydrated by several soaking in $95 \%$ ethanol and absolute ethanol, clarified in xylene (dimethylbenzene) and finally, embedded in paraffin. Serial coronal sections $(5 \mu \mathrm{m}$-thick) were made with a rotary microtome and stained with cresyl violet (Gabe, 1968). The images were analyzed on an Olympus BH-2 photomicroscope and Adobe Photoshop CS5.5 ${ }^{\circledR}$ was used for treatment of images. The different cell groups were identified according to the following criteria: 1) characteristic size, shape and intensity of the cell body; 2) packing density and distribution pattern of the cell bodies; 3) neuropil surrounding cell groups, and 4) consistency of cell groups in both hemispheres and different brains. 


\section{Brains Subdivisions and Nomenclature}

$\mathbf{L}$

ateral views of Steindachneridion parahybae* brain are shown in Figure 1, in which the left brain hemisphere is presented. As occurs in other actinopterigyans fish, in the catfish brain we have recognized four main areas: telencephalon, diencephalon, mesencephalon, and rhombencephalon (including the metencephalic cerebellum and the myelencephalon) (Nieuwenhuys, 1982). In turn, these areas can be subdivided into different regions, zones and nuclei, as presented in Table I.

As in other teleosts, the telencephalon (Tel) of $S$. parahybae shows in its rostral region a pair of olfactory bulbs (OB), followed by the caudal telencephalic hemispheres. However, catfish $\mathrm{OB}$ are separated from the cerebrum by a medium olfactory tract (OTM), which is evident from 22 days post-hatching (dph) of development, and exhibits a growth proportional to the size of the animal after $88 \mathrm{dph}$. This separation between the OB and the telencephalic hemispheres is common in other silurid species (Plotosus lineatus, Ictalurus punctatus, Silurus asotus, Clarias gariepinus, Pimelodella transitory, P. kronei, Oxydoras sifontesi, Ariopsis seemanni) and also in other fish Orders, such as Cypriniformes (Carassius auratus, Cyprinus carpio), Osteoglossiformes (Xenomystus sp., Gnathonemus sp.) and Gymnotiformes (Eigenmannia sp) (Bass, 1981; Trajano, 1994; Saidel \& Butler, 1991; Wullimann et al, 1996; Kotrschal et al, 1998; Butler, 2000; Dubois et al, 2001; Ito et al, 2007; ChávezAponte et al, 2009; Londoño \& Giraldo, 2010). In addition, as it is showed in these studies, other feature of the siluriform brain is the well-developed cerebellum, which is emitted rostrally to cover the mesencephalon and part of the telencephalon, as it is recognized anatomically (Fig. 1) or in histological coronal sections.

With slight differences, the diencephalon of our catfish species is similar to that observed in other teleosts. Nevertheless, some areas such as the cell masses of the migrated nuclei of the posterior tubercle were grouped differently from that observed, for example, in Ictalurus punctatus (Striedter, 1990), although this study has served as the main reference. The diencephalon of catfish is organized in nine main areas: (1) preoptic area; (2) hypothalamus; (3) epithalamus; (4) ventral thalamus; (5) dorsal thalamus; (6) posterior

(*) Both "catfish" and "surubim" common names were eventually used to refer to the fish species studied in this Atlas - Steindachneridion parahybae. When referring to another catfish species, the name used was "Siluriformes", "silurids", "catfish species" or similar, but never "catfish" as a single word. 


\section{CHAPTER I - Brain areas in Catfish and their main subdivisions}

tubercle; (7) synencephalon; (8) pretectum and (9) accessory optic nuclei. More caudally, the midbrain is composed of the mesencenphalic tectum and tegmentum. The bilateral lobes of the tectum are bridged dorsally by the tectal commissure and are composed of the optic tectum and the longitudinal torus, which are located caudal to the habenular commissure and the finger-shaped habenular structures. In turn, the mesencephalic tegmentum is a complex region that in catfish has been organized into different zones - medial, central and lateral zones - each of them exhibiting several subdivisions. The rhombencephalon of catfish comprises a metencephalic prominent structure, the cerebellum, which is subdivided into the valvula of the cerebellum, the corpus of the cerebellum and the vestibulolateral lobe. Finally, we have considered four main regions in the rest of the catfish rhombencephalon: (1) reticular formation, (2) octavolateral area, (3) somatomotor and visceromotor area and (4) other nuclei.

Many nomenclatures have been used in literature for naming the different cell masses in fish brain, but in order to be consistent and avoid confusion, we have used the more accepted nomenclature for fish neuroanatomical studies. Thus, for the description of the telencephalic cell nuclei in S. parahybae, were followed the nomenclatures according to Northcutt and Braford (1980), Bass (1981), Northcutt and Davis (1983), Cerdá-Reverter et al. (2001a) and Muñoz-Cueto et al. (2001). For the diencephalon, we have followed classification as in Braford and Northcutt, (1983), Butler and Northcutt (1993) and Cerdá-Reverter et al. (2001b) with additional elaborations by Striedter (1990). And finally, for the description of the mesencephalon and rhombencephalon, we were based mainly in studies performed by McCormick (1982), Nieuwenhuys (1982), Finger and Tong (1984), Wulliman and Northcutt (1988), Finger and Kanwal (1992), Kanwal and Finger (1997) and CerdáReverter et al. (2008). 
Fig. 1 - Drawing of the catfish (Steindachneridion parahybae) and its brain. A) Drawing of a juvenile catfish of 100 days post-fertilization; B-D) Lateral views of the catfish brain showing the levels where coronal sections were made and illustrated in figures presented in this report. The figures indicate the planes of sections presented for the telencephalon (B), diencephalon (C), midbrain and hindbrain (D), respectively. Scale bar: A) $1 \mathrm{~cm}$; B-D) $2 \mathrm{~mm}$. The abbreviations used are show in Table 1. 
A

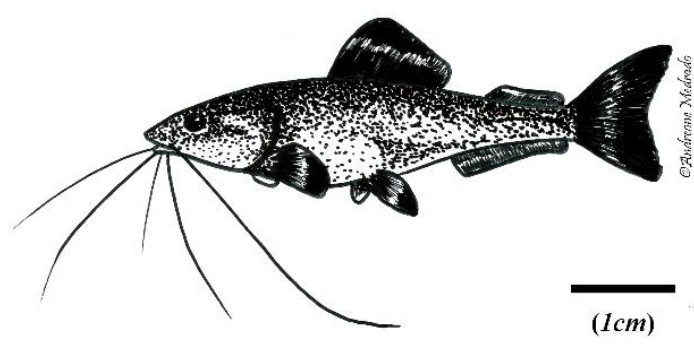

B

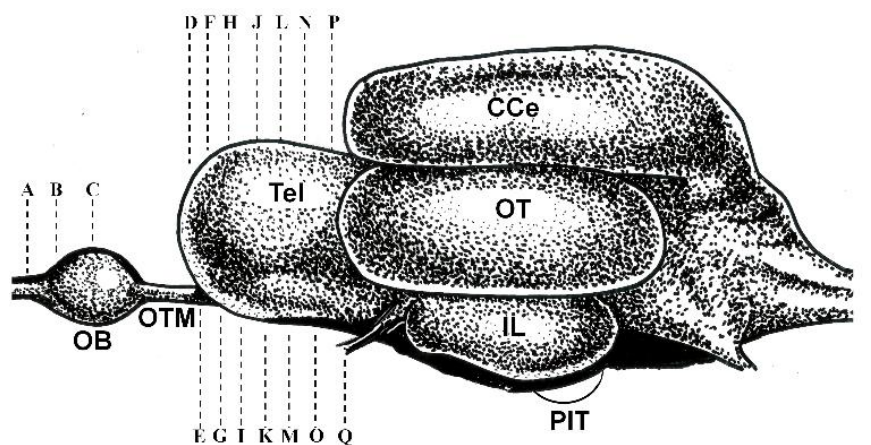

C

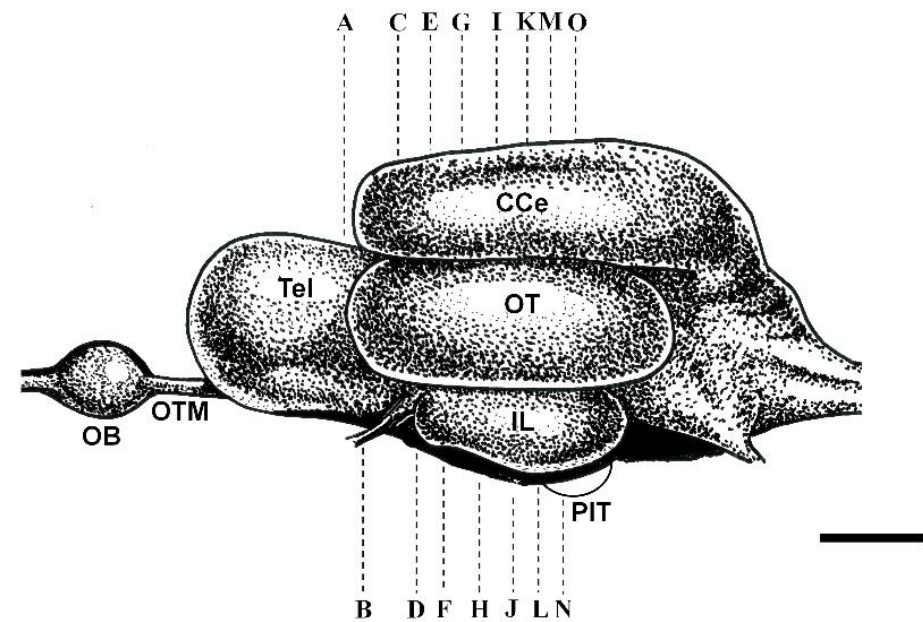

D

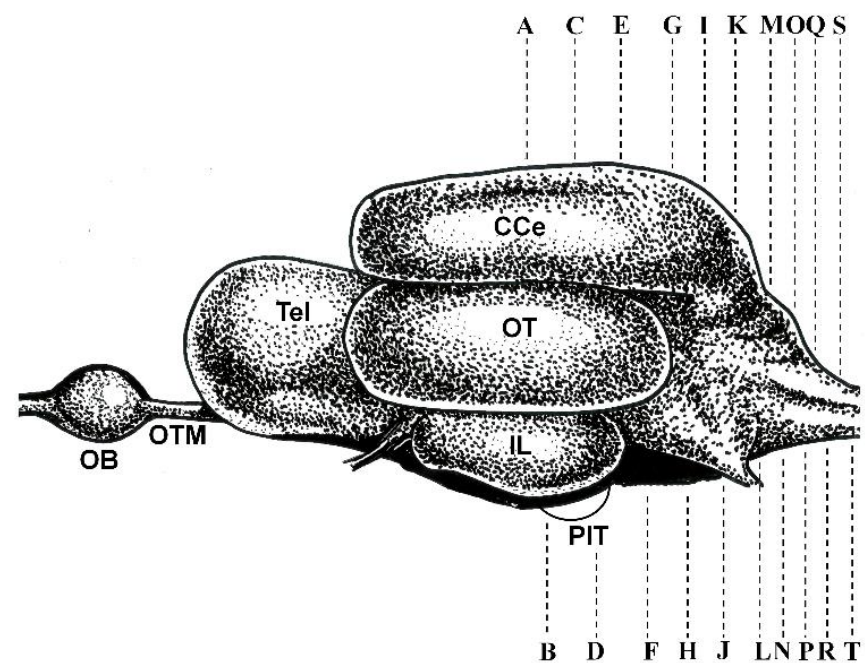

Figure 1. 


\section{TABLE I}

Organization of the brain areas of the catfish (Steindachneridion parahybae). 


\section{Telencephalon (Tel)}

\subsection{OLFACTORY BULBS (OB)}

Internal cellular layer of the olfactory bulbs (ICL)

Secondary olfactory fiber layer of the olfactory bulbs (SOF)

External cellular layer of the olfactory bulbs (ECL)

Glomerular layer of the olfactory bulbs (GL)

Olfactory nerve fiber layer of the olfactory bulbs (OLN)

\subsection{CEREBRAL HEMISPHERES}

\section{Dorsal Area (D)}

medial part $(\mathbf{D m})$

medial subdivision (Dmm)

dorsal subdivision (Dmd)

caudal subdivision (Dmc)

central part (Dc)

subdivision 1 (Dc1)

subdivision 2 (Dc2)

dorsal part (Dd)

lateral part (Dl)

dorsal subdivision (Dld)

ventral subdivision (Dlv)

posterior subdivision (Dlp)

posterior part (Dp)

taenia nucleus (NT)

\section{Ventral Area (V)}

central part (Vc)

dorsal part $(\mathbf{V d})$

lateral part (Vl)

ventral part $(\mathbf{V v})$

supracommissural part (Vs)

postcommissural part (Vp)

intermedial part (Vi)

entopeduncular nucleus (E)

lateral septal organ (LSO)

\section{Diencephalon (Die)}

\subsection{PREOPTIC AREA (POA)}

Parvocellular preoptic nucleus (NPO) 


\author{
parvocellular part (NPOpc) \\ magnocellular part (NPOmc) \\ gigantocellular part (NPOgc) \\ Anterior periventricular nucleus (NAPv) \\ Suprachiasmatic nucleus (NSC) \\ Posterior periventricular nucleus (NPPv)
}

\title{
2.2. HYPOTHALAMUS
}

\section{Medial tuberal zone}

lateral tuberal nucleus (NLT)

central part (NLTe)

dorsal part (NLTd)

inferior part (NLTi)

medial part (NLTm)

ventral part (NLTv)

anterior tuberal nucleus (NAT)

nucleus of the lateral recess (NRL)

dorsal part (NRLd)

ventral part (NRLv)

nucleus of the posterior recess (NRP)

\section{Lateral or inferior zone}

central nucleus of the inferior lobe (NCLI)

diffuse nucleus of the inferior lobe (NDLI)

lateral part of the nucleus of the lateral recess (NRLI)

posterior part of the nucleus of the lateral recess (NRLp)

\subsection{EPITHALAMUS}

Habenular nucleus (Ha)

ventral part (Hav)

dorsal part (Had)

Epiphysis (Ep)

\subsection{VENTRAL THALAMUS}

Ventromedial thalamic nucleus (VM)

Ventrolateral thalamic nucleus (VL)

Intermediate thalamic nucleus (I)

\subsection{DORSAL THALAMUS}




\section{DienCePhalon (Die), continued}

Anterior thalamic nucleus (A)

Central posterior thalamic nucleus (CP)

Dorsal posterior thalamic nucleus (DP)

\subsection{POSTERIOR TUBERCLE}

\section{Periventricular nuclei}

periventricular nucleus of the posterior tubercle (TPp)

paraventricular organ (PVO)

nucleus of the paraventricular organ (nPVO)

posterior tuberal nucleus (NPT)

\section{Migrated nuclei}

preglomerular nuclear complex

preglomerular anterior nucleus (NPGa)

preglomerular lateral nucleus (NPGI)

anterior part of the lateral preglomerular nucleus (NPGla)

dorsal part of the lateral preglomerular nucleus (NPGId)

ventral part of the lateral preglomerular nucleus (NPGlv)

preglomerular medial nucleus (NPGm)

supraglomerular nuclear complex

supraglomerular nucleus (SPG)

subglomerular nuclear complex

subglomerular nucleus (SG)

caudomedial nuclei

preglomerular commissural nucleus (NPGc)

mammillary bodies $(\mathbf{C M})$

outlying nuclei

nucleus of the lateral torus (TLa)

posterior thalamic nucleus (PT)

lateral thalamic nucleus (LT)

lobobulbar nucleus (LB)

\subsection{SYNENCEPHALON}

Periventricular pretectal nucleus

ventral part (PPv)

dorsal part (PPd)

Paracommissural nucleus (NP)

Nucleus of the medial longitudinal fascicle (nMLF)

Subcommissural organ (SCO) 


\section{Diencephalon (Die), continued}

Medial pretoral nucleus (MPN)

2.8. PRETECTUM

Central pretectal nucleus (NPC)

Electrosensory nucleus (NES)

\subsection{ACCESSORY OPTIC NUCLEI}

Dorsal accessory optic nucleus (DAO)

Ventral accessory optic nucleus (VAO)

\section{Mesencephalon (Mes)}

\subsection{MESENCEPHALIC TECTUM}

Optic tectum (OT)

superficial white and gray zone (SWGZ)

central zone $(\mathbf{C Z})$

deep white zone (DWZ)

periventricular gray zone (PGZ)

Longitudinal torus (TLo)

\subsection{MESENCEPHALIC TEGMENTUM}

\section{Medial zone}

oculomotor nerve nucleus (nIII)

secondary gustatory nucleus (NGS)

\section{Central zone}

lateral nucleus of the valvula (NLV)

anterior part (nLVa)

posterior part (nLVp)

dorsal posterior tegmental nucleus (DPTN)

isthmic nucleus (NI)

nucleus of the locus coeruleus (LC)

perilemniscular nucleus

medial part (PLm)

lateral part (PLI)

\section{Lateral zone}

semicircular torus (TS) 
central part (TSc)

ventral part (TSv)

lateral part (TSI)

\section{Rhombencephalon}

\subsection{Cerebellum}

Corpus of the Cerebellum (CCe)

molecular layer (M)

granular layer $(\mathbf{G})$

Purkinje cells (P)

Valvula of the Cerebellum (VCe)

molecular layer (M)

granular layer $(\mathbf{G})$

Vestibulateral Lobes (LV)

granular eminence (EG)

caudal lobe (LoC)

medial part of the caudal lobe ( $\mathbf{L o C m})$

eurydendroid cells of the caudal lobe (LoCe)

The rest of the rhombencephalon:

\subsection{RETICULAR FORMATION}

\section{Median zone}

superior nucleus of the raphe (SR)

\section{Medial zone}

nucleus of reticular formation (RF)

\section{Lateral zone}

lateral reticular nucleus (RL)

\subsection{OCTAVOLATERAL AREA}

\section{Octaval nerve nuclei}

anterior octaval nucleus (AON)

descending octaval nucleus (DON)

magnocellular nucleus (MAG)

tangential nucleus (T)

posterior octaval nucleus (PO)

\section{Lateral line nerve nuclei}


medial octavolateral nucleus (MON)

Molecular layer of the electrosensory lateral line lobe and nucleus medialis (m)

\subsection{SOMATOMOTOR AND VISCEROMOTOR NUCLEI}

Trochlear nucleus (nIV)

Trigeminal nerve motor nucleus $(\mathrm{Vm})$

Facial nerve motor nucleus (VIIm)

Vagal nerve motor nucleus $(\mathrm{Xm})$

\subsection{OTHER NUCLEI}

Interpeduncular nucleus (IP)

Electrosensory lateral line lobe (ELL)

Facial lobe (FL)

Granular cells associated with medial auditory nucleus (g aud)

Inferior olive (IO)

Medial auditory nucleus of medulla (MAN)

Mauthner cells (Mc)

nucleus praeminentialis $(\mathrm{PE})$

dorsal part (PEd)

ventral part (PEv)

Vagal lobe (VL)

Spinal trigeminal nerve (nST) 


\section{Abbreviation LIST}

Abbreviations used in this study 


\section{ABBREVIATION LIST}

2G secondary gustatory nucleus and tracts

A anterior thalamic nucleus

ac anterior commissure

AON anterior octaval nucleus

BC brachium conjunctivum

CCe corpus of the cerebellum

CM mammillary bodies

CP central posterior thalamic nucleus

CZ central zone of the optic tectum

D dorsal part of the telencephalon

DAO dorsal accessory optic nucleus

Dc1 central part of the dorsal telencephalon-subdivision 1

Dc2 central part of the dorsal telencephalon - subdivision 2

Dd dorsal part of the dorsal telencephalon

Die diencephalon

Dl lateral part of the dorsal telencephalon

Dld dorsal division of the lateral part of the dorsal telencephalon

Dlp posterior division of the lateral part of the dorsal telencephalon

Dlv ventral division of the lateral part of the dorsal telencephalon

Dm medial part of the dorsal telencephalon

Dmc central division of the medial part of the dorsal telencephalon

Dmd dorsal division of the medial part of the dorsal telencephalon

Dmm medial division of the medial part of the dorsal telencephalon

DON descending octaval nucleus

Dp posterior part of the dorsal telencephalon

DP dorsal posterior thalamic nucleus

DPTN dorsal posterior tegmental nucleus

DWZ deep white zone of the optic tectum

E entopeduncular nucleus

ECL external cellular layer of the olfactory bulbs

EG granular eminence 
ELL electrosensory lateral line lobe

FL facial lobe

FR retroflex fascicle

G granular layer of the cerebellum

g aud granule cells associated with medial auditory nucleus

GL glomerular cellular layer of the olfactory bulbs

Ha habenula

HaCo habenular commissure

Had dorsal habenular nucleus

Hav ventral habenular nucleus

I intermediate thalamic nucleus

IAF internal arcuate fibers

ICL internal cellular layer of the olfactory bulbs

IL inferior lobe of the hypothalamus

IO inferior olive nucleus

IP interpeduncular nucleus

LB lobobulbarnucleus

LC nucleus of the locus coeruleus

LFB lateral forebrain bundle

LL lateral lemniscus

LLn nucleus of the lateral lemniscus

LoC caudal lobe

LoCe eurydendroid cells of the caudal lobe

$\mathbf{L O C m}$ pars medialis of the caudal lobe

LSO lateral forebrain bundle

LT lateral thalamic nucleus

M molecular layer of the cerebellum

m molecular layer of the electrosensory lateral line lobe and medial nucleus

MAG magnocellular octaval nucleus

MAN medial auditory nucleus of the medulla

Mc Mauthner cells

MO medulla oblongata

MON medial octavolateral nucleus 
MOT medial olfactory tract

MPN medial pretoral nucleus

NAPv anterior periventricular nucleus

NAT anterior tuberal nucleus

NCLI central nucleus of the inferior lobe

NDLI dorsal nucleus of the inferior lobe

NES electrosensory nucleus

NGS secondary gustatory nucleus

NI isthmic nucleus

nIII oculomotor nerve nucleus

nIV trochlearnerve nucleus

NLT lateral tuberal nucleus

NLTc central part of the lateral tuberal nucleus

NLTd dorsal part of the lateral tuberal nucleus

NLTi intermediate part of the lateral tuberal nucleus

NLTm medial part of the lateral tuberal nucleus

NLTV ventral part of the lateral tuberal nucleus

$\mathbf{n L V}$ lateral nucleus of the valvula

nLVa lateral nucleus of the valvula, anterior part

$\mathbf{n L V p}$ lateral nucleus of the valvula, posterior part

nMLF nucleus of the medial longitudinal fascicle

NP paracommissural nucleus

NPC central pretectal nucleus

NPGa anterior preglomerular nucleus

NPGc commissural preglomerular nucleus

NPGId dorsal part of the lateral preglomerular nucleus

NPGIv ventral part of the lateral preglomerular nucleus

NPGm medial preglomerular nucleus

NPO parvocellular preoptic nucleus

NPOgc gigantocellular part of the parvocellular preoptic nucleus

NPOmc magnocellular part of the parvocellular preoptic nucleus

NPOpc parvocellular part of the parvocellular preoptic nucleus

NPPv posterior periventricular nucleus 
NPT posterior tuberal nucleus

nPVO nucleus of the paraventricular organ

NRL nucleus of the lateral recess

NRLd dorsal part of the nucleus of the lateral recess

NRLI lateral part of the nucleus of the lateral recess

NRLv ventral part of the nucleus of the lateral recess

NRP nucleus of the posterior recess

NSC suprachiasmatic nucleus

nST spinal trigeminal nucleus

NT nucleus taenia

OB olfactory bulb

OC optic chiasm

OLN olfactory nerve layer of the olfactory bulbs

ON olfactory nerve

OT optic tectum

P Purkinje cells

PCo posterior commissure

PEd nucleus praeminentialis, dorsal part

PEv nucleus praeminentialis, ventral part

PGZ periventricular gray zone of the optic tectum

PIT pituitary

PLI perilemniscular nucleus, lateral part

PLm perilemniscular nucleus, medial part

PO posterior octaval nucleus

POA preoptic area

PPd dorsal periventricular pretectal nucleus

PPv ventral periventricular pretectal nucleus

PS pineal stalk

PT posterior thalamic nucleus

PVO paraventricular organ

RF reticular formation

RL lateral reticular nucleus

SCO subcommissural organ 
Se sulcus externus

SG subglomerular nucleus

Sl sulcus limitans

SOF secondary olfactory layer of the olfactory bulbs

SPG supraglomerular nucleus

SR superior nucleus of the raphe

SV vascular sac

SWGZ superficial white and gray zone of the optic tectum

Sy sulcus ipsilyformis

T tangential nucleus

TEG tegmentum of the midbrain

Tel telencephalon

TLa nucleus of the lateral torus

TLo nucleus of the longitudinal torus

TPp periventricular nucleus of the posterior tubercle

TSc central part of the semicircular torus

TSI lateral part of the semicircular torus

TSv ventral part of the semicircular torus

TTB tectum bulbar tract

TV trigeminal nerve

$\mathbf{V} \quad$ ventral part of the telencephalon

VAO ventral accessory optic nucleus

Vc central nucleus of the ventral telencephalon

VCe valvula of the cerebellum

Vd dorsal nucleus of the ventral telencephalon

Vi intermediate nucleus of the ventral telencephalon

VII facial nerve

VIIm facial nerve nucleus

VI lateral nucleus of the ventral telencephalon

VL ventrolateral thalamic nucleus

VLo vagal lobe

VM ventromedial thalamic nucleus

Vm trigeminal nerve motor nucleus 
Vp postcommissural nucleus of the ventral telencephalon

Vs supracommissural nucleus of the ventral telencephalon

$\mathbf{V v}$ ventral nucleus of the ventral telencephalon

$\mathbf{X}$ vagal nerve

Xm vagal nerve motor nucleus 


\section{The Telencephalon}

A cytoarchitectonic analysis of the catfish (Steindachneridion parahybae) telencephalon, performed by using cresyl violet-stained serial transverse section is presented in this chapter. Although the main brain areas have comparable patterns of organization among teleost fish, the topological morphology of the brain, as well as the precise distribution of the telencephalic cell masses may vary among different teleost groups, or even among species of the same Order or Genus. The telencephalon of $S$. parahybae is composed of 25 nuclei, which are distributed in three main brain zones: paired of olfactory bulbs, dorsal telencephalon and ventral telencephalon. The olfactory bulbs are subdivided into five layers from the outer to the inner part: olfactory nerve fiber layer, glomerular layer, external cellular layer, secondary olfactory fiber layer and the internal cellular layer. The dorsal telencephalon is formed by eleven cell masses, which can be organized into five major zones: medial part, central part, dorsal part, lateral part and posterior part. The nucleus taenia is also found in the dorsal telencephalon, but in the caudal portion. We have recognized nine main cell masses in the ventral telencephalon: central, dorsal, lateral, supracommissural and postcommissural nuclei, as well as four migrated cell masses: lateral, intermediate, central and entopeduncular nuclei. This study will be very useful for deepen into the knowledge of the regulation of reproduction in this species, because it represents an important tool for the precise localization of the neuroendocrine brain areas participating in the control of this and other relevant physiological processes.

\subsection{Olfactory bulbs}

The catfish olfactory bulbs (OB) are paired and well developed structures that lie in the most rostral pole of the forebrain. They appear attached to the telencephalon via a fiber tracts that connect with the respective cerebral hemispheres (Fig. 1). The OB are organized into five concentric cell layers, arranged in a centripetal manner, but not entirely uniform along the length of this structure. From the periphery to the inner part, we have recognized different layers: (1) a layer composed of fibers coming from the olfactory rosettes of the nasal cavity, the olfactory nerve fiber layer of the olfactory bulbs (OLN) (Plate 1A-C, Fig. 2A-B), which surrounds the olfactory bulbs, and becomes thinner as the OB become greater; (2) OLN is covering an easily distinguishable glomerular layer (GL) due its appearance, which present a homogeneous texture that permeates the OB substantially along their entire length (Plate 1BC, Fig. 2B); (3) the external layer of the olfactory bulbs (ECL) is characterized by the 
presence of mitral cells of varying sizes, but with remarkably few very large cells; although this layer is not very thick, it is surrounding the entire OB, being more evident in cross sections at the mid rostro-caudal level of the OB (Plate 1B-C, Fig. 2B-C); (4) another nerve fiber layer that constitutes the OB is the secondary olfactory fiber layer (SOF) (Plate1B-C, Fig. 2B-C), which lies among the ECL and (5) the internal cellular layer of the olfactory bulbs (ICL), which represents the central layer of $\mathrm{OB}$ and it is easily recognized in histological sections because the presence of a compact group of intensely-stained cells (Plate 1B-C, Fig. 2B-C).

\subsection{Telencephalic hemispheres}

\section{Dorsal telencephalon}

The dorsal telencephalon (D) of S. parahybae has been subdivided into six main areas: medial (Dm), dorsal (Dd), lateral (D), central (Dc), posterior (Dp) and nucleus taenia (NT), as presented in Table I. The most rostral pole of Tel is represented by two distinct cell mass, Dm and Dl, disposed in medial and lateral region, respectively (Plate 2D). The Dm is characterized by the presence of small to medium sized rounded cells, which exhibit a uniform distribution and an intense staining, while Dl has smaller cells and occupies a minor area compared to Dm. As we progress from rostral to caudal in the telencephalon, we observed the emergence of Dm and Dl subdivisions, which can be identified taking into account some criteria such as the packing density of cells, their size, the intensity of staining and some regions of neuropil between cell masses. Thus, in Dm we recognize medial (Dmm) and dorsal (Dmd) subdivisions, while the most rostral subdivisions of Dl are dorsal (Dld) and ventral (Dlv) ones (Plate 2E, Fig. 2A). Dmm adopts a medial position in the medial zone of the dorsal Tel. This cell mass is characterized by the presence of rounded and intensely staining cells that appear densely packed in a periventricular position. In turn, Dmd occupies the dorsal part of the dorsomedial telencephalon. This nucleus represents a large telencephalic cell mass that extends over much of the rostrocaudal extension of the Tel, although its shows a gradual decrease in size according to the emergence of the different subdivisions of the ventral telencephalon (Plates 2-4). The cells of Dmd are higher in size and appear more loosely distributed than those of Dmm (Fig. 3A).

Placed ventrolaterally to the dorsal telencephalon, Dlv cells are easily recognized by its characteristic rounded shape and small size (Fig. 3D), being more densely packed and slightly smaller than those located more dorsally within the Dmd (Plate 2E, Fig. 3A, 3E). The Dld, 
which contains cells similar to those of Dlv, is delimited dorsally from Dmd by the sulcus ipsilyformis (Sy) and ventrally by Dlp. This latter nucleus has medium-sized cells, and a histologically visible delineation (Fig. 3F), being limited dorsally by another cell mass, the dorsal nucleus of the dorsal telencephalon (Dd) (Fig. 3F). This nucleus occupies progressively the place left by Dld and is bounded dorsomedially by Dmd, from which appears delimited by the $\boldsymbol{S y}$ (Plate 4I). Another major sulcus that can be recognized in the telencephalic hemispheres is the sulcus externus (Se), which strongly marks the boundary between the dorsal and ventral region of the telencephalon (Plate 4J).

In the central zone of the dorsal telencephalon, we identified the Dc, which has been divided into two parts that appear very close to one another. These subdivisions are located in the ventral (Dc1) and dorsomedial (Dc2) area of the dorsocentral telencephalon (Plate 3G). Composed of medium-sized rounded cells, Dc1 is distinguished from other nuclei because it presents a characteristic arrangement of cells in clusters, keeping a boundary with them (Plate 3G, Fig. 3B). Dc1 is limited laterally and dorsally by Dlv and Dmd, respectively, while Dmm and Dmd bound Dc2 medially and dorsally, respectively (Plate 3G-I; Fig. 3B, D, C). At the rostral pole, Dc1 and Dc2 are joined, being difficult to establish their boundaries (Plate 3G), but at the caudal pole both cells masses appear clearly segregated (Plates 3H, 4I). In addition, Dc2 represents the subdivision that reaches the most caudal positions, where it is bounded dorsally by the caudal subdivision of the dorsomedial telencephalon (Dmc) and medially by the supracommissural (Vs), and postcommissural $(\mathbf{V p})$ parts of the ventral telencephalon (Plates 4J, 5K-L, 6M-N).

Caudally, in the medial zone of the dorsal telencephalon, we have been identified a cell mass that we have named as Dmc (Plate 4J), which is initially located between Dmm and Dmd and occupies progressively a more dorsal position as Dmm and Dmd disappear. The Dmc cells present a medium size and can be easily identified because they are more intensely stained in relation to Dmm and Dmd cells (Plates 2K; Fig. 3G). This nucleus reaches the caudal region of the dorsal telencephalon, where it is bounded laterally by Dlp (Plates 5L, 6M-N) and subsequently by the posterior part of the dorsal telencephalon (Dp, Plate 70). The Dp appear shortly after Dlv disappears, being limited dorsally by Dlp. This is a large cell mass that extends up to the end of the dorsal telencephalon, which can be differentiated from Dlv because the former exhibits slightly larger and more intensely stained cells (Plates 5-8).

Finally, the nucleus taenia (NT) is the most caudal cell mass that we have observed in the dorsal telencephalon, with dorsal and ventral delimitation by neuropil. The NT always 
occupies a ventral position in relation to $\mathrm{Dp}$, and its cells, which were highly stained in comparison to those of Dp, showed a layered arrangement (Plate 7P).

\section{Ventral telencephalon}

The ventral telencephalon (V) of $S$. parahybae has a lower number of cell masses compared to the dorsal telencephalon. We have subdivided the ventral telencephalon into eight nuclei: dorsal (Vd), ventral (Vv), central (Vc), lateral (VI), intermediate (Vi), supracommissural (Vs), postcommissural (Vp) and entopeduncular nucleus (E), as shown in Table 1. In addition, we have recognized a lateral septal organ (LSO). The most rostral cell mass that we have identified in $\mathrm{V}$ is the dorsal nucleus (Vd), composed of densely packed cells with intense staining of the soma (Plate 3, Fig. 4A). A sulcus although initially smooth, marks the transition from $\mathrm{D}$ and $\mathrm{V}$ in the medial zone of the telencephalon, the sulcus limitans ( $\mathrm{Sl}$ ) (Plate 3H). As indicated above, the ventro-lateral limit between $\mathrm{D}$ and $\mathrm{V}$ is marked by the sulcus externus (Se) (Plate 4J). Vd cells occupy the rostral pole of V, bordered dorsally by Dmm and laterally by Dc1 (Plate 3). In caudal positions, Vd moves laterally and its periventricular placement is occupied by the supracommissural cell mass of the ventral telencephalon (Vs), which contains thickly grouped cells but separated by neuropil that delimits Vs from Vd (Fig. 4B). The Vs is bounded dorso-medially by Dmm, as occurs with $\mathrm{Vd}$ in this position, but it is laterally delimited by Dc2 (Plate 4I). In the ventromedial periventricular surface of telencephalon arises a very densely packed and stained nucleus, the ventral nucleus of the ventral part of the telencephalon $(\mathbf{V v})$, which shows smaller cells when compared to those present in Vd and Vs (Plate 4I; Fig. 4C). The Vv is a cell mass that extends for almost the whole extent of the $\mathrm{V}$, starting ventro-caudal to the $\mathrm{Vd}$ and reaching in its caudal pole up to the anterior commissure (ac). As in other teleosts, S. parahybae exhibits a group of intensely stained and compressed ependymal cells, located in the medial-dorsal region of $\mathrm{Vv}$ and associated to the ventricular wall, which appears similar to the lateral septal organ (LSO) described in birds (Baylé et al, 1974; Kuenzel \& Mansson, 1988; MuñozCueto et al, 2001; Cerdá-Reverter, et al., 2001a) (Plate 4; Fig. 4C).

Two cellular masses migrated laterally have been classified in the ventral forebrain region that precedes the anterior commissure of catfish. Rostrally, medium-sized scattered neurons, arranged in clusters in the lateral region of the $\mathrm{V}$, were characterized in the lateral nucleus of the ventral telencephalon (VI) (Plate 4I; Fig. 4D). This cell mass is bordered rostrally by $\mathrm{Dl}$ and, as it moves caudally, is progressively bounded by $\mathrm{Dp}$. Vl is also delimited by $\boldsymbol{S e}$, which remains as its lateral border along the whole telencephalic extent (Fig. 2J). 
Dorsally to the Vl, with neurons larger and more intensely stained, lies the central part of the ventral telencephalon (Vc) (Plate 4J; Fig. 4D). This nucleus is a relatively small cell mass in extension when compared with those present in the $\mathrm{V}$, being noticed until the rostral pole of the anterior commissure in catfish (Plate 5K).

According to its name, dorsally and after the appearance of the anterior commissure, we have identified a postcommissural nucleus (Vp) composed of medium-sized neurons, loosely distributed and intensely stained (Plate 5L; Fig. 4F). Rostrally, Vp is bounded dorsally and ventrally by Vs and Vv, respectively (Plate 5L), being delimited caudally on its dorsal aspect by Dmc and ventrally by the most rostral neurons from the preoptic area. The caudal portion of $\mathrm{Vp}$, as well as the intermediate nucleus of the ventral telencephalon (Vi), marks the transition between the telencephalon and diencephalon (Plate 8). The Vi arises in the postcommissural region of the telencephalon. It adopts a lateral position in the ventral telencephalon and can be distinguished from the V1 because it represents a small cell mass arranged in clusters (Fig. 4E). Dorsally Vi is bordered by neurons of the Dp, cells of the NT bound it laterally and, further caudal, its cells are located dorsally to the fibers of the lateral forebrain bundle (LFB) (Plates 7P, 8Q; Fig. 4E). Also in this region, we found the entopeduncular nucleus (E). This nucleus is composed of densely packed and darkly stained small cells, which behave a dorsal migration from the ventral surface of the brain so that in its final position these cells appear in the ventral border of the LFB (Plate 8Q; Fig. 4E). 


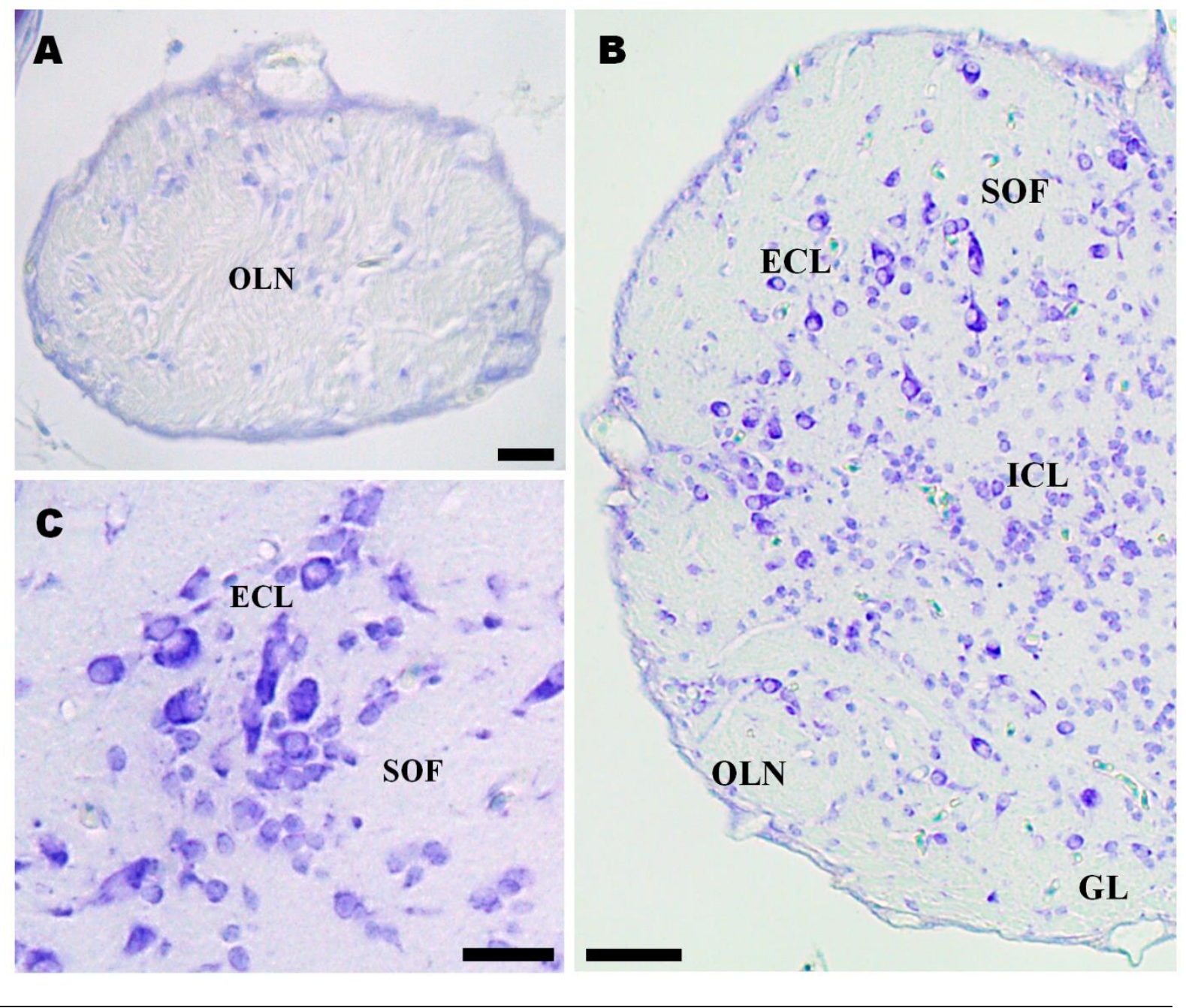

Fig. 2. Photomicrographs of transverse (coronal) sections of catfish brain (Steindachneridion parahybae) stained with cresyl-violet showing at higher magnification the different layers of the olfactory bulbs. A) Section at the level of the Plate 1A. B) Section at the level of the Plate 1C. C) Section at the level of Plate 1B. Scale bar: A and C: $20 \mu \mathrm{m}, \mathbf{B}: 35 \mu \mathrm{m}$. For abbreviations, see the list of abbreviations (on the beginning of this Atlas) and Table I. 


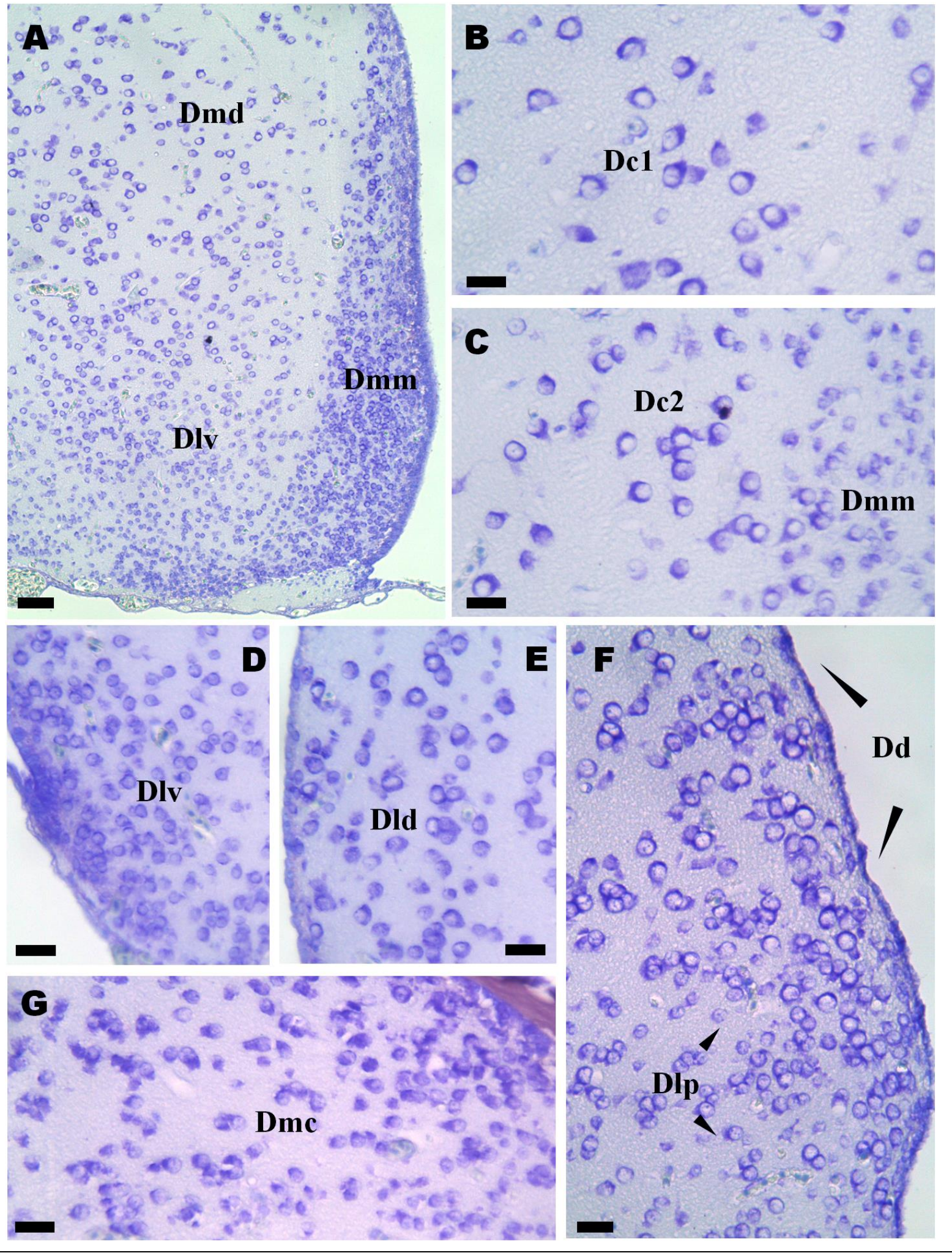

Fig. 3. Photomicrographs of transverse (coronal) sections of catfish brain (Steindachneridion parahybae) stained with cresyl-violet showing at higher magnification the different nuclei of the dorsal telencephalon. Scale bar: A: $35 \mu \mathrm{m}$, B-G: $17 \mu \mathrm{m}$. For abbreviations, see the list of abbreviations (on the beginning of this Atlas) and Table I. 
Fig. 4. Photomicrographs of transverse (coronal) sections of catfish brain (Steindachneridion parahybae) stained with cresyl-violet showing at higher magnification the different nuclei of the ventral telencephalon. Scale bar: A-E: $17 \mu \mathrm{m}, \mathbf{F}$ : $34 \mu \mathrm{m}$. For abbreviations, see the list of abbreviations (on the beginning of this Atlas) and Table 1.

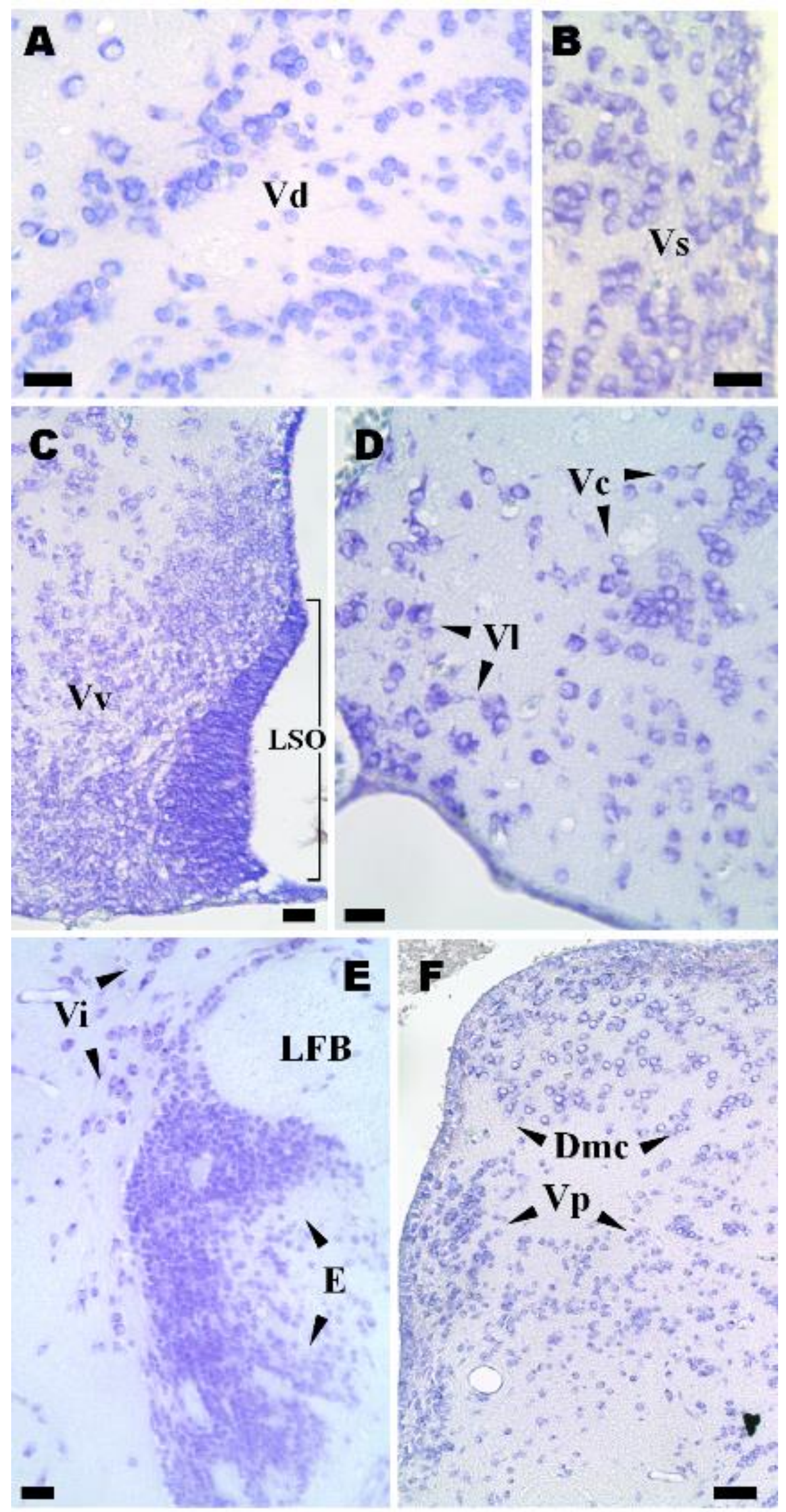




\section{THE DiEnCEPHALON}

Morphologically, the organization of adopting predominantly the organization of different diencephalic cell masses of catfish - the diencephalic areas described by Steindachneridion parahybae, do not differ Bradford and Northcutt (1983), Striedter too much from that observed for the majority (1990) and Cerdá-Reverter (2001b). of teleost fish described so far. However, the Accordingly, for the diencephalon of catfish diencephalon is one of the most complex - S. parahybae - we have identified more regions of the brain and the comparison has than 50 cell masses organized in nine main been difficult because of the lack of areas: (1) preoptic area; (2) hypothalamus; consistency in the nomenclatures used for the description of different cell masses. (3) epithalamus; (4) dorsal thalamus (5) Therefore, in this study we follow the ventral thalamus (6) posterior tubercle (7) synencephalon; (8) pretectum and nomenclatures more commonly accepted, accessory optic nuclei.

\subsection{Preoptic area}

As in other teleost fish, the onset of the preoptic area (POA) in juvenile catfish is marked by the rostral pole of the anterior commissure (ac), being limited dorsocaudally by the ventral thalamus, ventrocaudally by the hypothalamus and ventrally by the optic chiasm (OC) (Bradford \& Northcutt, 1983; Muñoz-Cueto et al, 2001). The catfish preoptic area can be subdivided into four main nuclei: (1) parvocellular preoptic nucleus (NPO); (2) anterior periventricular nucleus (NAPv); (3) suprachiasmatic nucleus (NSC) and (4) posterior periventricular nucleus NPPv (Table I).

\section{Parvocellular preoptic nucleus (NPO)}

The NPO in catfish is divided, from rostral to caudal region, in three main subnuclei: parvocellular or anterior part (NPOpc), magnocellular part (NPOmc) and gigantocellular part (NPOgc) (Plates 9, 10, 11E). The parvocellular part of the parvocellular preoptic nucleus shows rounded and strongly stained cells, small in size, and is characterized by its condensed appearance along the preoptic recess, $($ Fig. 5A). The cells of NPOpc are bordering the ventral zone of the third ventricle, forming a cell mass that initially occupies a large area, but it reduces its size as we progress caudally in the POA (Plates 9, 10). Slightly caudal to the onset 
of NPOpc, and just dorsal to it, appears the magnocellular part of the parvocellular preoptic nucleus (NPOmc, Plates 9B, 10C). This nucleus contains medium-sized to large cells that appear more loosely distributed in clusters and exhibit a paler coloration in relation to NPOpc cells (Fig. 5A). The NPOmc is replaced caudally by the cells of the gigantocellular part of the parvocellular preoptic nucleus (NPOgc, Plates 10D, 11E). The NPOgc is characterized by the presence of lower number of cells, which are rounded in shape and exhibit slighter coloration and larger size than those present in NPOmc. These NPOgc cells appear scattered and isolated or in clusters of up to 3-4 cells (Fig. 5C). In our study, the extent of NPOgc coincides in transverse sections with the onset of the posterior commissure (PCO) and subcommissural organ (SCO), and its caudal pole is also coincident with the end of these structures (Plate 10D, 11E).

\section{Anterior periventricular nucleus (NAPv)}

The anterior periventricular nucleus (NAPv) surges at the caudal pole of NPOpc replacing it in the ventral periventricular zone of the POA (Plate 10D). It is composed of intensely stained cells, small in size and rounded in shape, densely packed in the periventricular zone and more loosely distributed in the lateral region of the nucleus (Plate 10D; Fig. 5B). The NAPv in catfish do not represent a large cell mass, being its rostral pole coincident with the onset of the optic tectum (OT) and the longitudinal torus (TLo), and its caudal border with the end of the posterior commissure and the development of the characteristic "C-shape" of the OT (Plates 10D, 11E). NPOgc cells limit the NAPv dorsally, while it is bounded ventrally by the cells of the suprachiasmatic nucleus (Plates 10D, 11E).

\section{Suprachiasmatic nucleus (NSC)}

The suprachiasmatic nucleus (NSC) starts at the end of the optic chiasm and contains rounded, ovoid and bipolar cells, slightly larger and with a lighter stained that the neighboring cells from NAPv (Plates 10D, 11E, Fig. 5B). This nucleus is located in the ventromedial region of the rostral diencephalon and its cells display different arrangements: scattered, in pairs and triplets or in the form of clusters with many cells (Fig. 5B). Rostrally, the cell mass of NSC is visualized separately on both hemispheres but, as it progresses caudally, these bilateral cell masses are joined in the midline, adopting a compact appearance (Plates 10D, 11E). 


\section{Posterior periventricular nucleus (NPPv)}

The posterior periventricular nucleus (NPPv) represents the most caudal cell mass from the preoptic area and marks the limit between posterior tubercle and periventricular hypothalamic cell masses (Plate 11F). This small nucleus occupies the place left by the NAPv and its rounded and ovoid cells are more loosely distributed and larger in size than those of NAPv, being some of them darkly stained (Fig. 5D).

\subsection{Hypothalamus}

In catfish, the hypothalamus is formed by several cell masses that encompass a great part of the ventral diencephalon, including two paired lobes visible macroscopically. We classify the hypothalamus of surubim into two main areas: (1) the medial tuberal zone and (2) lateral (or inferior) zone - also called as inferior lobes of the hypothalamus (IL) (Plates 11-16).

\section{Medial tuberal zone of the hypothalamus}

The medial tuberal zone consists of distinct cellular masses that arise just ventrocaudal to the preoptic area, surrounding the periventricular region of the third ventricle. This tuberal zone is organized into four main nuclei, some of them exhibiting different subnuclei: (1) lateral tuberal nucleus (NLT), (2) anterior tuberal nucleus (NAT), (3) nucleus of the lateral recess (NRL) and (4) nucleus of the posterior recess (NRP)(Table I, Plates 11-14).

The lateral tuberal nucleus of the medial hypothalamus can be subdivided, in catfish, into five main parts: dorsal (NLTd), ventral (NLTv), medial (NLTm), intermediate (NLTi) and caudal (NLTc). The NLTd comprises small and rounded cells with intense staining, which are arranged in a compressed column along the periventricular wall of the rostral hypothalamus (Plates 11F-12G, Fig. 6B). The location of this cell mass in catfish can be delineated by using two marked invaginations of the ventricular wall as references (Plate 12G, Fig. 6B). Below the NLTd is located NLTv, whose cells present similar characteristics to those of NLTd, and extend ventrally joining the right and left hemispheres (Plates 11F, 12G; Figs. 6B, C). However, its small to medium-sized cells appear organized in columns narrower than those of NLTd (Figs. 6B). The cells of NLTm, unlike the cells of NLTd and NLTv, have a scattered distribution in the neuropil, and can be observed as single, pairs or triplets of cells. This cell mass is tiny in extension and, if compared with other cell masses of the NLT, it has a few number of cells (Fig. 6C).

Caudally in NLT and below the lateral recess arise the cells of NLTi, with intensely stained rounded cells that adopt a more compact arrangement in the periventricular zone and a 
more scattered distribution in the lateral part of the nucleus (Plates 12H, 13I-J; Fig. 6A). As we progress caudally in the medial tuberal region, the NLTi gives rise to the caudal part of the lateral tuberal nucleus (NLTc) (Plate 14), which shows smaller rounded and fusiform cells that exhibits a more intense staining than NLTi cells and a very crowded arrangement (Figs. 6D, 7A).

The anterior tuberal nucleus (NAT) represents one of the first cell masses that arise in medial tuberal region. The NAT is formed by a few pale stained cells, which appear laterally and in close contact with the cells of the NLTd and dorsally to NLTm cells (Plate 11F, 12G). These medium sized cells show a rounded shape, and are located immediately caudolaterally to the cells of the anterior periventricular region (Fig. 6C). This cell mass ends caudally just when mediolaterally directed extensions of the lateral recess are evident in the tuberal hypothalamus and the nucleus of the lateral recess arises (Plate 12H).

We have found along the catfish lateral recess some clusters of tightly packed cells that have been ascribed to three different nuclei: dorsal (NRLd), ventral (NRLv) and lateral (NRLI) nuclei of the lateral recess. Although the three cell masses are considered as belonging to the same nucleus, the latter subdivision will be described within the lateral or inferior hypothalamic zone because its anatomical position (Table I). The cells of the NRLd have intensely stained small to medium-sized cell body, which are rounded or ellipsoid in shape (Plate 12H; Fig. 6A). Although forming a compact cell mass, the NRLd cells are more loosely distributed than those that appear bordering the ventromedial zone of the rostral lateral recess (Plate 12H, 13I; Fig. 6A). These latter cells belong to the NRLv, which is characterized by the presence of densely packed, darkly stained rounded cells, slightly smaller in size than those of NRLd (Fig. 6A).

The most caudal cell mass appearing in the medial tuberal zone is the nucleus of the posterior recess (NRP). This cells mass is easily recognized because its cells, small in size and darkly stained, appear tightly packed as a columnar thickening of the ependymal cell layer around the laterally directed diverticula of the posterior recess (Plate 14K; Fig. 6D). The thickness of this column of cells is higher in the dorsal pole of NRP in relation to the ventral border (Plate 14K; Fig. 6D).

\section{Lateral - or inferior - zone of the hypothalamus}

The lateral zone or inferior lobe of the hypothalamus (IL) is a paired and lobular structure that protrudes in the ventral forebrain and occupies a large part of the ventral diencephalon (Fig. 
1). In catfish, this area has been organized into four main cellular groups: (1) the lateral part of the nucleus of the lateral recess (NRL1), (2) posterior part of the nucleus of the lateral recess (NRLp), (3) diffuse nucleus of the inferior lobe of the hypothalamus (NDLI) and (4) the central nucleus of the inferior lobe of the hypothalamus (NCLI) as shown in Table I.

As indicated above, although the nucleus of the lateral recess in catfish is a part of the medial tuberal zone, we have considered the lateral and posterior regions of this nucleus as part of IL zone because they are present within this lobe in almost all their extent (Plates 11F15). The NRLI can be observed before the opening of the lateral recess in catfish as a compact cell mass distinguishable because the presence of cells larger than those of NRLd and NRLv, with rounded cell body displaying intensely stained cytoplasm (Plate 11F, Figs. 6A, D, 7A, E). Rostrally, the NRLl cells exhibit a more scattered organization, adopting caudally a more packed appearance around the lateral recess. Furthermore, close to the lateral recess, the NRLl cells appear smaller and more intensely stained. At the caudal pole of the inferior lobe, these cells appear more loosely arranged around the lateral recess, composing the posterior region of the nucleus of the lateral recess (NRLp), whose cells have a less rounded shape than those from NRLl, but similar staining features (Plate 16I).

The cellular masses that actually represent the pair of inferior lobes of the hypothalamus from catfish are organized into two different nuclei: the diffuse (NDLI) and the central (NCLI) nuclei of the hypothalamic inferior lobes. The NDLI cells are medium-sized, rounded to ovoid in shape, and exhibit a light staining along the whole rostrocaudal length of the lobe (Figs. 7A, B). These cells are distributed regularly in small clusters or isolated all over the inferior lobes. Rostrally, these cells are organized in small clusters that occupy the ventrolateral part of catfish brain (Plate 12) and caudally NDLI cells fill the entire lobe until it disappearance (Plate 16I; Fig. 7B).

As the NDLI, the central nucleus of the inferior lobe of hypothalamus (NCLI) is a large cell mass when compared with other nuclei of the catfish brain. It arises just caudal and laterally to the opening of the posterior recess and can be viewed by almost the entire length of IL (Plate 14L, 15, 16). The cells of NCLI can be distinguished because they are more heterogeneous in size (from small to large) shape (rounded, ovoid and polygonal) and staining (from pale to darkly staining) when compared to NDLI cells and appear more loosely arranged within a profuse neuropil (Plates 14L, 15, 16; Fig. 7C). 


\subsection{Epithalamus}

The epithalamus of catfish is composed of the habenula, the habenular commissure, and the epiphysis. The habenula $(\mathrm{Ha})$ is a paired finger-shaped structure connected bilaterally through the habenular commissure ( $\mathrm{HaCo}$ ) (Plate 9B). No apparent asymmetry was found between left and right habenula. Rostrally, the Ha is apparently an even cell mass without subdivisions; however, in the caudal zone, two different subnuclei can be discerned: (1) the dorsal part of the habenular nucleus (Had), and (2) the ventral part of the habenular nucleus (Hav) (Plate 10C). The dorsal habenular nucleus contains intensely labeled cells of small size that appear arranged in many clusters separated from each other by neuropil-rich zones (Fig. 8D). In turn, the ventral habenular nucleus is composed of cells slightly smaller, more intensely stained and more densely packed than those of Had (Fig. 8E). This feature is observed up to the caudal end of the habenula, before being replaced by the posterior commissure and the subcommissural organ (Plate 10D).

\subsection{Ventral thalamus}

The ventral thalamic region of catfish surges in the rostrodorsal pole of the diencephalon, replacing the caudal nuclei of the telencephalon and coinciding with the onset of the optic tectum (Plate 9B). The ventral thalamus is organized into three cell masses: (1) ventromedial thalamic nucleus (VM), (2) ventrolateral thalamic nucleus (VL), and (3) intermediate thalamic nucleus (I).

Rostrally, the cells of VM and VL seem merged (VL + VM), but caudally they form two definite and well-segregated clusters. The ventromedial nucleus is located in the periventricular region of the rostral thalamus and consists predominantly of rounded mediumsized cells, but a few large neurons can also be found; in some regions of the nucleus its cells appear scattered but normally they form clusters of neurons (Fig. 8A). The ventrolateral region, located laterally to $\mathrm{VM}$, is composed of neurons predominantly rounded (with some fusiform cells), larger and more intensely stained than those of VM, which appear aggregated in condensed clusters (Plates 9B-11E; Fig. 8A). Although they maintain their anatomical disposition, i.e., VM in the periventricular zone and VL remaining in its lateral position, caudally the VM cells appear more grouped and the VL cells assume a more dispersed pattern (Plates 10D, 11E).

The intermediate thalamic nucleus (I) starts immediately below the ventral region of the habenular nucleus and above to ventromedial thalamic nuclei, occupying at its rostral pole a periventricular position (Plate 10C). Their cells are small and densely packed, have a rounded 
shape and exhibit a strong staining (Fig. 8A). At its caudal end, the intermediate thalamic nucleus is displaced laterally by the anterior nucleus of the dorsal thalamus (Plate 11E).

\subsection{Dorsal thalamus}

The dorsal thalamus in catfish appears as a cluster of cells extending laterally from the ventricle, which appear organized in three main nuclei: (1) anterior thalamic nucleus, (2) central posterior thalamic nucleus, and (3) dorsal posterior thalamic. In the dorsal thalamus, the first nucleus to appear is the anterior thalamic nucleus (A), which occupies the periventricular position and displaces laterally the intermediate nucleus of the ventral thalamus (Plate 11E). It contains intensely stained cells of varying sizes (from small to medium size) and shapes (rounded or fusiform) (Plate 11E; Fig. 8B). Caudally, the anterior thalamic nucleus is replaced by the dorsal posterior thalamic nucleus (DP), which represents a much more prominent cell mass formed by small and medium-sized neurons, with moderate staining, that extended mediolaterally below the retroflex fascicle (Plate 11F; Fig. 8C, D). Also, within the dorsal thalamus, the neurons of the central posterior thalamic nucleus (CP) appear just ventrally to the DP. The CP is typically differentiated by the presence of bipolar neurons clearly visualized for its intense staining. This nucleus exhibits loosely distributed cells in the periventricular zone and a more compact arrangement in its lateral aspect (Fig. 8C, F). The DP and CP can be delineated clearly because the presence of a stronger labeling in cells from the latter and the existence of a neuropil-rich area that separates both cell masses (Fig. 8F). In addition, the DP reaches more caudal levels than the CP (Plate 12G).

\subsection{Posterior tubercle}

The posterior tubercle of catfish is a complex diencephalic area, which in this study was organized into two main groups of nuclei: (1) cell masses that are located in the periventricular region and (2) migrated nuclei (Plates 11-16).

\section{Periventricular nuclei}

The periventricular area of the posterior tubercle comprises: (1) the periventricular nucleus of the posterior tubercle (TPp), (2) the paraventricular organ (PVO), (3) the nucleus of the paraventricular organ (nPVO) and (4) the posterior tuberal nucleus (NPT).

The cells of TPp show variability in size (from small to medium-sized cells, with few large neurons), and intense staining (Fig. 8C); it represents a cell mass that, despite its 
dispersed cells arrangement, is bounded by neuropil forming a triangular-shaped cell mass, whose base is given by the ventricular wall (Plate 12G). Just below this cell masses, we found a compact group of intensely stained ependymal cells that forms a columnar structure termed paraventricular organ (PVO). These small cells form a thick band along the ventricular surface (Fig. 8C, Plate 12G,H, 13I). The nucleus of the paraventricular organ (nPVO) lies lateral to PVO and is composed of few neurons with moderate staining that appear distributed in a dispersed way within the nucleus, maintaining its disposition around the PVO for almost its entire length (Plate 12; Fig. 8C). Finally, the most caudal cell group displayed in the periventricular region is the posterior tuberal nucleus (NPT). This cell mass can be discerned caudal to NRLd in a dorsal position in relation to the posterior opening of the lateral recess, reaching up to the caudal end of the posterior recess (Plates 13J, 14K). Its cells, rounded in shape or slightly flattened and intensely stained, are organized in large clusters although some isolated cells from this nucleus can eventually be mixed with cells of the NRP (see in Fig. 6D).

\section{Migrated nuclei}

The region described as migrated nuclei represents one of the most complex regions in the catfish diencephalon, and contains the highest number of cell masses of the posterior tubercle. These cell masses were organized into five major groups: (1) preglomerular complex (NPG), (2) supraglomerular nucleus (SG), (3) subglomerular nucleus (SPG), (4) caudomedial nuclei and (5) outlying nuclei.

The preglomerular nuclei form a set of different cell masses, interspersed within a profuse neuropil; they occupy different regions from the lateral to the medial part of the diencephalon. As a result they have been named according to their location as: anterior preglomerular nucleus (NPGa), lateral preglomerular nucleus (NPGl) and medial preglomerular nucleus (NPGm).

The anterior preglomerular nucleus appears in the rostral pole of the posterior tubercle, in the ventral surface of the diencephalon, and lateral to the rostral hypothalamic cells masses (Plate 11F). The NPGa exhibits small and medium-sized cells that resemble those of the NDLI but appear much more densely packed and more darkly stained (Figure 9C). The lateral preglomerular nucleus (NPGI) arises slightly rostral to NPGa and dorsolaterally to it (Plate 10). This nucleus forms a bulge in the lateral part of the rostral pole of the inferior lobes and contains small, medium-sized and large cell distributed in clusters, (Plates 11E,F, 12G; Figs. 9A, B). Rostrally it is characterized by the presence of a single cell mass with 
small and medium-sized cells, exhibiting a relatively intense staining. These cells are grouped in clusters that may have few or many cells per cluster. As it progresses caudally, a sulcus present in the ventrolateral surface of the brain, as well as a neuropil-rich region devoid of cells, mark the separation of this cell mass into two different subnuclei: (1) dorsal part and (2) the ventral part of the lateral preglomerular nucleus (NPGld and NPGlv, respectively) (Plate 10D). The dorsal part of the NPGl keeps the features described before, however, the ventral part presents most uniformly grouped cells, higher in size than those of NPGld (Fig. 9A, B). When the cells of NDLI arise, both NPGld and NPGlv nuclei move slightly towards the central region of the inferior lobes, exhibiting a gradual reduction in size until they disappear (Plate 12). At the caudal pole of NPLl arises the medial preglomerular nucleus (NPGm), which occupies a central position in the ventral part of each brain hemisphere (Plate 12G). This migrated nucleus is characterized by its rounded to ovoid faintly stained cells (Fig. 9G). Rostrally, the NPGm is bounded laterally by the cells of the posterior thalamic nucleus, and dorsally by the cells of the supraglomerular nucleus (Plate 12G,H, 13I,J). Caudally, the cells of the commissural preglomerular nucleus limit NPGm cells ventrally, before being replaced by the neurons of the subglomerular nucleus (Plates 13J, 14K).

Two distinct cell masses can be observed surrounding the caudal pole of the preglomerular nuclear complex, in the central region of the posterior diencephalon: the supraglomerular nucleus (SPG) and subglomerular nucleus (SG). The first cell mass to appear is the supraglomerular nucleus, which arises laterally to TPp (Plate 12H). The SPG shows intensely stained cells dispersed into a glomerular neuropil (Fig. 9F). These cells, rounded, elongated and poligonal in shape, also exhibit some heterogeneity in size ranging from small to medium size, but a few dispersed large neurons can also be found within SPG (Fig. 9F). The SG starts more caudally than SPG, at the posterior margin of the NPGm and medially to LT (Plate 13J). This nucleus contains small to medium cells, with rounded or fusiform shapes, that appear in some case arranged in cord-like structures (Figure 9G). Caudally, both SPG and SG end just rostral to the onset of the lobobulbar nucleus (Plates 14L, 15M).

The caudomedial nuclei are represented by two cell masses that emerges close to the midline, in the caudal posterior tubercle: the commissural preglomerular nucleus (NPGc) and the mammillary bodies (CM). The most rostral cells of NPGc arise ventromedially to NPGm in the central part of the brain, and near to the horizontal commissure (Plates 13I,J). These cells migrate medially from their rostral position to reach the midline, just above the mammillary bodies, in the caudal pole of the nucleus (Plates 14, 15, 16I). It is composed of intensely stained granular cells that are evenly distributed within the cell mass (Plate 15; Fig. 
9D). The mammillary bodies are paired midline cell masses that surge in the ventral-posterior diencephalon of catfish, just caudal to the NLTc and the posterior recess (Plates 14L, 15M). These large and rounded structures lie below to NPGc, and are composed of small tightly packed granular cells in the central region, which resemble those of the nucleus of the posterior recess, and an abundant neuropil in the periphery (Plates 15M,N, 16I; Fig 9D). The mammillary bodies on catfish represent the point of anlage of the pituitary (PIT), which is attached to the brain via a long neurohypophysary stalk that exits between the two lobes of the CM (Plates 15M,N, 16I). The pituitary gland in catfish is positioned much more caudal when compared to other teleost fish.

We have also considered in the posterior tubercle four outlying nuclei: the lateral torus (TLa), the posterior thalamic nucleus (PT), the lateral thalamic nucleus (LT) and the lobobulbar nucleus (LB). The TLa is located laterally in the caudal diencephalon, ventral to the midbrain tegmentum and the optic tectum and dorsal to the inferior lobe of the hypothalamus (Plates 14, 15). The TLa cells, which are emitted medially form a marked sulcus present in the lateral region of the inferior lobes, show a similar aspect than those of NDLI (rounded shape, small to medium size, moderate staining) and appear separated from NDLI cells by a profuse neuropil (Fig. 7A, D). The posterior thalamic nucleus lies between the preglomerular nuclear complex and the diffuse nucleus of the inferior lobe (Plates 12, 13). The PT is composed of medium-sized cells that exhibit an intense staining and appear grouped in clusters of up to 10 neurons (Fig. 9E). Further caudal, it is bounded medially by two other migrated cell masses from the posterior tubercle (SPG and SG), and its place is occupied by the lateral thalamic nucleus (Plates 13I, J). The lateral thalamic nucleus arises just caudal to the PT in the lateral margin of the posterior tubercle, being replaced caudally by the central nucleus of the inferior lobe (Plates 13J, 14K, L). This cell mass is bounded by the SPG and SG in its dorsomedial pole and by the diffuse nucleus of the inferior lobe in its ventrolateral border (Plate 13J, 14K; Fig. 9G). The LT is formed by rounded medium-sized cells that appear aggregated in the center of the nucleus but adopt a more dispersed arrangement in the periphery (Fig. 9G). The lobobulbar nucleus (LB) represents the most caudal migrated nucleus from the posterior tubercle, lying dorsally to the central nucleus of the hypothalamic inferior lobes (Plates 15M, N, 16I). The LB contains small rounded cells but its main characteristic is the presence of large and giant fusiform and bipolar neurons (Fig. 10D). These cells exhibit an intense staining and are found in the same transverse plane than the mammillary bodies (Plates 15M, N, 16I). 


\subsection{Synencephalon}

Although some authors use the term "Synencephalon" (Syn) in different ways and classify pretectal nuclei and the optical accessories nuclei as part of this diencephalic area, in this study we will follow the nomenclature of other authors that consider these regions in a separate way (see Braford \& Northcutt, 1983, Striedter, 1990). The organization adopted for this study is presented in Table I and considers the synencephalon as a transition area between the caudal diencephalon proper and the rostral mesencephalon. The synencephalon in catfish starts rostrally at the transverse level where the posterior commissure arises, its beginning being marked by the appearance of a compressed longitudinal fibrous tract, the retroflex fascicle (FR) (Plate 10D). It extends laterally and caudally along the dorsal border of the caudal diencephalon, and ends at the onset of the mesencephalic tegmentum (Plates 14K, L). The synencephalon of catfish is organized into five major cellular masses: (1) the subcommissural organ (SCO) (2) the periventricular pretectal nuclei (PPd and PPv), (3) the paracommissural nucleus (NP), (4) the nucleus of the medial longitudinal fascicle (nMLF), and (5) the medial pretoral nucleus (MPN) (Table I).

The subcommissural organ (SCO) surges caudally to the habenula, in the ventral margin of the posterior commissure (Plate 10). It is composed of densely packed and darkly stained small cells that appear arranged as a compact column in the dorsal roof of the 3rd ventricle (Plate 10D). The periventricular pretectum occupy the rostromedial part of the synencephalon and lie around the retroflex fascicle (FR) (Plates 10D to 12 G). In catfish, as in other teleost fish, the periventricular pretectum can be divided into dorsal (PPd) and ventral (PPv) periventricular nuclei. The PPd cells arise more rostrally in the synencephalon, and borders the dorsal and dorsolateral margins of the FR (Plates 10D-12G). It is bounded medially by the posterior commissure, dorsally by the paracommissural nucleus, laterally by the central pretectal nucleus and ventrally by PPd. Its small to medium-sized neurons are rounded, triangular and polygonal in shape and show a moderate staining, lacking a compact grouping (Fig. 8C). In turn, the PPv lies ventral and ventrolateral to the FR and presents smaller, more rounded and compact cells (Plates 10D-12G; Fig. 8B, C). In its rostral pole, the PPv limits ventrally with the anterior and intermediate thalamic nuclei, but further caudal the dorsal posterior thalamic nucleus represents its ventral border. Dorsally to PPd, we found the paracommissural nucleus (NP), which arises in the dorsal surface of the brain at the same transverse level than the posterior commissure and the longitudinal torus, laterally and ventrally to them, respectively. (Plate 10D). It is possible to observe abundant fibers from the posterior commissure that are coursing medially through the NP (Fig. 10A). The NP presents 
small to medium-sized cells, with intense staining and arranged mediolaterally in clusters containing numerous cells (Fig. 10A). Lateral to the NP starts the medial pretoral nucleus (MPN), which arises in the dorso-lateral surface of the brain, close to the rostral pole of the semicircular torus (Plates 11F, 12G, H). This nucleus exhibits rounded, triangular and polygonal neurons, with small to medium size, and intensely stained, which appear more packed next to the tectal ventricle, but showed a more scattered distribution in the periphery of the nucleus (Fig. 10E).

The periventricular pretectal nuclei is replaced caudally by the cell mass of the medial longitudinal fascicle (nMLF) that covers the medial-dorsal region of the caudal synencephalon and reach until the onset of the midbrain tegmentum (Plates 12-14). The nMLF shows darkly stained cells with sizes ranging from small to large, interspersed within a fibrous neuropil (Fig. 10F). Some of the neurons present in nMLF represent the largest and most intensely stained neurons of the diencephalon, most of them located close to the medial periventricular walls (Plates 12-14; Fig. 10F).

\subsection{Pretectum and Accessory preoptic nuclei}

The dorsolateral region of the diencephalon of catfish is occupied by the pretectum and the accessory preoptic nuclei, lying medially to the rostral margin of the optic tectum (Plates 1012). Two cell masses form the pretectum of catfish: (1) the central pretectal nucleus (NPC) and (2) the electrosensory nucleus (NES). The NPC has cells from small size, with intense staining, that form sparse clusters in the dorsolateral region of the diencephalon. This large pretectal cell mass begins laterally to the paracommissural nucleus and its cells initially lie medial to the optic tectum (Plate 10D, Fig. 10E). Further caudal, this nucleus is bordered laterally by the cells of the semicircular torus (TS) (Plate 12). The cell mass of the electrosensory nucleus from catfish is located just below the NPC, and laterally to the thalamic cell masses. It has an ellipsoid or rounded shape in transverse sections, with a profuse neuropil in the center of the nucleus, being neurons concentrated in the periphery (Fig. 10B). The NES exhibits intensely stained cells, with a rounded shape and different sizes, containing predominantly medium-sized neurons (Plate 11; Fig. 10B).

The accessory optic nuclei of surubim contain two conspicuous cell masses: (1) the dorsal accessory optic nucleus (DAO) and (2) the ventral accessory optic nucleus (VAO). The dorsal accessory optic nucleus begins in the ventral margin of the rostral optic tectum, keeping constant its location along its entire length (Plate 10D-11F). Its cells have a rounded and bipolar aspect, with intense coloration with cresyl violet and appear arranged to form a 
uniform and compact cell group (Fig. 10B). In turn, the ventral accessory optic nucleus lies laterally to the ventrolateral thalamic nucleus, moving gradually to the lateral part of the brain (Plates 10D, 11E). The VAO neurons show similar characteristics in shape and staining than those of DAO but adopt a more compact arrangement and have smaller size (Fig. 10C). 

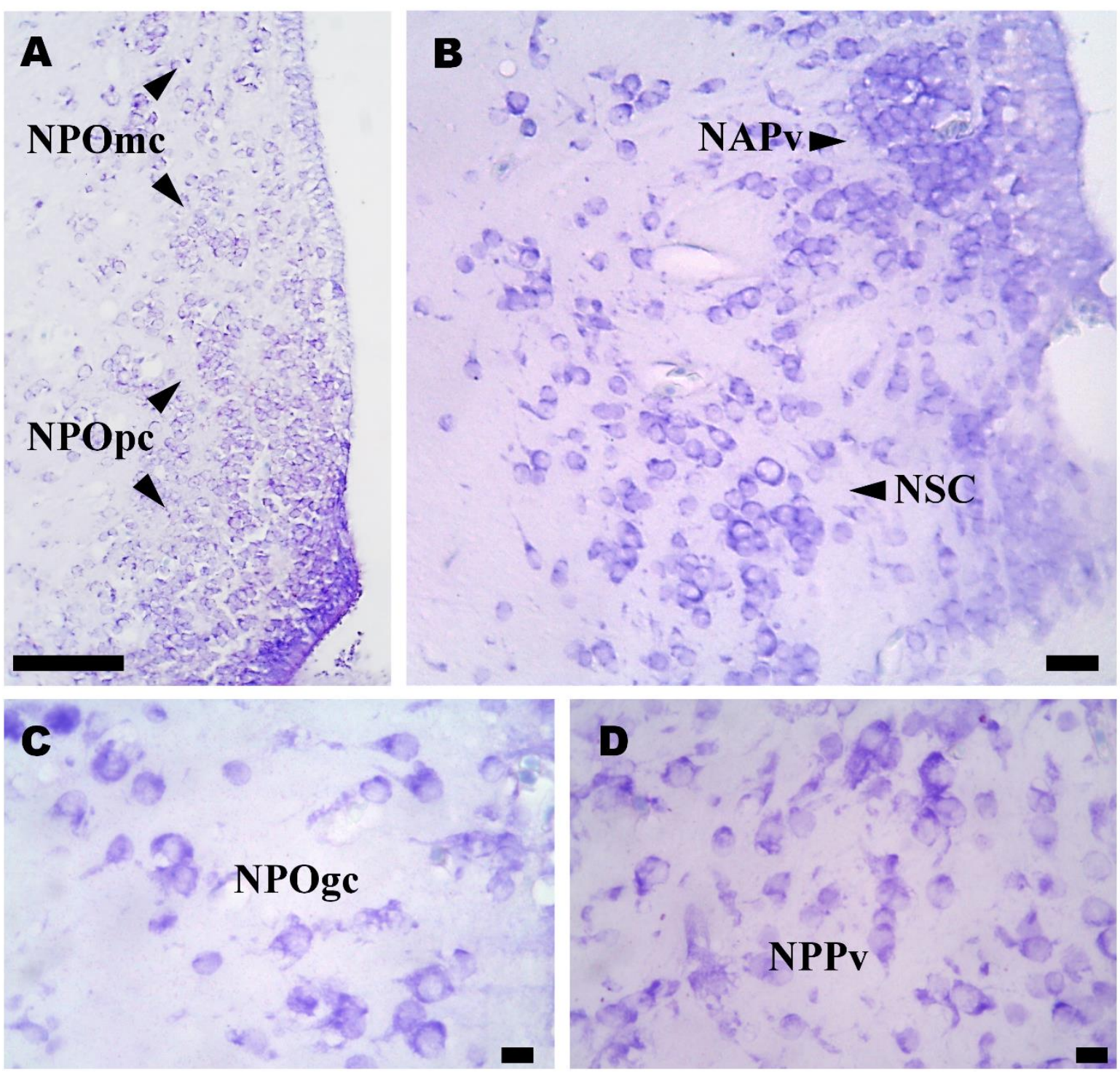

Fig. 5. Photomicrographs of transverse sections of the catfish brain (Steindachneridion parahybae) stained with cresyl-violet showing at higher magnification the different nuclei of the preoptic area. Section at the level of (A) Plate 9B, (B) Plate 10D, (C) Plate 10D and (D) Plate 11F. Scale bar: A = $50 \mu \mathrm{m}, \mathbf{B}=$ $17 \mu \mathrm{m}$ and $\mathbf{C}$ and $\mathbf{D}=7 \mu \mathrm{m}$. For abbreviations, see the list of abbreviations (on the beginning of this Atlas) and Table 1. 

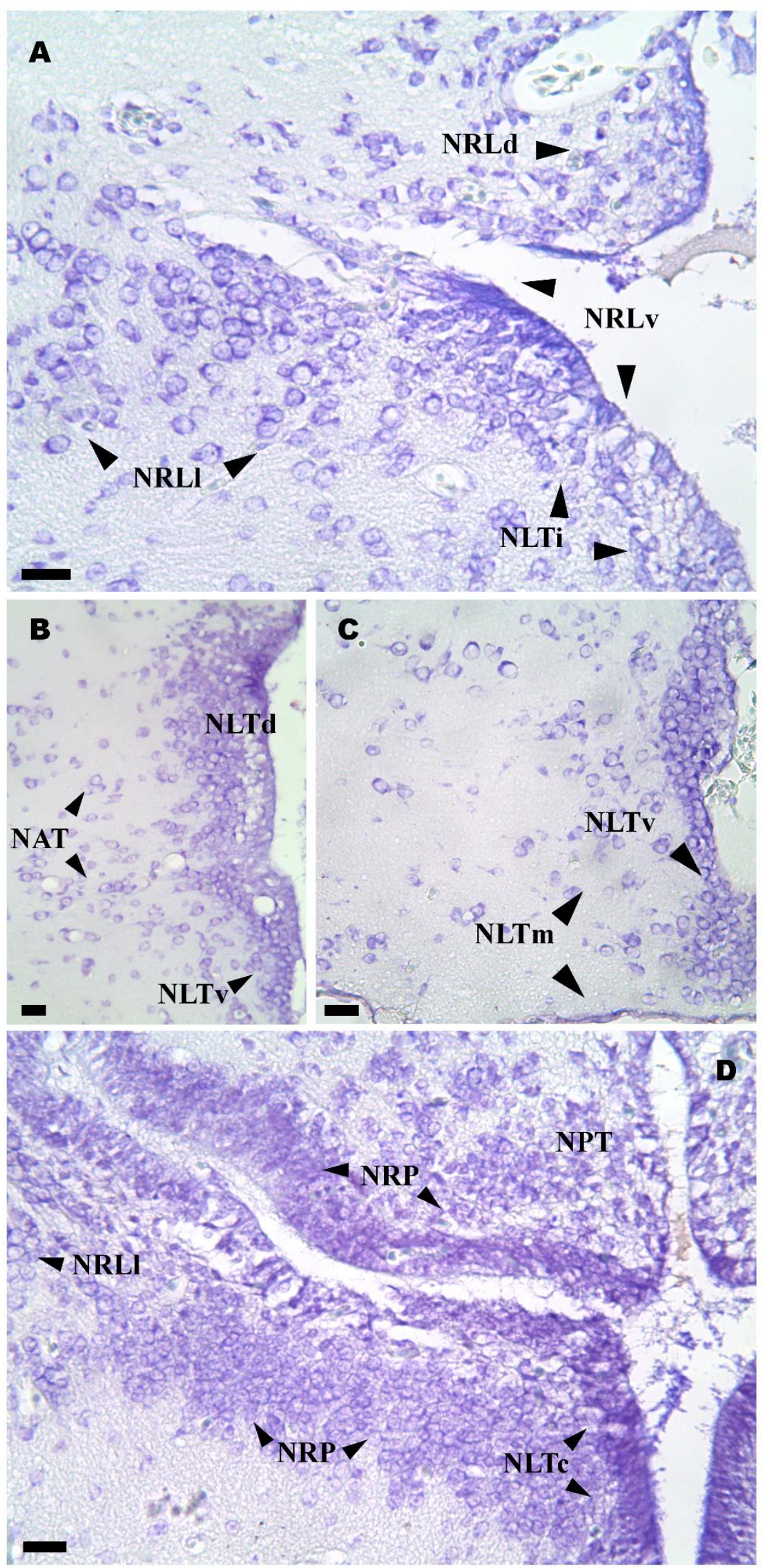

Fig. 6. Photomicrographs of transverse sections of the catfish brain (Steindachneridion parahybae) stained with cresyl-violet showing at higher magnification the different nuclei of the medial tuberal zone of the hypothalamus. Section at the level of (A) Plate 13I, (B) Plate 12G, (C) Plate $11 \mathrm{~F}$ and (D) Plate $14 \mathrm{~K}$. Scale bar $=17 \mu \mathrm{m}$. For abbreviations, see the list of abbreviations (on the beginning of this Atlas) and Table 1. 


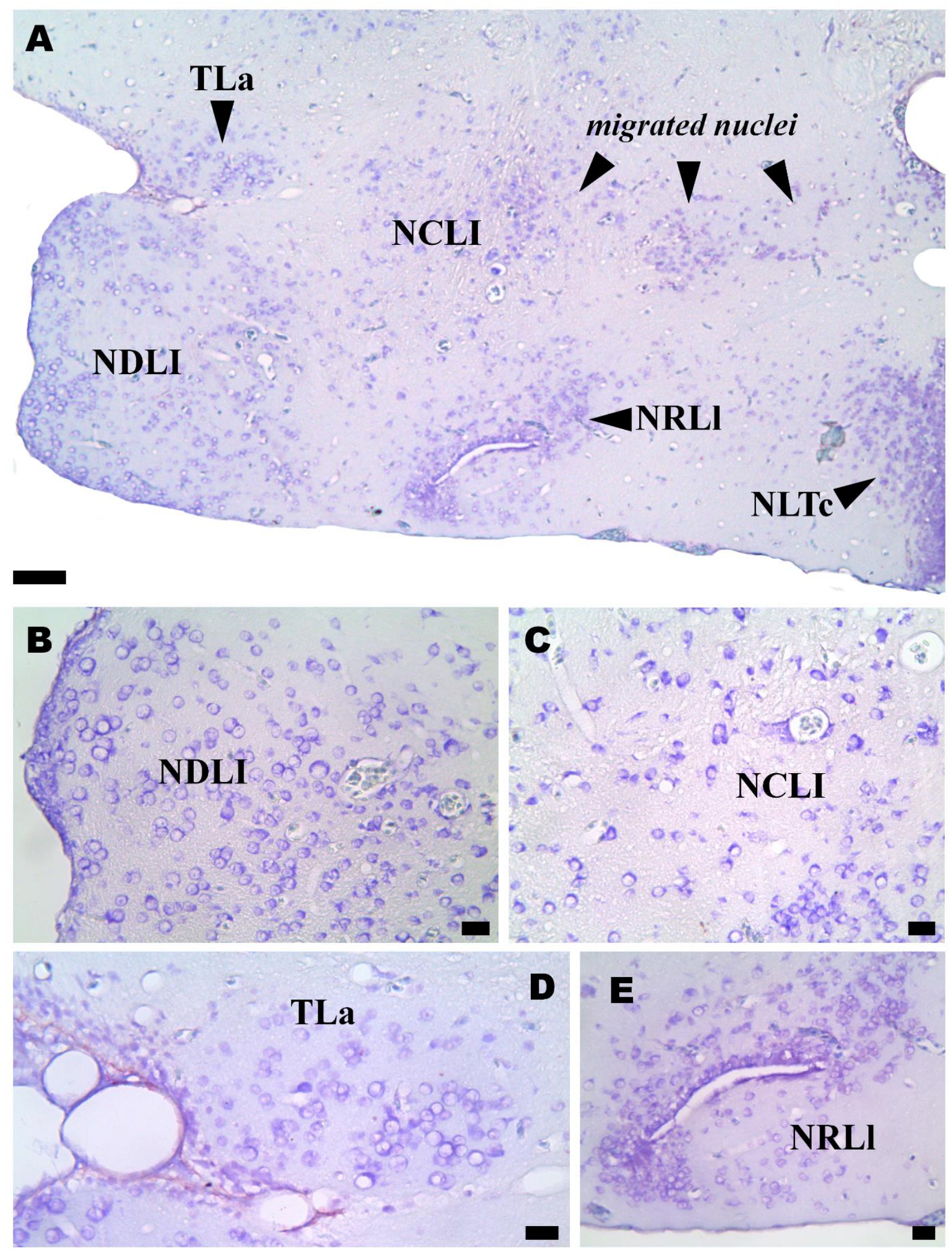

Fig. 7. Photomicrographs of transverse sections of catfish brain (Steindachneridion parahybae) stained with cresyl-violet showing at higher magnification the lateral torus and the nuclei of the inferior lobe of the hypothalamus. Sections at the level of Plate 15. Scale bar: $A=70 \mu \mathrm{m}, \mathrm{B}-\mathrm{E}=17 \mu \mathrm{m}$. For abbreviations, see the list of abbreviations (on the beginning of this Atlas) and Table 1. 

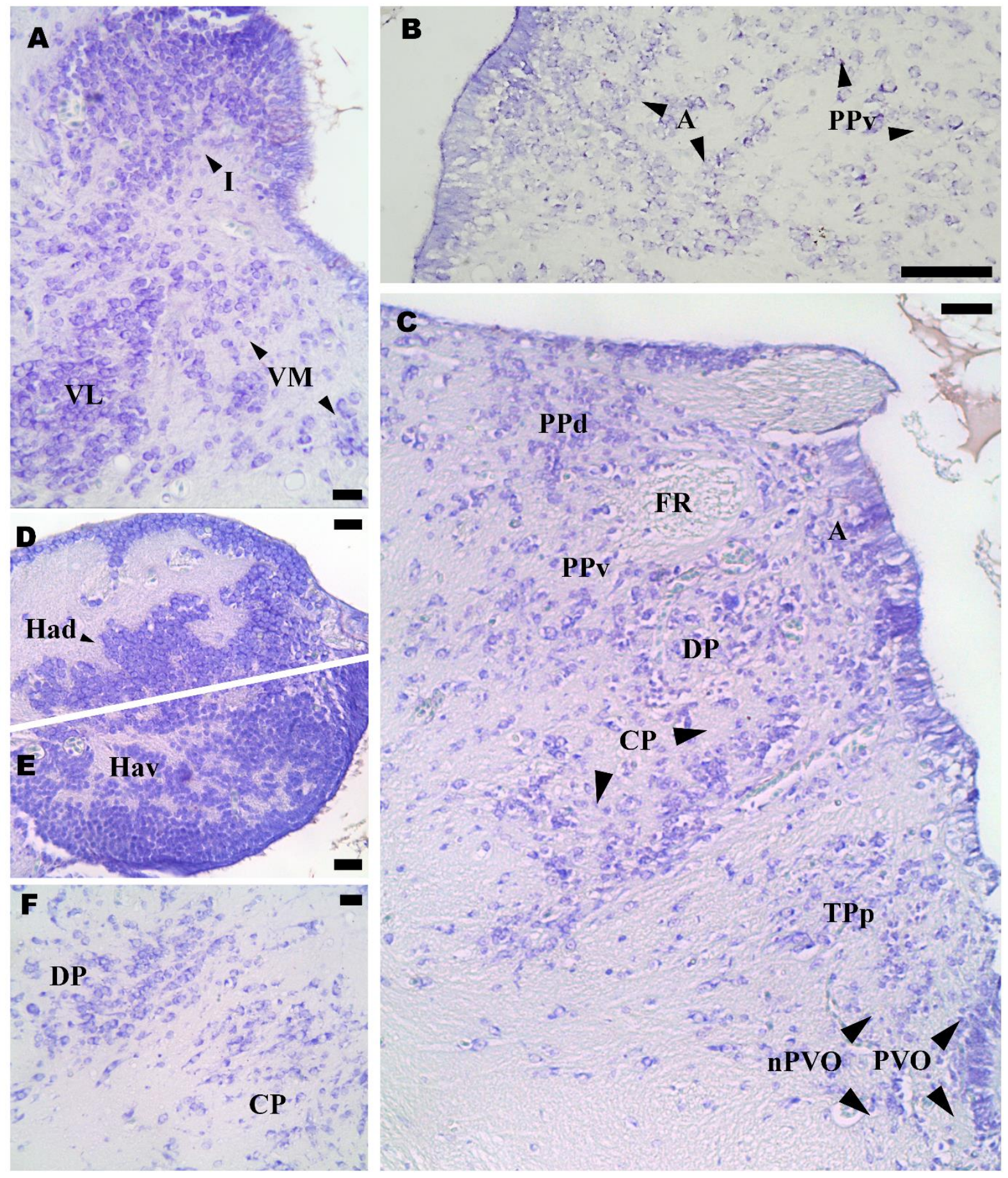

Fig. 8. Photomicrographs of transverse sections of catfish brain (Steindachneridion parahybae) stained with cresyl-violet showing at higher magnification the different nuclei of the epithalamus, thalamus and posterior tubercle. A-B) ventral thalamus. C-D) habenular nuclei. E) dorsal thalamus. F) posterior tubercle. Sections at the level of (A) Plate 10C, (B) Plate 11E, (C) slightly rostral to Plate 11F, (D and E) Plate 10C, (F) Plate 11F. Scale bar: A, D, E and $F=17 \mu \mathrm{m}, \mathrm{B}=50 \mu \mathrm{m}$ and $\mathrm{C}=34 \mu \mathrm{m}$. For abbreviations, see the list of abbreviations (on the beginning of this Atlas) and Table 1. 


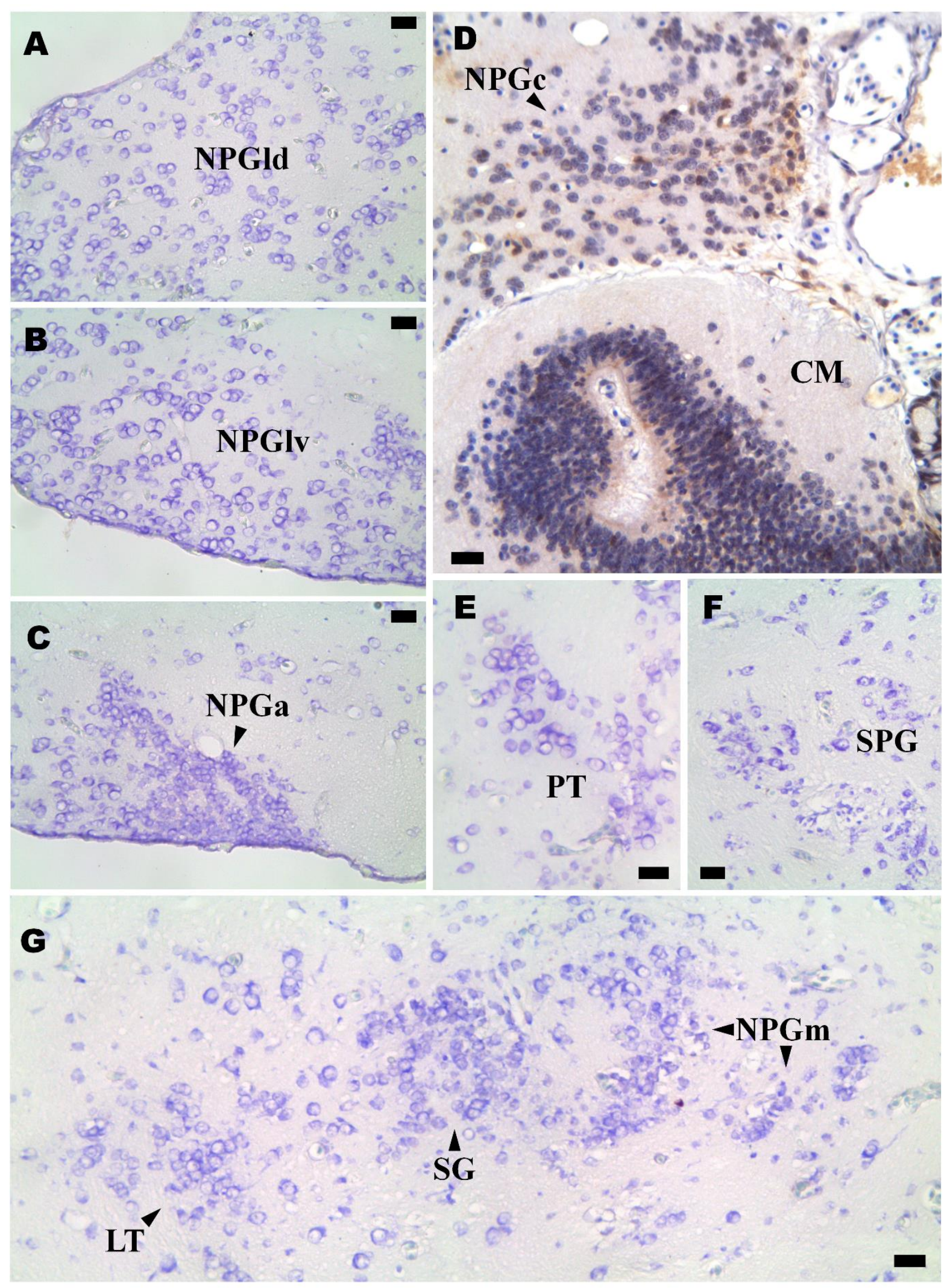

Fig. 9. Photomicrographs of transverses sections of catfish brain (Steindachneridion parahybae) stained with cresyl-violet showing at higher magnification the different migrated nuclei of posterior tubercle. Sections at the level of (A-C) Plate 11F, (D) Plate 15N, (E) Plate 12G, (F) Plate 14K and (G) Plate 13J. Scale $\mathrm{bar}=17 \mu \mathrm{m}$. For abbreviations, see the list of abbreviations (on the beginning of this Atlas) and Table 1. 


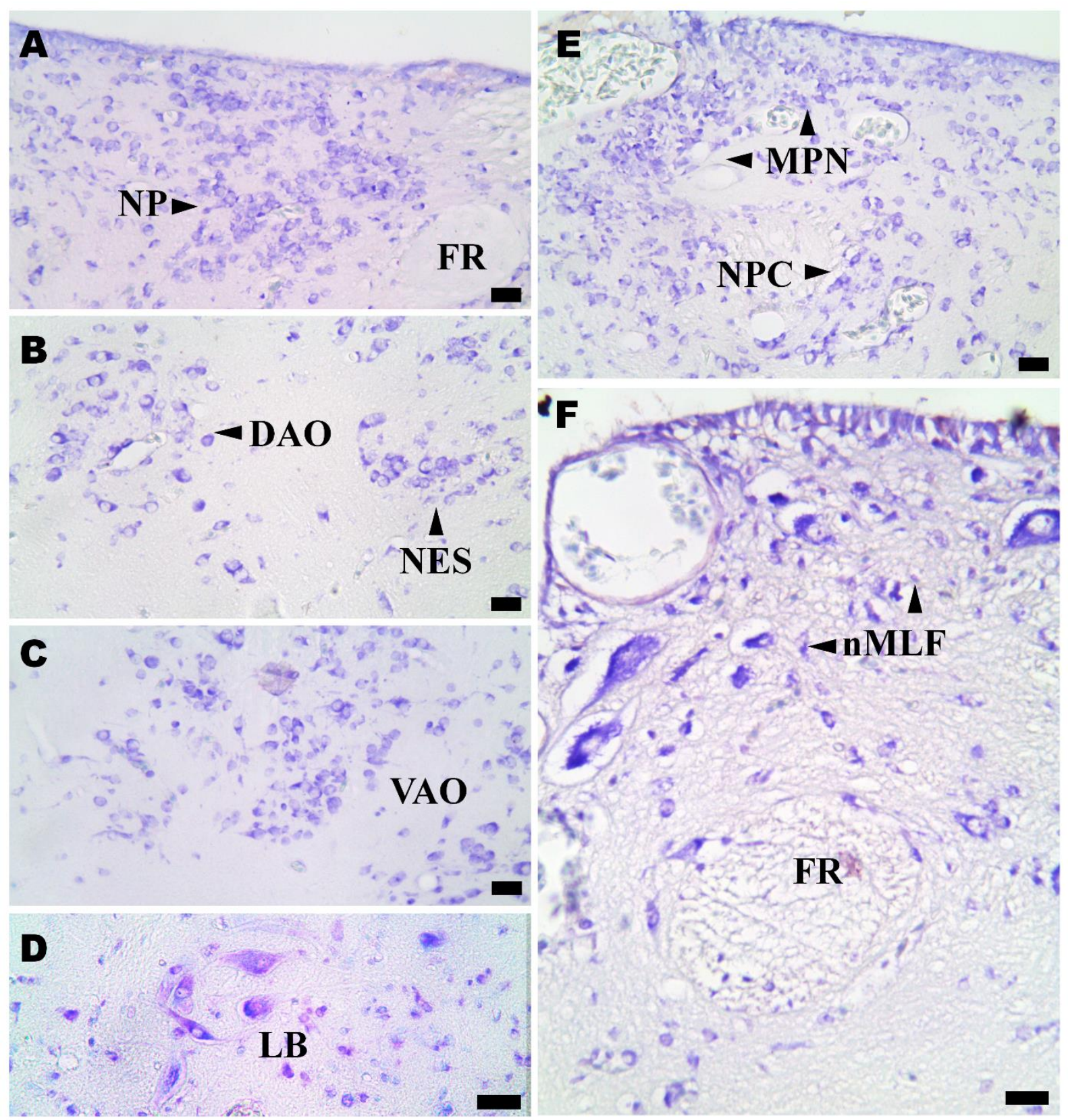

Fig. 10. Photomicrographs of transverse sections of catfish brain (Steindachneridion parahybae) stained with cresyl-violet showing at higher magnification different posterior tubercle, synencephalic, pretectal and accessory optic nuclei. Sections at the level of (A) Plate 11F, (B) Plate 11F, (C) Plate 11E, (D) Plate 15N, (E) Plate 12G and (F) Plate 13I. Scale bar: A, B, C, E, F $=17 \mu \mathrm{m}$ and D $=25 \mu \mathrm{m}$. For abbreviations, see the list of abbreviations (on the beginning of this Atlas) and Table 1. 


\section{The MesenCePhalon}

The mesencephalon (or midbrain) in catfish into three different zones: medial, central - Steindachneridion parahybae - is formed and lateral, each one with particular by both mesencephalic tectum and the subdivision, and mainly distributed in the tegmentum. The mesencephalic tectum is dorso-medial and dorso-lateral regions of composed of a pair of optic lobes, distributed the brain. The brain areas reported in this bilaterally in the brain, and the longitudinal study seem to have a similar pattern or torus, arising caudally to the habenula and organization to that observed in different dorsal to the posterior commissure. The silurids, being most differences noticed in the mesencephalic tegmentum is composed of at location of some nuclei distributed along of least twelve-cell mass, which were organized the brain.

\subsection{Mesencephalic tectum}

\section{Optic tectum}

The optic tectum (OT) of surubim is formed by bilateral pair of lobes that have its onset in the caudal pole of the telencephalic hemispheres and extends up to the rostral margin of the rhombencephalon (Plates 10-19). The cytoarchitecture of the optic tectum shows a laminar organization that, from external to internal direction, permit us to recognized four different layers or zones (Table I): (1) superficial white and gray zone (SWGZ), (2) central zone (CZ), (3) deep white zone (DWZ) and (4) the periventricular gray zone (PGZ)(Fig. 11A).

The superficial white and gray zone represents the most external layer from the OT and is formed by numerous fibers and neuropil that extends up from dorsal to ventral in the outer region of the OT. The SWGZ shows a conspicuous neuropil layer, in which neurons processes are disposed centripetally. In the ventral part of SWGZ a dense bundle of axons forms a prominent fiber layer, which is thicker in the medial and dorsal part of the OT, but is decreasing gradually in width in the lateral region. More deeply in the SWGZ another neuropil layer is evident, being thinner compared to the first layer. The SWGZ displays also a few rounded cells, being also possible to recognize some ovoid and pyramidal cells slightly stained (Figs. 11A, B). 
The central zone of the optic tectum lies just internally to the superficial white and gray zone (Fig. 11A). In catfish, the central zone represents the thickest layer of the OT, and although difficult to delineate in some parts, three different lamina can be identified in this layer: external, middle and internal laminas, the external and internal ones containing more neurons and the middle one being richer in neuropil (Fig. 11A). The $\mathrm{CZ}$ is characterized by the presence of fibers disposed horizontally in whole extent of the optic tectum (Fig. 11A). Mainly small and some large neurons are seen in CZ, presenting a few and dispersed fusiform cells with smooth staining (Figs. 11A,C). Large and darkly stained cells from CZ appear more concentrated in the external and internal laminas of the layer (Fig. 11A). The deep white zone (DWZ) is placed between the $\mathrm{CZ}$ and the periventricular gray zone of the optic tectum (Fig. 11A). It is a zone characterized by the presence of a distinct fiber layer, presenting few ovoid cells of medium size and pale staining. Eventually, the fibers of DWZ can be superficially mixed with the cells of periventricular gray zone (Fig. 11A, D). Finally, the most internal layer in the optic tectum corresponds to the periventricular gray zone (PGZ). This layer can be clearly identified in the optic tectum because it presents small and rounded tightly packed cells, forming a compressed cell layer observed all over the extension of the OT (Fig. 11A). The PGZ neurons display a dark staining in cells bodies, with a granular aspect, that border an internal layer of ependymal cells, which form the periventricular wall (Fig. 11D Some large blood vessels are seen in the PGZ, besides fascicles that seems to run from the semicircular torus to the optic tectum (Fig. 11A).

\section{Longitudinal torus}

The longitudinal torus (TLo) from catfish is a paired structure that lies attached to the optic tectum. At its rostral pole, this paired structure is large and appears positioned medially in the tectal ventricle and dorsally to the posterior commissure (Plates 10D-11), being displaced laterally and reducing considerably its size in the caudal border as the valvula of the cerebellum arises (Plate 17A). The cells of the longitudinal torus are small, exhibit a dark staining and appear firmly packed resembling those of the PGZ. These cells adopt a laminar arrangement in the central part of TLo while the dorsal border is fibrous and appears almost devoid of cells (Plates 11-12, Fig. 11E). In addition, some medium cell bodies can be seen dorsally in this structure. 


\subsection{Mesencephalic tegmentum}

In catfish, the mesencephalic tegmentum is located caudally to the synencephalon and has its caudal margin is bordered by the hindbrain, being located ventral-medially to the optic tectum and dorsally to the inferior lobes of the hypothalamus. We recognized three main areas (and its respective subdivisions) within the mesencephalic tegmentum: (1) Medial Zone, composed of the oculomotor nucleus (nIII), and secondary gustatory nucleus (NGS); (2) Central zone, consisting of the lateral nucleus of the valvula (nLV) - in turn subdivided into anterior and posterior parts, $\mathrm{nLVa}$ and $\mathrm{nLVp}$, respectively -, dorsal posterior tegmental nucleus, isthmic nucleus (NI), nucleus of the locus coeruleus (LC), perilemniscular nucleus (PL) - subdivided into medial and lateral parts, PLm and PLl, respectively -, and (3) Lateral Zone, represented by the semicircular torus and its subdivisions, central, ventral and lateral parts (TSc, TSv and TSl, respectively) (Table I).

\section{Medial Zone}

Located in the dorsomedial area of the midbrain, the oculomotor nucleus (nIII) arises just caudal to the synencephalic nucleus of the medial longitudinal fascicle (Plate 17B) and has its cells embedded between oculomotor nerve fibers. The cells of nIII display small to medium sizes, although some large neurons can also be recognized (Fig. 12A). These cells exhibit intense staining and have predominantly rounded shape, although some slightly flattened neurons can be found (Fig. 12A).

The secondary gustatory nucleus (NGS) is a large cell mass located in the medial zone of the mesencephalon, and extending laterally from the fourth ventricle. The NGS is initially situated near the fourth ventricle, bordered medially by the fibers of the brachium conjunctivum and bounded dorsally by the cerebellum (Plate 18D); in its caudal margin the NGS is located dorso-laterally to the nucleus of the reticular formation (RF), lateral to the granule cells associated with medial auditory nucleus $(g a u d)$ and ventral to the granular eminence from the cerebellum (Plates 18D-21 I). The NGS cells present a strong staining and variable sizes and shapes, with cells from small to large (but predominantly large cells), and rounded to ovoid for most of them, but with few slightly elongated neurons (Fig. 12E). The cells of NGS are more abundant in the periphery of the nucleus, being the more interne region rich in neuropil (Plates 19, 20). Additionally, the brachium conjunctivum (BC) is a condensed vertical tract, bordered laterally by the secondary gustatory nucleus and extended from the place where the granular eminence stars (Plate 18D; Fig. 19E). Rostrally, the BC appears in contact with the wall of the fourth ventricle and further caudal is bordered by 
granule cells associated with medial auditory nucleus ( $g$ aud $)$, which replaces it to adopt a periventricular disposition (Plate 19; Fig. 19E). Apart from their granular characteristics, $g$ aud cells are round and small, with a strong coloration, appearing densely packed in clusters composed of many cells (see Fig. 19E).

\section{Central Zone}

The lateral nucleus of the valvula $(\mathbf{n L V})$ is a dense cell mass, which initially lies in the region of the dorsal mesencephalon, medially to the semicircular torus, at the caudal end of the longitudinal torus (Plate 17A). Further caudally, its cells are embedded in the posterior pole of the valvula of the cerebellum (Plate 17B). As indicated above, the lateral nucleus of the valvula of catfish is divided into two parts: (1) the anterior (nLVa) and (2) the posterior (nLVp) parts. The nLVa is bordered laterally by the cells of the part central of the semicircular torus and medially by the cells of the nMLF (Plate 17A). Slightly caudal, it lies lateroventral to the dorsal posterior tegmental nucleus (Plate 17B). The nLVa displays rounded cells of small size and very intense staining arranged in dense clusters (Fig. 13A), while the posterior part of the lateral nucleus of the valvula (nLVp) also shown small granular cells darkly stained, although, arranged in clusters of cells less densely packed and infiltrated by neuropil (Fig. 13B, C). Both nLV subdivisions have some of their cells intermixed with fibers exiting form the dorsal posterior tegmental nucleus (DPTN), being these projections much more evident between nLVp and DPTN (Plate 17B; Fig. 13C). The DPTN contains small-sized cells that border the lateral apex of the fourth ventricle (Plate 17B) and are arranged much more loosely than those of the nLV (Fig. 13C).

In the caudal part of the mesencephalon we have identified the three remaining nuclei of the central part of the tegmentum. The isthmic nucleus (NI) is placed medially to the caudal semicircular torus and is surrounded by fibers of the lateral lemniscus (Plate 19E). In catfish, it is a tiny cell mass, presenting few small neurons strongly stained and arranged in cluster, although it is also possible to recognize some scattered cells (Fig. 13D). The perilemniscular nucleus (PL) in catfish has been subdivided into lateral and medial parts. The lateral part of the perilemniscular nucleus (PLI) is formed by neurons exhibiting strong staining, varying from small to medium sizes (but presenting predominantly small neurons), which are scattered dorsolaterally to the lateral lemniscus, between the cells of NGS and TSv (Plate 18D; Fig. 12C). In turn, the medial part of the perilemniscular nucleus (PLm) arises slightly rostral, medially to the lateral lemniscus, and also presents small neurons, but stained less intensely than those of PLl (Plate 17B; Fig. 12D). Its cells appear arranged in strips or rods in 
the dorsal margin of the nucleus, although some neurons scattered within a conspicuous neuropil can also be observed (Fig. 12D). Both lateral and medial parts of the perilemniscular nucleus present neurons with rounded, ellipsoid and triangular in shape (Fig. 12C, D). The nucleus of the locus of coeruleus (LC) is one of the most distinguishable nuclei of the mesencephalon due to the presence of very large, rounded neurons very intensely stained arranged in clusters (Fig. 17B). The cells of the LC appear in the caudal margin of the tegmentum, lying above the reticular formation (Plate 19F), and extend until the end of the optic tectum (Plate 20G).

\section{Lateral Zone}

The lateral zone of the mesencephalic tegmentum of catfish is occupied by the semicircular torus, which represents a prominent group of cell masses that surges just caudal to the onset of the optic tectum and ventromedially to it (at level of the Plate 11F), being covered by the optic lobes in its total extension (Plates 17-19). As indicated above, we divided the semicircular torus in three regions, TS1, TSc and TSv, described below (Fig. 14A; Table I).

Rostrally in the mesencephalic tegmentum, the lateral part of the semicircular torus (TSl) is located covering the dorsal area of the semicircular torus lining the tectal ventricle (Plate 17A). Further caudal, the TSl migrates laterally in the tegmentum, being replaced partially by the cells of the central part of the semicircular torus (Plates 17B, 18C,D; Fig. 14A). Ventrally to both TSI and TSc lies the ventral part of the semicircular torus (Plate 17B), which seems to migrate slightly medial from its ventro-lateral position to cover the ventral part of the TSc, remaining in this position until the end of this cell mass (Plates 1719). The lateral part of the semicircular torus (TSl) is composed of rounded cells, clustered regularly within the nucleus, which show a small size and exhibit moderate staining (Fig. 14B). The central part of the semicircular torus (TSc) possesses cells of different sizes (ranging from small to medium size, some of them slightly larger than those of TSl and TSv) and shapes (from rounded to oval). These cells are intensely stained with cresyl violet and appear scattered homogeneously all over the nucleus (Fig. 14C). The ventral part of the semicircular torus (TSv) present small and rounded neurons, slightly stained, and more loosely distributed than those of TS1 and TSc (Plates 17-19; Fig. 14D). 

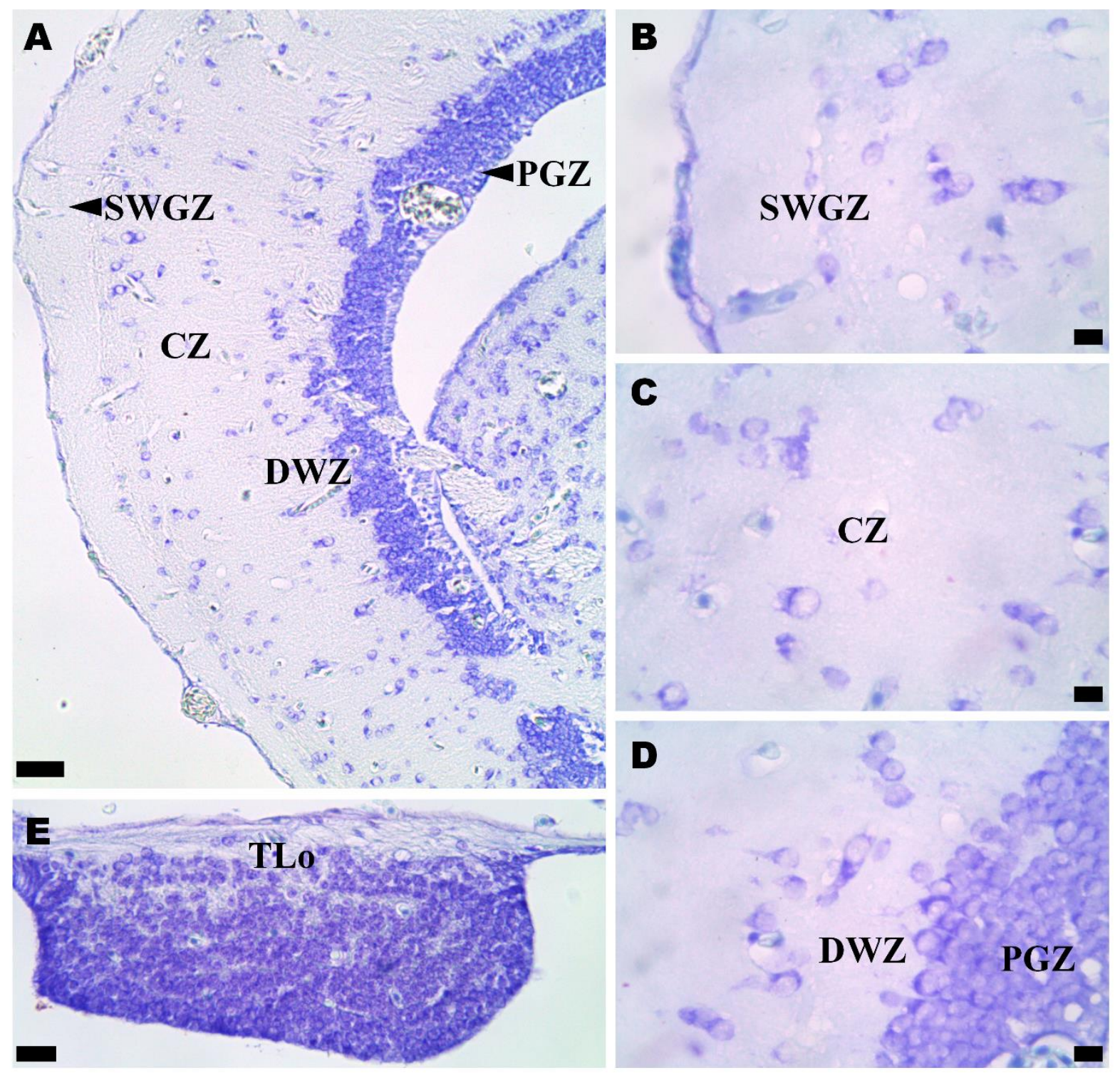

Fig. 11. Photomicrographs of transverse sections of the catfish brain (Steindachneridion parahybae) stained with cresyl-violet showing at higher magnification the different structures of the mesencephalic tectum. Sections at the level of (A-D) slightly rostral to the Plate $12 \mathrm{H}$ and (E) Plate 13I. Scale bar: A $=35 \mu \mathrm{m}$, $\mathrm{B}-\mathrm{D}=7 \mu \mathrm{m}$ and $\mathrm{E}=17 \mu \mathrm{m}$. For abbreviations, see the list of abbreviations (on the beginning of this Atlas) and Table I. 


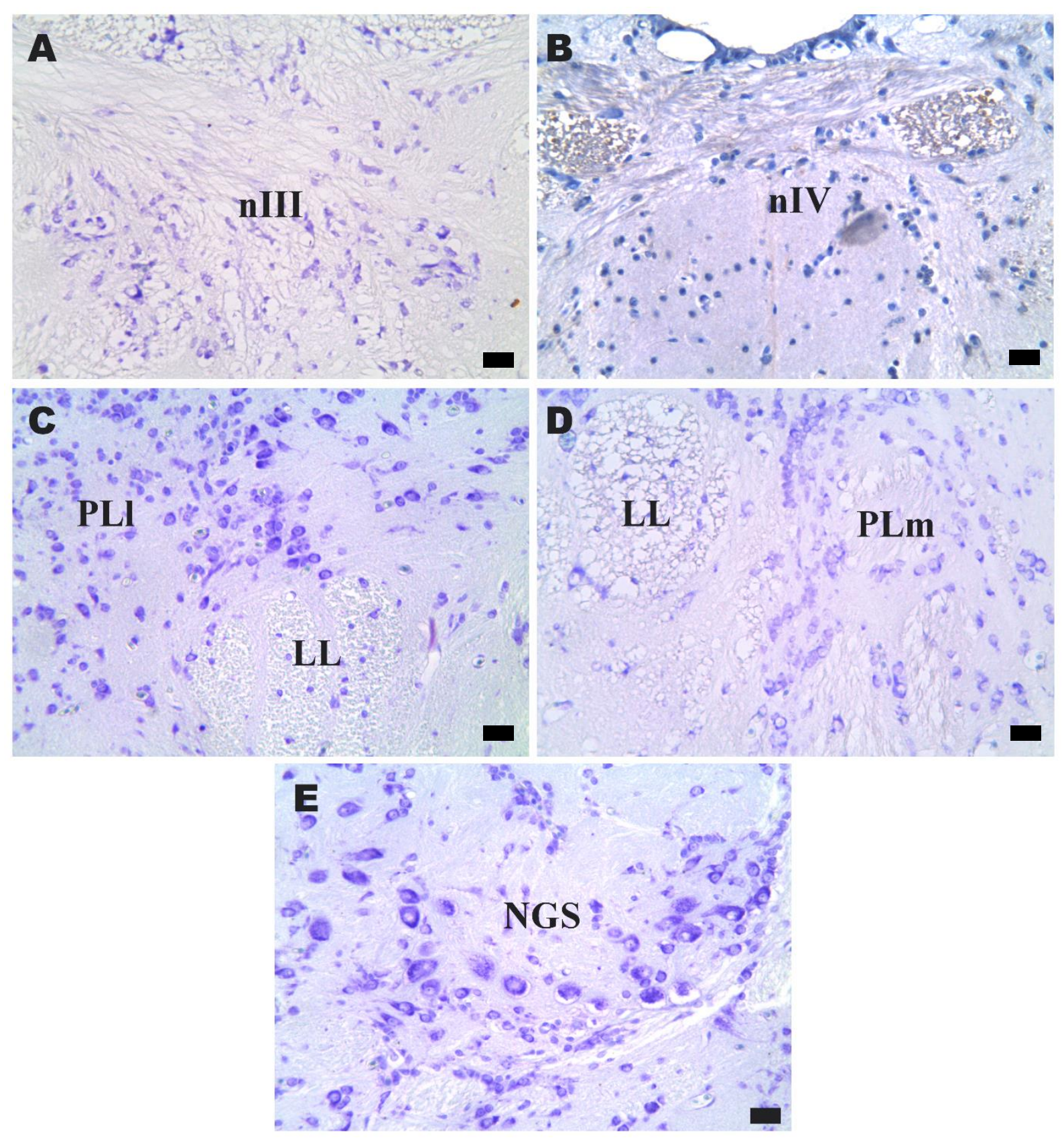

Fig. 12. Photomicrographs of transverse sections of the catfish brain (Steindachneridion parahybae) stained with cresyl-violet showing at higher magnification the different cell masses of the medial zone of the mesencephalic tegmentum and the perilemniscular nuclei. Sections at the level of (A) Plate 17B, (B) Plate 18C, (C) Plate 17B, (D) Plate 18D and (E) Plate 19E. Scale bar $=17 \mu \mathrm{m}$. For abbreviations, see the list of abbreviations (on the beginning of this Atlas) and Table I. 

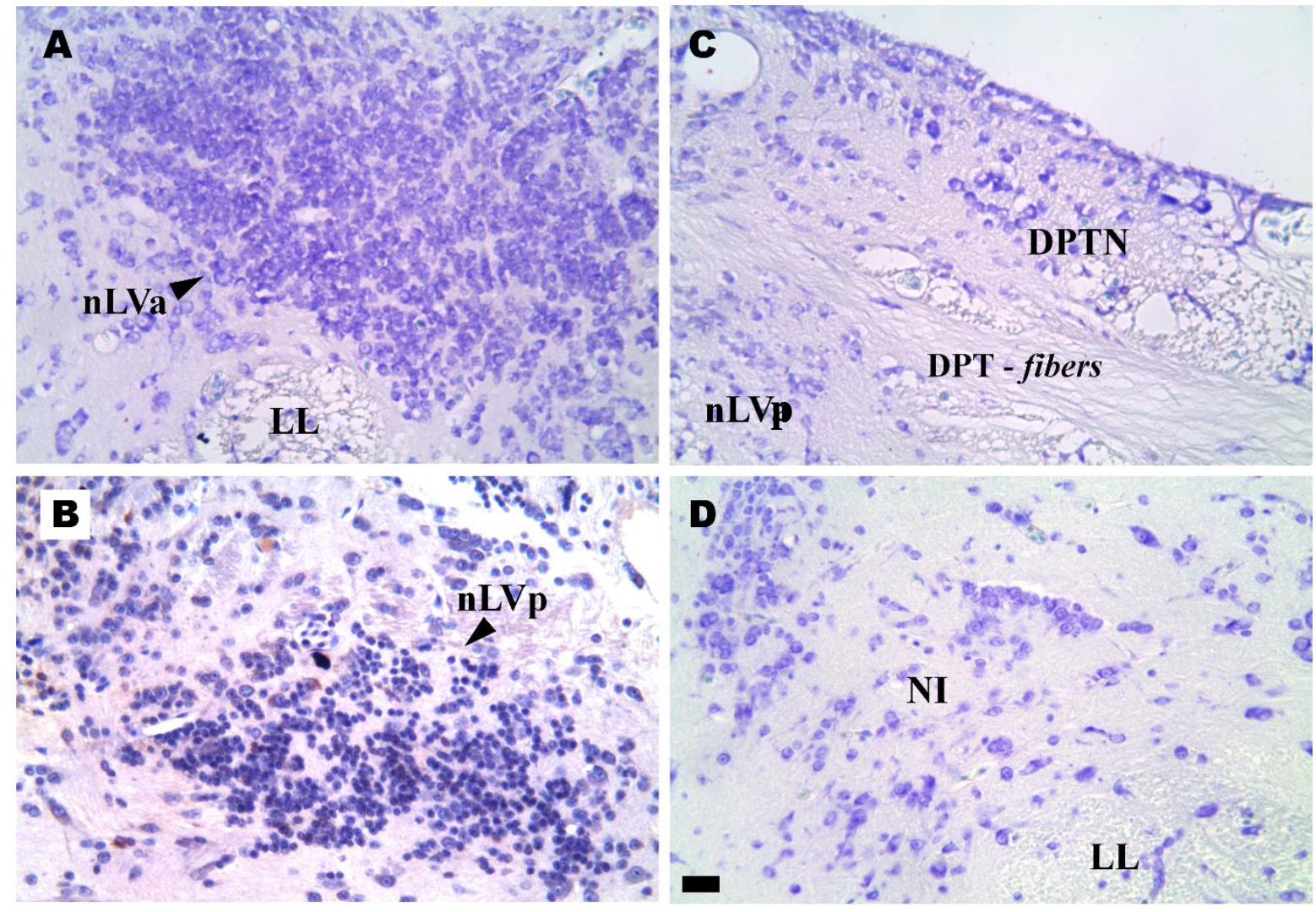

Fig. 13. Photomicrographs of transverse sections of the catfish brain (Steindachneridion parahybae) stained with cresyl-violet showing at higher magnification the different nuclei of the central zone of the mesencephalic tegmentum. Sections at the level of (A) Plate 17B, (B) Plate 18C, (C) Plate 17B, (D) Plate $18 \mathrm{D}$ and (E) Plate 19E. Scale bar $=17 \mu \mathrm{m}$. For abbreviations, see the list of abbreviations (on the beginning of this Atlas) and Table I. 


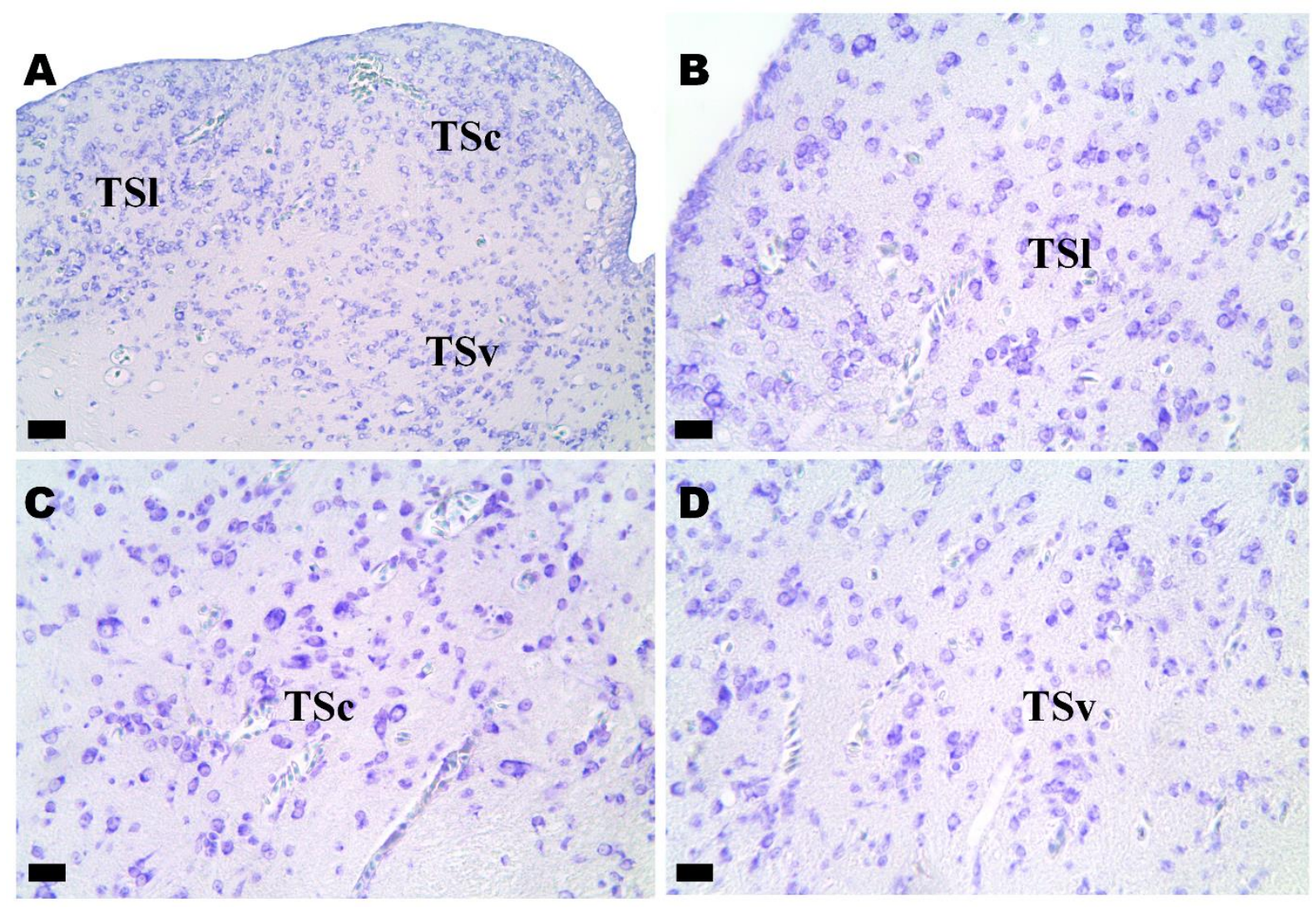

Fig. 14. Photomicrographs of transverse sections of the catfish brain (Steindachneridion parahybae) stained with cresyl-violet showing at higher magnification the cell masses of the lateral zone of the mesencephalic tegmentum. Sections at the level of Plate 17B. Scale bar: A $=34 \mu \mathrm{m}, \mathrm{B}-\mathrm{D}=17 \mu \mathrm{m}$. For abbreviations, see the list of abbreviations (on the beginning of this Atlas) and Table 1. 


\section{THE RHOMBENCEPHALON}

The rhombencephalon or hindbrain is the most caudal part of brain, being limited rostrally by the tegmentum of the mesencephalon and caudally by the spinal cord. This region presents a variety of areas and nuclei and, as in other studies (e.g.
Muñoz-Cueto, et al. 2001; Cerda-Reverter et al., 2008), we have divided the rhombencephalon into the following areas: the cerebellum and the rest of the rhombencephalon.

\subsection{Cerebellum}

The Siluriformes shares a notable feature among them, the great development of the cerebellum. As in other teleost fish, the cerebellum of catfish Steindachneridion parahybae is divided into three different regions that are presented in Table I: (1) corpus of the cerebellum, (2) valvula of the cerebellum, and (3) vestibulateral lobe (Nieuwenhuys, 1982; Finger, 1983). The corpus of the cerebellum from Siluriformes is a large lobe that covers a great surface of the brain, and in some species, as in our catfish species, this lobe is extended (from caudal to rostral) over the dorsal mesencephalon, the dorsal diencephalon and the caudal portion of the telencephalic hemispheres. Below the corpus of the cerebellum we found a protuberant structure that rostrally is separated from it but caudally is joined ventrally to it. This structure is the valvula of the cerebellum, which is present between the corpus of the cerebellum and the tectal ventricle, and is replaced caudally by the vestibulolateral lobe.

\section{Corpus of the cerebellum}

The corpus of the cerebellum (CCe) of catfish is still observed rostrally at the caudal pole of the telencephalic hemispheres, at level of the Plate 9, ending where arises the granular eminence, at level of the Plate 18. The CCe is composed by three cell layers, which are the granular layer, the molecular layer and the Purkinje cells layer (Fig. 15A). The granular layer of the cerebellum $(\mathbf{G})$ occupies the central layer of the CCe and is composed of densely packed small cells with a dark staining (Fig 15A, C). The granular layer of CCe is separated from the molecular layer by scattered and large Purkinje cells $(\mathbf{P})$. These cells have been reported in different teleosts as neurons exhibiting abundant ramifications of its main dendrite (Butler, 2000) but only their oval-shaped and strongly stained perykarya can be seen using cresyl violet staining (Plates 9-18; Fig. 15B). In addition, some Purkinje cells interspersed in 
the granular layer can be recognized (Fig. 15E). The molecular layer of the corpus of the cerebellum is a thick layer of neuropil that surrounds the $\mathrm{CCe}$ and presents round, fusiform and triangular cells sparsely distributed between the neuronal processes (Fig. 15C).

\section{Valvula of the cerebellum}

The valvula of the cerebellum (VCe) appears rostrally in the medial part of the tectal ventricle (Plate 12G), and displaces progressively the longitudinal torus to more lateral positions (Plates 12H-14, 17A). In the anterior pole, two separated lobes that only contained the molecular layer can be observed (Plates 12H, 13I). However, slightly caudal becomes also evident a granular layer in the ventrolateral surface of the VCe, with its characteristic small, densely packed and darkly stained cells (Plates 13J-15N, 17A,B). Further caudal, the VCe joins to CCe and the mesencephalic tegmentum (Plate 17B), before being replaced by the granular eminence and the cell masses from the central zone of the mesencephalic tegmentum (Plates 18C, D).

\section{Vestibulateral lobe}

As in other teleost fish, the vestibulolateral lobe $(\mathbf{L V})$ of catfish can be divided into two main structures: a paired granular eminence (EG) and the caudal lobe (LoC). The EG is initially observed at level of the Plate 18C and disappears at level of the Plate 21I. The EG is a compact cell mass formed by rounded and granular cells similar to those of the granular layer of CCe and VCe (Fig. 15E). The cells of EG appear initially interspersed with those of the granular layer of the CCe being difficult to delineate their limits (Plates 18D, 19E). Further caudal, the cells of G lie above the EG cells and show a slightly more condensed aggregation than those of EG (Plates 19F, 20G,H; Fig. 15E), and at the posterior pole only the granule cells of EG are observed (Plate 21I). Although two discrete cell masses have been reported in the EG of Ictalurus punctatus based on immunohistochemical experiments (Finger \& Tong, 1984), we cannot recognized two different subnuclei in the EG by using histological sections and cresyl violet staining (Plates 20, 21I).

The caudal lobe (LoC) is an extension of the CCe, starting just caudal to the granular eminence and exhibiting a similar aspect than the molecular layer of the cerebellum (Plate 21J). The medial part of the caudal lobe $(\mathbf{L o C m})$ becomes evident slightly caudal to the rostral margin of LoC (Plate 21K), and is characterized by the presence of small and medium-sized cells, with granular aspect, arranged in dense clusters and forming horizontal bands in transverse sections (Plate 21K; Fig. 16A,C). The ventral area of the LoC is occupied 
by the eurydendroid cells (LoCe), rounded to ovoid in shape, which exhibit a paler staining and a higher size than those of LoCm (Fig. 16A, B). These cells form a band oriented from the dorsolateral to the ventromedial surface of the lobe (Fig. 16A, B). The caudal limit of LoC is coincident with the rostral pole of the facial lobes (Plates 21K, 22L). 


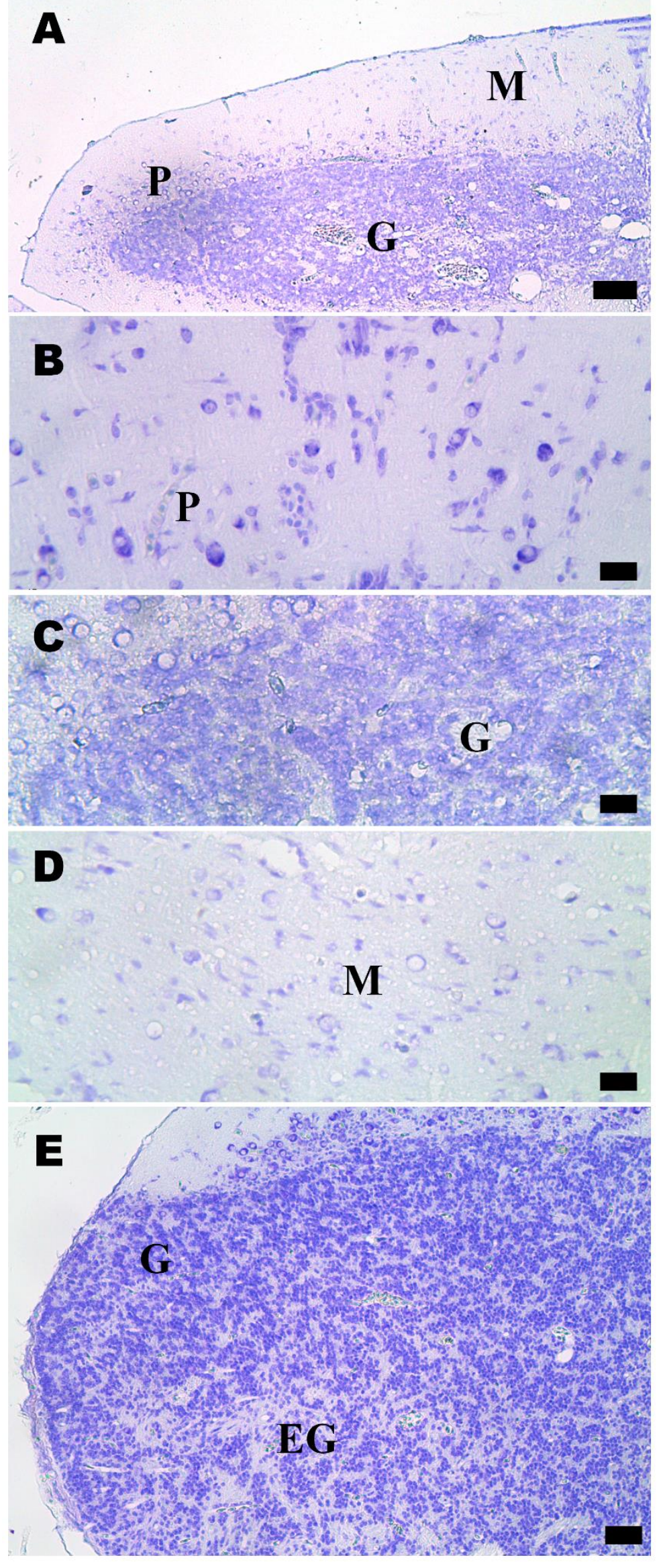

Fig. 15. Photomicrographs of transverse sections of the catfish brain (Steindachneridion parahybae) stained with cresyl-violet showing at higher magnification the different areas of the corpus and valvula of the cerebellum. Section at the level of (AD) Plate 14L and (E) Plate 20G. Scale bar: $\mathrm{A}=70 \mu \mathrm{m}, \mathrm{B}-\mathrm{D}=17 \mu \mathrm{m}$ and $\mathrm{E}=$ $35 \mu \mathrm{m}$. For abbreviations, see the list of abbreviations (on the beginning of this Atlas) and Table 1. 


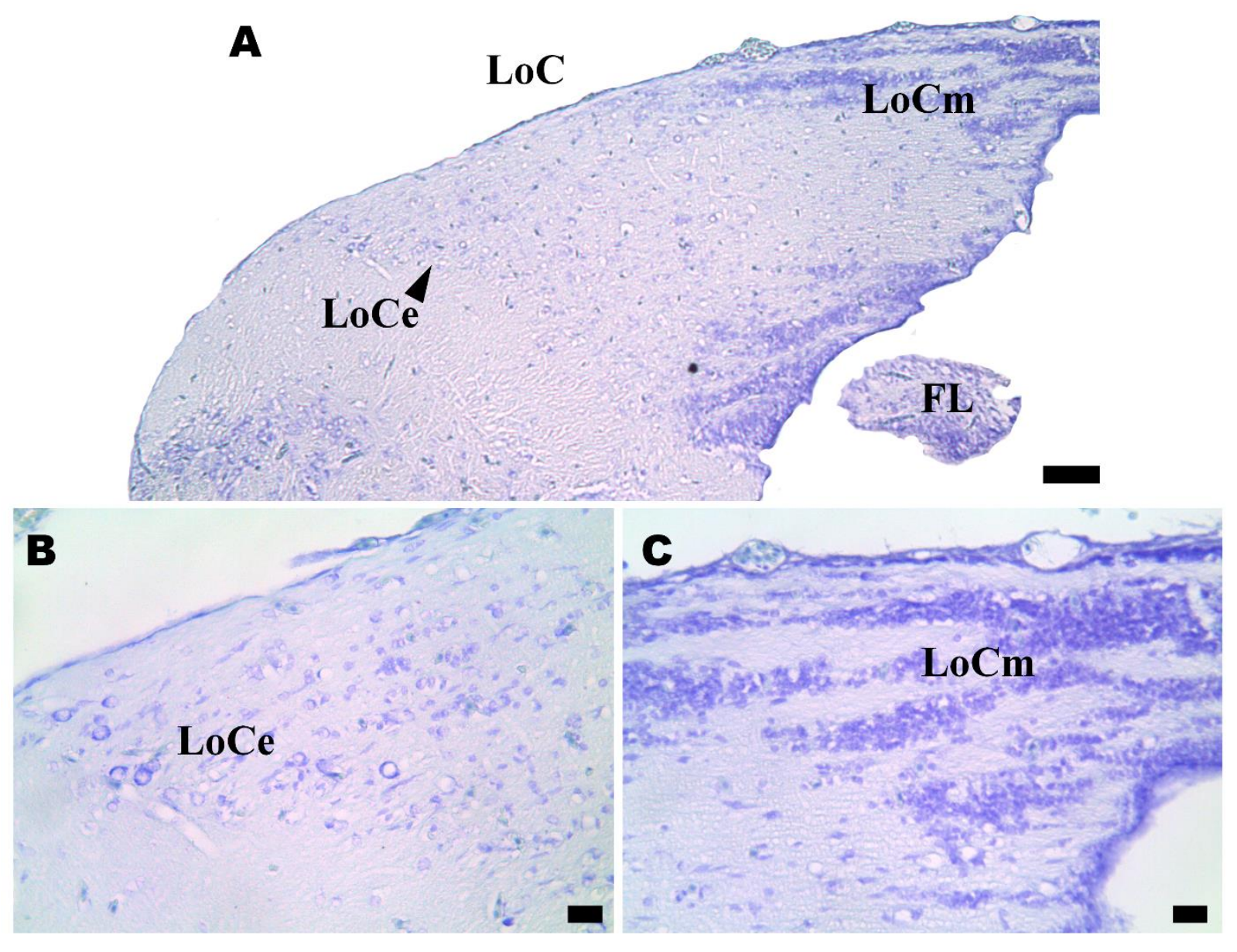

Fig. 16. Photomicrographs of transverse sections of the catfish brain (Steindachneridion parahybae) stained with cresyl-violet showing at higher magnification the different parts of the caudal lobe. Sections at the level of Plate $21 \mathrm{~K}$. Scale bar: $\mathrm{A}=70 \mu \mathrm{m}, \mathrm{B}, \mathrm{C}=17 \mu \mathrm{m}$. For abbreviations, see the list of abbreviations (on the beginning of this Atlas) and Table 1. 


\section{CHAPTER I - An Atlas of Catfish Brain - The rest of the Rhombencephalon}

\section{The rest of the Rhombencephalon}

The rest of the rhombencephalon divided the rest of the rhombencephalon in corresponds to the myelencephalon or the following areas: reticular formation, medulla oblongata, which is the most caudal octavolateral area, somatomotor and part of brain, being limited rostrally by the visceromotor nuclei and other nuclei. tegmentum of the mesencephalon and Additionally, the catfish rhombencephalon is caudally by the spinal cord. This region the area that presents the cranial nerves, and presents a variety of areas and nuclei and, as in different teleost fish has represented the in other studies (e.g. Muñoz-Cueto, et al. target of abundant neurophysiological 2001; Cerda-Reverter et al., 2008), we have studies.

\subsection{Reticular formation}

As in other teleost fish, the reticular formation in catfish present three different zones: (1) the median zone, occupied by the superior nucleus of the raphe, (2) the medial zone, containing the nucleus of the reticular formation and (3) the lateral zone, including the lateral reticular nucleus.

\section{Median Zone}

The median zone of the reticular formation in catfish lies in the middle of the rhombencephalon and can be viewed in transverse sections from the Plate 18D to 21I. This rhombencephalic zone is occupied by the superior nucleus of the raphe (SR), which starts caudal to the end of the trochlear nerve (Plates 18C, D). In its rostral pole, the SR lies in the dorsal part of the median zone, bordered in its dorsal part by a compact layer of ependymal cells, and lining the wall of the forth ventricle (Plate 18D). Further caudal, as the interpeduncular nucleus disappears, the SR cells displace ventrally and occupy the central zone of the rhombencephalon (Fig. 17A). The cells from the dorsal pole of SR are rounded and small in size, but more ventrally in the midline we found small cells interspersed with clusters of larger cells, more intensely stained and with more variable shapes, i.e., rounded, ovoid, pyramidal and fusiform (Fig. 17A). The caudal margin of SR is coincident with the end of the inferior lobes of the hypothalamus (Plate 21I).

\section{Medial Zone}

At the transverse level where SR arises, and more lateral to it (Plate 18), we also observe the onset of the nucleus of the reticular formation (RF). This nucleus occupies a large area in the median rhombencephalon, increasing in width from rostral to caudal poles (compare Plates 
18 and 19-22). It also has a wide rostrocaudal extension reaching caudally the spinal cord (Plate 24). The cells of the nucleus of the reticular formation are intensely stained with cresyl violet, varying considerably in shape (ovoid, pyramidal, bipolar and round) and size (small to large). The RF neurons appear scattered all over the nucleus, but in some regions some cell clusters can be observed (Fig. 17B). Although some studies (Nieuwenhuys \& Oey, 1983; Cerdá-Reverter et al., 2008) divide the median zone of the reticular formation in three different cells masses, superior, medial and inferior reticular nuclei, such division was not clear in our catfish species and, therefore, we have assigned all these cells to a single nucleus of the reticular formation. Some other cell masses can be observed embedded in the RF; rostrally, we observed the large cells of the nucleus of the locus coeruleus (Plate 19F, Fig. 17B) and further caudal, the giant Mauthner's cells (Plate 22L, Fig. 19I).

\section{Lateral zone}

The lateral zone of the reticular formation is occupied by the lateral nucleus of the reticular formation (RL), which represents one of the most caudal cell masses from the catfish rhombencephalon (Plate 24T). This nucleus contains few and poorly stained scattered neurons, with variable sizes and shapes (rounded, ovoid and pyramidal) that lie in the lateral surface of the hindbrain (Fig. 17C).

\subsection{Octavolateral Area}

The octavolateral area of catfish comprises the octaval nerve nuclei, lateral line nerve nucleus, the molecular layer of the electrosensory lateral line lobe and the medial nucleus.

The octaval nerve nuclei are represented by five main cell masses: (1) the anterior octaval nucleus (AON), (2) the descending octaval nucleus (DON), (3) the magnocellular nucleus (MAG), (4) the tangential nucleus (T) and (5) the posterior octaval nucleus (PO). The organization of this area is presented in Table I. The anterior octaval nucleus (AON) is the most rostral nucleus of the octavolateral area. It appears ventrolaterally to the caudal lobe, and is bounded ventrally by the trigeminal nerve (TV) and dorsally by the cells of the medial octavolateral nucleus (Plates 21J, K). This cells mass is relatively small in rostrocaudal extension, and its neurons, which show an intense staining and a rounded or ovoid cell body, appear scattered within the nucleus (Fig18A). In its caudal border, the AON is ventro-laterally bounded by the fibers of trigeminal and facial nerves, being replaced by the cells of the descending octaval nucleus (DON) (Plates 21K, 22L). 


\section{CHAPTER I - An Atlas of Catfish Brain - The rest of the Rhombencephalon}

The DON begins as a small cell mass, surrounded by three rhombencephalic nuclei (MAN, MON and m), adopting further caudal a larger size between the facial lobe and the ventrolateral surface, and ending in the lateral portion of the posterior hindbrain (Plates 22L$\mathbf{2 4 S}$ ). Other rhombencephalic cell masses surrounding the DON are the magnocellular nucleus (ventrolaterally), the tangential nucleus (ventrally), the facial lobe (dorsomedially) and the posterior octaval nucleus (dorsally) (Plates 230, P, Q, 24R, S). The cells of the DON vary in size between small and medium-sized, and exhibit an intense staining, being disposed scattered although the cell density is higher than in AON (Fig. 18B).

The MAG is formed by large neurons, with strong staining and diverse shapes ranging from rounded and ovoid to polygonal. Small fusiform cells can also be recognized in this cell mass (Fig. 18D). The cells of MAG appear embedded in a profuse neuropil and are bounded rostrally by the fibers of the trigeminal nerve (ventromedially) and more caudally by the fibers of the vagal nerve (ventrolaterally), being covered dorsally by the DON (Plate 22N, 230). The tangential nucleus $(\mathbf{T})$ is found in the ventrolateral border of the caudal rhombencephalon, at the entering of the vagal nerve (Plates 23P, Q). The $\mathrm{T}$ is a small nucleus, presenting few cells (between teen and twelve neurons) varying from medium to large sizes. Its neurons show a slight staining and exhibit ovoid shapes, although round cells can also be recognized (Fig. 18E).

In the posterior part of the rhombencephalon, at the caudal pole of the facial lobe and lateral to it, arises the posterior octaval nucleus (PO). This nucleus contains densely packed and intensely stained cells, round and ovoid in shape (Fig. 18F). It occupies the dorso-lateral margin of the brainstem, and is bordered dorsally by the molecular area of the electrosensory lateral line lobe and nucleus medialis (m) and ventrally by the DON (Plate 24). The $\mathbf{m}$ arises ventral to the posterior end of the eurydendroid cells of the caudal lobe, lateral to the rostral margin of the facial lobe and dorsal to the octavolateral nerve nuclei (Plate 21K). This nucleus represents a continuum with the molecular layer of the cerebellar components, and has been reported in other teleost fish as the cerebellar crest (Muñoz-Cueto et al, 2001). As the molecular layer of this metencephalic structure, the $\mathbf{m}$ presents some round and slightly stained cells, interspersed in a dense layer of neuropil and fibers (Fig. 18F, 19F).

As in other teleost fish, the medial octavolateral nucleus (MON) of catfish can be considered as a lateral line nerve nucleus. This nucleus starts laterally under the large area occupied by the LoC (Plate 21J), bordered laterally by the ELL and extending caudally in the rhombencephalon up to the onset of the vagal lobe (Plate 23). The MON presents small and rounded cells of medium size, with intense staining and uniformly scattered within the 


\section{CHAPTER I - An Atlas of Catfish Brain - The rest of the Rhombencephalon}

nucleus (Fig. 18G). Additionally, some cells of MON may be observed mixed with cells of adjacent nuclei.

\subsection{Somatomotor and Visceromotor nuclei}

In catfish, one somatomotor and three visceromotor nuclei had been identified in the rhombencephalon. These nuclei are, from rostral to caudal, the trochlear nucleus (nIV), the trigeminal nerve motor nucleus (Vm), facial nerve motor nucleus (VIIm) and vagal nerve motor nucleus $(\mathrm{Xm})$.

Caudally to oculomotor nucleus lies a cell mass that also presents some neurons surrounded by fibers, in this case from the trochlear nerve. This is the nucleus of the trochlear nerve (nIV), with cells of small to medium size and granular aspect, highly stained, and distributed loosely within the nucleus (Plate 18C; Fig. 12B). The rostral border of the trigeminal nerve motor nucleus $(\mathbf{V m})$ is coincident with the caudal pole of the inferior lobes and the onset of the facial lobe. It arises in the ventrolateral border of the rhombencephalon and is bordered by the cells of the reticular formation (medially) and the fibers of the secondary gustatory tract (2G) (laterally) (Plate 21J). Rostrally, the Vm presents an ovoid shape, and migrates progressively in a dorsomedial direction, assuming caudally an elliptical form (Plate 21K, 22L,M). It is composed of round and ovoid neurons, although fusiform neurons can also be observed (Fig. 19A). These medium-sized and large cells show strong staining and are grouped rather condensed (Fig. 19A).

The facial nerve motor nucleus (VIIm) starts at the same transverse level than the tangential nucleus, slightly rostral to the onset of the vagal lobe (Plate 23P). The VIIm lies lateral to RF, and its neurons present a variable shape (ovoid, round and fusiform) and size (from small to medium-sized cells) (Fig. 19B). These cells are intensely stained, although less labeled than those of $\mathrm{Vm}$, and appear distributed slightly more aggregated than $\mathrm{Vm}$ neurons (Fig. 19B). Finally, the vagal nerve motor nucleus $(\mathbf{X m})$ is placed close to the midline, ventrally to the vagal lobe, and bordering dorsally the caudal reticular formation (Plate $\mathbf{2 4 R}$, 24S). The cells of the Xm are interspersed with other vagal cells that vary considerable in size (from small to large) and shape (round, pyramidal and fusiform) but can be distinguished from those of the vagal lobe because of their larger size and stronger staining (Fig. 19C).

\subsection{Other nuclei}

The remaining nuclei of the rhombencephalon in catfish will be considered in this item. They are organized, from rostral to caudal, in into eight nuclei: granular cells associated to medial 


\section{CHAPTER I - An Atlas of Catfish Brain - The rest of the Rhombencephalon}

auditory nucleus ( $g$ aud), preemential nucleus (PE), medial auditory nucleus of the medulla (MAN), electrosensory lateral line lobe (ELL), cells of Mauthner (Mc), cells of the facial lobe (FL), cells of the vagal lobe (VL) and inferior olive (IO).

The preemential nucleus in catfish in predominantly located in the lateral part of the rhombencephalon, and have been divided in two nuclei, both the dorsal and ventral part of the preemential nucleus (PEd and PEv, respectively). The PEd is observed initially bordered in its dorsal part by EG, in ventral and medial is surrounded by the nuclei of the mesencephalon (Plate 18D), seeming to migrate laterally, forming a slight protuberance in the lateral rhombencephalon (Plate 20). The PEv can be observed just after the final protion of the optic tectum (Plate 20G), located just below to PEd. Although the PEd and PEv present similar feature, as a strongly staining of cells, with a predominantly round shape (fusiform neurons can be recognized) and a condensed arrangement, two main difference between the subdivision of PE can be observed: (1) the moment of appearance of these nuclei and (2) the limitation of one another, that form two macroscopically and microscopically notable nuclei (Plate 21I; Fig. 19D). In its final position, the PEd is observed bordered dorsal by the trigeminal nerve (TN) (Plate 21; Fig. 19D).

The MAN is observed after the $\boldsymbol{g}$ aud, making border with the ventricular wall during all its extension (Plates 21J-22M). The cells of MAN are distributed in a scattered form, presenting round and ovoid neurons that vary from small to medium-sizes, with a slight staining (Fig. C). Caudally, MAN is ventrally bordered by the internal arcuate fiber, which comprise a set of fibers that is observed crossing both, left and right hemispheres of the rhombencephalon (Plate 22L). In the same histological cross-section of the emergence of MAN, the ELL is observed located in the lateral of the rhombencephalon. The cells of the ELL are from small to medium-sizes, with a not very strong staining, but most evident than to MAN (Fig. 19F). Its cells can be viewed at the moment of the emergence of the vagal lobe cells.

The giant cells of Mauthner, in catfish, appear below to IAF and dorsal to RM (Plate 22L). As in another teleost fish, the Mc represent the largest neurons of the brain, and in catfish, these cells have a medial-lateral extent of $149 \mu \mathrm{m}$ (Fig. 19I). In teleosts, these cells send descending projections to the spinal cord (Oka et al, 1986; Prasada Rao et al, 1987, 1993; Behrend \& Donicht, 1990).

In the caudal brainstem, the cells of the facial lobe appears between the final part of the caudal lobe and the MAN (Plate 21K). From rostral to caudal, the FL have a considerable increase of its size (Plates 22L-23Q), decreasing sharply at level of the Plate 24R. The cells 
of FL present a homogeneous size (small) and distribution, with a medium staining. Located medially to FL, is the vagal lobe, which appear between the dorsal and ventral rhombencephalon (Plate 23Q). The cells of VL are arranged of a scattered way, present various shape (round, ovoid and fusiform) and sizes (from small to large), with a strong staining (Fig. 19C). Further, caudally, the cells of VL occupy the entire medial vertical wall in the rhombencephalon (Plate 24).

Finally, the last one nucleus reported in the brain of catfish, is the inferior olive. The few cells of IO are distributed along the ventral surface of rhombencephalon below of the nucleus of reticular formation (Plate 24T). Its cells are poorly stained, presenting a small size grouped in the basal rhombencephalon (Fig. 19G). This nucleus have been reported as present in all actinopterygians (Nieuwenhuys \& Pouwels, 1983). Additionally, in teleost it has been observed that the IO projects to the VCe (Wulliman \& Northcutt, 1989; Ito \& Yoshimoto, 1990) and the CCe (Finger, 1978; Ito et al, 1982; Wulliman \& Northcutt, 1988; Ito \& Yoshimoto, 1990). 


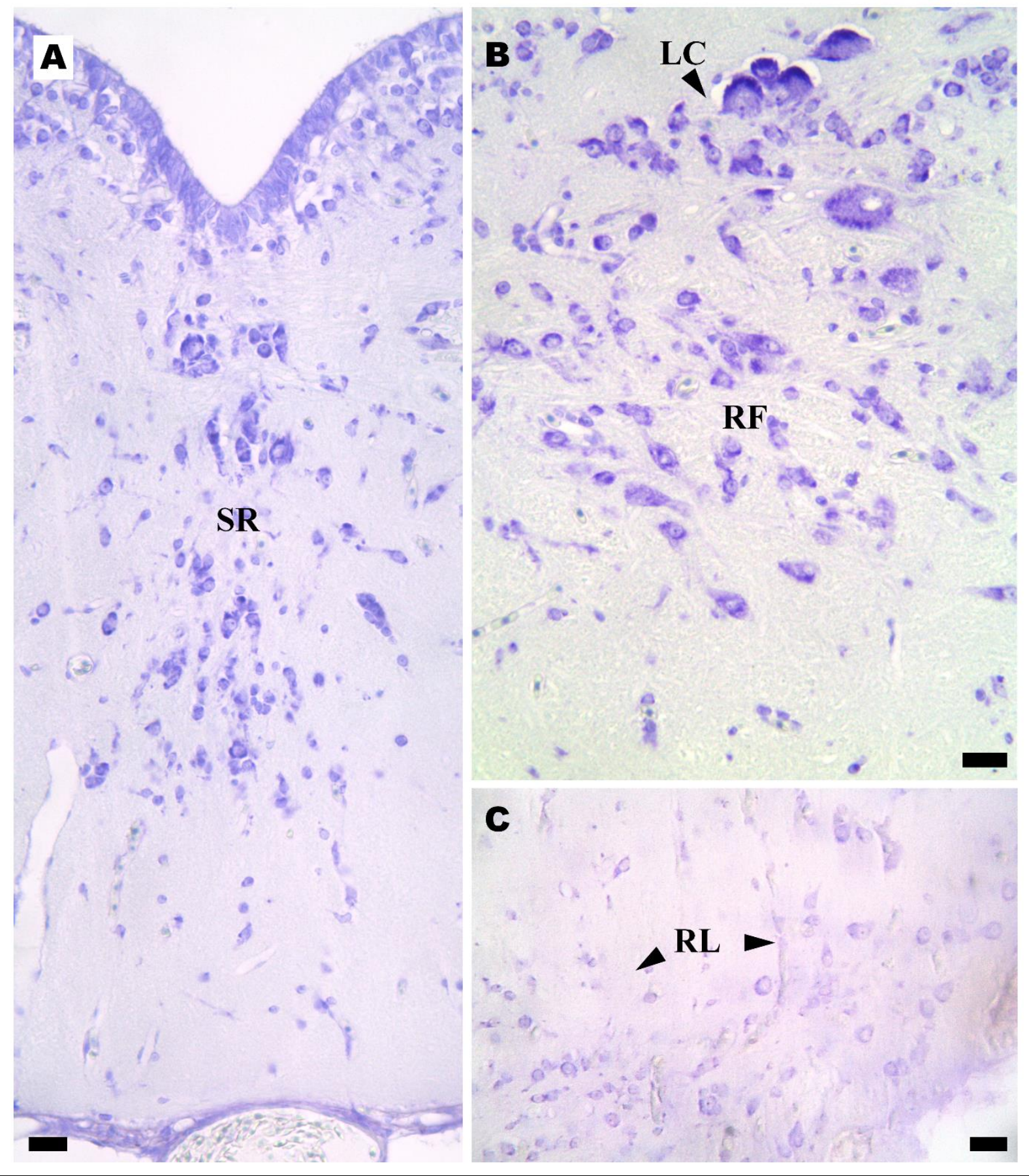

Fig. 17. Photomicrographs of transverse sections of the catfish brain (Steindachneridion parahybae) stained with cresyl-violet showing at higher magnification the raphe and reticular formation nuclei. Sections at the level of (A) Plate 19F, (B) Plate 20G, (C) Plate 24T. Scale bar $=17 \mu \mathrm{m}$. For abbreviations, see the list of abbreviations (on the beginning of this Atlas) and Table $\mathbf{I}$. 


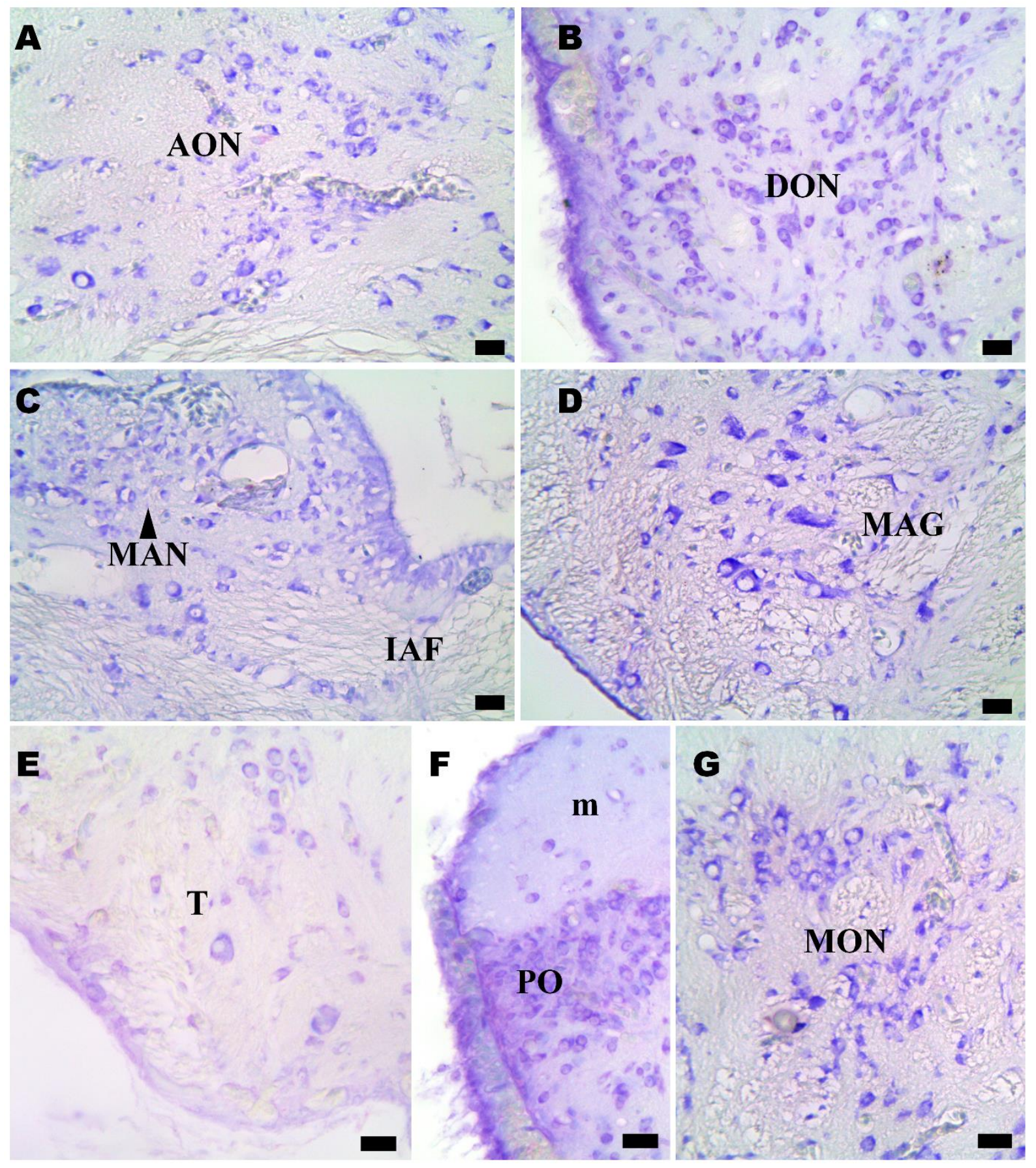

Fig. 18. Photomicrographs of transverse sections of the catfish brain (Steindachneridion parahybae) stained with cresyl-violet showing at higher magnification the different nuclei of the octavolateral area. Sections at the level of (A) Plate 21J; (B) Plate 23Q, (C) Plate 22L, (D) Plate 22N, (E) Plate 23P, (F) Plate 24R and $(\mathrm{G})$ Plate $21 \mathrm{~K}$. Scale bar $=17 \mu \mathrm{m}$. For abbreviations, see the list of abbreviations (on the beginning of this Atlas) and Table 1. 
Fig. 19. Photomicrographs of transverse sections of the catfish brain (Steindachneridion parahybae) stained with cresyl-violet showing at higher magnification the visceromotor and other rhombencephalic nuclei. (A) Plate 22L and (B) Plate 22P, (C) Plate 24R, (D) Plate 21I, (E) Plate 19E, (F) Plate 22M, (G) Plate 24T, (H) Plate 22M and (I) 22L. Each picture presents a scale bar of $17 \mu \mathrm{m}$, with exception of the picture D, which presents a scale bar of $70 \mu \mathrm{m}$. For abbreviations, see the list of abbreviations (on the beginning of this Atlas) and Table 1. 


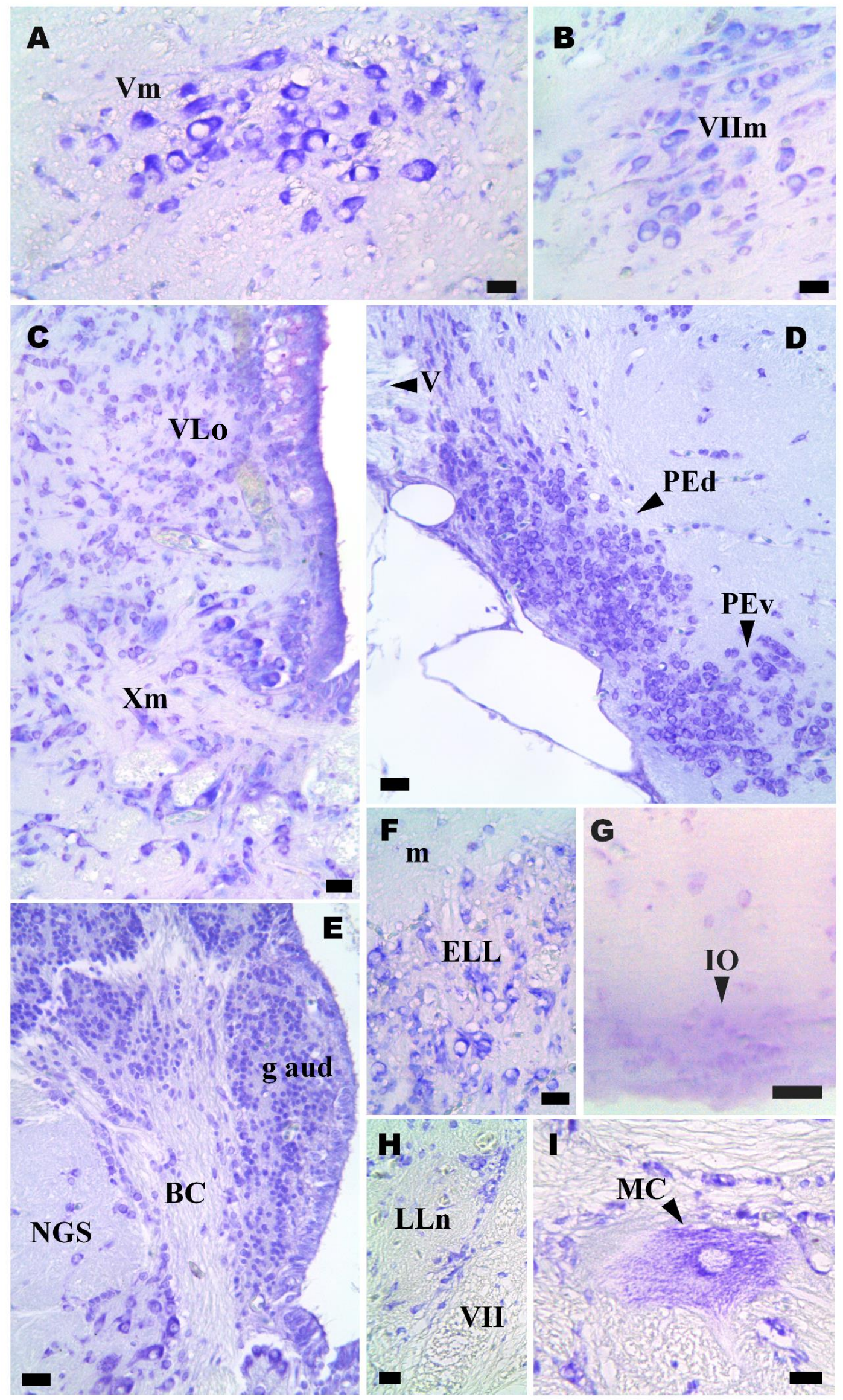

Figure 19. 


\section{DISCUSSION}

\section{Telencephalon}

As observed in other species of catfish, the brain of $S$. parahybae is very similarly, especially with regard to brain hemispheres compared to another catfish species: Pimelodella kronei and P. transient (Trajano, 1994), Clarias gariepinus (Dubois et al., 2001), Oxydoras sifontesi (Chavez-Aponte et al., 2009), Ariopsis seemanni (Londoño \& Giraldo, 2010). Accordingly, when compared with other teleosts (Kotrschal $\boldsymbol{e t}$ al, 1998; Ito et al, 2007), we highlight the presence of an extended medium elongated olfactory tract in $S$. parahybae, which separates the pair of olfactory bulbs from the telencephalon hemispheres. The presence of this elongation is reported for other species, as goldfish (Carassius), mormyrids (Gnathonemus) (Nieuwenhuys et al, 1998). In this context, the medium olfactory tract is not observed in Perciformes species, for example, its $\mathrm{OB}$ is attached to the telencephalon hemispheres (called sessile olfactory bulb), (Kotrschal et al. 1998; Cerdá-Reverter, 2001a; Muñoz-Cueto et al, 2001; Mukuda \& Ando, 2003, Burmeister et al, 2009).

Although the animals used in this study were juveniles, preliminary analyses of the brain in adults of catfish show slight hypertrophy in the lateral telencephalon but with a very similar arrangement of the brain cytoarchitecture (Honji, 2011). Nevertheless, when compared to Ictalurus punctatus, it can be observed a similar division of the brain areas according to a more general position of the nuclei (Bass, 1981). For example, in the present study, the dorsal area of the telencephalon was divided into six main areas (Dm, Dc, Dd, Dl, Dp, NT, as in Table I), the same division has been used in I. punctatus, however these areas have received a different subdivision (Bass, 1981). This author named the Dm without subdivisions for all extension of the telencephalon, and three subdivisions for the Dc, while for S. parahybae we have classified the Dm in three subdivisions (Dmm, Dmd and Dmc) and the Dc in two different cell masses (Dc1 and Dc2). Moreover, the posterior part of the dorsal telencephalon (Dp) in catfish is represented by only one cell mass, while in I. punctatus have been recognized the rostral and caudal parts (named by the author as DPr and DPc).

Among the teleost fish studied so far, the telencephalon subdivisions are reported with a very similar compartmentalization, changing in the size of the cell mass or ever in the number of subdivision, as observed in different species: Anguilla japonica (Mukuda \& Ando, 2003), Dicentrarchus labrax (Cerdá-Reverter, 2001a), Sparus aurata (Muñoz-Cueto et al., 2001), Carassius auratus (Morita \& Finger, 1987; Rupp, B. et al, 1996), Oncorhynchus mykiss 
(Nieuwenhyus et al., 1998), Danio rerio (Wullimann et al., 1996) and Ictalurus punctatus (Bass, 1981) (for review see Northcutt \& Davis, 1983; Northcutt, 2008). However, the dorsal part of the telencephalon seems to show the major particularity among the species, and can vary inside a same Order, Genre or among the same species (Trajano, 1994; Ito et al., 2007). Several studies in different teleost fish indicate that the dorsal part of telencephalon remains with no clear reasons for its subdivision, maybe the different names vary because of the nomenclature used. Additionally, several cells masses can be different in relation to subdivisions of the same area, or even considering the position of an area with the same features but that lies in a different portion of the dorsal telencephalon. In contrast, the ventral part of the telencephalon seems to be conserved in almost all teleost species studied so far, presenting a few variations about the nomenclature or feature (Northcutt \& Braford, 1983; Murukami et al, 1983; Cerdá-Reverter et al, 2001a; Northcutt, 2006).

Studies in a catfish species - Clarias gariepinus - point the olfactory bulb as an important structure related to embryological development of the endocrine system, like the $\mathrm{GnRH}$, which has its origin in the olfactory placode, migrating through the ventral telencephalon reaching on pituitary gland (Dubois et al, 2001). Previous studies performed in animals of the same group used in this Atlas have demonstrated the presence of immunoreactive neurons for $c f \mathrm{GAP}$ and its fibers since the olfactory bulb (in the external cell layer of the $\mathrm{OB}$ ) into different regions of the ventral telencephalon (see the nomenclature of GnRH and details about the experiment in the Chapter II).

About the projections of the olfactory bulb, Braford \& Northcutt (1983), suggest that in ray-finned fish with simply organized telencephalon, the olfactory projections seem to be restricted to the medial, i.e. the topological lateral part. While in teleost fish, the dorsal telencephalic projections terminate in the Dp, which supposedly secondarily migrated to a lateral position, and they are even also widely spread to all ventral regions of the telencephalon (von Bartheld et al, 1984; Levine \& Deither, 1985).

\section{Diencephalon}

The diencephalon is the most complex area in teleosts. Different authors use several terms to classify the diencephalic regions, however, in this study we have used mainly the nomenclature proposed by Bradford and Northcutt, (1983) and Muñoz-Cueto et al, (2001). Among the teleost fish, the diencephalic cytoarchitecture has been studied in all of the four main teleost radiations: Osteoglossomorpha, Elopomorpha, Clupeomorpha and Euteleostei. Even, a great number of these studies were performed in two groups of euteleosts: the 
ostariophysans and percomorphs (Peter \& Gill, 1975; Peter et al., 1975; Braford and Northcutt, 1983; Ito et al., 1984; Fernald and Shelton, 1985; Murakami et al., 1986a, 1896b, 1986c; Gómez-Segade and Anadón, 1988; Northcutt and Wullimann, 1988).

Although the preoptic area (POA) have been included as a part of the telencephalon in channel catfish - Ictalurus punctatus (Bass, 1981), posterior studies with this species have described the POA in the diencephalon (Striedter, 1990), and this classification has been used in the present study. The POA in catfish is very similar to observed in channel catfish, changing mainly in the position of some nuclei in the brain. We have observed that in juvenile catfish both, the gigantocellular and magnocellular part of the parvocellular preoptic nucleus (NPOgc and NPOmc, respectively), cannot been strongly recognized, although we found differences between them. In turn, if observed in goldfish (Carassius) or gilthead seabream (Sparus aurata), these regions present more distinguishable cells than catfish, which present a larger-size features, more evident than that (Braford \& Northcutt, 1983; Muñoz-Cueto et $\boldsymbol{a l}, \mathbf{2 0 0 1}$ ). On the other hand, this difference of cell-sizes of the NPOgc and NPOmc seems to vary seasonally in both teleosts species, the shore rockling (Gaidropsarus mediterraneus) and the Mediterranean rainbow wrasse (Coris julis) (Gómez-Segade et al, 1986).

The simplest pattern of hypothalamic organization have been described in Polypterus. In Polypterus, hypothalamic portion of the third ventricle is only a strait structure, and the walls of the hypothalamus just show a dorsal, ventral and caudal periventricular nucleus. In neopterygians, the medial-rostral and caudal portion of the third ventricle are more expanded laterally and originates the lateral and posterior recesses, respectively. As observed in Polypterus, the hypothalamus walls in neopterygians also present the dorsal, ventral and caudal periventricular nucleus, but the walls are thickest if compared to Polypterus and they are further characterized by the presence of numerous migrated nucleus (Rupp \& Northcutt, 1998). In Lepsosteus, only two migrated nuclei have been described: (1) a small diffuse nucleus located in the lateral surface of the inferior lobe, and (2) a more medially located, a smaller central nucleus, both of which are cytoarchitectonically conservative in comparison with other neopterygians species (Braford and Northcutt, 1983; Northcutt and Butler, 1993).

As observed in other teleosts, the hypothalamic walls in of the third ventricle in $S$. parahybae are even more expanded; both the diffuse and the central nucleus of the inferior lobe are larger, moreover, a lateral hypothalamic nucleus as well as ventral, lateral and anterior tuberal nuclei are present (Braford and Northcutt, 1983). A similar pattern of the hypothalamus, observed in juvenile catfish in this study, have been described for adult 
females of this species, during the reproductive cycle, showing a difference just related to the relative size of the IL, which in adults seems to be more bulky than in juveniles (Honji, 2011).

Previous analyses allow to infer the presence of GnRH1 in the hypothalamus of juveniles catfish (see in the Chapter II), with fibers of GnRH1 extending through the inferior lobe of the hypothalamus, reaching the PIT and bordering the walls of the lateral recess. It is also observed its fibers in the thalamus. The distribution of the $\mathrm{GnRH}$ forms and its roles in the brain of fish is widely studied in the literature (Zohar et al, 2010).

The dorsal and ventral thalamus in catfish have a very similar (but not the same) organization and features described in several fish, as Carassius auratus (Braford \& Northcutt, 1983), Haplochromis burtoni (Fernald \& Shelton, 1985), Lepomis cyanellus (Northcutt \& Butler, 1991), Dicentrarchus labrax (Cerdá-Reverter et al, 2001b) and Sparus auratus (Muñoz-Cueto et al, 2001). Although in catfish we adopted the main nomenclature used above, the thalamus in juvenile catfish present a slight similarity if compared with both species, I. punctatus and Pantodon buchholzi, in which the ventromedial nucleus of the thalamus (VM) have been described with two portions, the caudal and rostral part (Striedter, 1990a; Butler \& Saidel, 1991). Nevertheless, it is recognized as a different grouping of VM in catfish, because this arrangement is not clear enough for admit that are indeed a subdivision in this nucleus that could be called as rostral and caudal portions. Additionally, as for any of the previous experimental studies of ictalurid catfishes (Fraley \& Sharma, 1986; Babu \& Prasada Rao, 1988; Striedter, 1990a) and the fresh water butterfly (Butler \& Saidel, 1991), in the VM of catfish the nucleus of the thalamic eminence (nTE) was not described, which is reported in different Orders of teleosts, as Perciformes - Sparus auratus (Muñoz-Cueto et al, 2001) and Cypriniformes - Carassius auratus (Braford \& Northcutt, 1983).

The posterior tubercle in catfish has a similar arrangement compared to other teleosts. We suggest that the difference observed in catfish may be related to the age of the animals. In ictalurid fish studies, comparing the differences of the posterior tubercle between juveniles and adults there is a different organization of this area (Striedter, 1991; Kanwal et al, 1988). By the way, the preglomerular nuclei of Ictalurus punctatus and Steindachneridion parahybae present a very similar feature, differing in the relative position in the brain, lying more caudally in catfish than in channel catfish.

As opposed to catfish, in channel catfish it is observed that the appearance of the TLa and the PIT is so rostral. Beyond these nuclei, in catfish, the CM is visualized at the end of 
PIT, while in channel catfish the emergence of the CM is viewed after the point where the PIT is attached to hypothalamus. Its visualization in channel catfish occurs just after the first appearance of the vascular sac, seeming to migrate from central to periventricular area of the diencephalon (Striedter, 1990). The pattern observed in catfish is also not common if compared with other teleost species, as Salmo gardineri (Billard \& Peter, 1982), Sparus aurata (Muñoz-Cueto et al, 2001), Dicentrarchus labrax (Cerdá-Reverter et al, 2001b), Anguilla japonica (Mukuda \& Ando, 2003). Additionally, the mammillary bodies (CM) of catfish seem to be associated with the PIT through a peduncle, and for this reason we believe that this nucleus is found near to beginning of this gland (see in Chapter II).

Many studies performed in several teleosts fishes have been revealed that the preglomerular nuclei are of particular interest, as they receive ascending auditory, electrosensory, gustatory, mechanosensory lateral line, and tectal inputs and project to the dorsal telencephalic area (Ito \& Vanegas, 1983; Ito et al, 1986; Murakami et al, 1986a; Kanwal et al, 1988; Wullimann, 1988; Striedter, 1990b; Wullimann \& Northcutt, 1990).

The synencephalon is very variable due to the complex organization of this area. In catfish, this region, as described by other authors, is considered as a transition between the diencephalon proper and the mesencephalon (Braford \& Northcutt, 1983; Wulliman and Northcutt, 1988; Puelles \& Rubestein, 1993). Striedter (1990) divides the synencephalon as a periventricular portion and a more lateral pretectal portion, while Braford \& Northcutt (1983) classify these same portion as synencephalon and the reminder portion of the pretectum, respectively. In turn, we have used the references above, but adopting the subdivision present in Table II, dividing the synencephalon in PP, NP, nMLF, SCO and MPN, whereas the pretectum is composed by the CPN and NES.

In the present study, in the pretectum of catfish two pretectal nuclei were described, however in Sparus auratus (Muñoz-Cueto et al, 2001) and Dicentrarchus labrax (CerdáReverter et al, 2001b) five pretectal nucleus are described. On the other hands, in channel catfish it is reported only one pretectal nucleus (Striedter, 1990). The nucleus reported in channel catfish is the electrosensorius nucleus (NES). Its nucleus is recognized in the catfish Corydoras paleatus (Miller, 1940), but it is not described in the electric catfish, Malapterurus etetricus (Ebbeson \& O'Donnel, 1980). Although the catfish is not known as an electric catfish, we have recognized the NES with agreement to proposed by Striedter $(1989 ; 1990)$, who suggest a homology to the nucleus with the same name in gymnotoid electric fish Eigenmannia (Carr et al, 1981; Keller et al, 1980). As in Ictalurids, the NES in catfish is a remarkable nucleus, with strong staining, but not larger than in gymnotoid electric fish. 
In the diencephalon of catfish, we have recognized two accessory preoptic nuclei - the dorsal accessory preoptic nucleus (DAO) and ventral accessory preoptic nucleus (VAO). The features as well as the relative location in the brain is similar to described for other teleost fish (Northcutt \& Wulliman, 1988; Striedter, 1990a; Butler and Northcutt, 1993; MuñozCueto et al, 2001; Cerdá-Reverter et al, 2001b). Compared to other teleost, the VAO is a relative small nucleus in Carassius auratus (Wulliman \& Northcutt, 1988) and, as in channel catfish (Striedter, 1990) the VAO in S. parahybae can be even smaller. The dorsal and ventral accessory optic nuclei have been described as recipients of retinofugal projections and as the origin of corpopetal projections, and in Lepomis and Carassius projects to the valvula of the cerebellum (Northcutt \& Wulliman, 1988; Wulliman \& Northcutt, 1988; Wulliman \& Northcutt, 1989).

\section{Mesencephalon}

The mesencephalon of Steindachneridion parahybae can be compared to another teleost fish, differing in some features as size, number of nuclei and relative position of this nucleus. Here, we divided the mesencephalon of catfish in two great areas: (1) the mesencephalic tectum and (2) the mesencephalic tegmentum, as in the Table I.

The mesencephalic tectum of catfish is composed by the optic tectum (OT) and the longitudinal torus (TLO). The last, is described here as a densely packed with small neurons that resemble the small granule cells of the cerebellum. In teleosts, this structure receives an input from the valvula of the cerebellum and telencephalic input via tegmental and preglomerular nuclei, and projects to the optic tectum (Ito \& Kishida, 1978; Northmore et al, 1983; Wulliman \& Roth, 1994). The optic tectum in catfish have a similar proportional size if compared to channel catfish (Striedter, 1990), while it seems proportionally smaller when compared to Dicentrarchus labrax (Cerdá-Reverter et al, 2001b), Sparus auratus (Muñoz-Cueto et al, 2001), Salmo gardineri (Billard \& Peter, 1982, Northcutt \& Davis, 1983) and Lepomis cyanellus (Northcutt \& Davis, 1983). The organization of layers of the optic tectum described in catfish is very similar to reported by Muñoz-Cueto et al. (2001). However, these authors present a more detailed description of the superficial white gray zone (SWGZ) of the optic tectum in gilthead seabream than we did for the catfish, because SWGZ in catfish is not so clear. Interestingly, in Anguilla japonica, in the optic tectum there was recognized only one condensed layer reported as somata, corresponding to the preglomerular gray zone of the optic tectum (Mukuda \& Ando, 2003). These authors have not describe the 
fibrous layers present in the optic tectum for A. japonica, possibly viewable in the crosssection on their study.

Although the role of the optic tectum is widely studied in fish, so far there are no evidences studies showing the minimal function to this structure in Steindachneridion parahybae. Nevertheless, it is known that the importance of tectum in a teleost fish can be shown by damaging it. Complete removal (ablation) can make the animal effectively blind. Damage to the tectum in teleosts also results in losses that go beyond blindness, being impaired in their ability to swim using non-visual senses, bumping into objects in a way that eyeless fish would not, because the tectum holds other sensory modalities besides vision (Jacobson and Gaze 1964; Springer et al, 1977; Maximov et al. 2005; Damjanovic et al. 2009a, 2009b).

Also in this sense, experiments performed in Carassius auratus have demonstrated the importance of the optic tectum and their implication if these lobes are partial or entirely removed. In studies performed in Carassius, five visually mediated behaviors were evaluated following the removal (ablation) of one or both lobes of the optic tectum, being observed that three of the behaviors disappeared following tectal removal: (1) optomotor response (swimming with the stripes in a rotating striped drum), (2) food pellet localization and (3) shadow-induced deceleration of respiration. Still in the same experiments, two of the behaviors persisted following tectal removal: (1) optokinetic nystagmus (eyes movements with the stripes in a rotating striped drum) and (2) dorsal light reflex (tilting of the vertical axis toward the brighter of two laterally placed lights) (Springer et al, 1977).

While the mesencephalic tectum predominantly receives visual input and in ray-finned fish has an associated, medially lying structure, the mesencephalic tegmentum contains a variety of cranial nerves and other nuclei, and receives predominantly auditory and lateral line inputs (Butler, 2000). The mesencephalic tegmentum in catfish have been divided into three main areas also previously reported in other teleosts, including different Orders (Butler, 2000, Cerdá-Reverter et al, 2001b; Muñoz-Cueto et al, 2001; Mukuda \& Ando, 2003) (the organization of the mesencephalic tegmentum in catfish can be seen in Table I).

A mesencephalic area that is very studied in the field of neurophysiology is the torus semicircular (TS). As observed in catfish, the torus semicircular is generally formed by three parts - a lateral, central and ventral part. The central nucleus is reported as relaying auditory inputs to multiple sites, including the anterior tuberal nucleus of the hypothalamus and the anterior nucleus of the thalamus (Echteler, 1984). In neuroendocrinology studies, 
immunohistochemistry assay was made in adult females of Steindachneridion parahybae, recognizing GnRH2-neurons in the lateral part of the TS (Honji, 2011).

On the other hand, although similar topography, the TS presents different sizes that can vary among species. For example, in passively electrosensory teleosts as ictalurid catfish and notopterid xenomystines (knifefishes), the TS is large and present a medial acoustic relay zone, a lateral electrosensory relay zone and a mechanosensory relay zone in the intermediate position (Knudsen, 1977 and 1978; Finger, 1986; Braford, 1986). In gymnotoid (electric ells and knifefishes) and mormyrids fish, the torus semicircular is even larger, presenting somewhat difference, reflecting its independently achieved elaboration in these two fish groups (Bell et al, 1981; Bell \& Szabo, 1986).

\section{Rhombencephalon}

Several studies about the fish brain have been made so far, and the topographic morphology reveals some particularity shared among groups of fish from the same Order, Genre, Family or even among species. About the features of cerebellum of catfish, the same characteristic has been reported in many catfish species, as Ictalurus punctatus (Bass, 1981; Striedter, 1990), Pimelodella transitoria and Pimelodella kronei (Trajano, 1994), Clarias gariepinus (Dubois et al., 2001), Oxydoras sifontesi (Cháves-Aponte et al., 2009), Ariopsis seemanni (Londoño \& Giraldo, 2010). While the catfish studied here are juveniles the presence of a developed cerebellum is observed also in adults of this species (Honji, 2011).

The arrangement of the cerebellum cells is presented here as formed by the corpus of the cerebellum and the valvula of the cerebellum. Some author have included one more nucleus in the cerebellum, the crest of the cerebellum (Nieuwenhuys, 1982; Finger, 1983a; Muñoz-Cueto et al, 2001), however in catfish the structure that resembles the crest is the $m$ (molecular layer of the electrosensory lateral line lobe and nucleus medialis). Efferent fibers coming from the corpus of the cerebellum run inside of the anterior mesencephalocerebellar tract and innervate regions of the longitudinal torus, while the posterior mesencephaloncerebellar tract fibers terminate in the lateral nucleus of the valvula, octaval nuclei and the inferior reticular formation (Finger, 1983b; Wulliman \& Northcutt, 1988).

The main outcome of this study has been the availability of a complete Atlas of the brain of catfish, which has been used to localize precisely the distribution of cells and fibers of the Gonadotropin-releasing hormone in the brain. This Atlas will also represent a valuable tool for future endocrine analyses, allowing the precise mapping of the different 
neurohormones in the brain of catfish, as well as for the study of neural connections among different brain areas. 


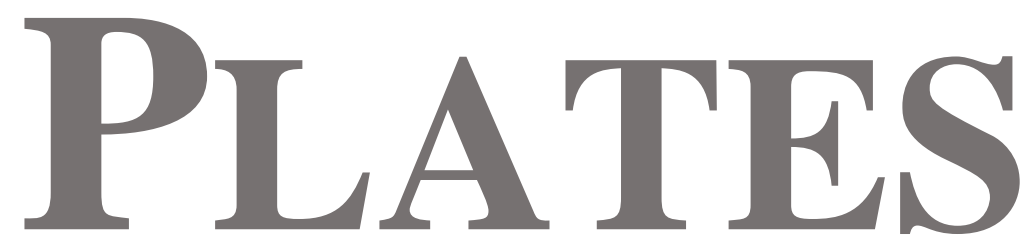

Detailed histological cross-section of the catfish (Steindachneridion parahybae) brain. 
PLATES $_{\text {of }}$

\section{THE}

Sequences of cross-sections from rostral (Plate 1) to caudal part (Plate 8) of the brain of juvenile Steindachneridion parahybae.

The photomicrographs on the left were stained with cresyl-violet; right schemes represent different cell masses in the telencephalon. The white arrows represent the main telencephalic sulcus (sulcus externus, ipsilyformes and lateralis). The position that each one cross-section can be viewed through the Fig. 1. Scale bar: $550 \mu \mathrm{m}$. For abbreviations, see the list of abbreviations (on the beginning of this Atlas) and Table I. 
A
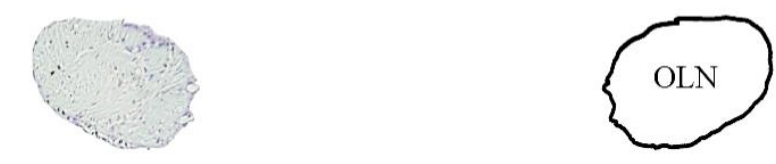

B
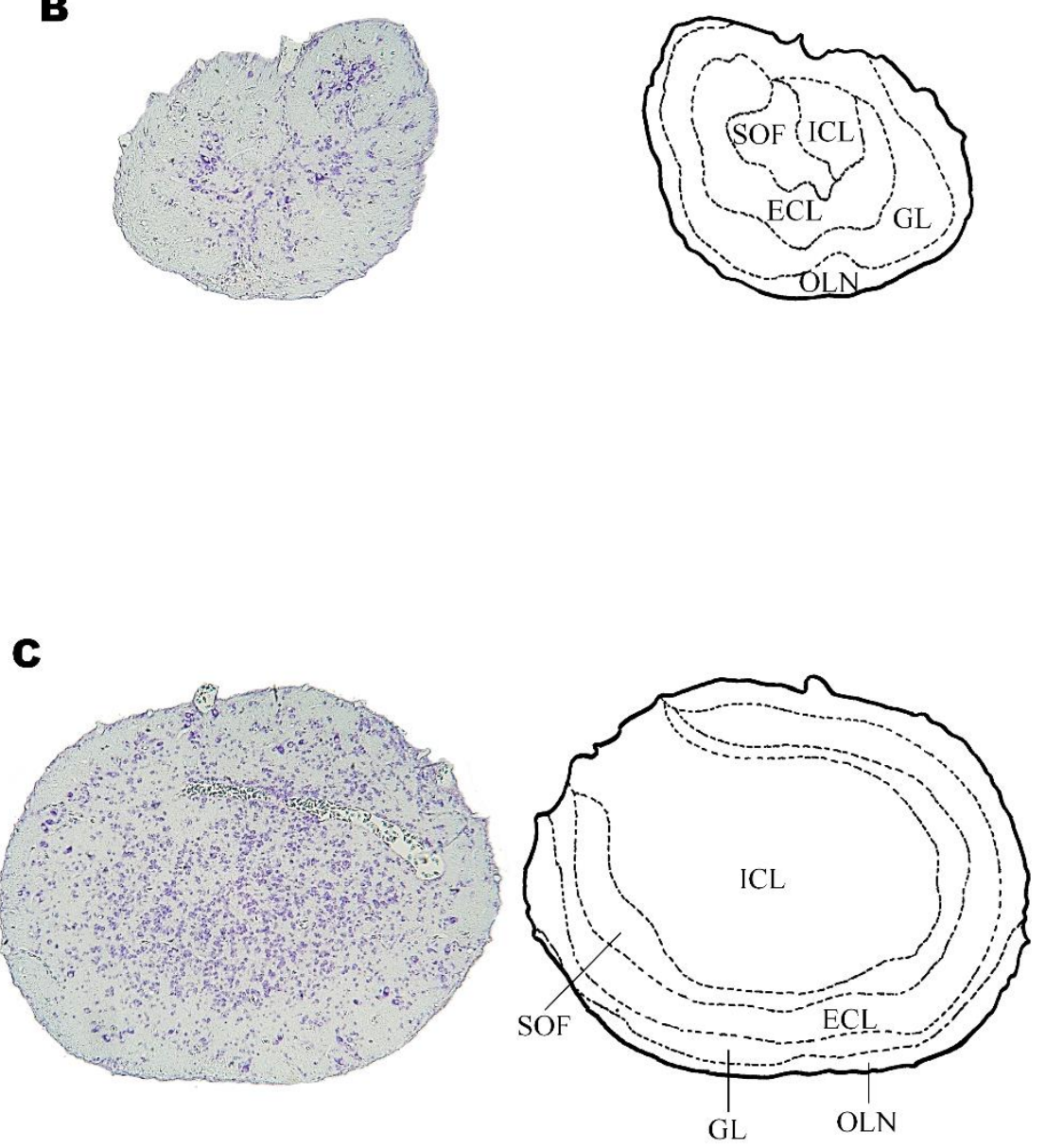

Plate 1 
D

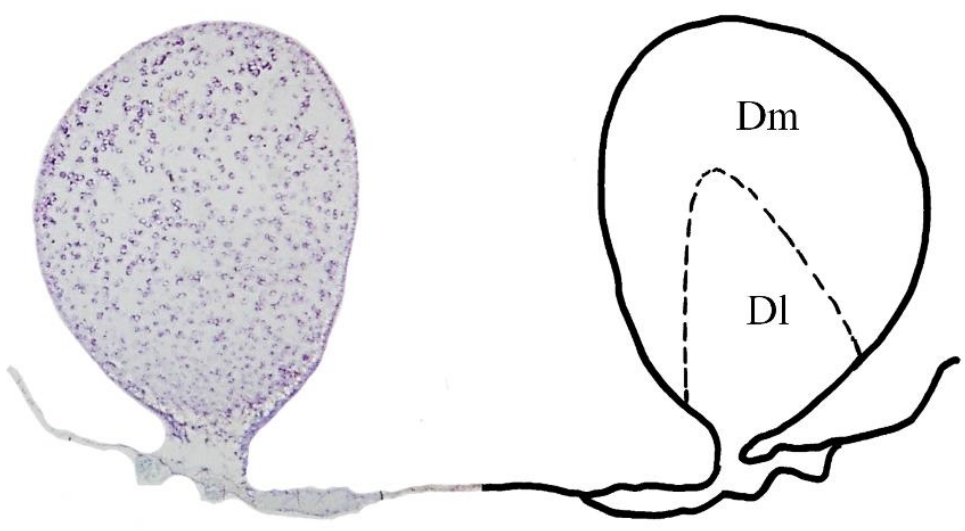

E

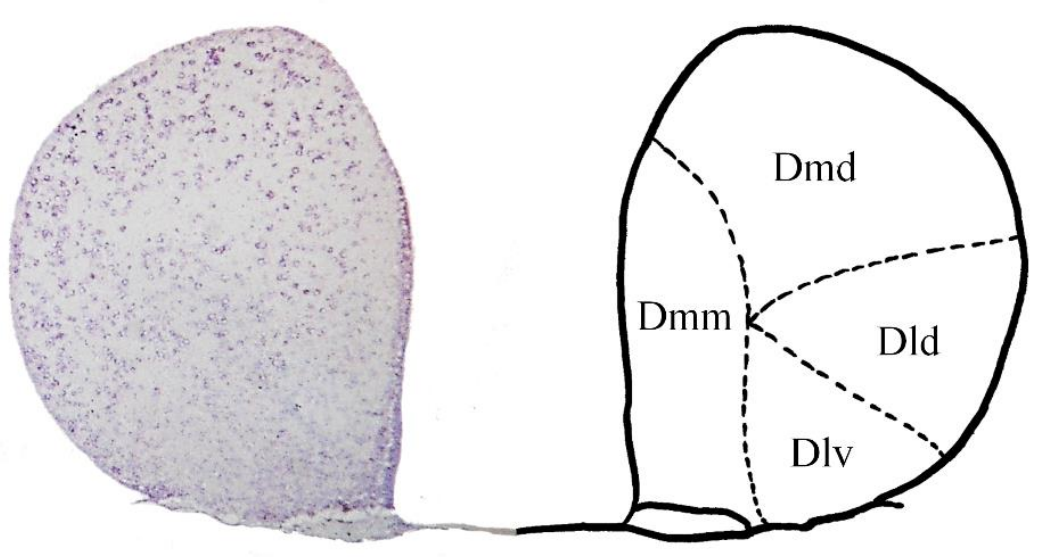

F

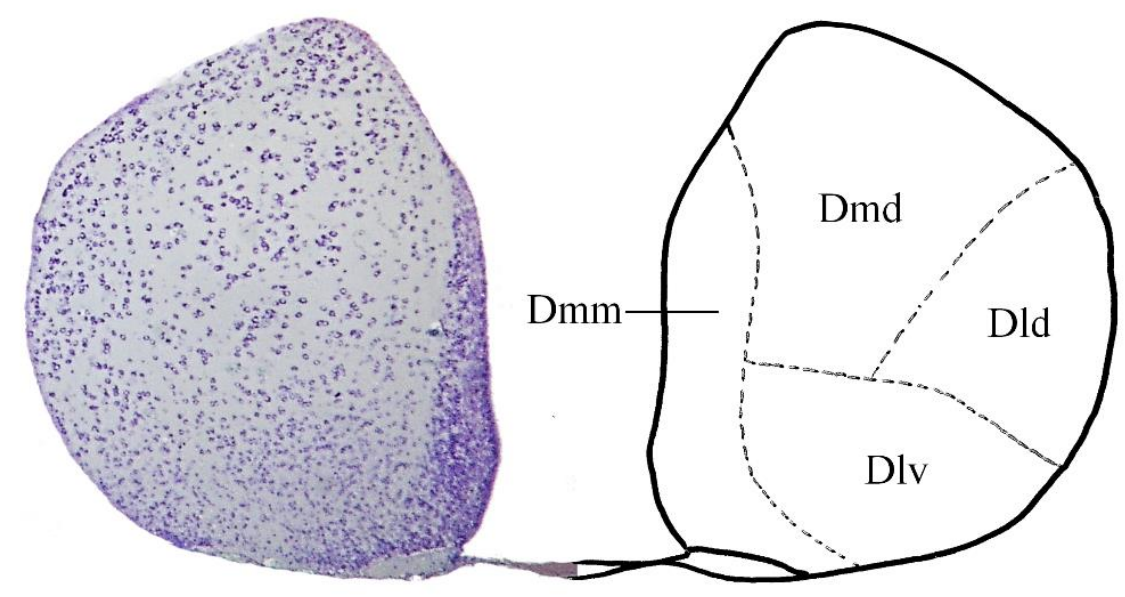

Plate 2 

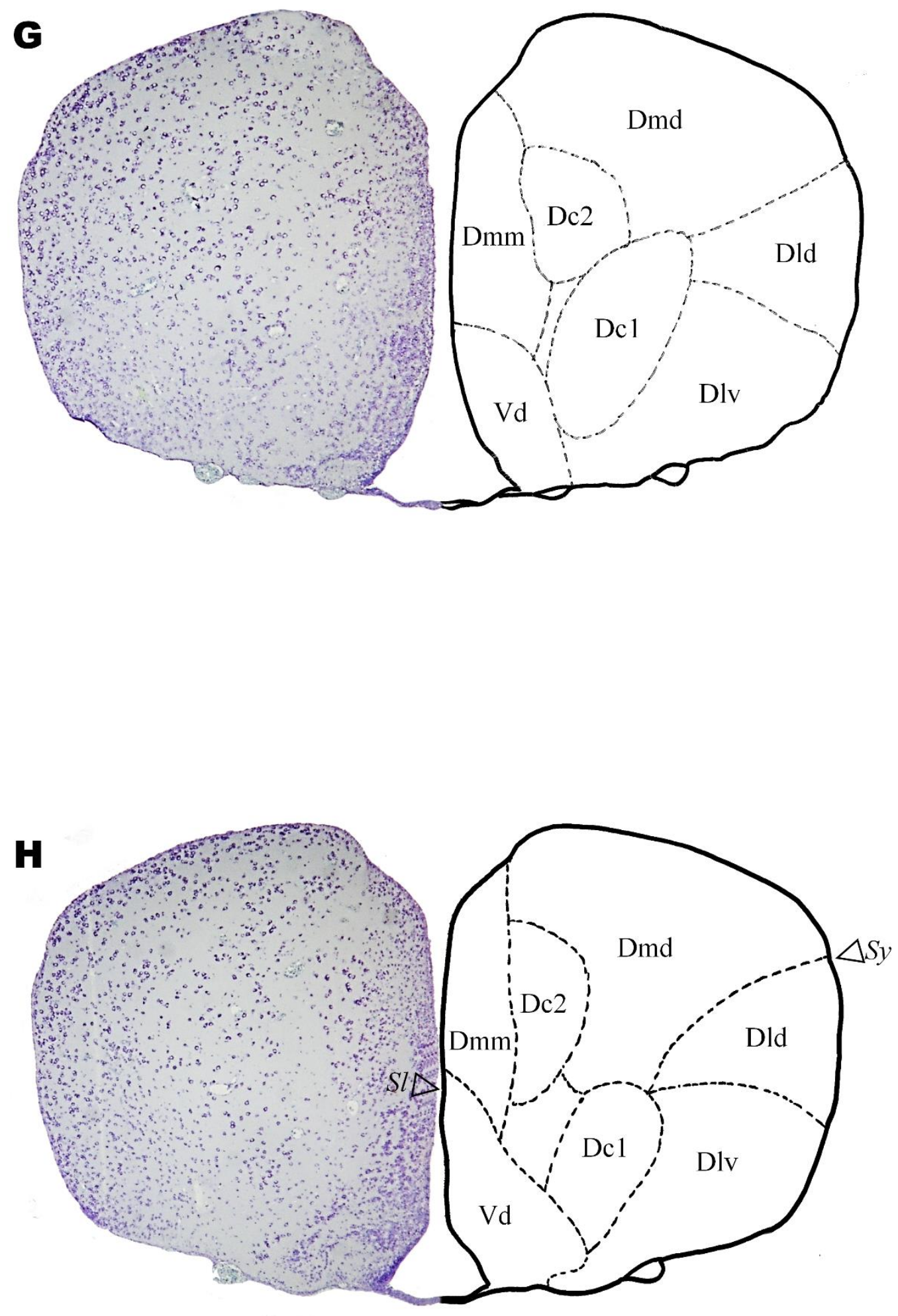

Plate 3 

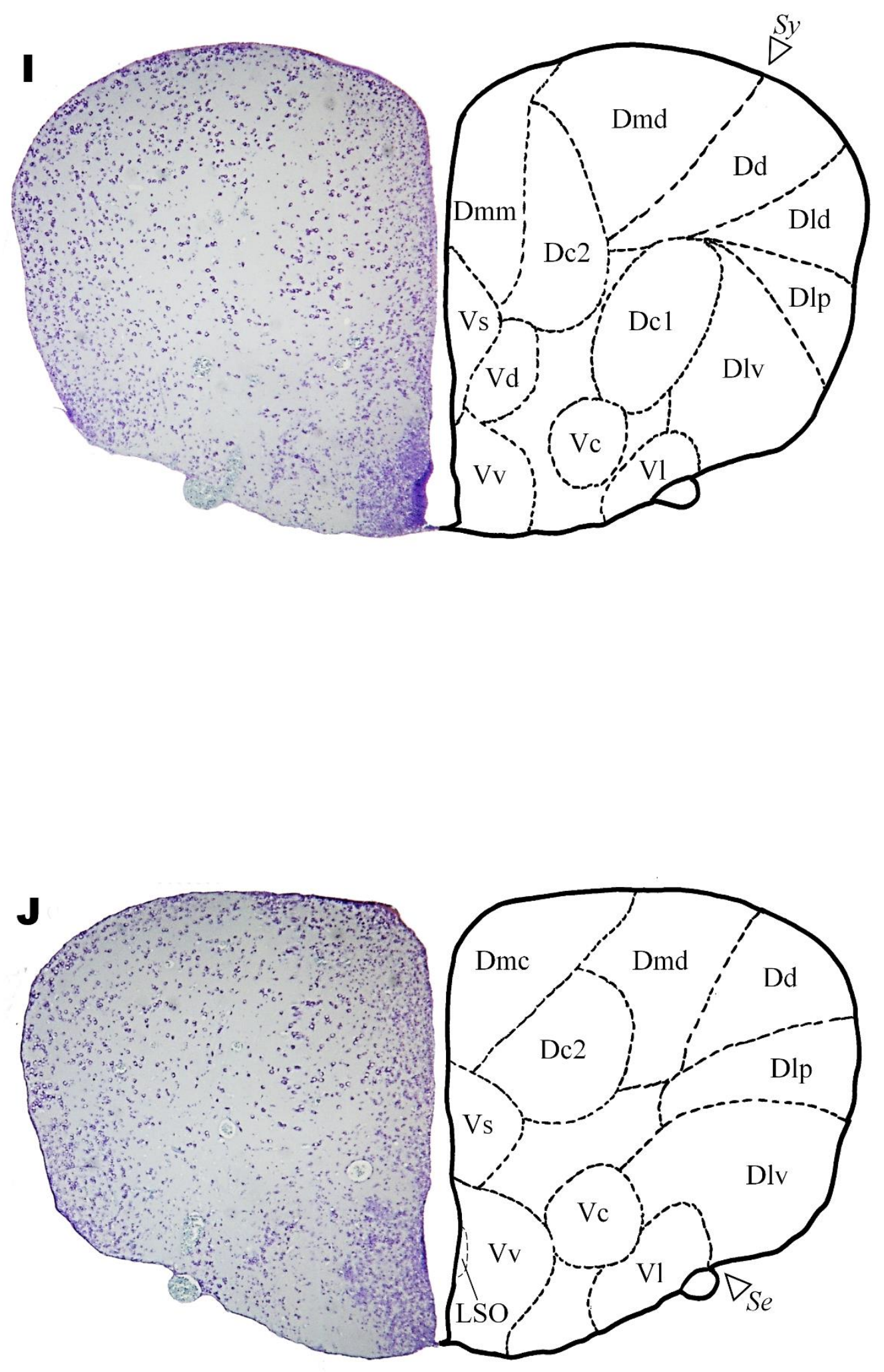

Plate 4 

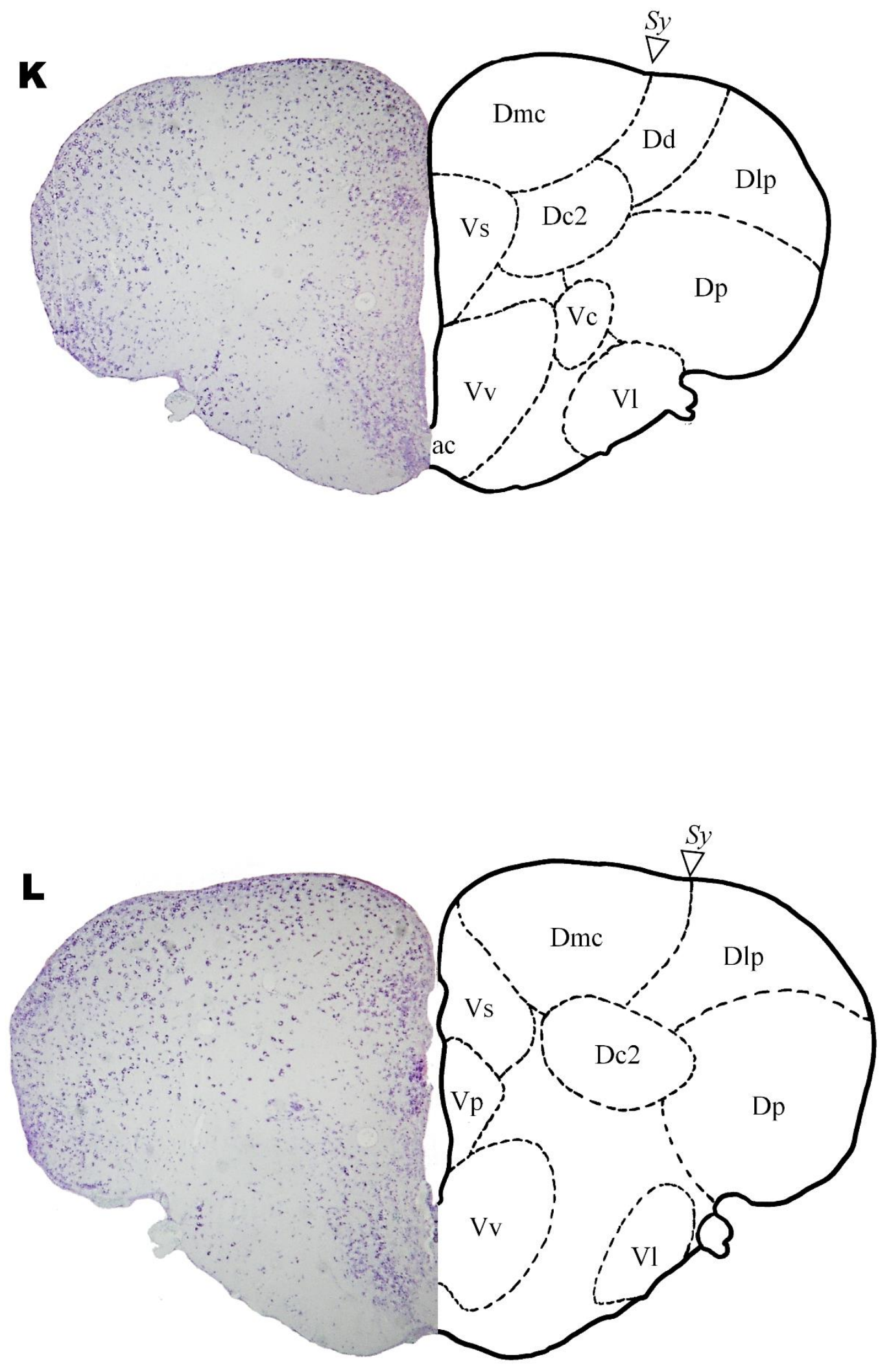

Plate 5 

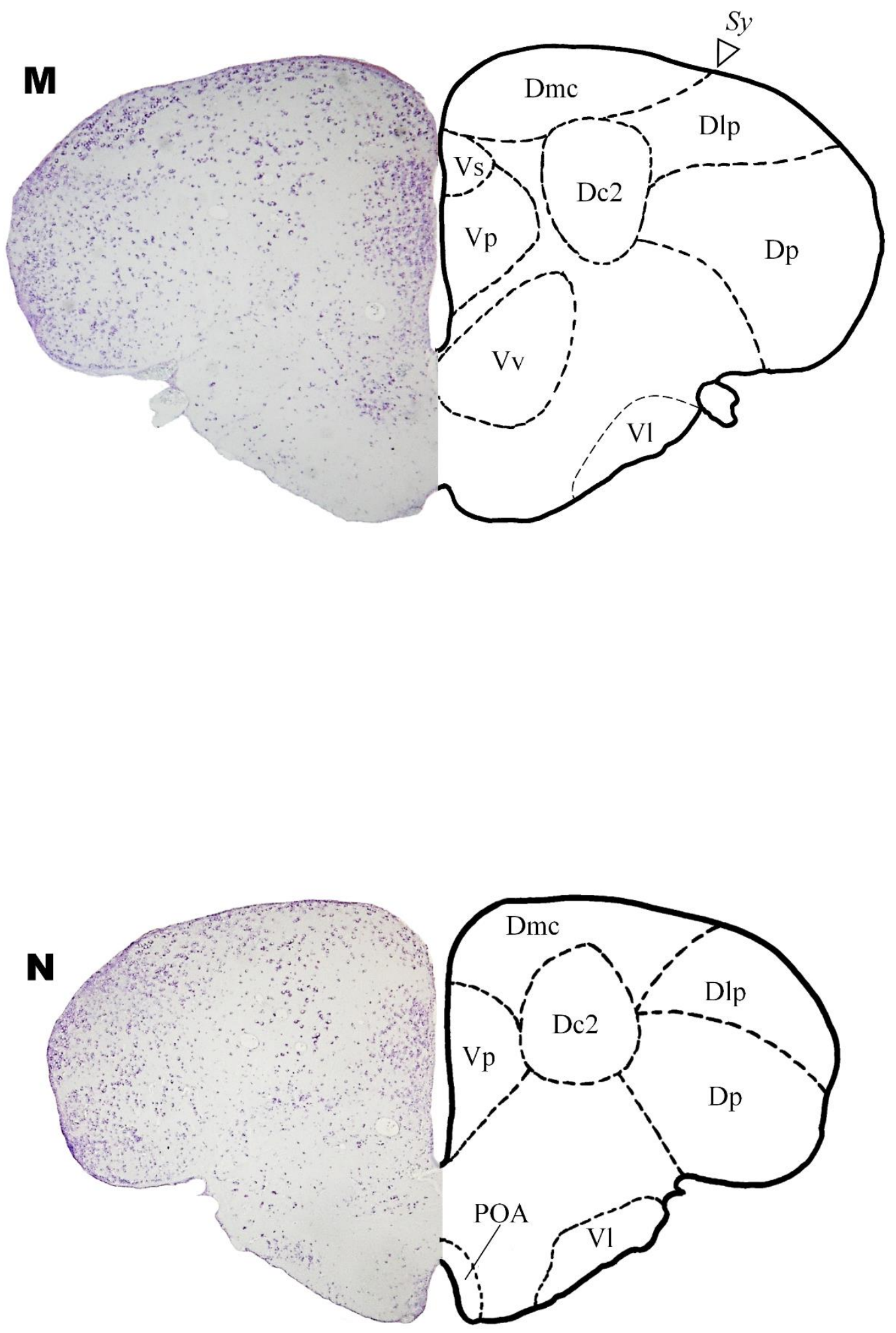

Plate 6 

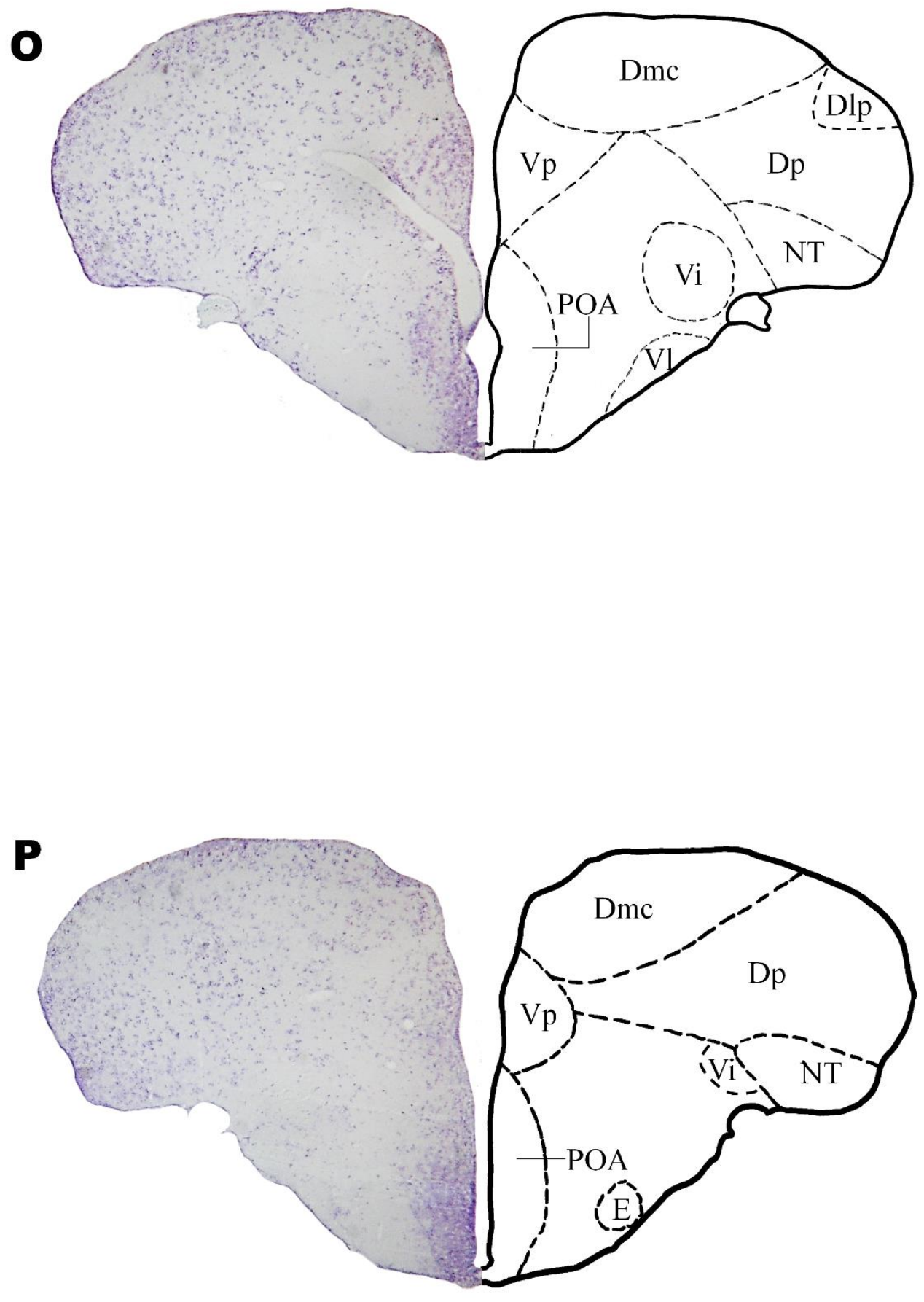

Plate 7 


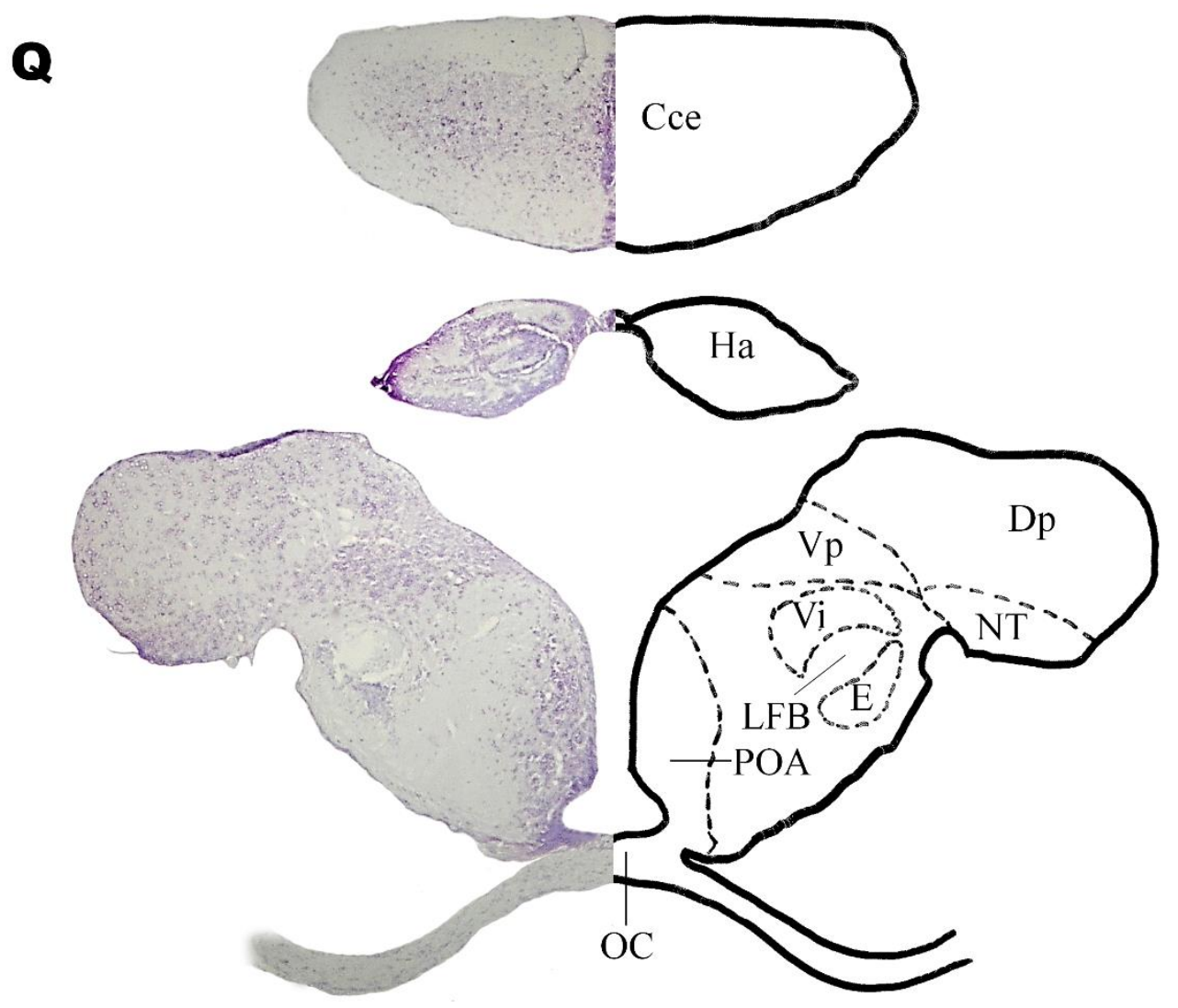




\section{PLATES $_{\text {of }}$}

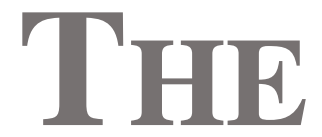

\section{DIENCEPHALON}

Sequences of cross-sections from rostral (Plate 9) to caudal part (Plate 16) of the brain of juvenile Steindachneridion parahybae.

The photomicrographs on the left were stained with cresyl-violet; right schemes represent different cell masses in the telencephalon. The position that each one cross-section can be viewed through the Fig. 1. Scale bar: $550 \mu \mathrm{m}$. For abbreviations, see the list of abbreviations (on the beginning of this Atlas) and Table I. 
A

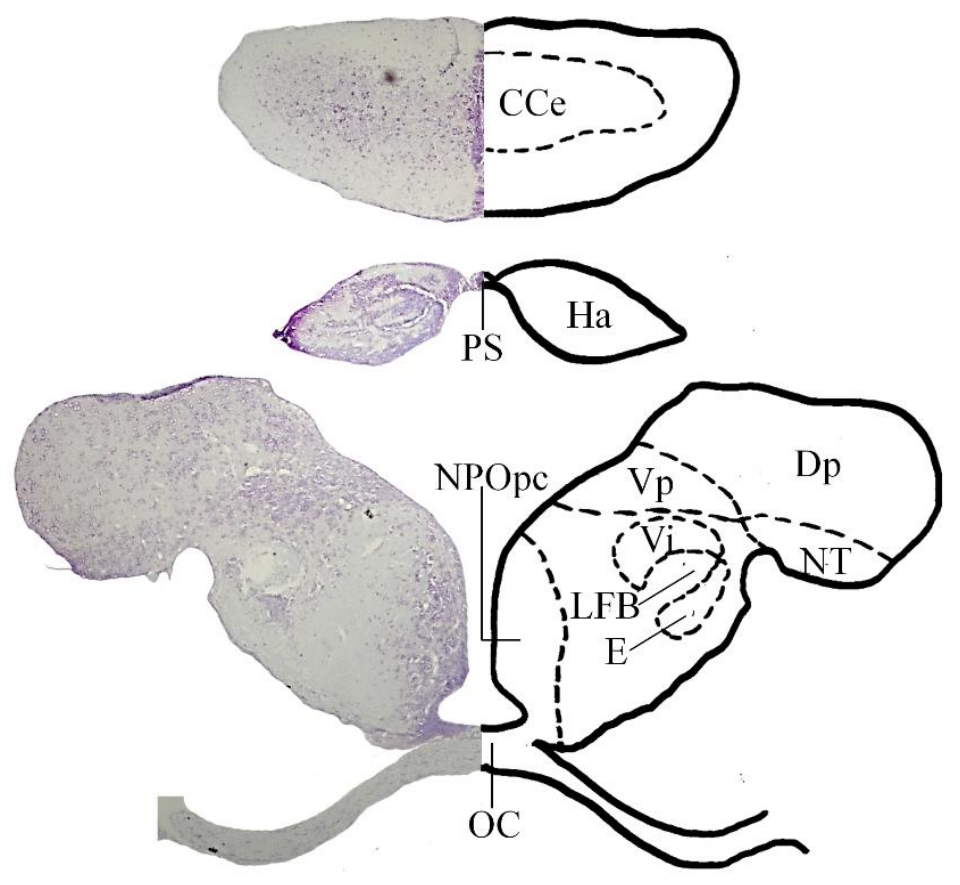

B

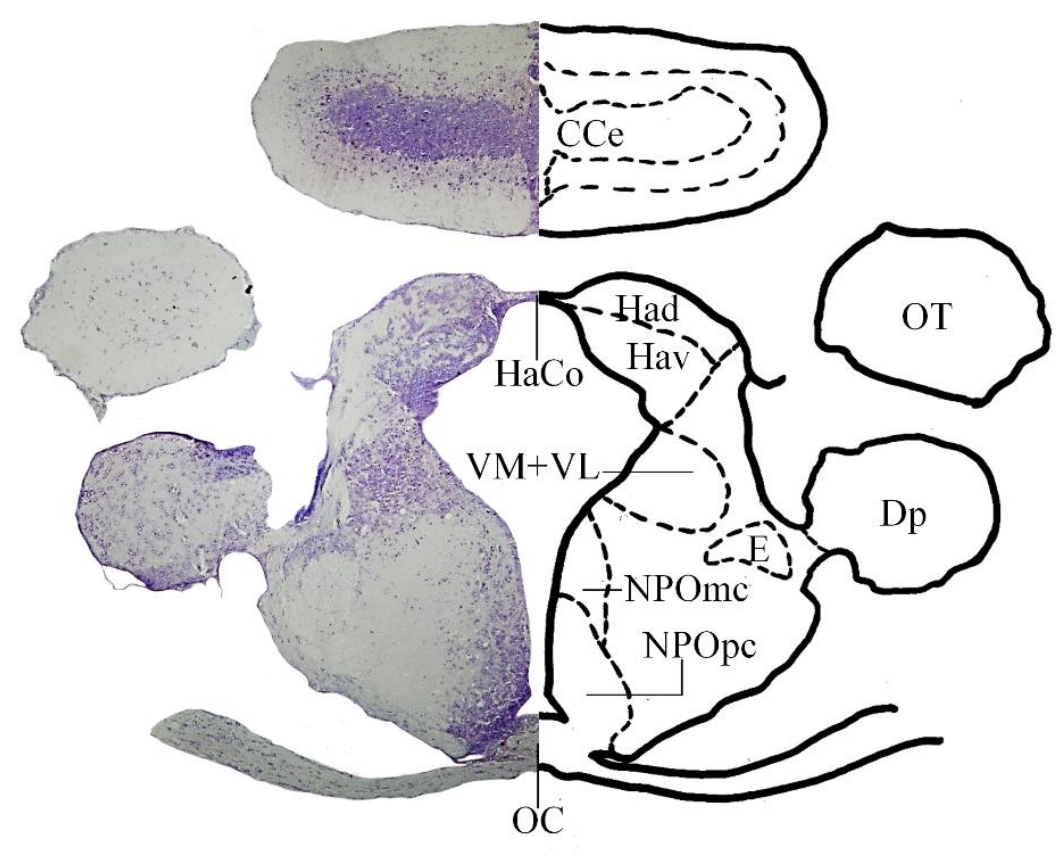

Plate 9 

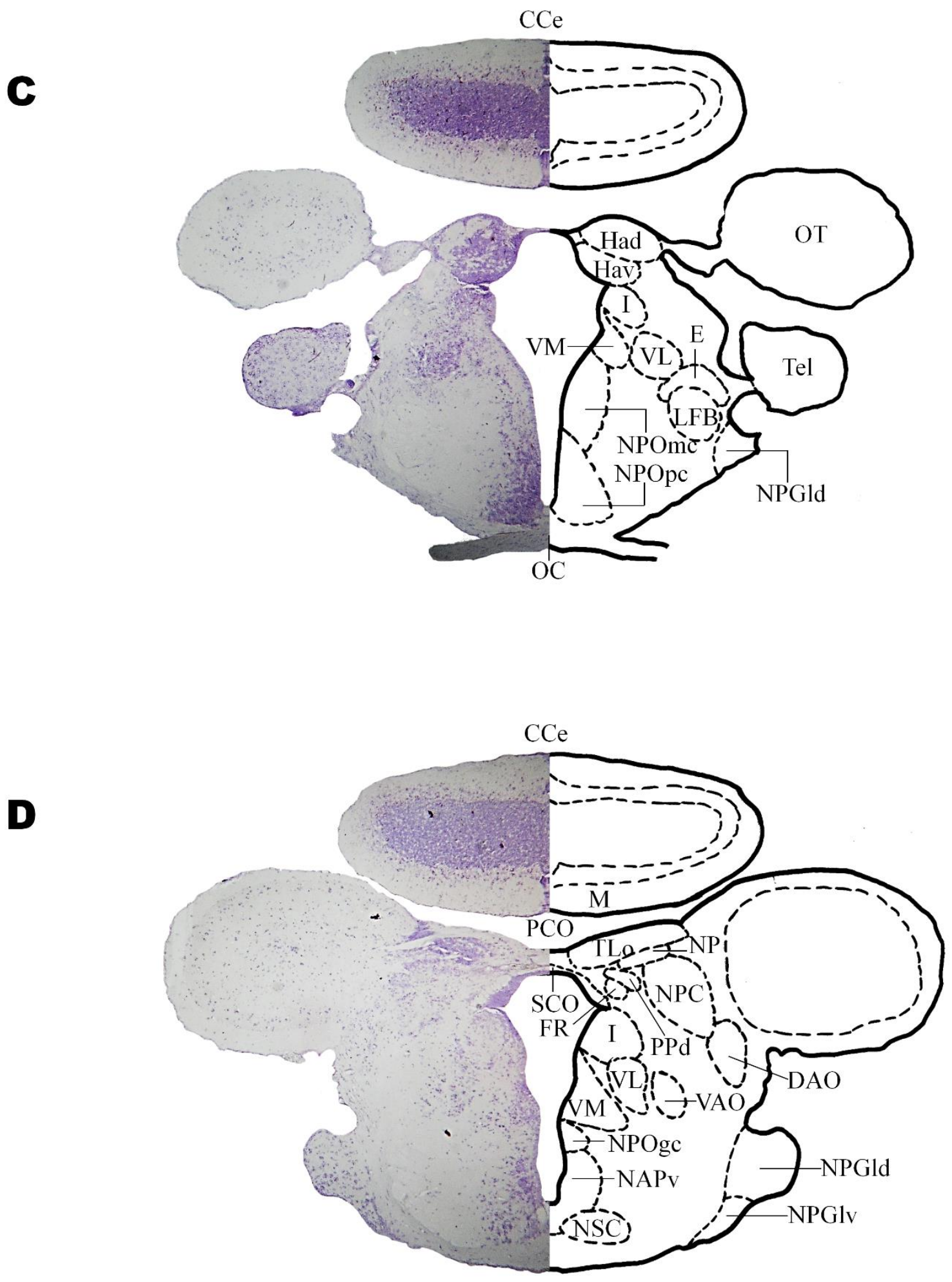

Plate 10 

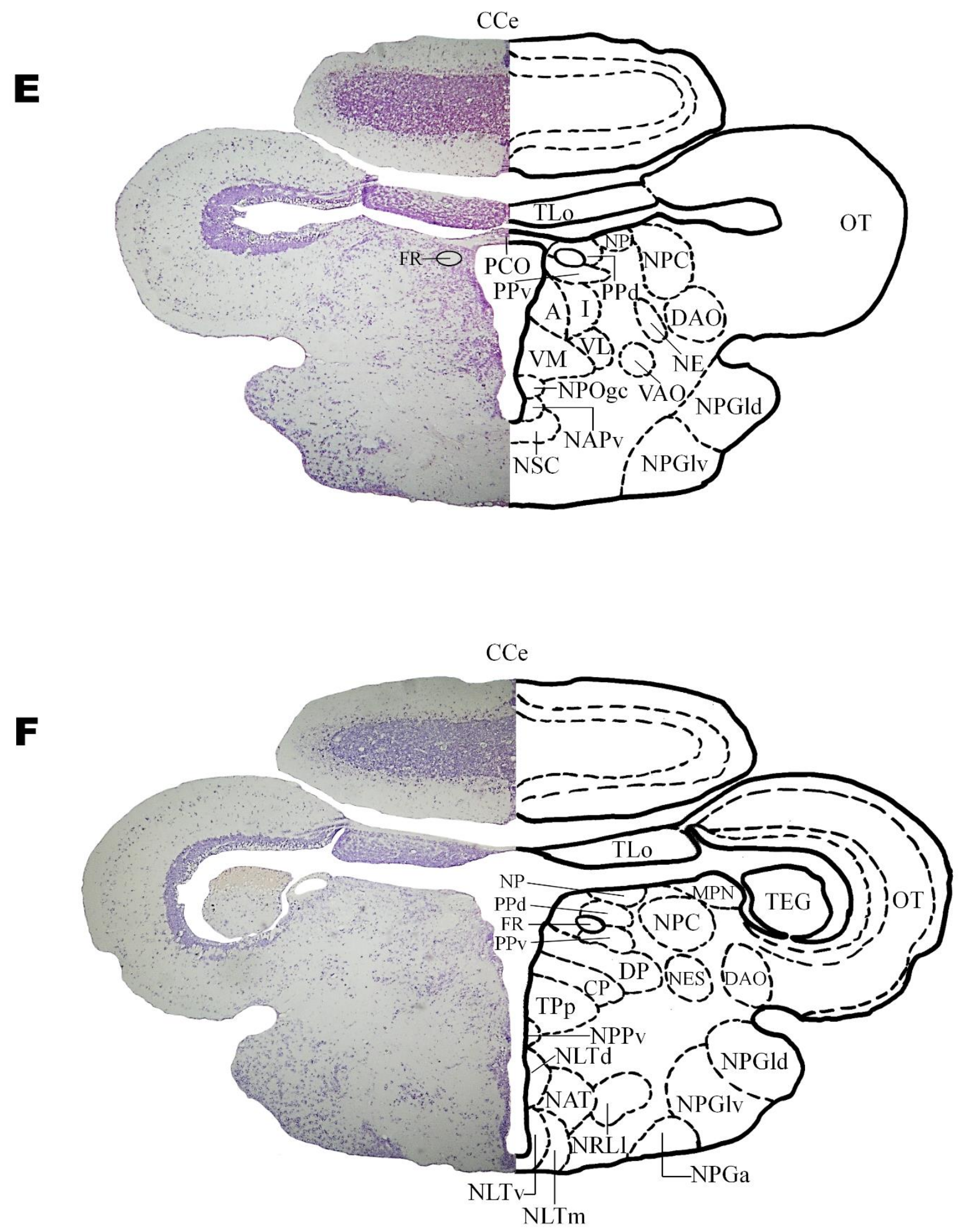

Plate 11 

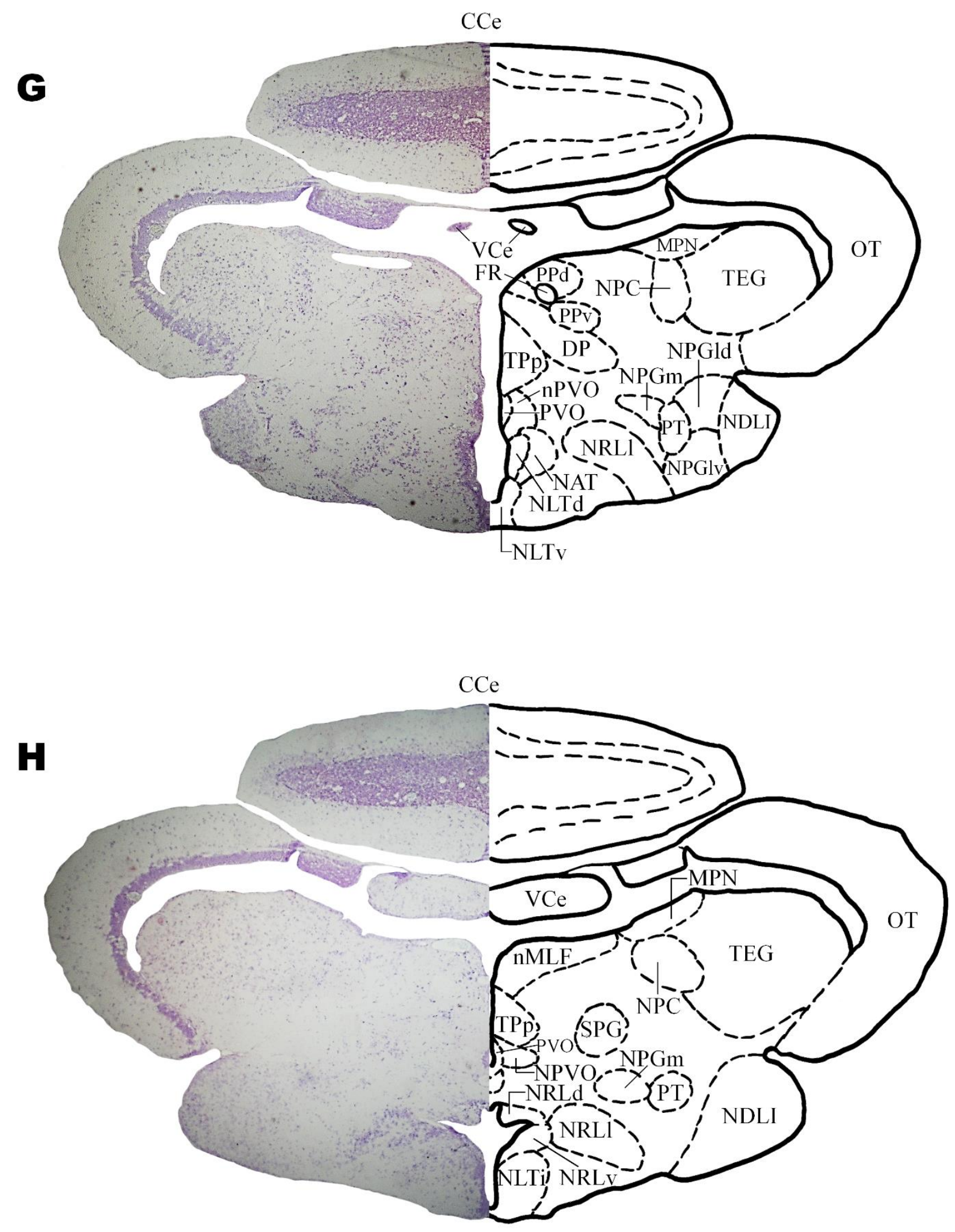

Plate 12 

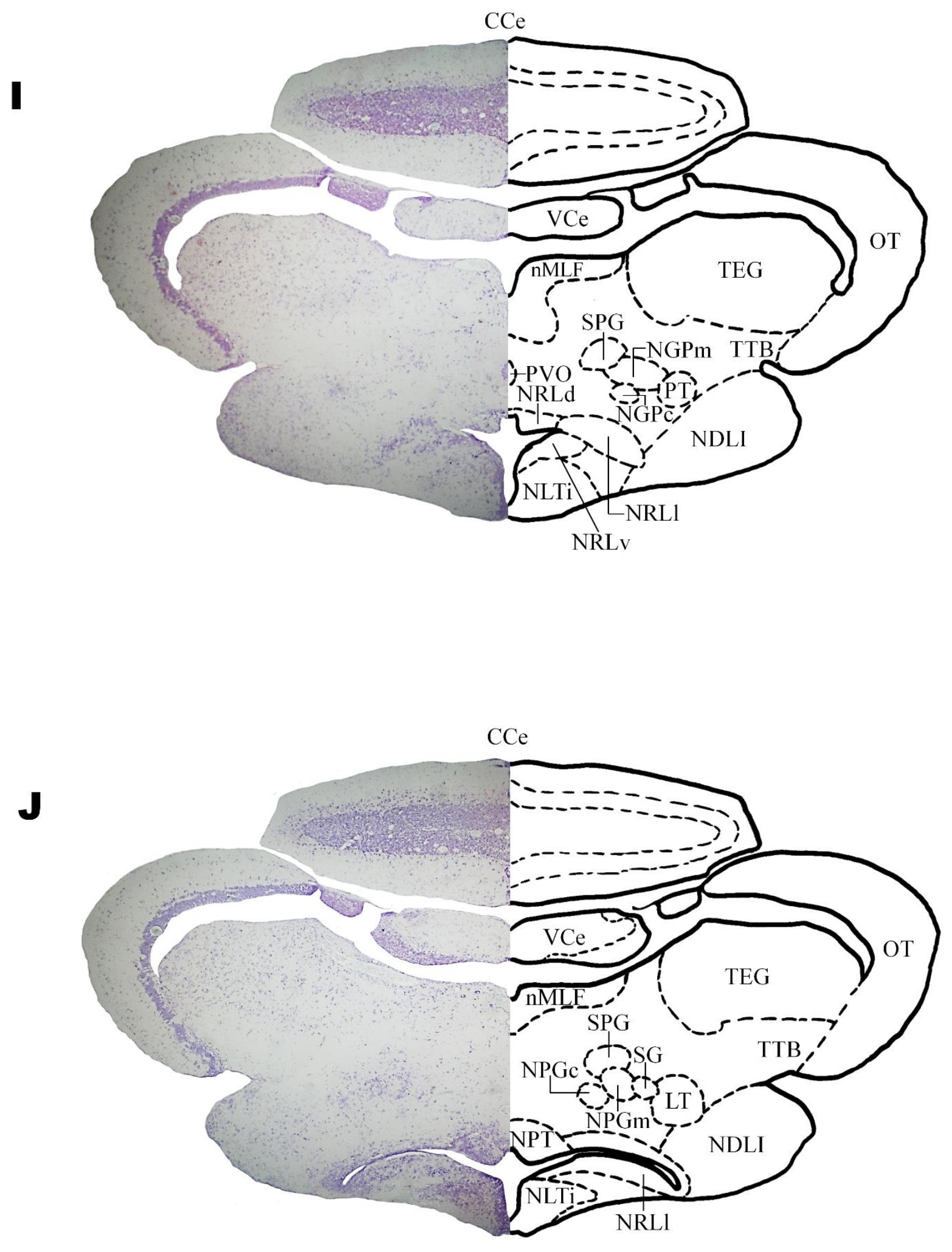

Plate 13 

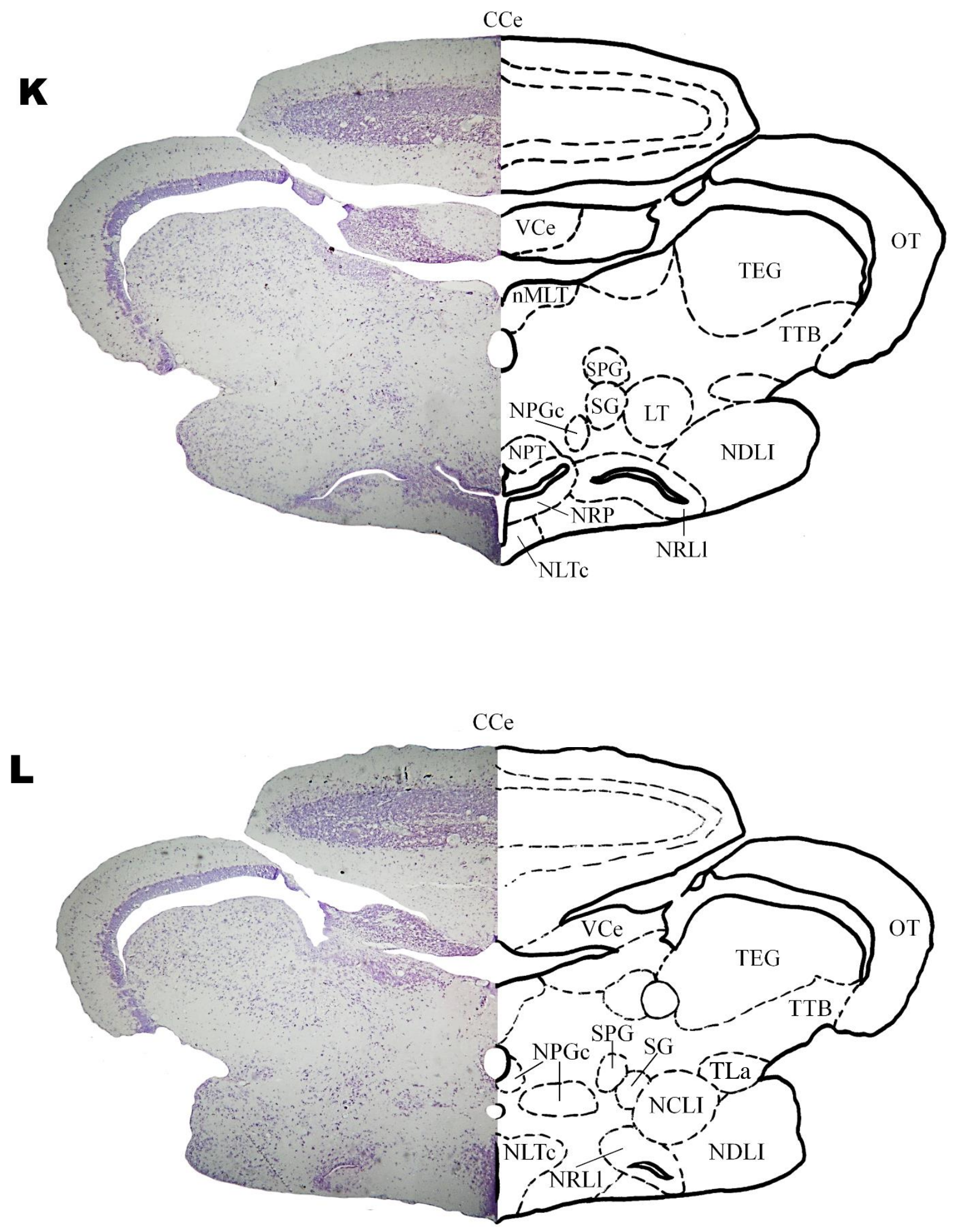

Plate 14 

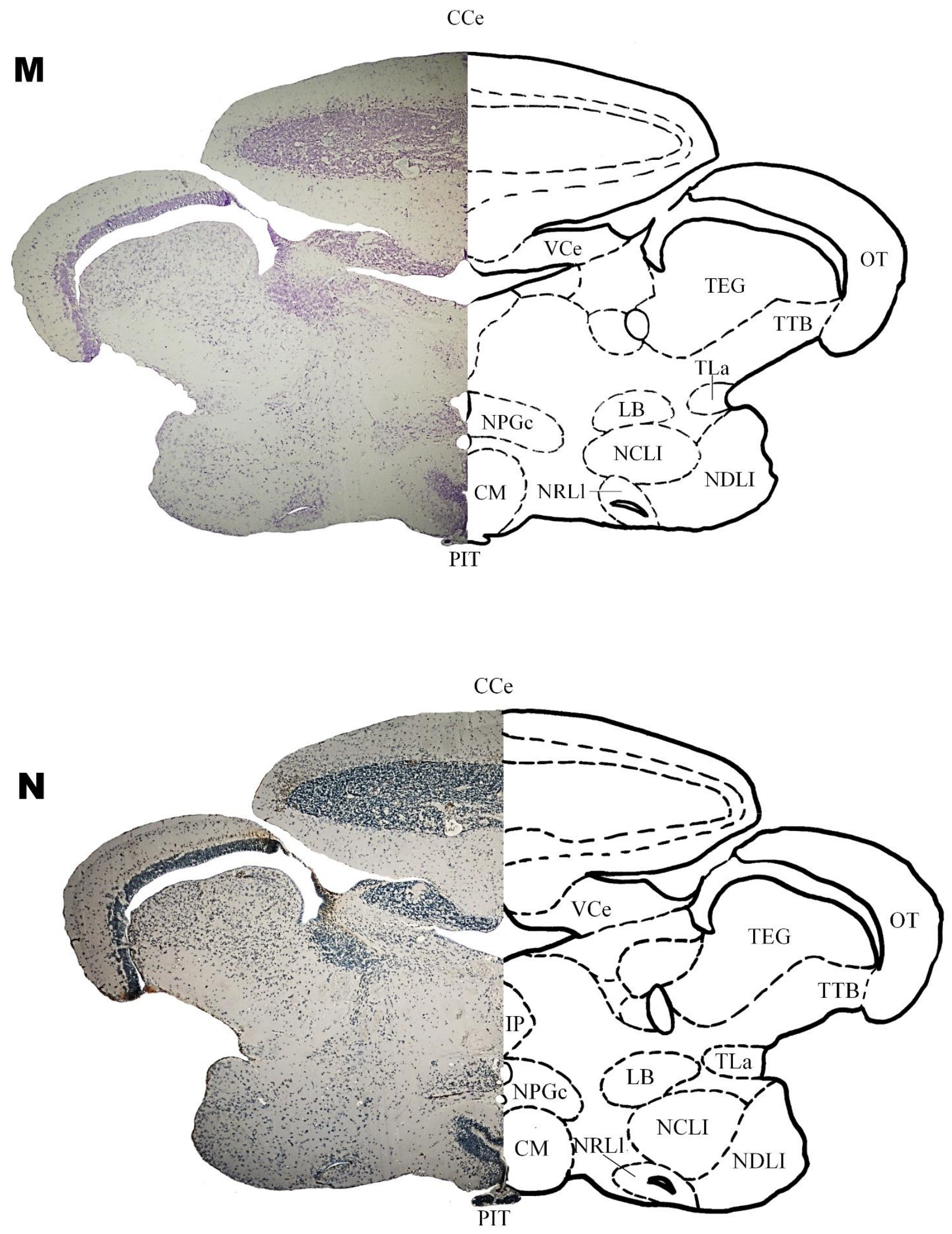

Plate 15 


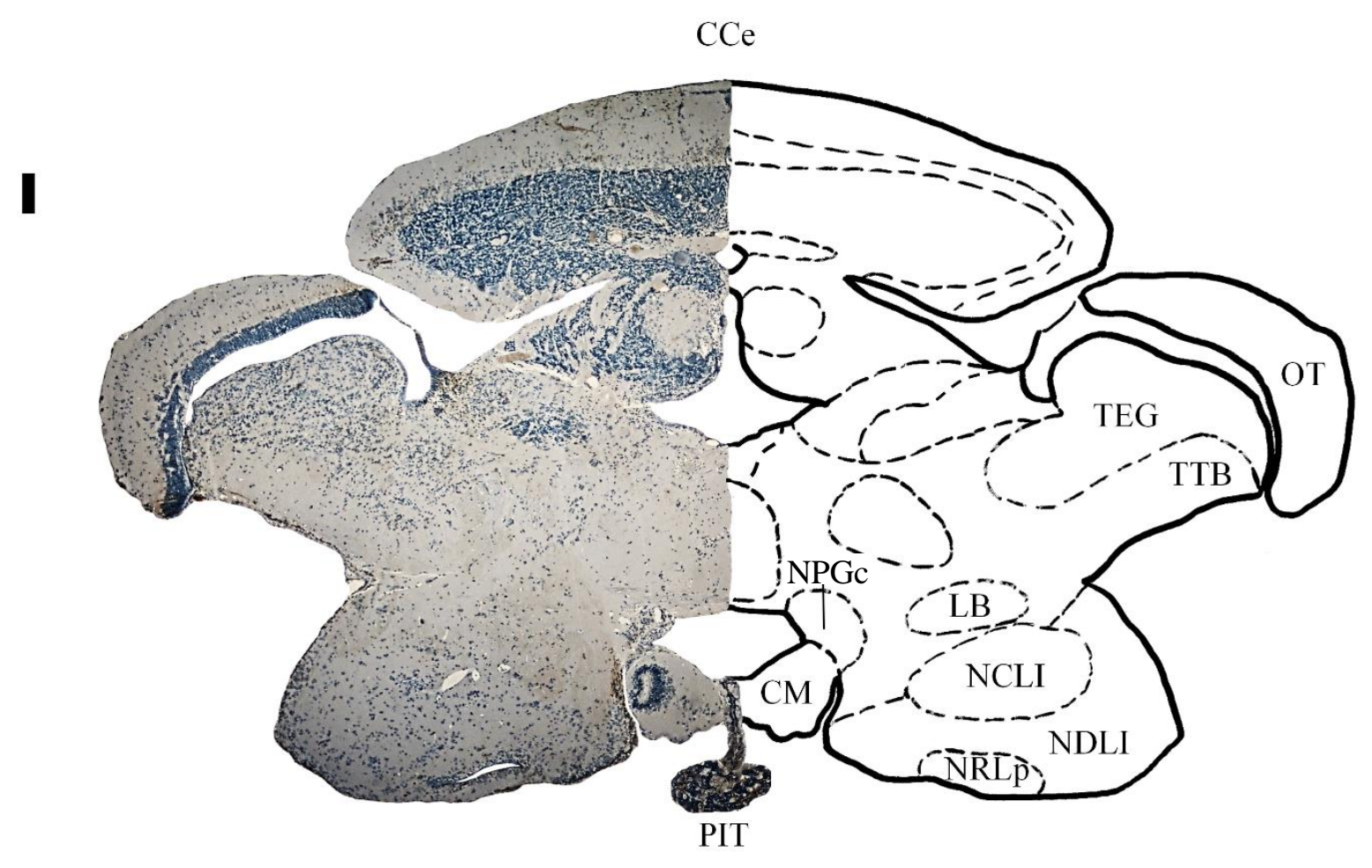

Plate 16 


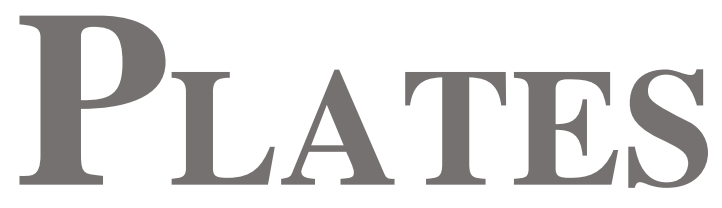

of

THE

MidBRAIN*

and HindBRAIN**

Sequences of cross-sections from rostral (Plate 17) to caudal part (Plate 24) of the brain of juvenile Steindachneridion parahybae.

The photomicrographs on the left were stained with cresyl-violet; right schemes represent different cell masses in the mesencephalon, cerebellum and rhombencephalon. The position that each one crosssection can be viewed through the Fig. 1. Scale bar: $550 \mu \mathrm{m}$. For abbreviations, see the list of abbreviations (on the beginning of this Atlas) and Table I. 

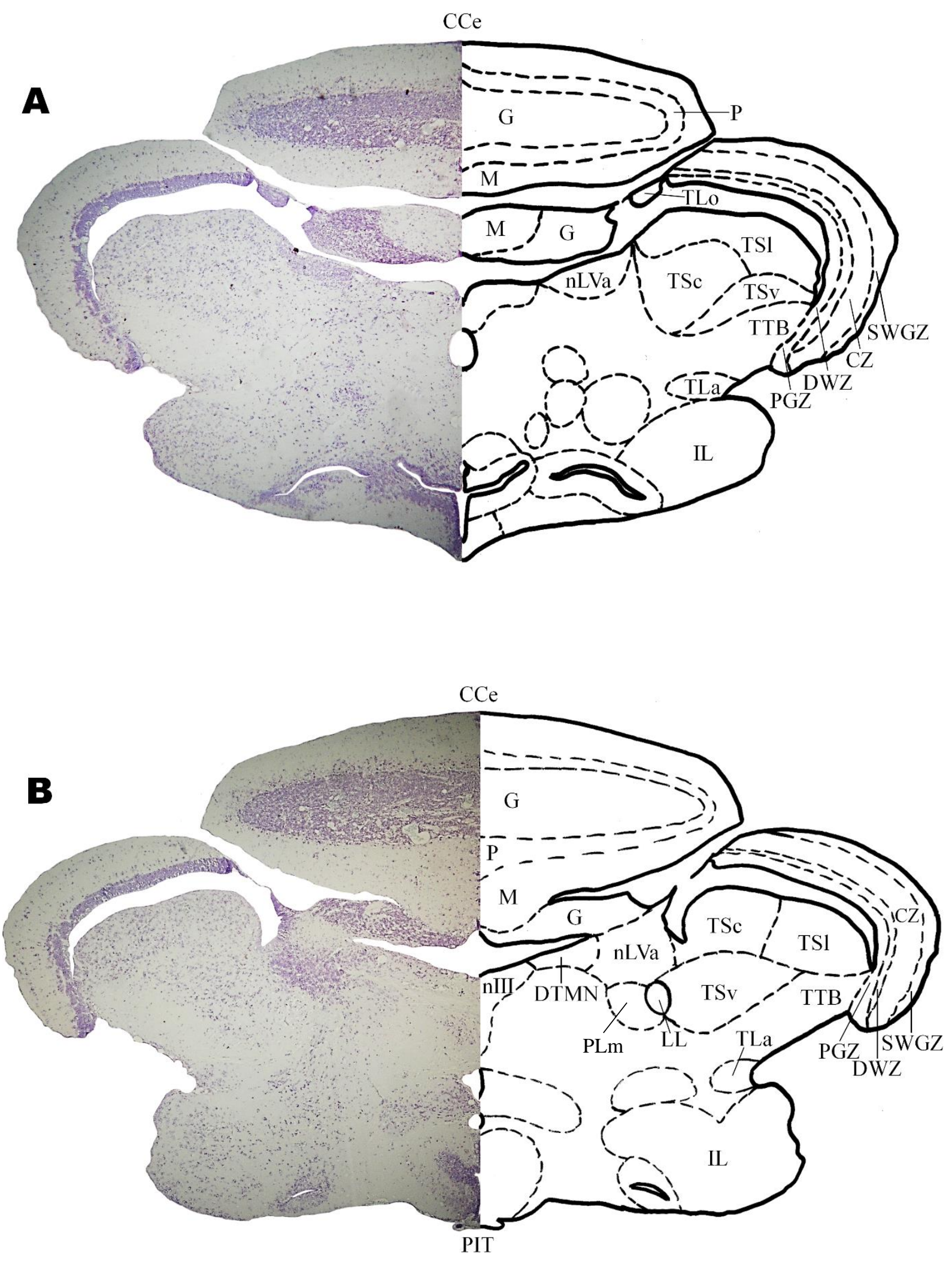

Plate 17 

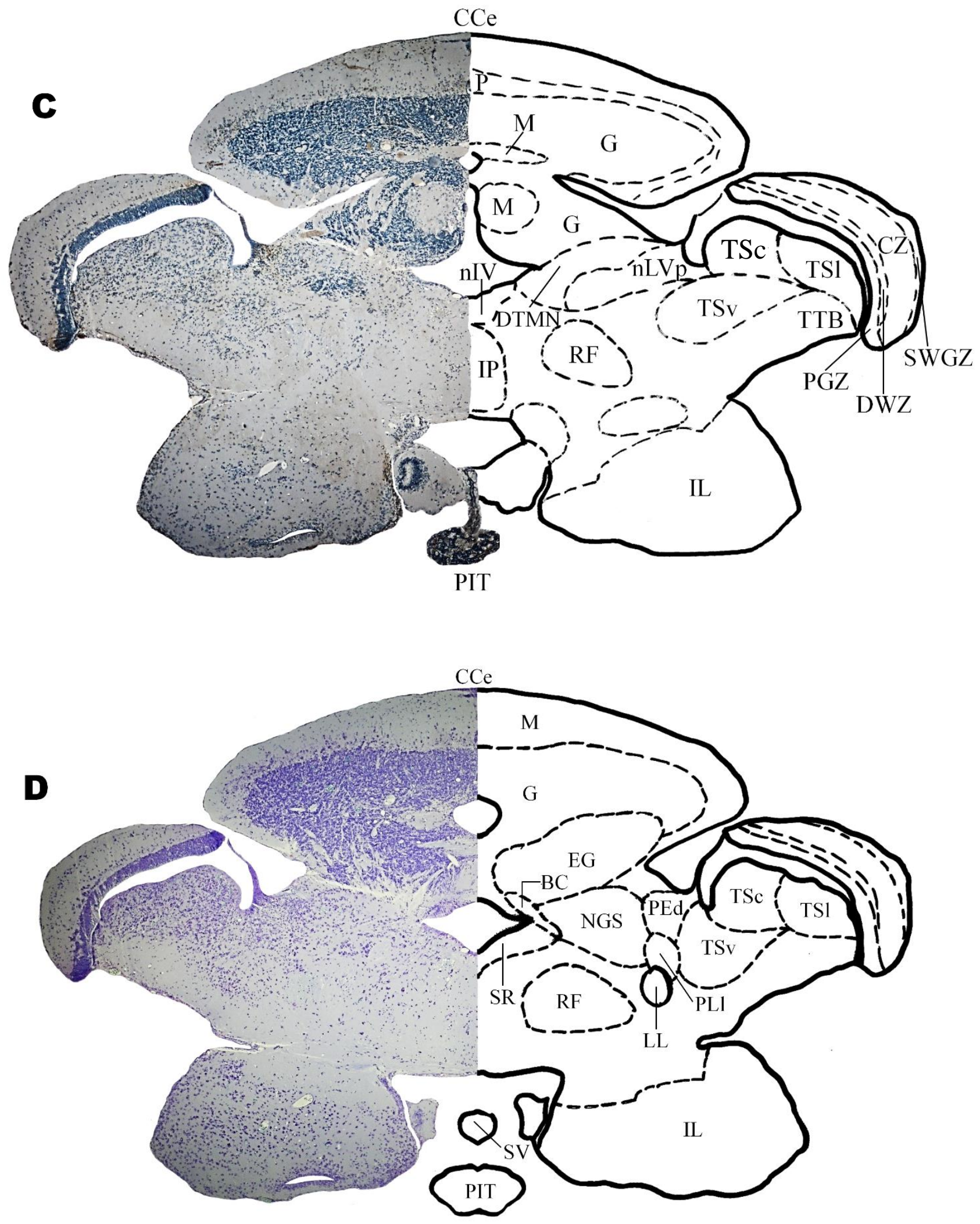

Plate 18 

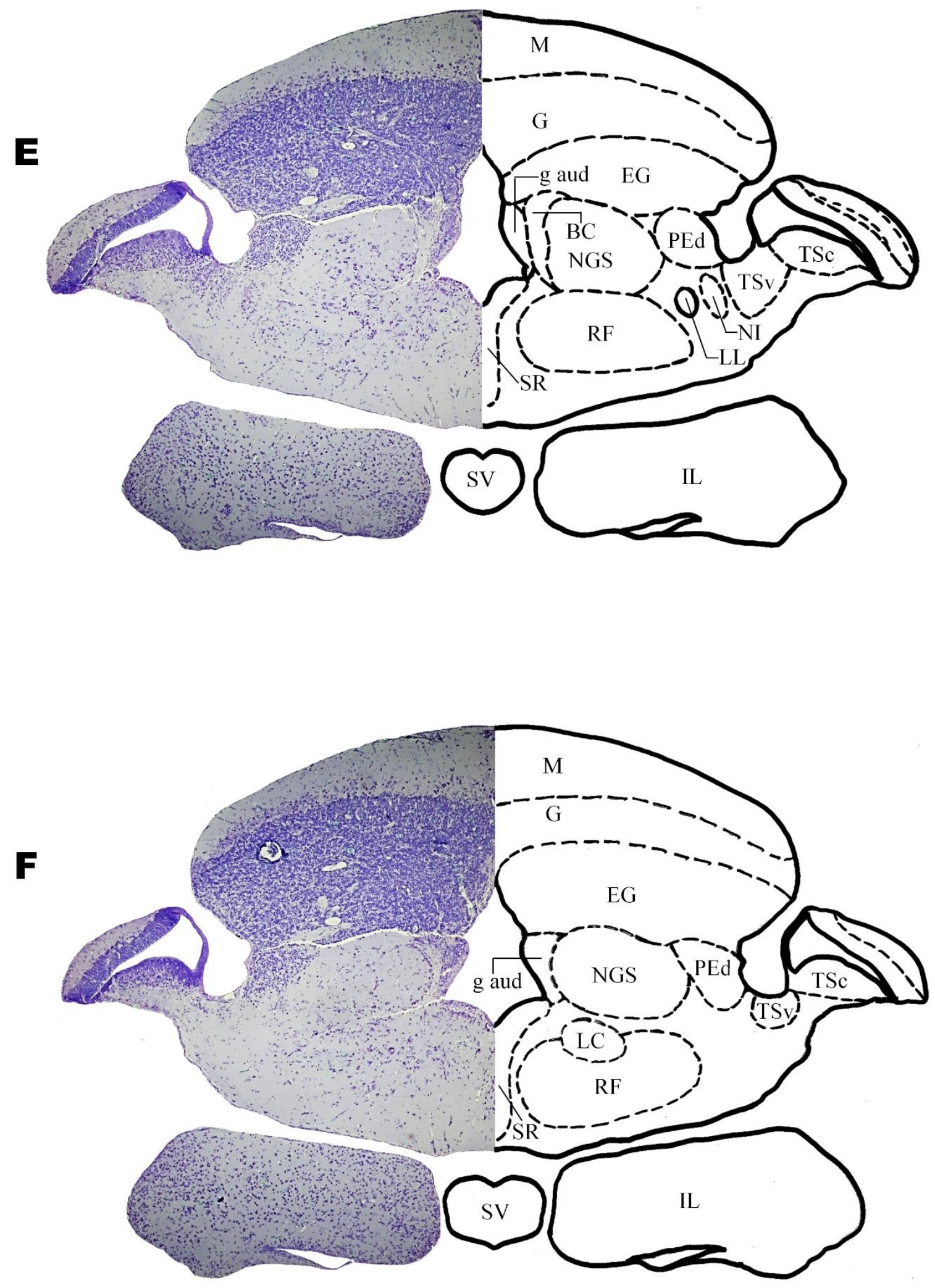

Plate 19 
G

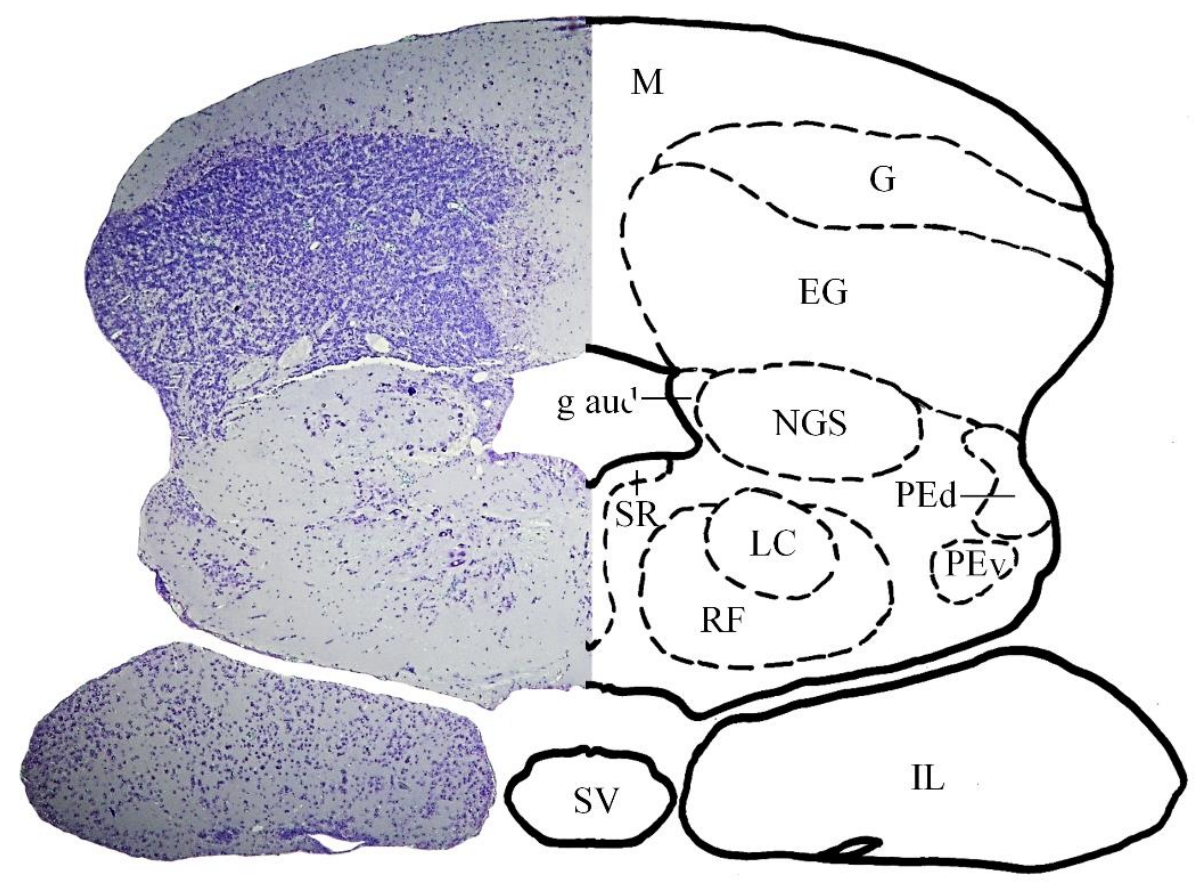

H

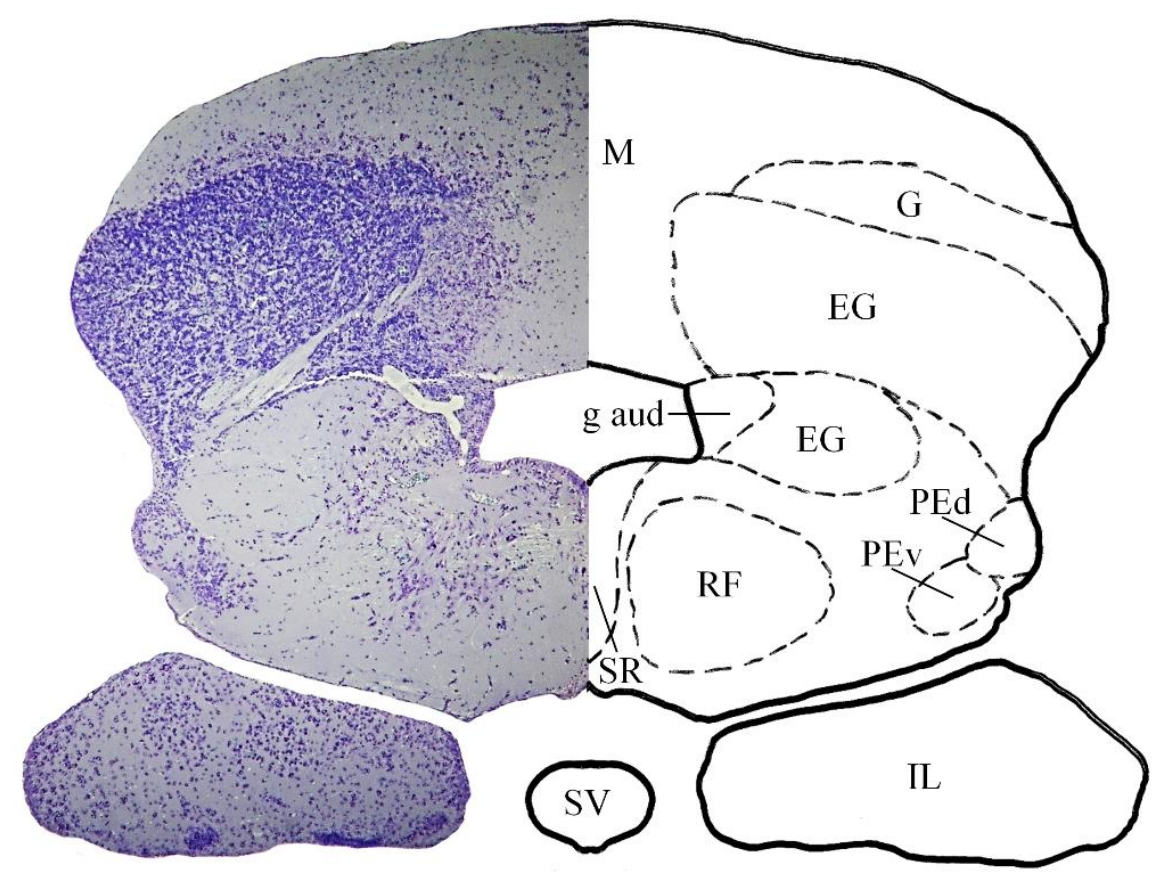

Plate 20 

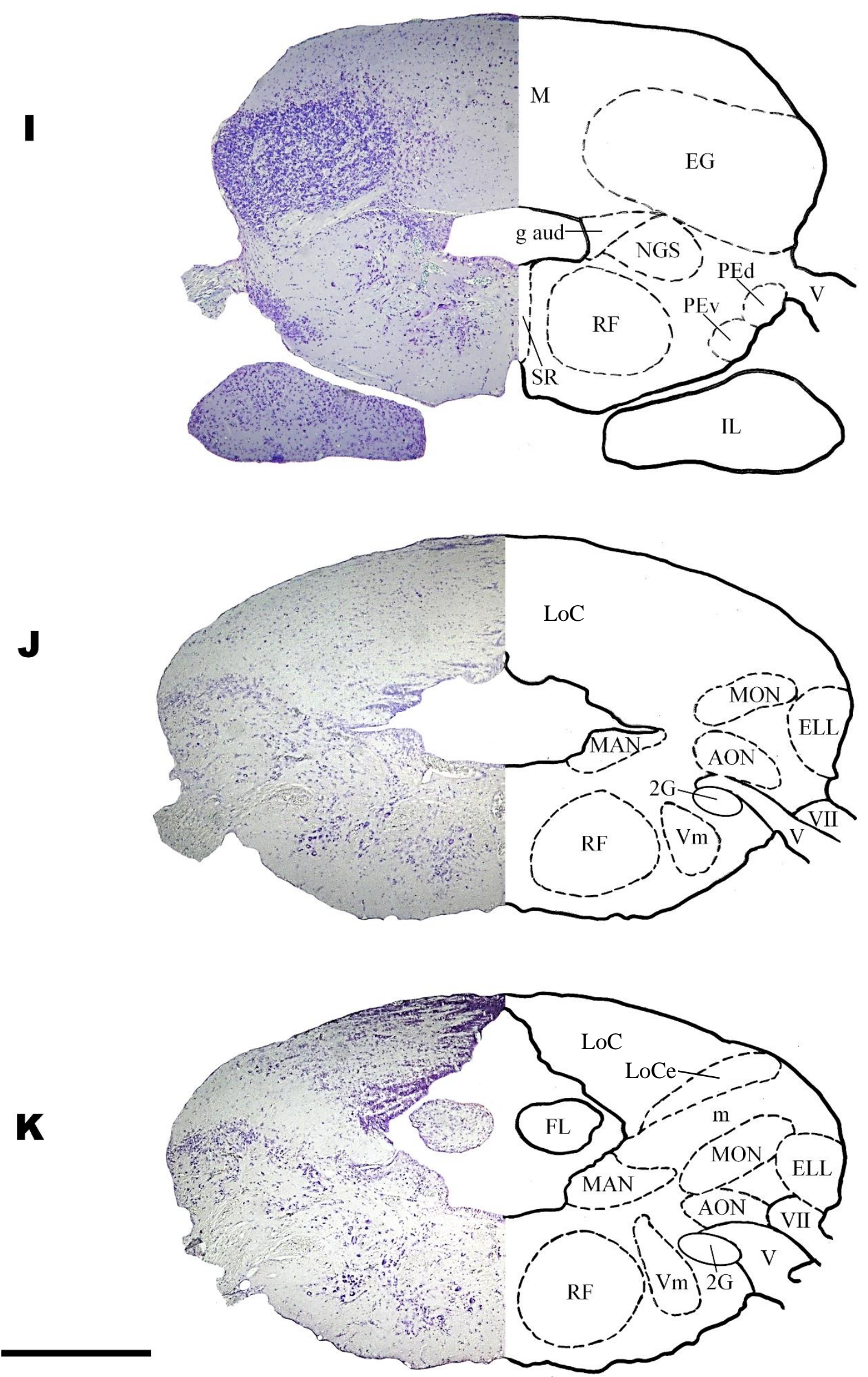

Plate 21 

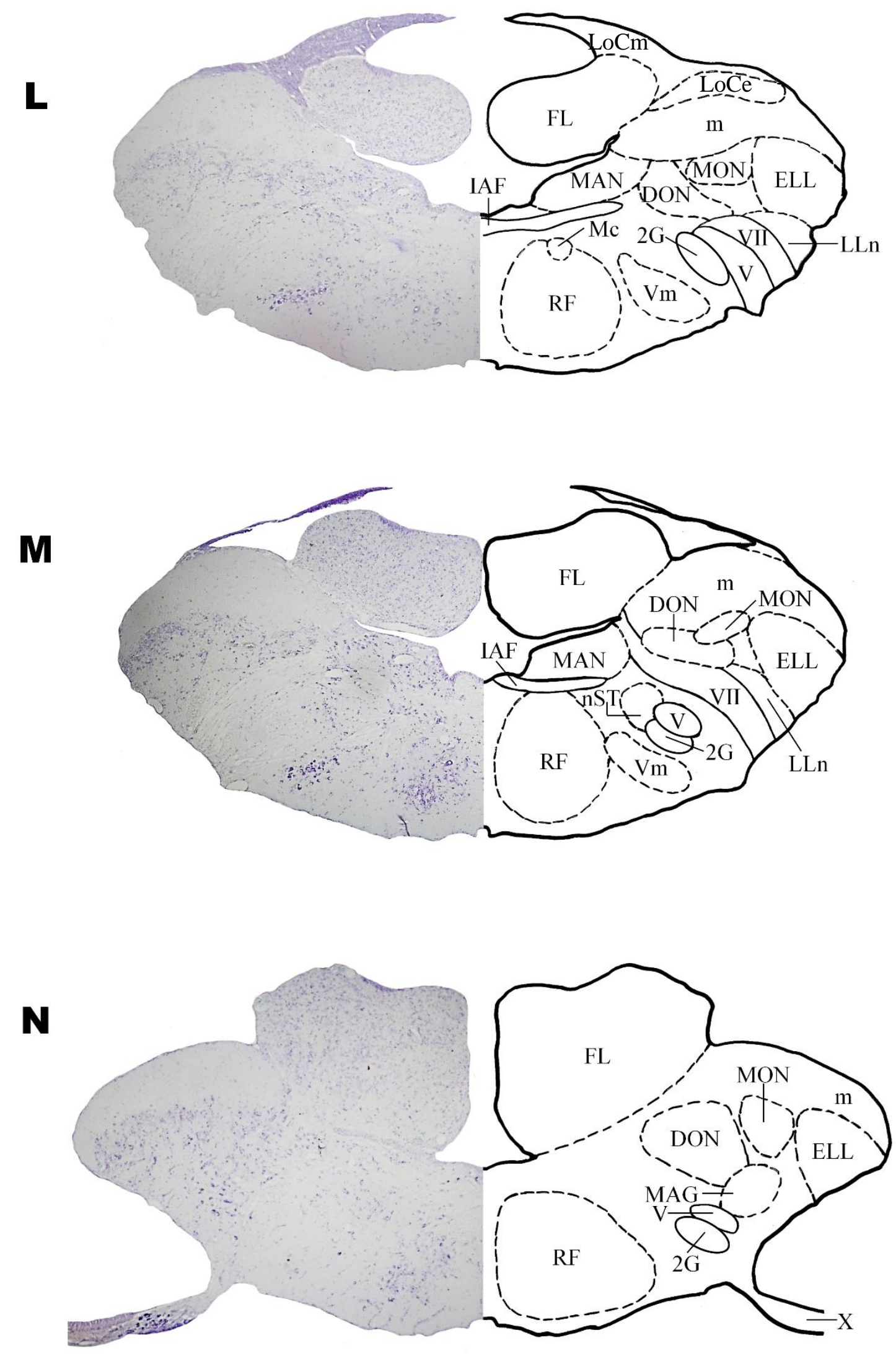

Plate 22 


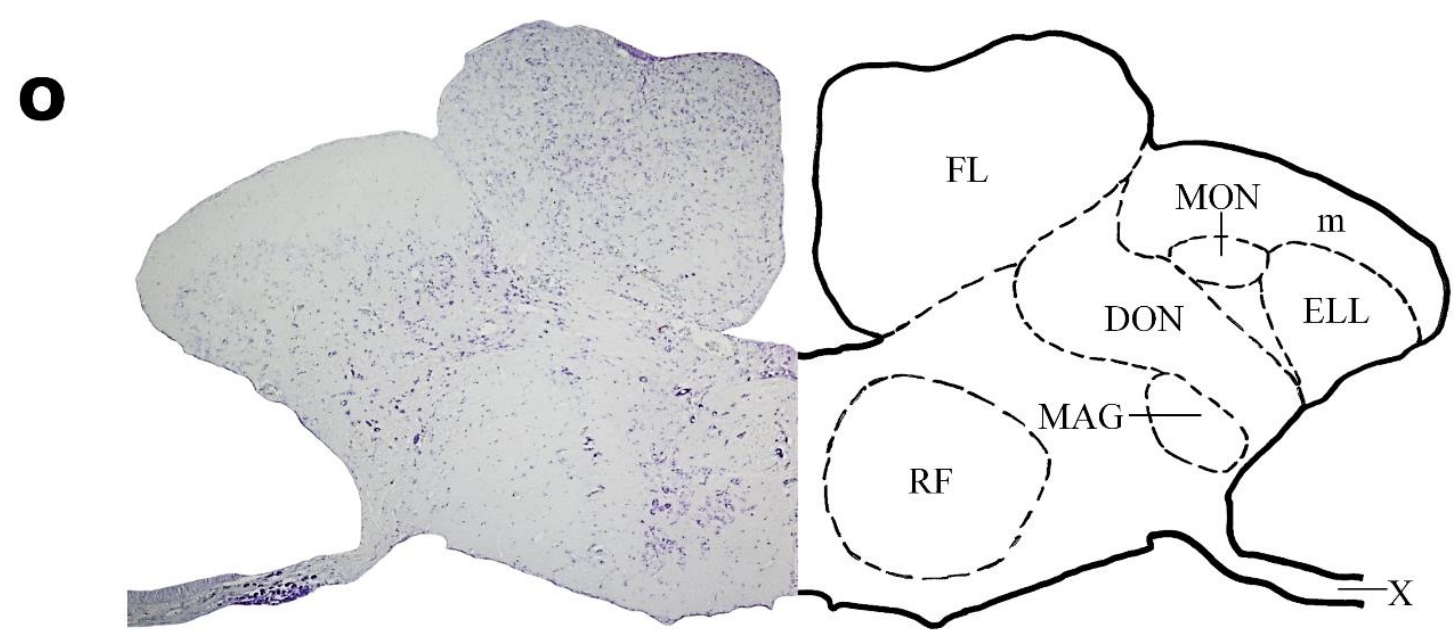

P

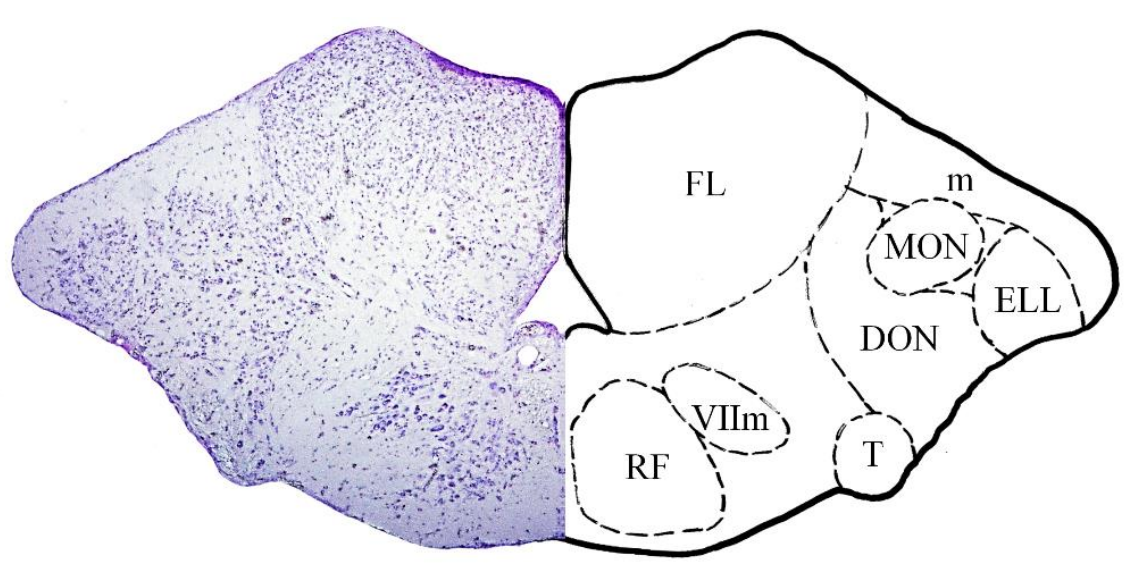

Q

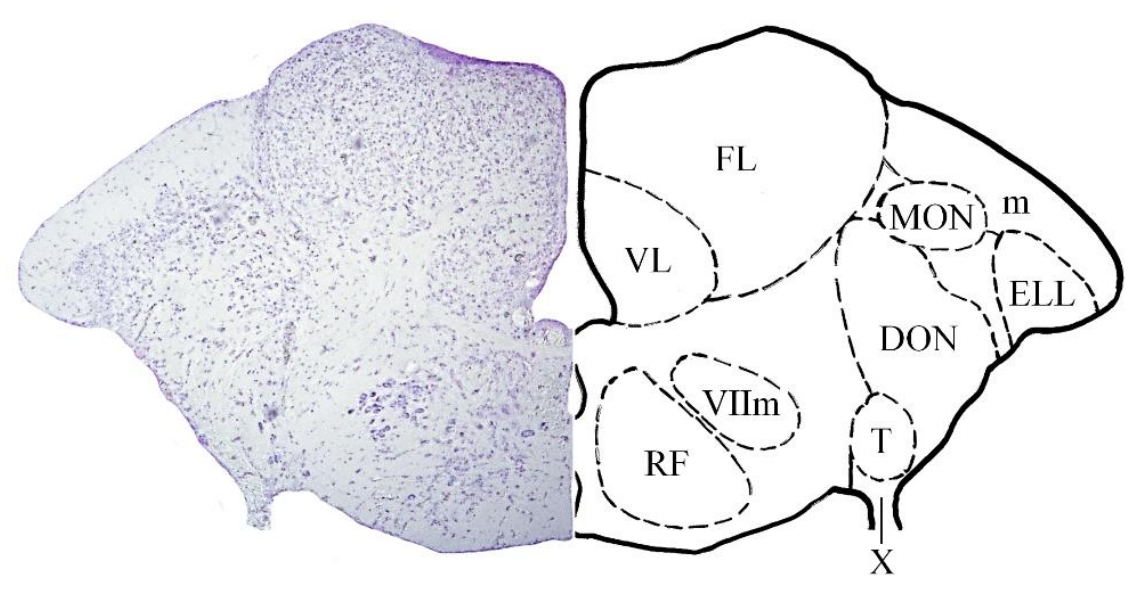

Plate 23 
$\mathbf{R}$

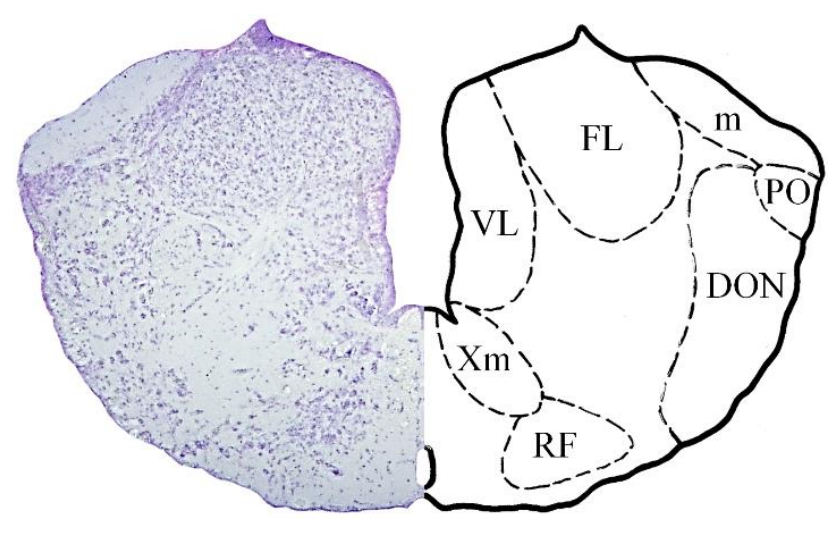

$\mathbf{S}$

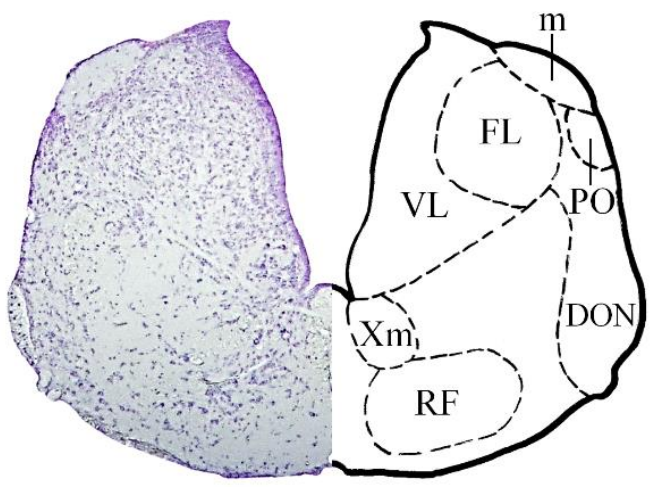

$\mathbf{T}$

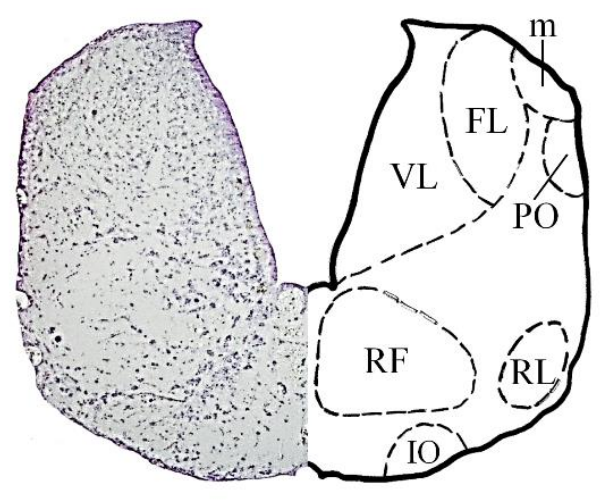

Plate 24 


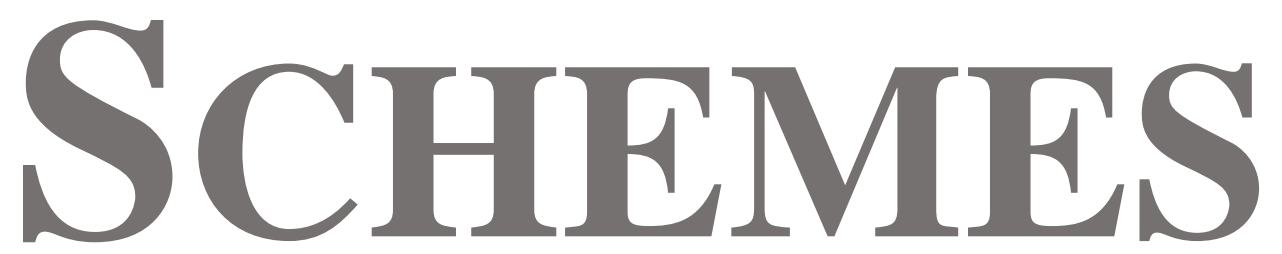

Detailed schemes of the catfish (Steindachneridion parahybae) brain. This part is to provide a use in the different analyses, i. e. immunohistochemistry, using also as a tool for different studies. 

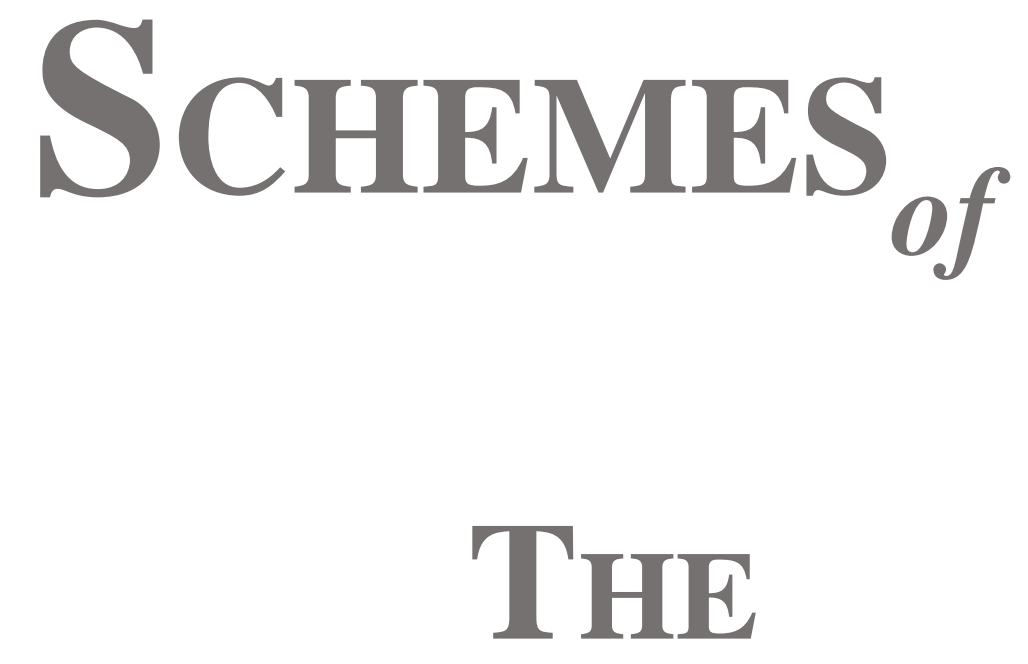

\section{TELENCEPHALON}

Sequences of cross-sections from rostral (Plate 1) to caudal part (Plate 8) of the brain of juvenile Steindachneridion parahybae.

Schemes representing different cell masses in the telencephalon. The white arrows represent the main telencephalic sulcus (sulcus externus, ipsilyformes and lateralis). The position that each one crosssection can be viewed through the Fig. 1. Scale bar: $550 \mu \mathrm{m}$. For abbreviations, see the list of abbreviations (on the beginning of this Atlas) and Table I. 
Plates \& Schemes of Catfish Brain 
A
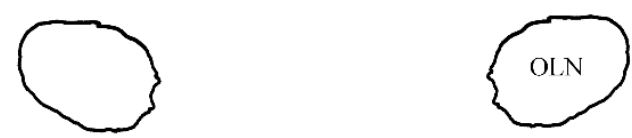

B
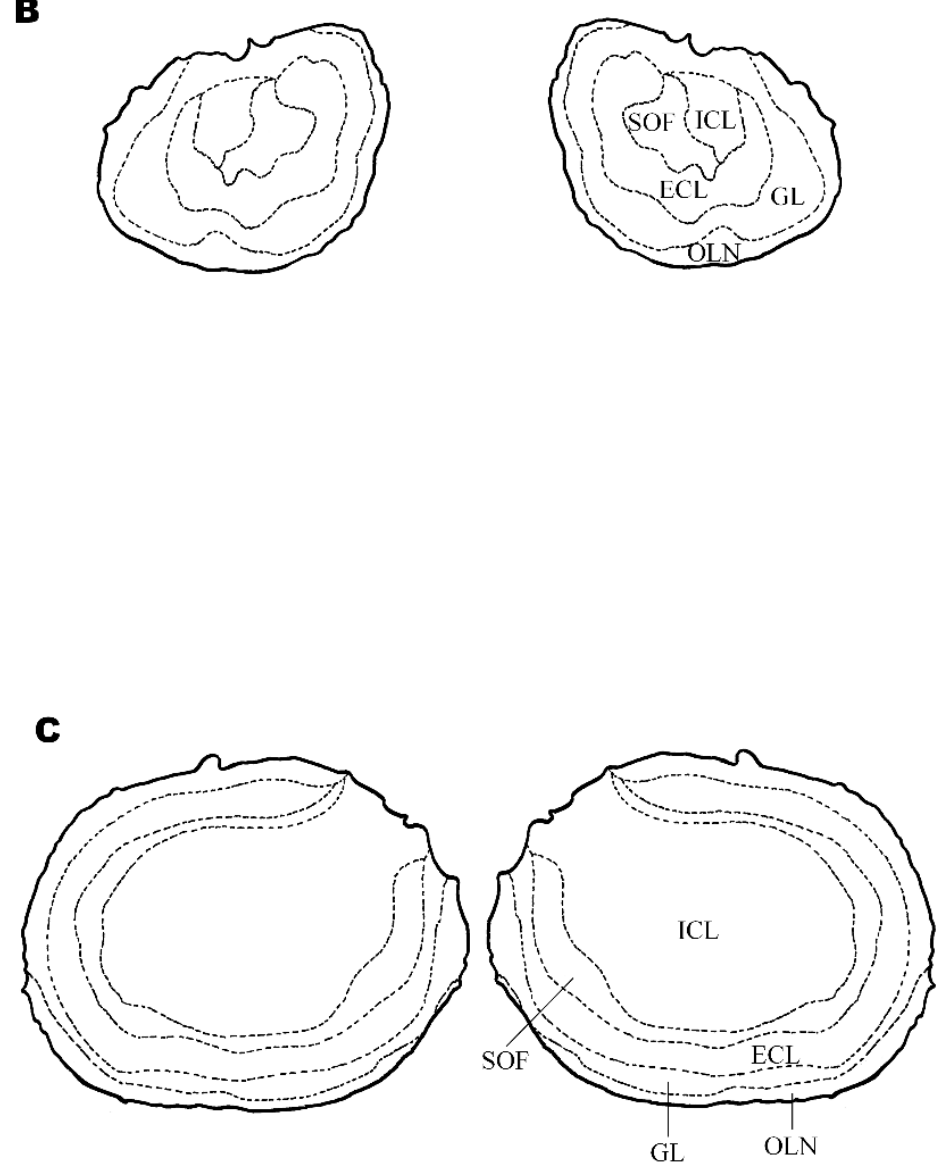

Scheme 1 
D
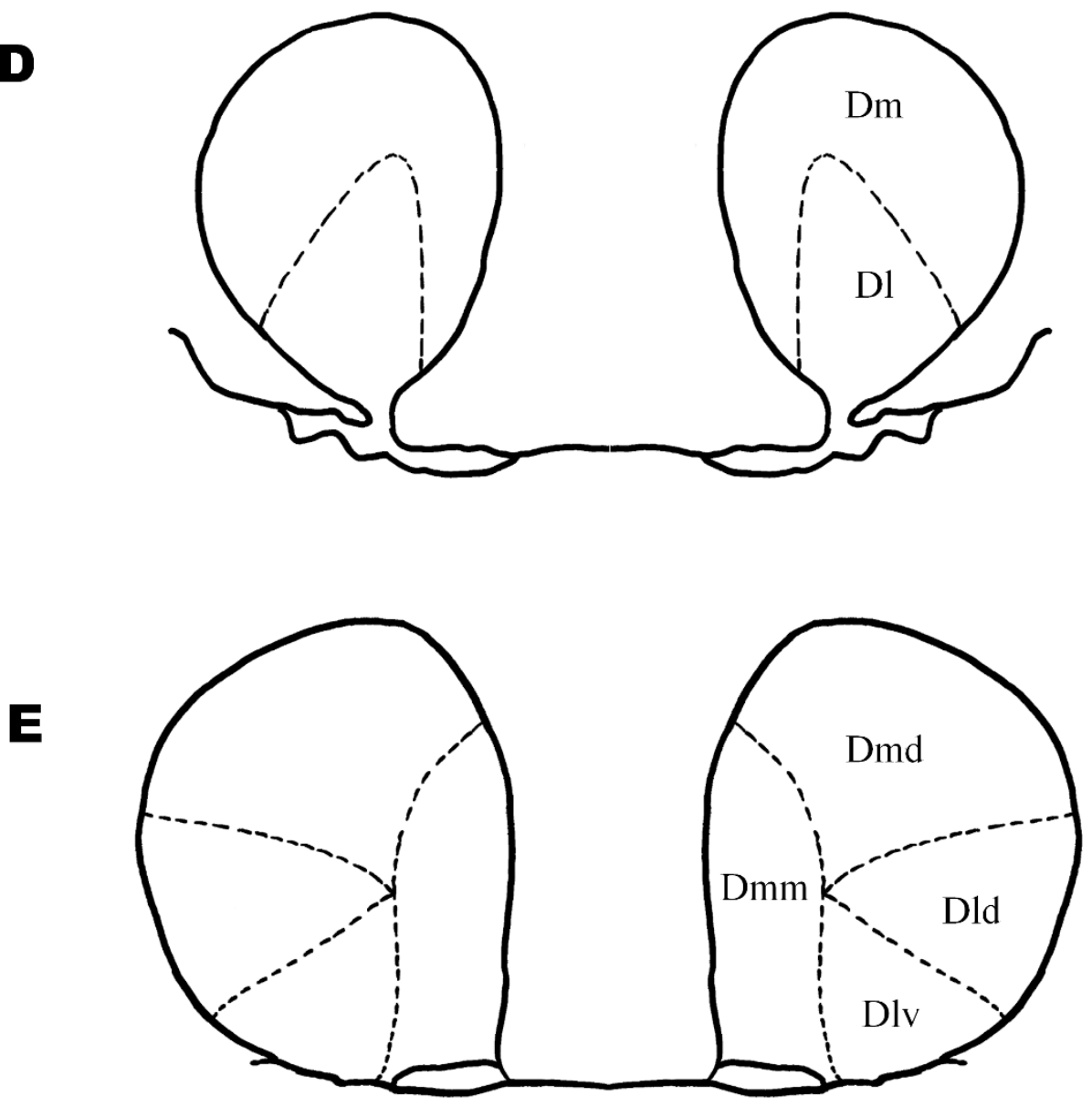

F

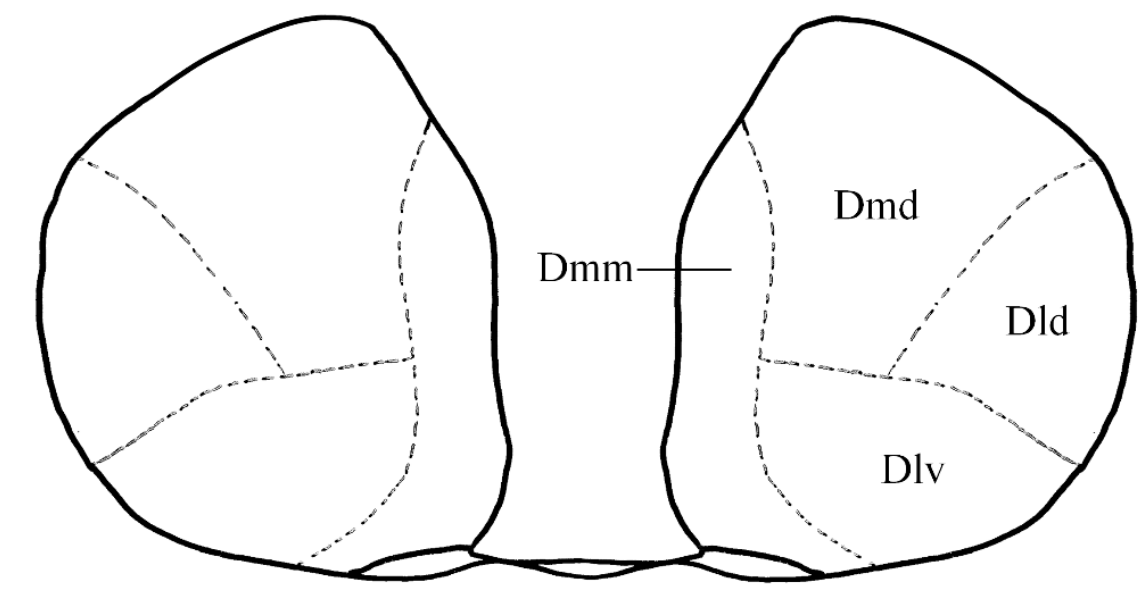

Scheme 2 

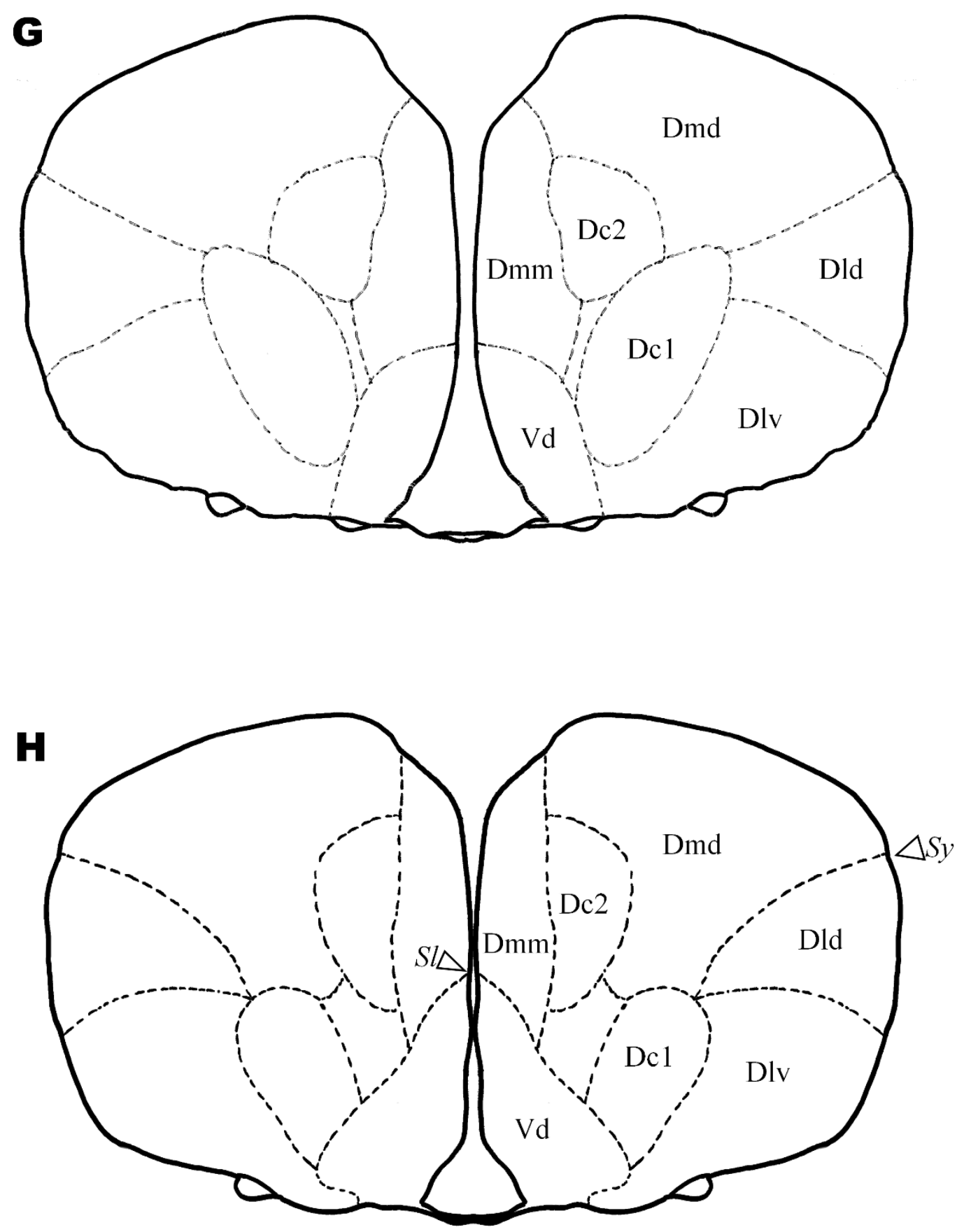

Scheme 3 

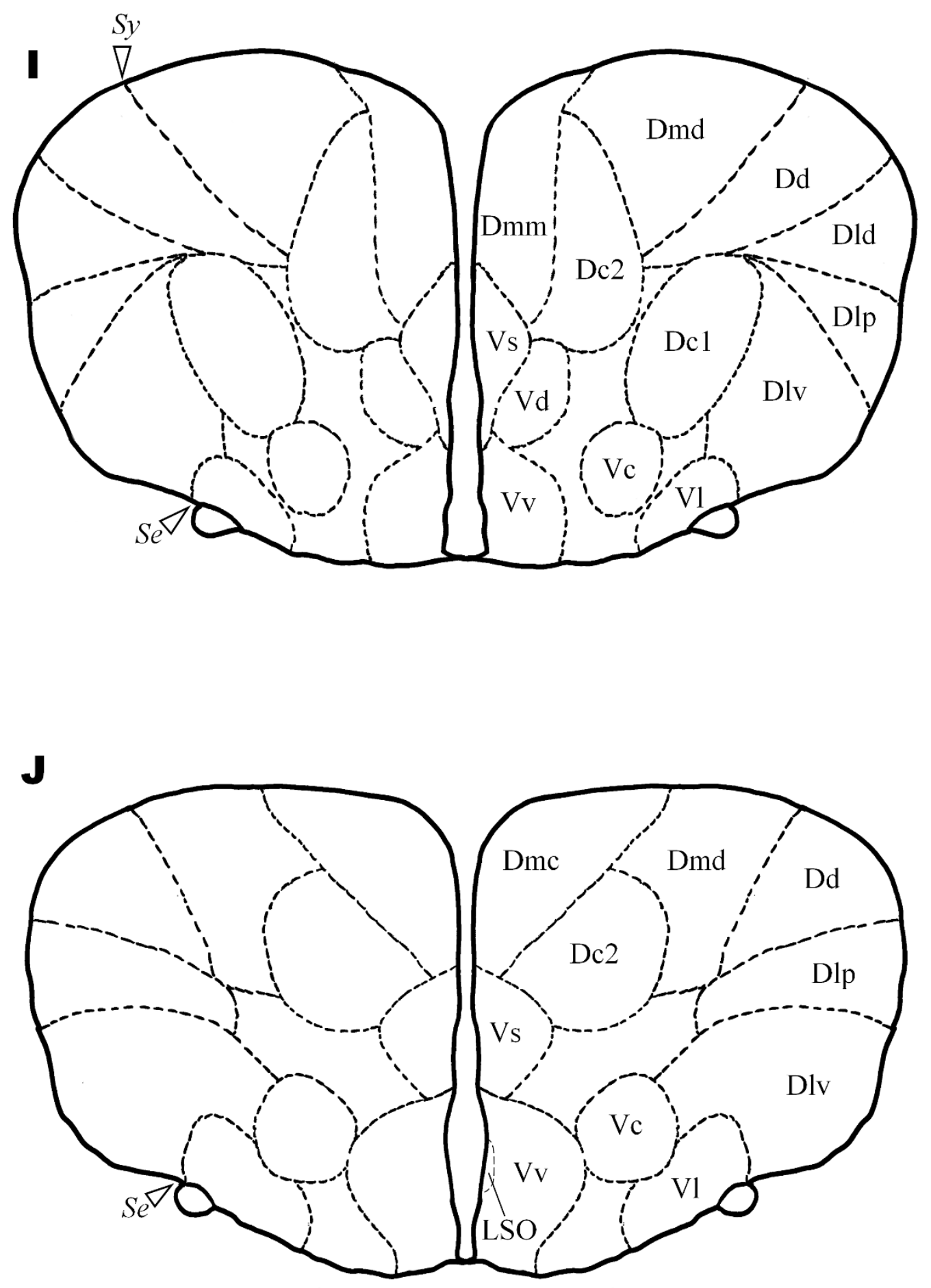

Scheme 4 

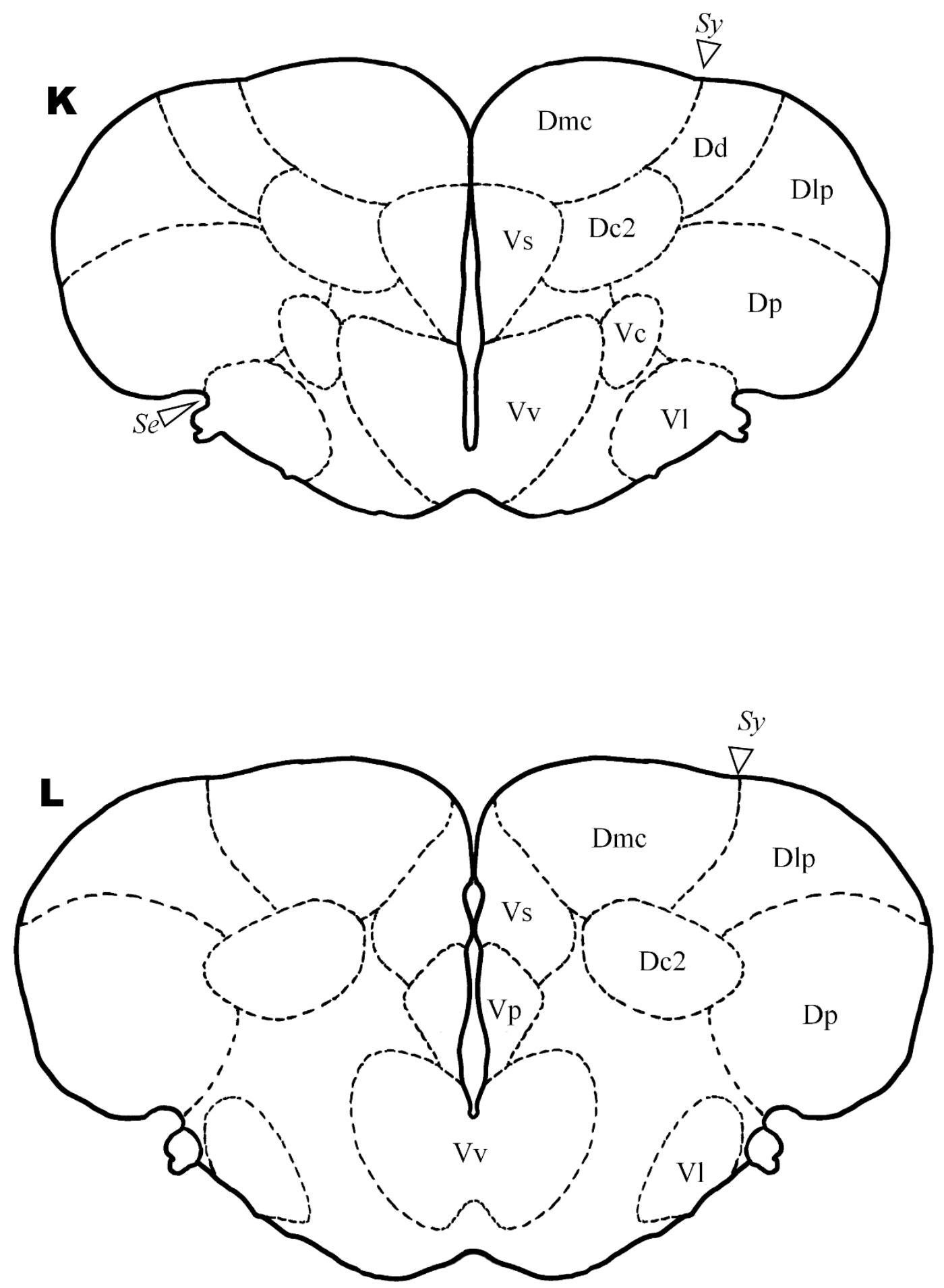

Scheme 5 

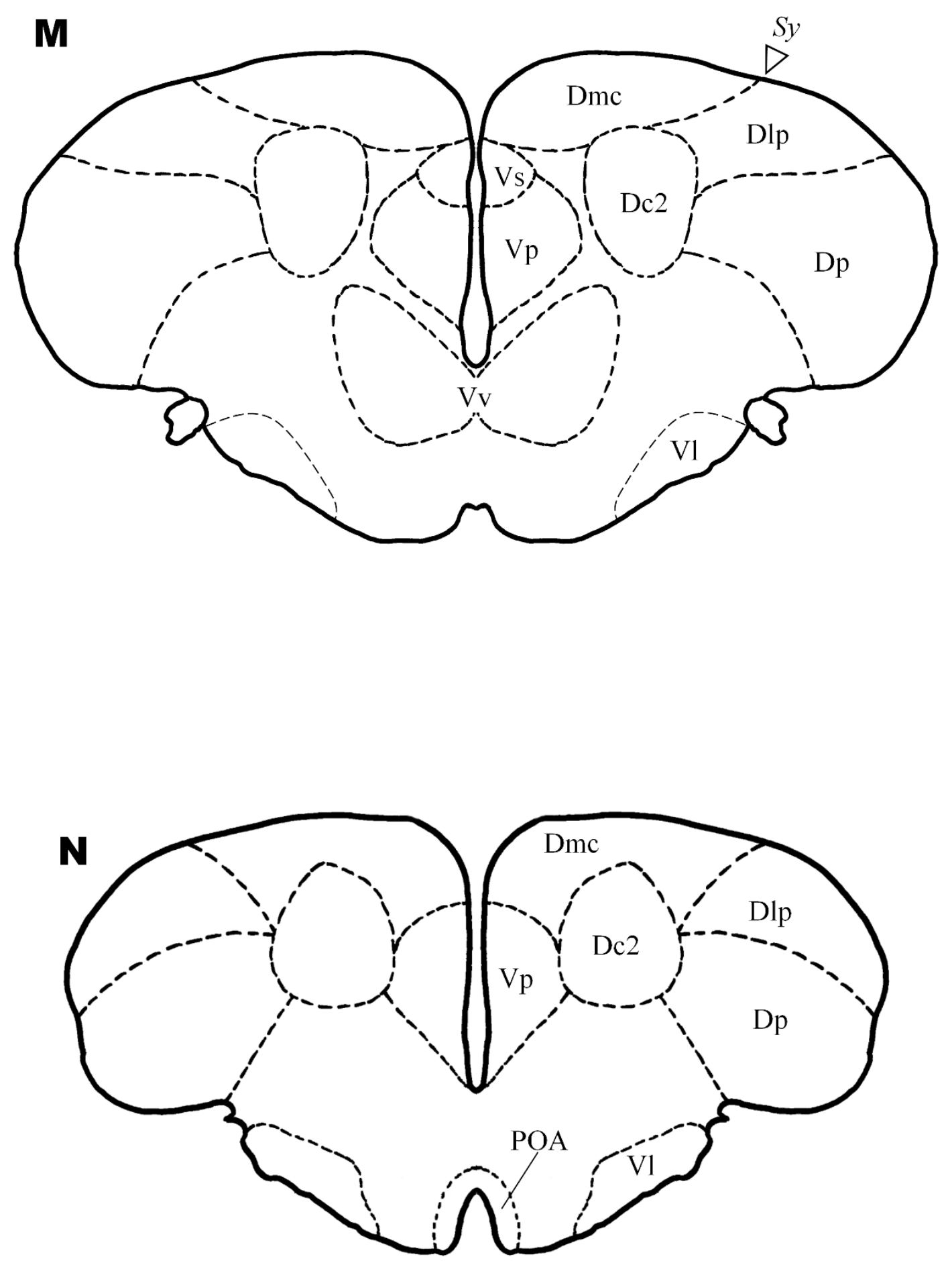

Scheme 6 
o

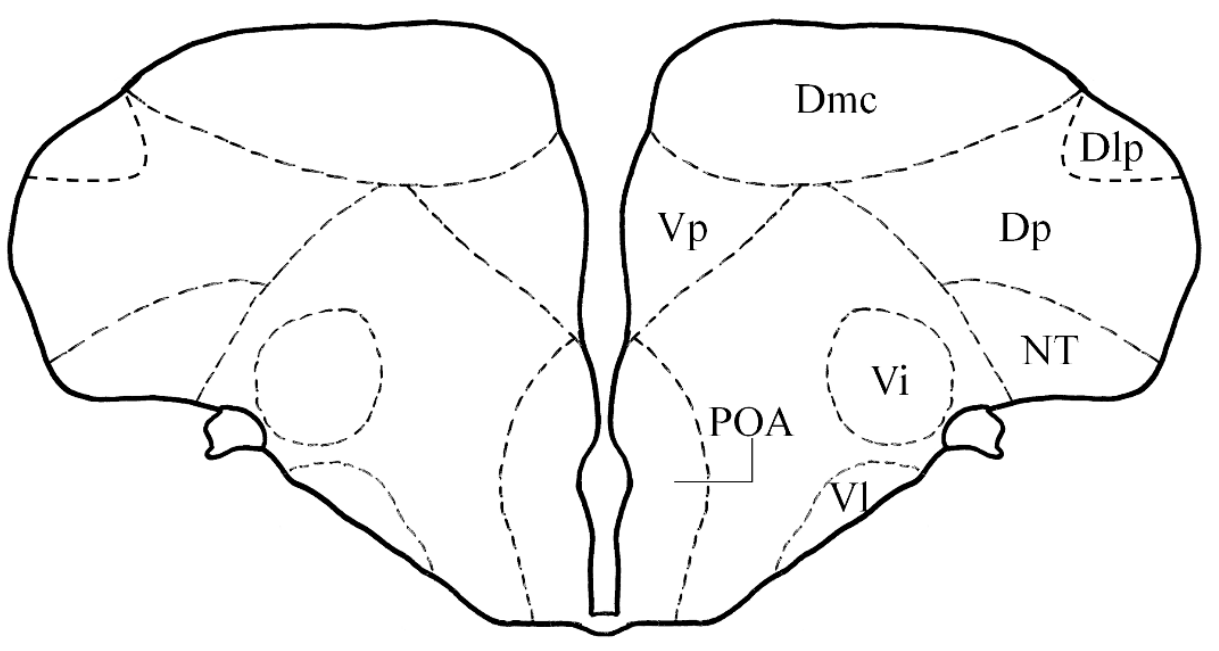

P

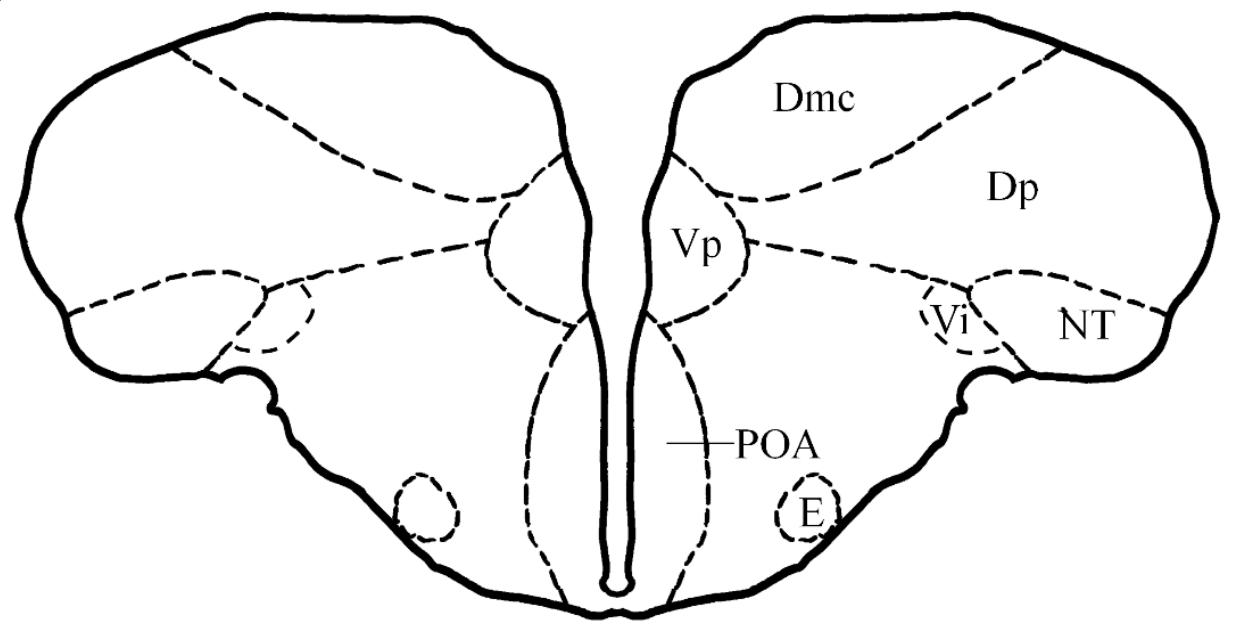

Scheme 7 


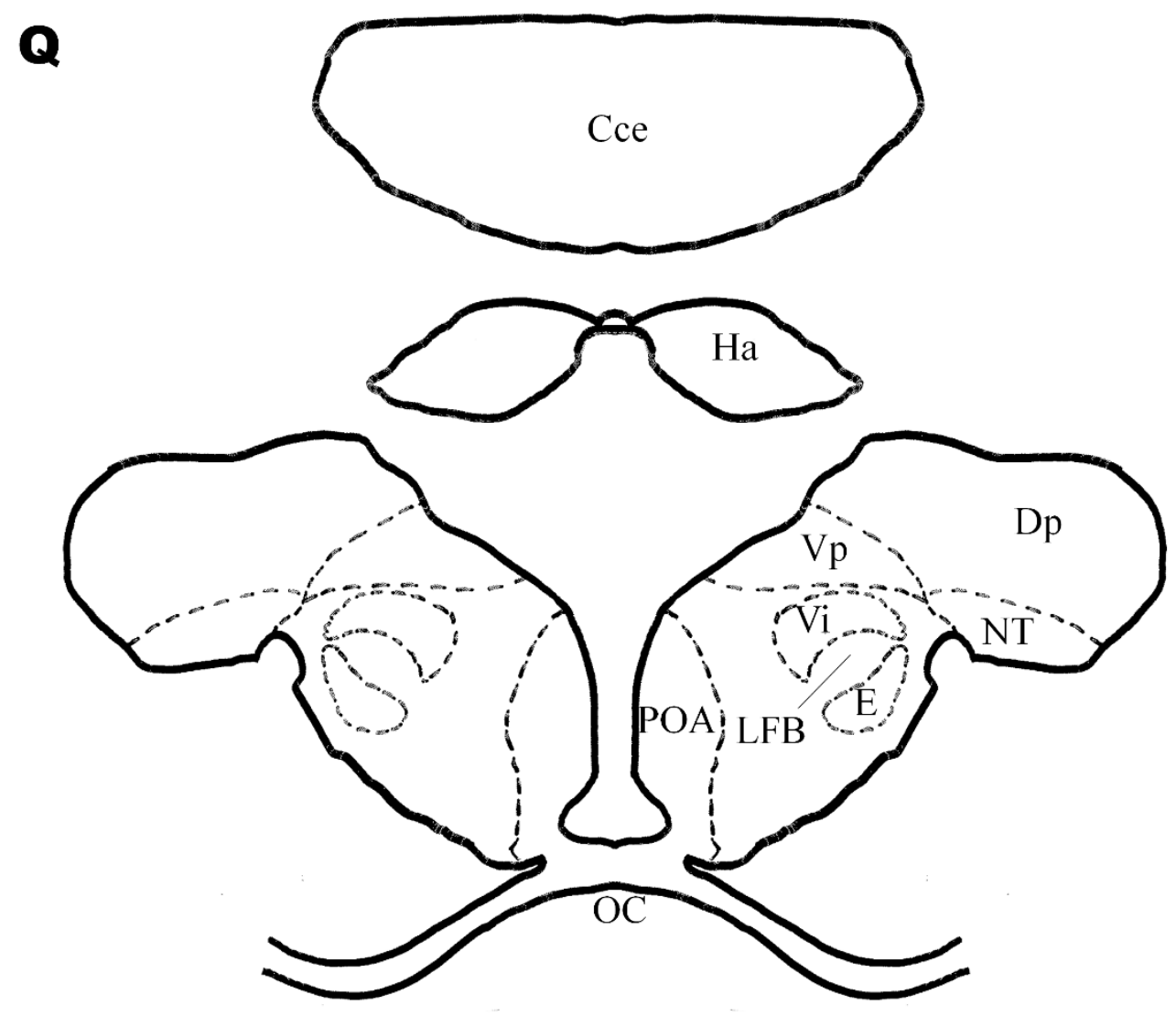

Scheme 8 

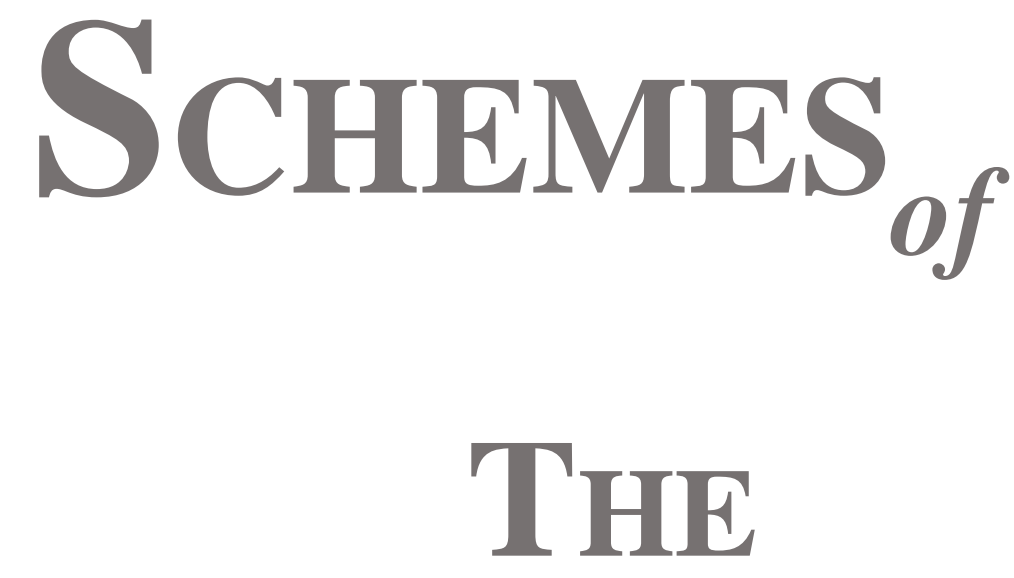

\section{DiENCEPHALON}

Sequences of cross-sections from rostral (Plate 9) to caudal part (Plate 16) of the brain of juvenile Steindachneridion parahybae.

Schemes representing different cell masses in the diencephalon. The position that each one crosssection can be viewed through the Fig. 1. Scale bar: $550 \mu \mathrm{m}$. For abbreviations, see the list of abbreviations (on the beginning of this Atlas) and the Table I. 
A

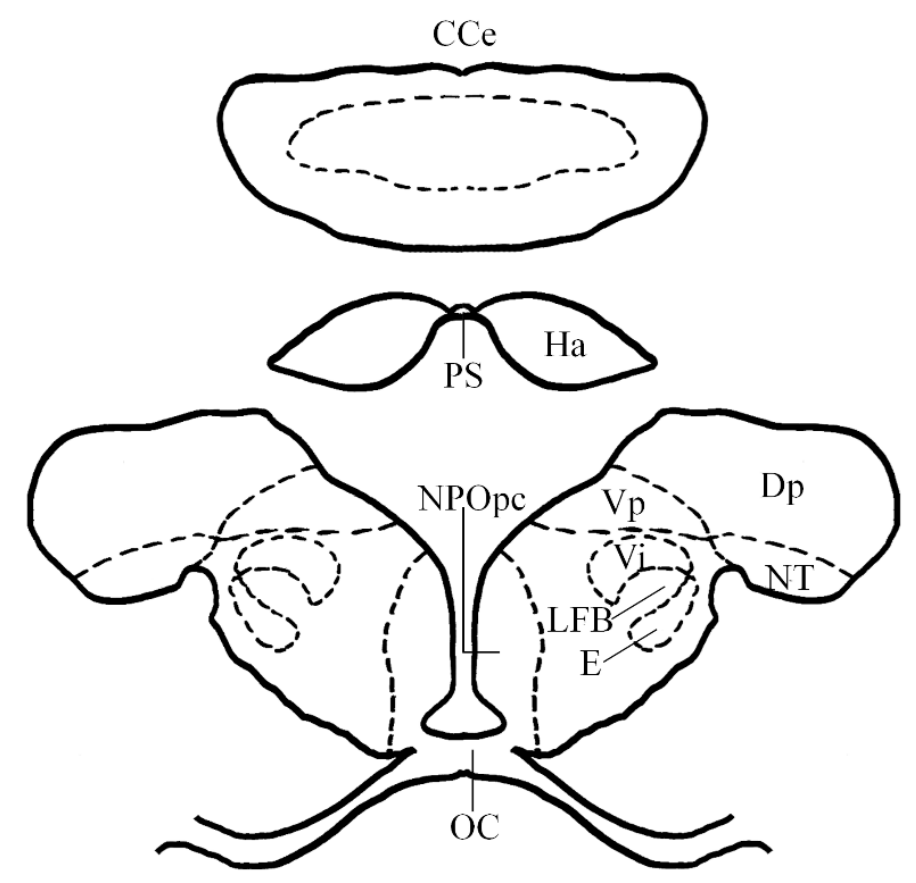

B

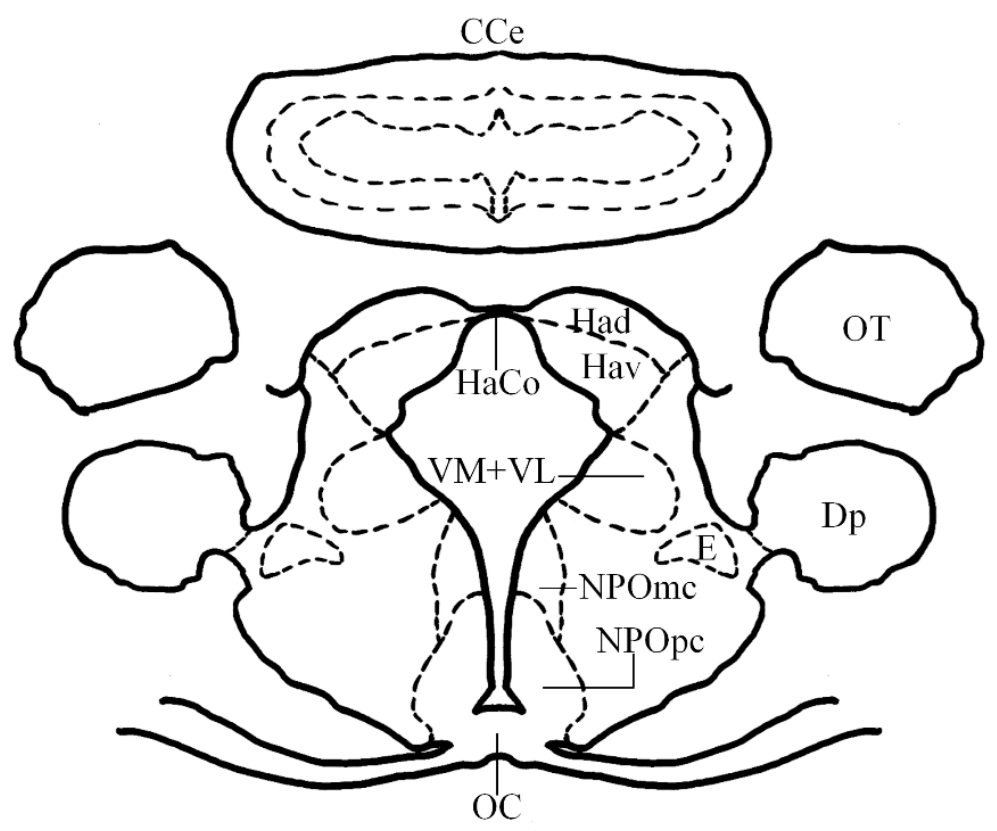

Scheme 9 
C

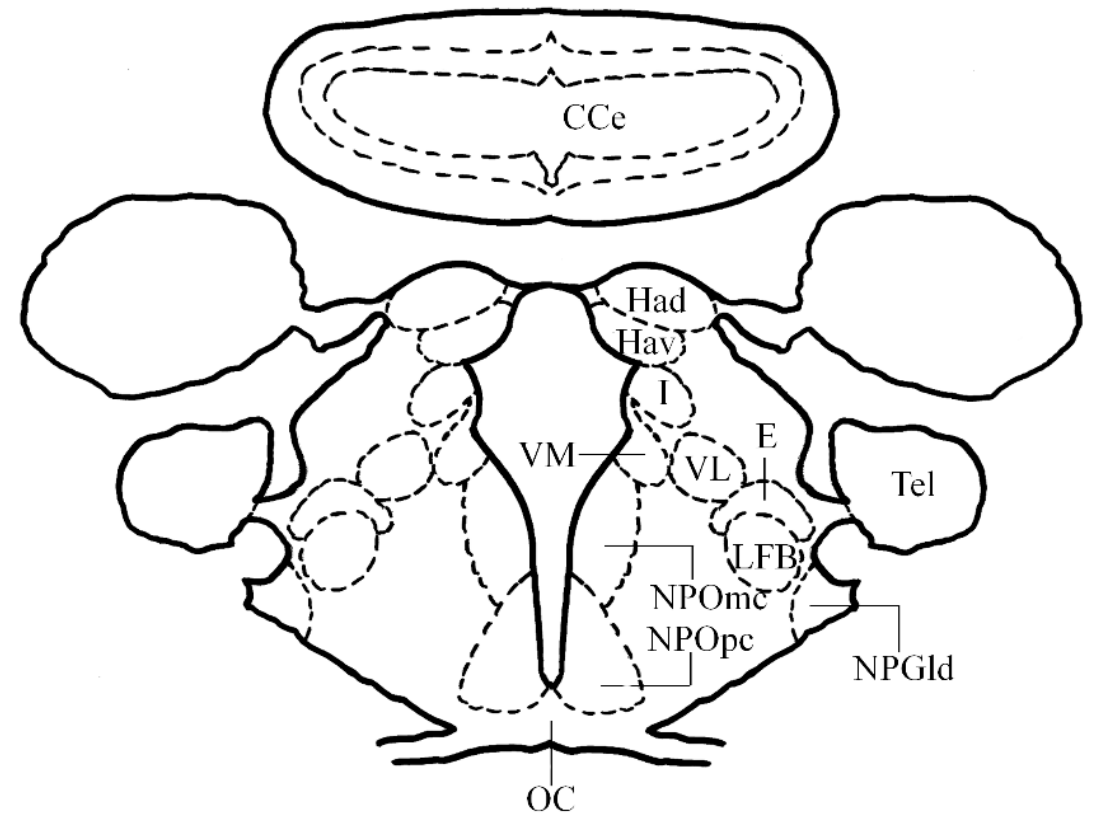

D

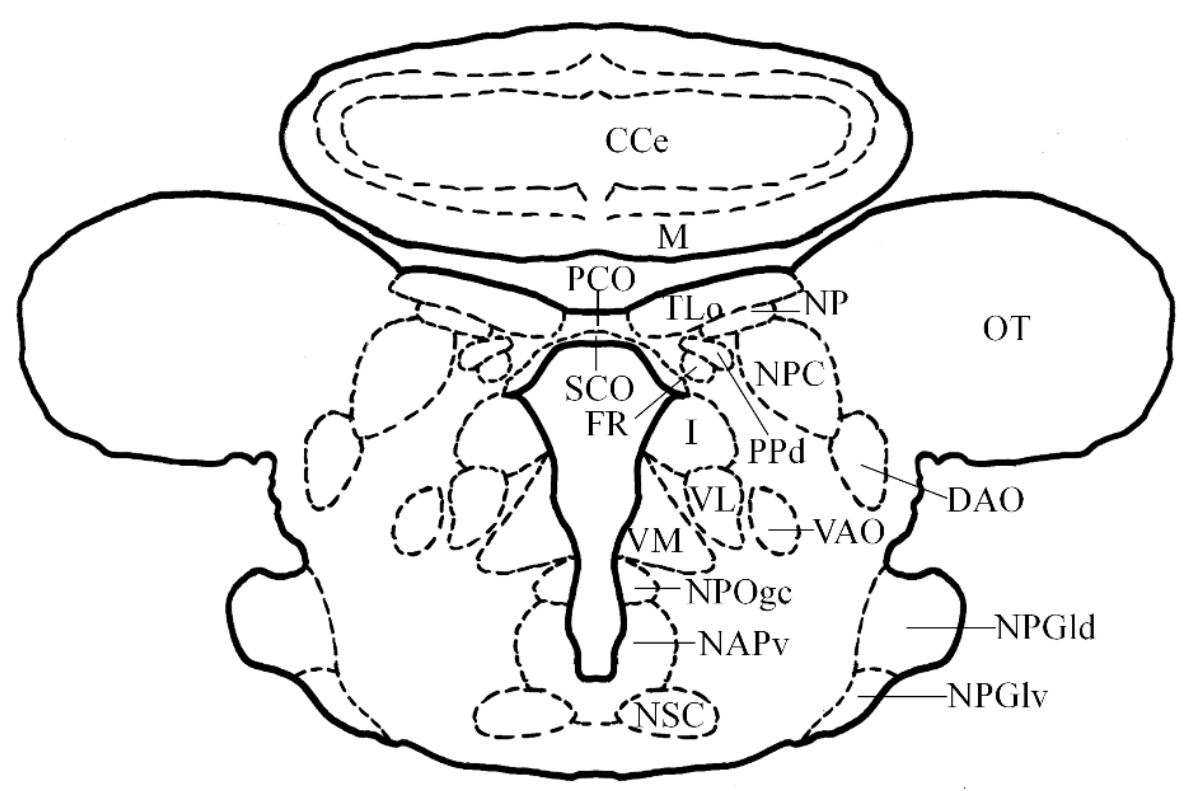

Scheme 10 

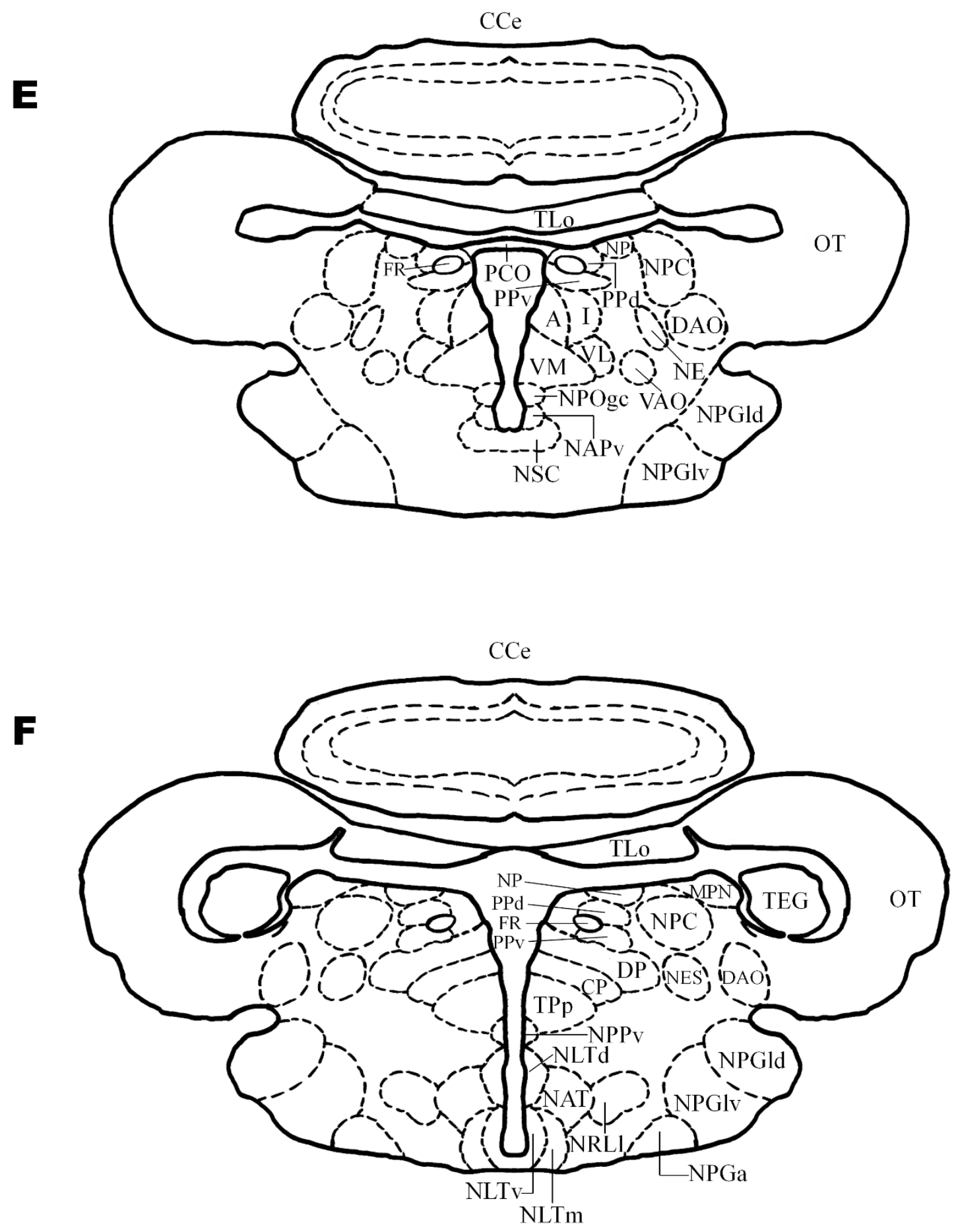

Scheme 11 

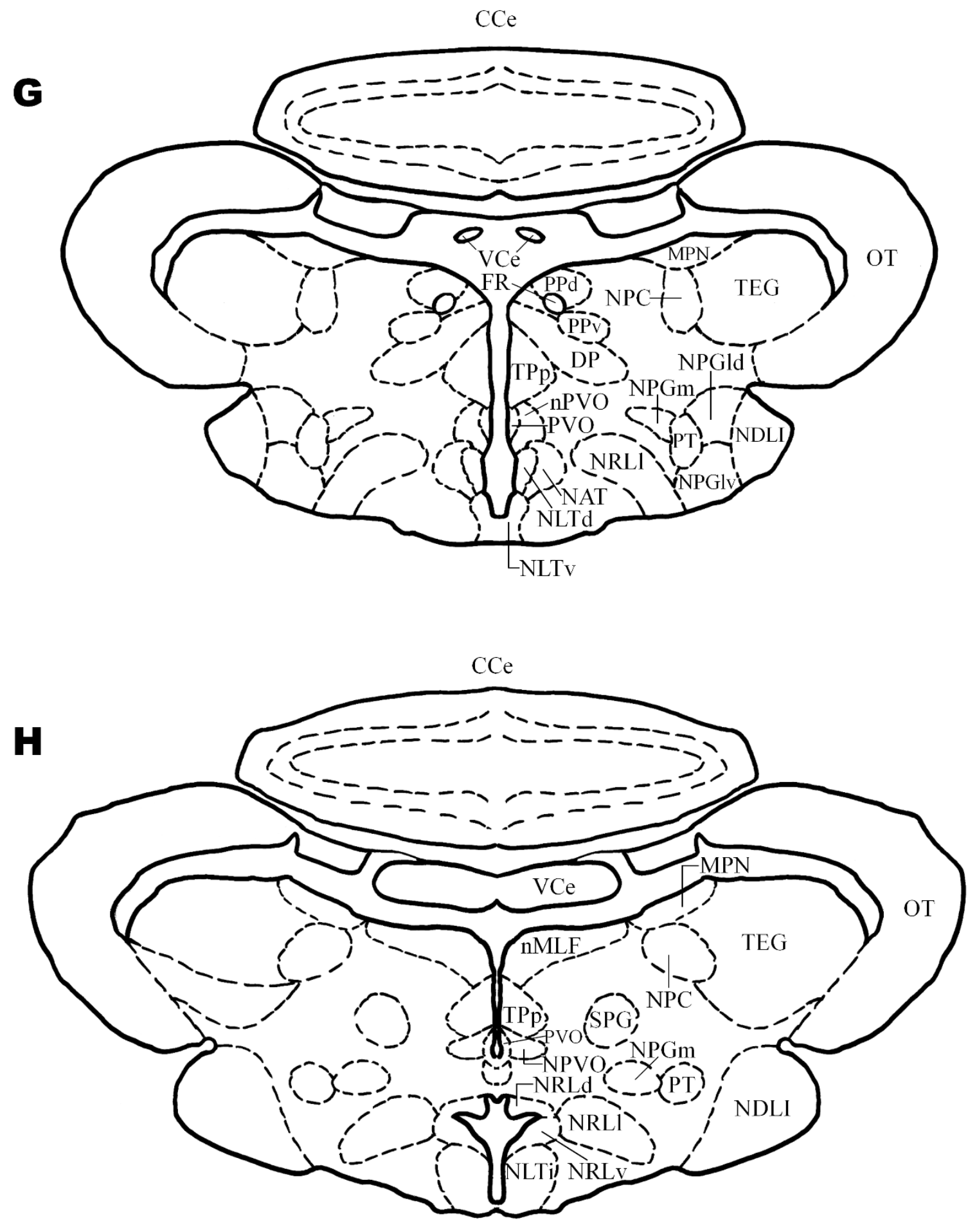

Scheme 12 

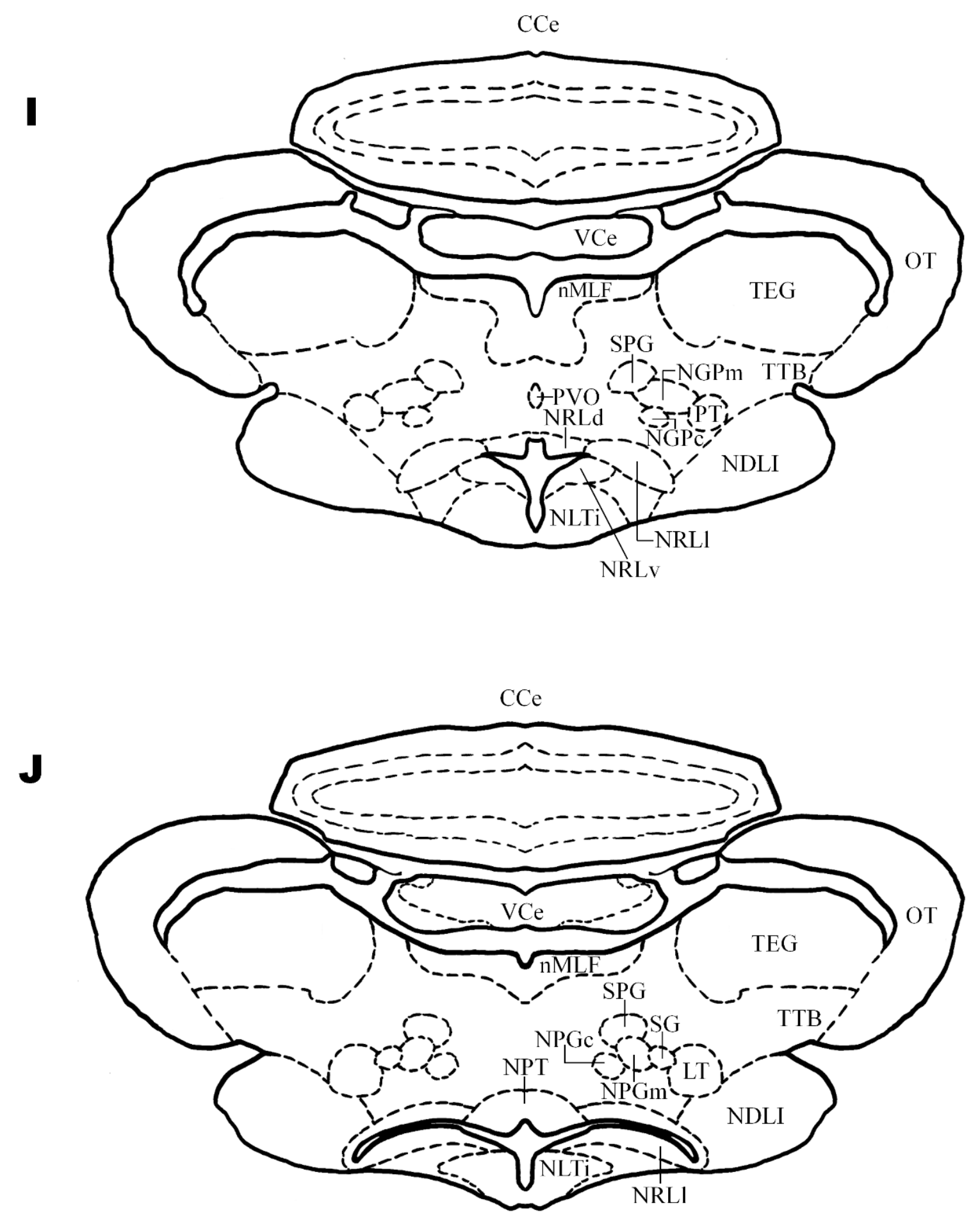

Scheme 13 

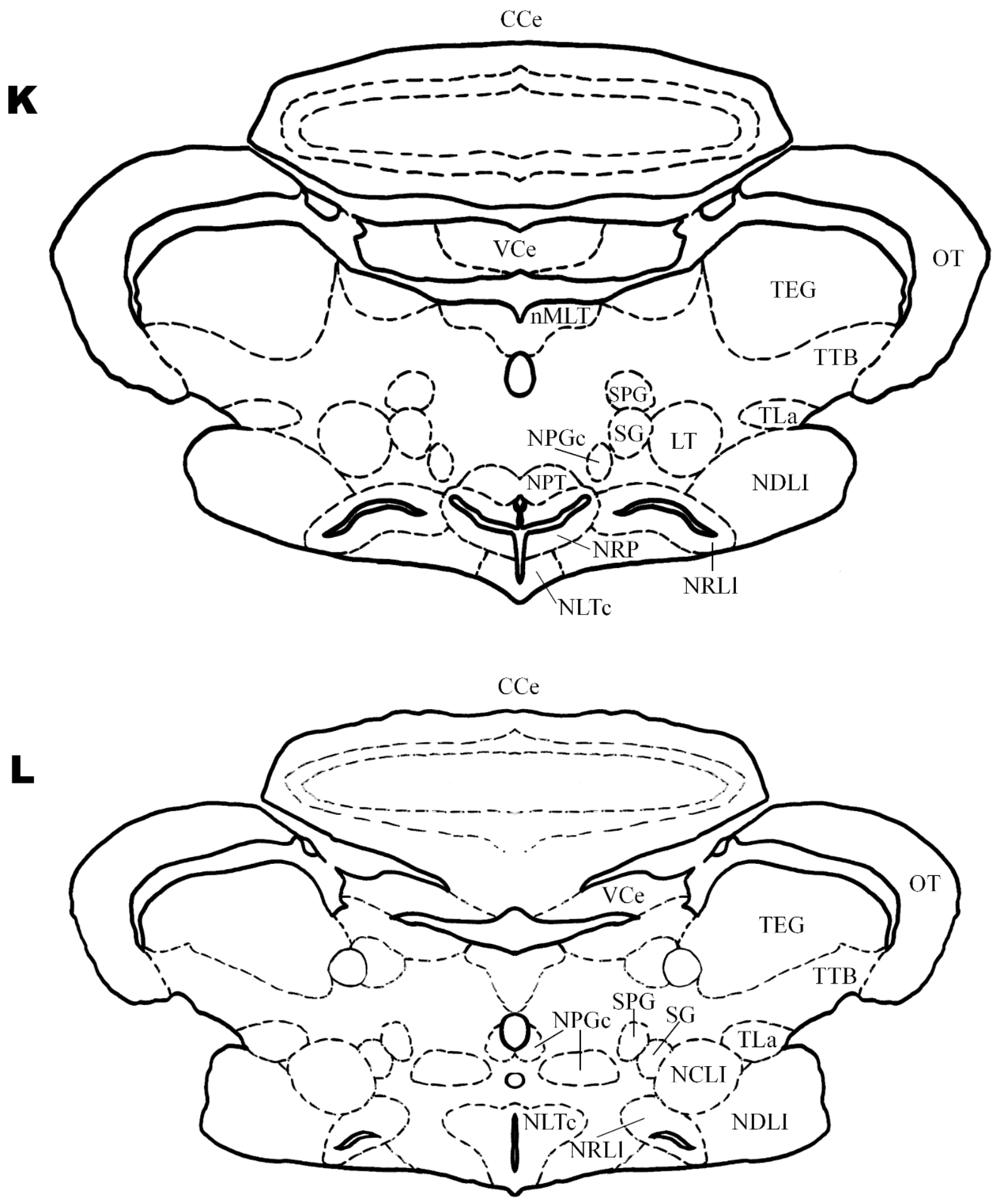

Scheme 14 
$\mathrm{CCe}$
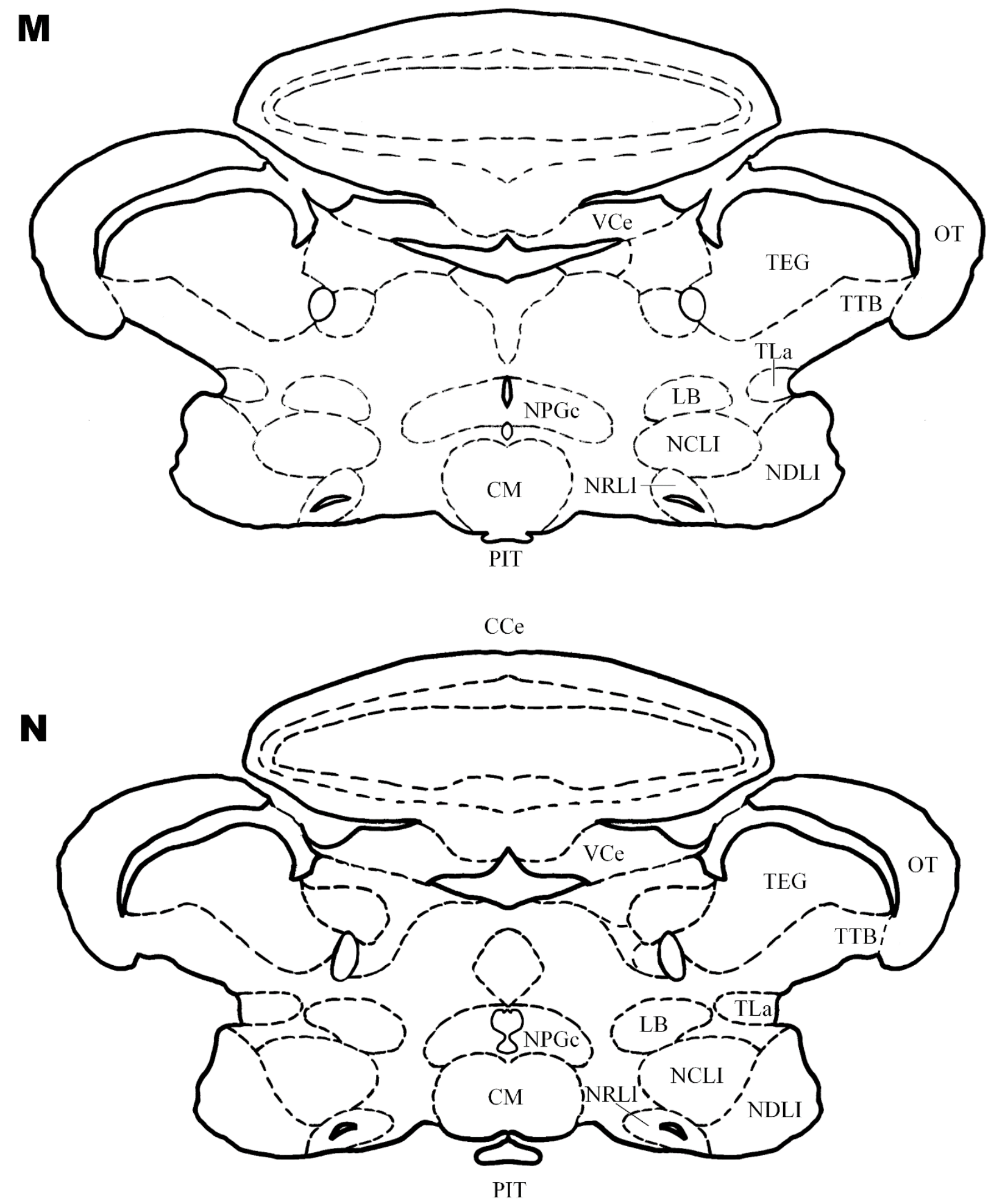

Scheme 15 


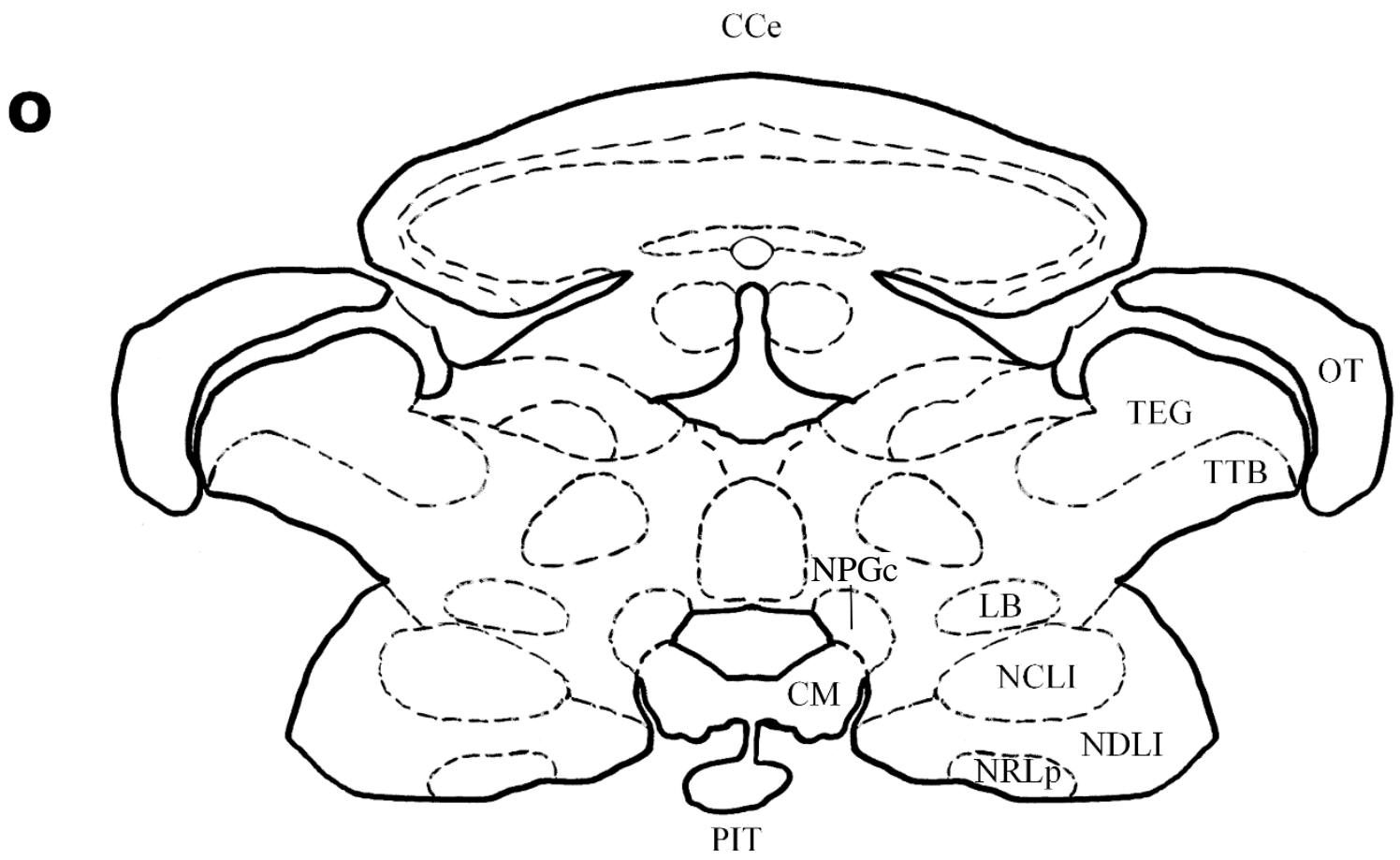

Scheme 16 


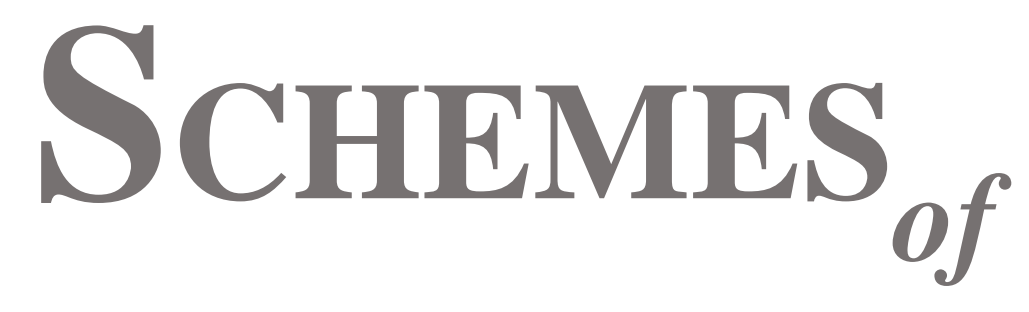

THE

\section{Midbrain*}

\section{and HiNDBRAIN**}

Sequences of cross-sections from rostral (Plate 17) to caudal part (Plate 24) of the brain of juvenile Steindachneridion parahybae.

Schemes representing different cell masses in the mesencephalon, cerebellum and rhombencephalon. The position that each one cross-section can be viewed through the Fig. 1. Scale bar: $550 \mu \mathrm{m}$. For abbreviations, see the list of abbreviations (on the beginning of this Atlas) and the Table I. 

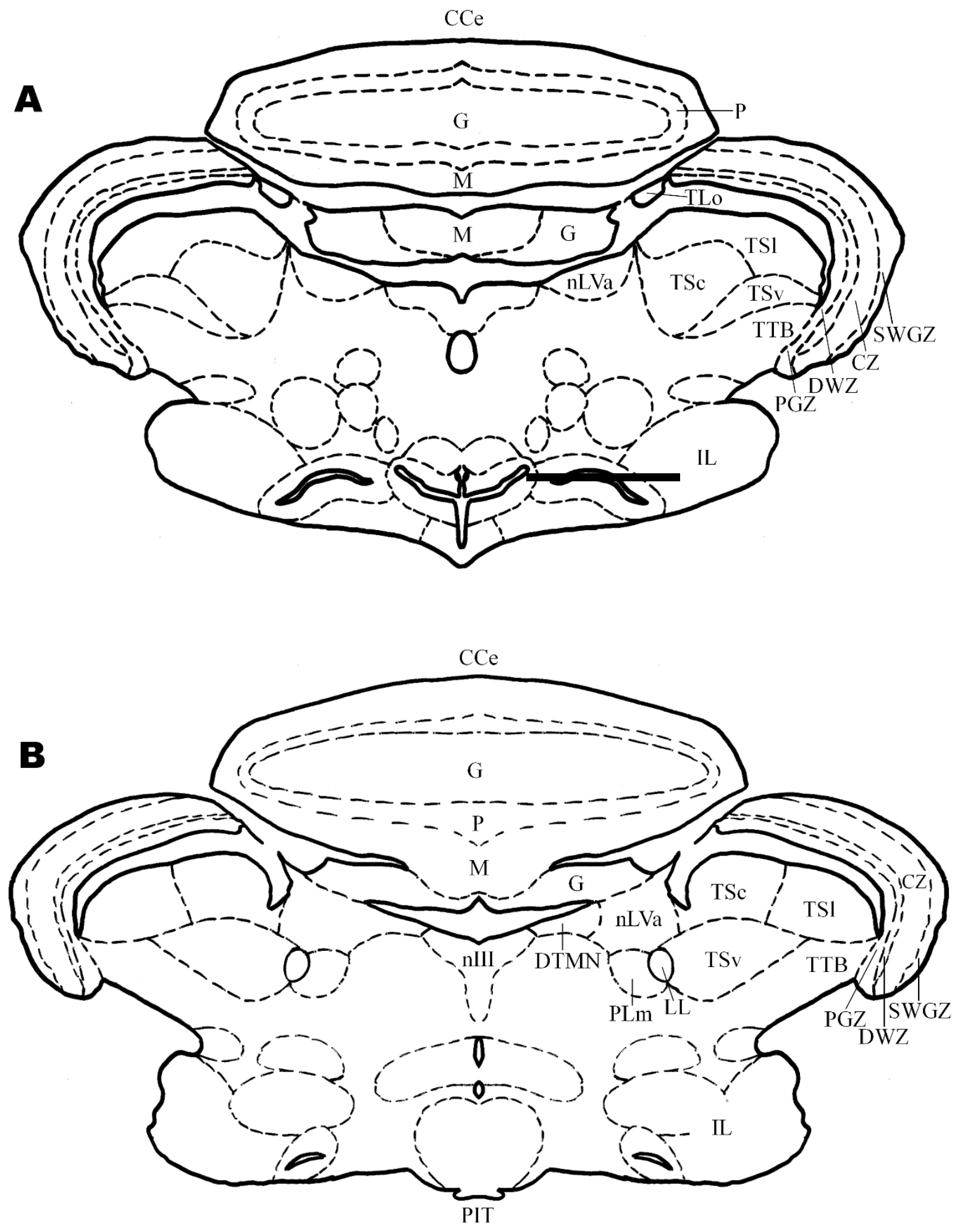

Scheme 17 


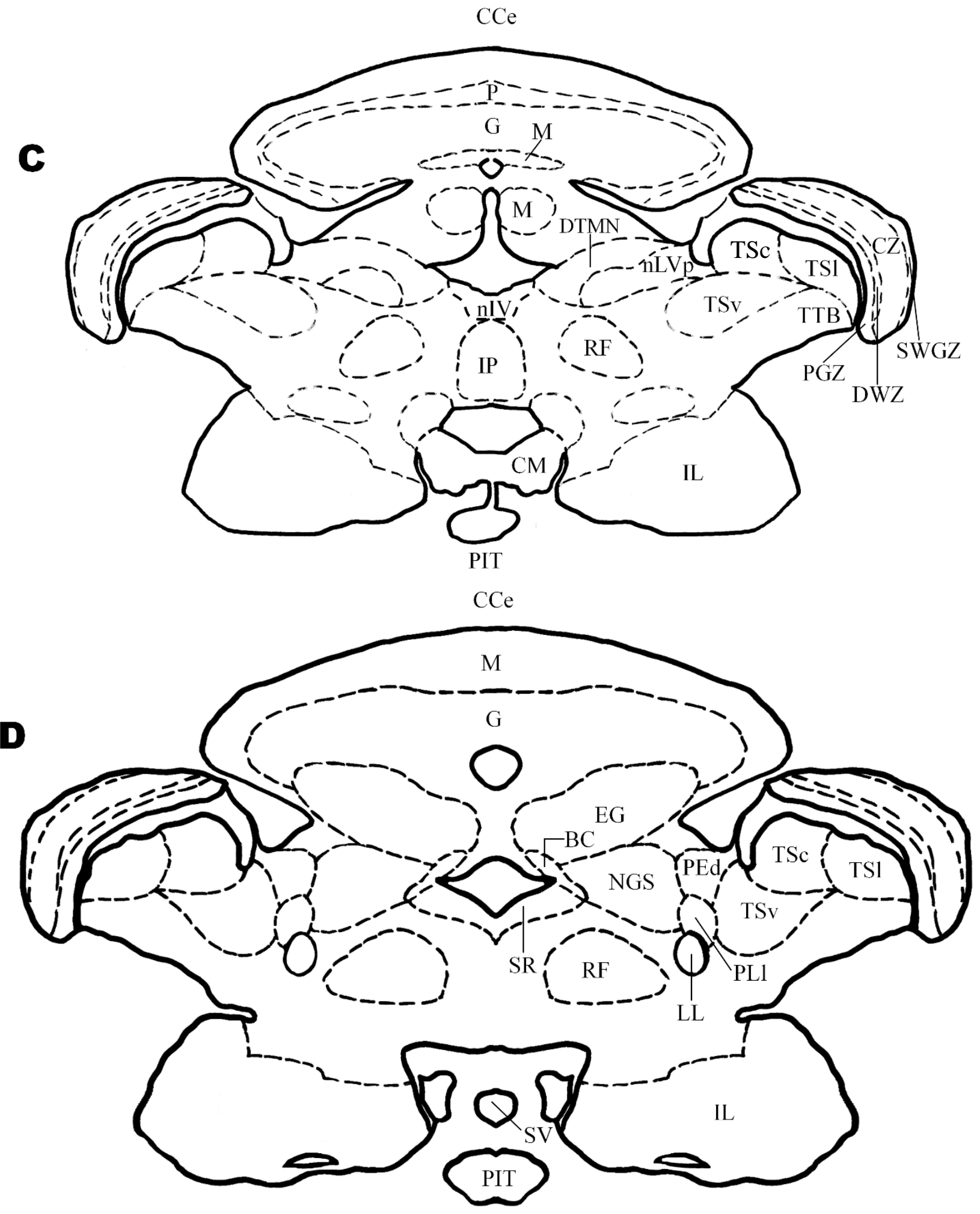

Scheme 18 

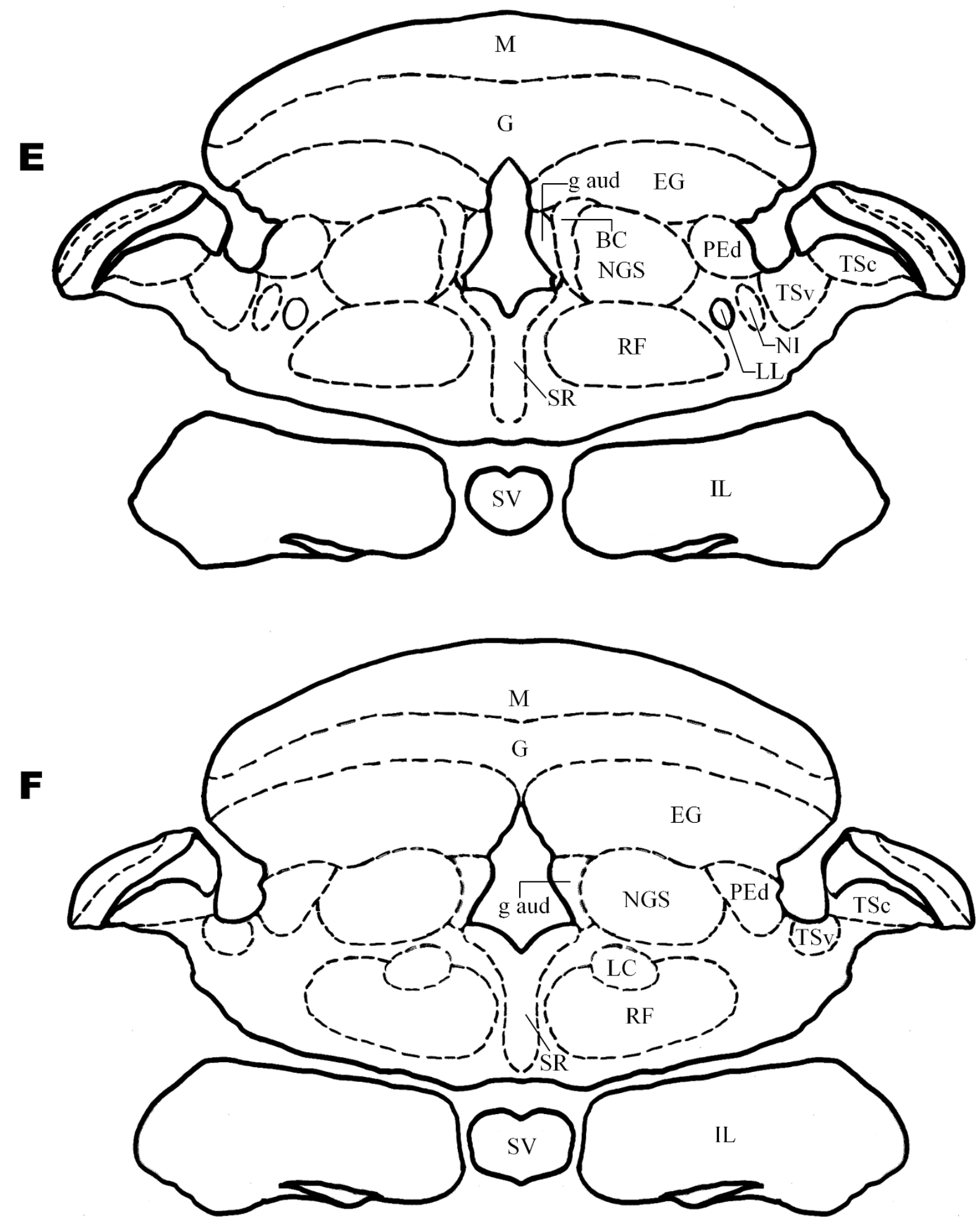

Scheme 19 
G

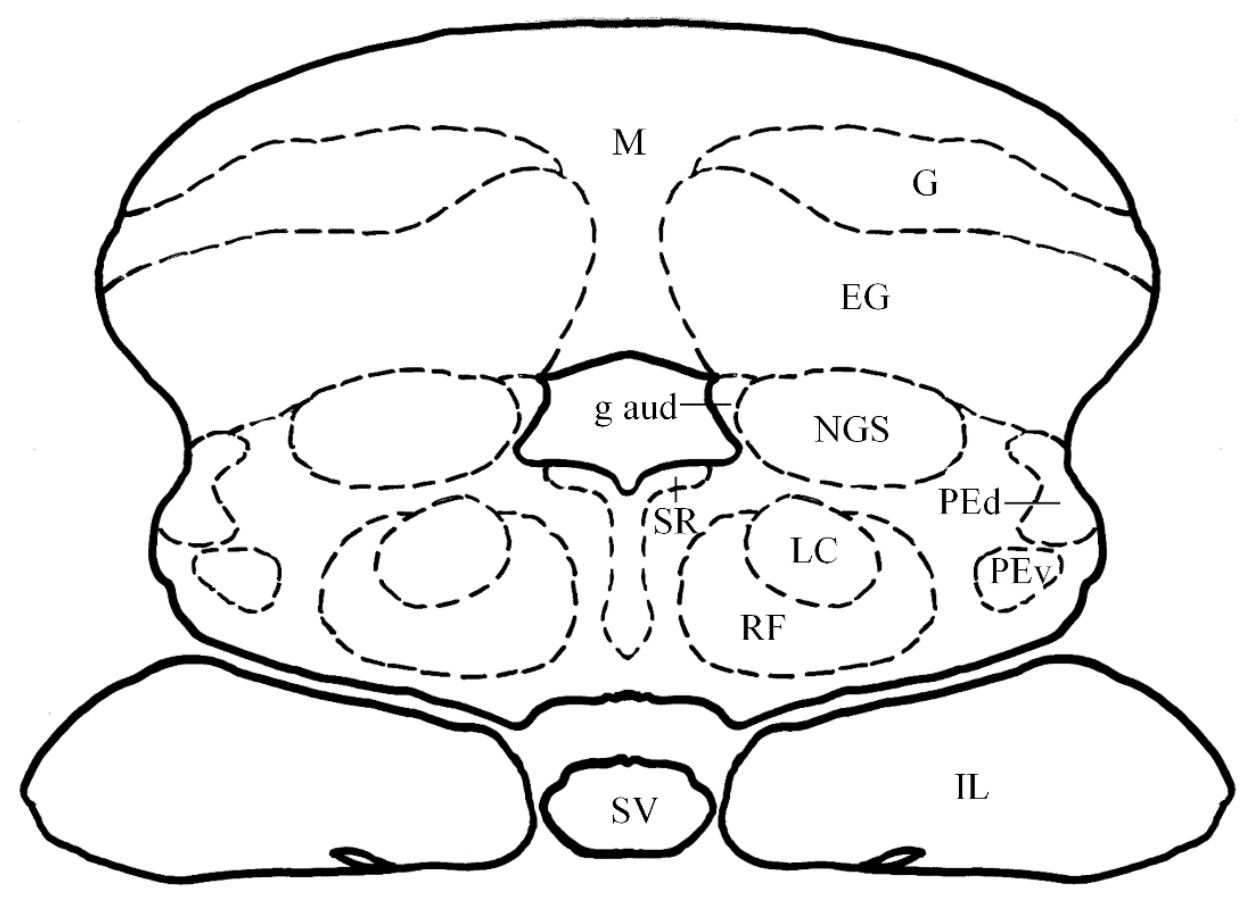

H

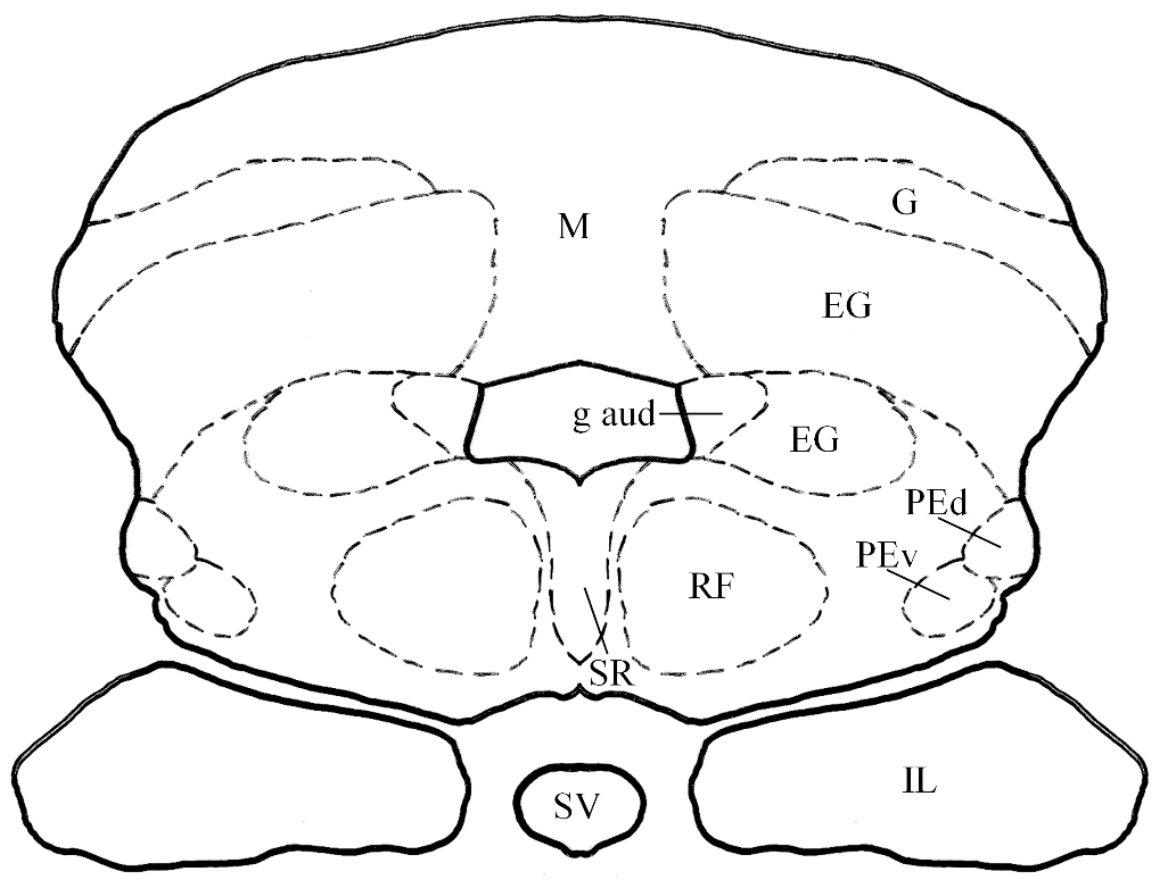

Scheme 20 


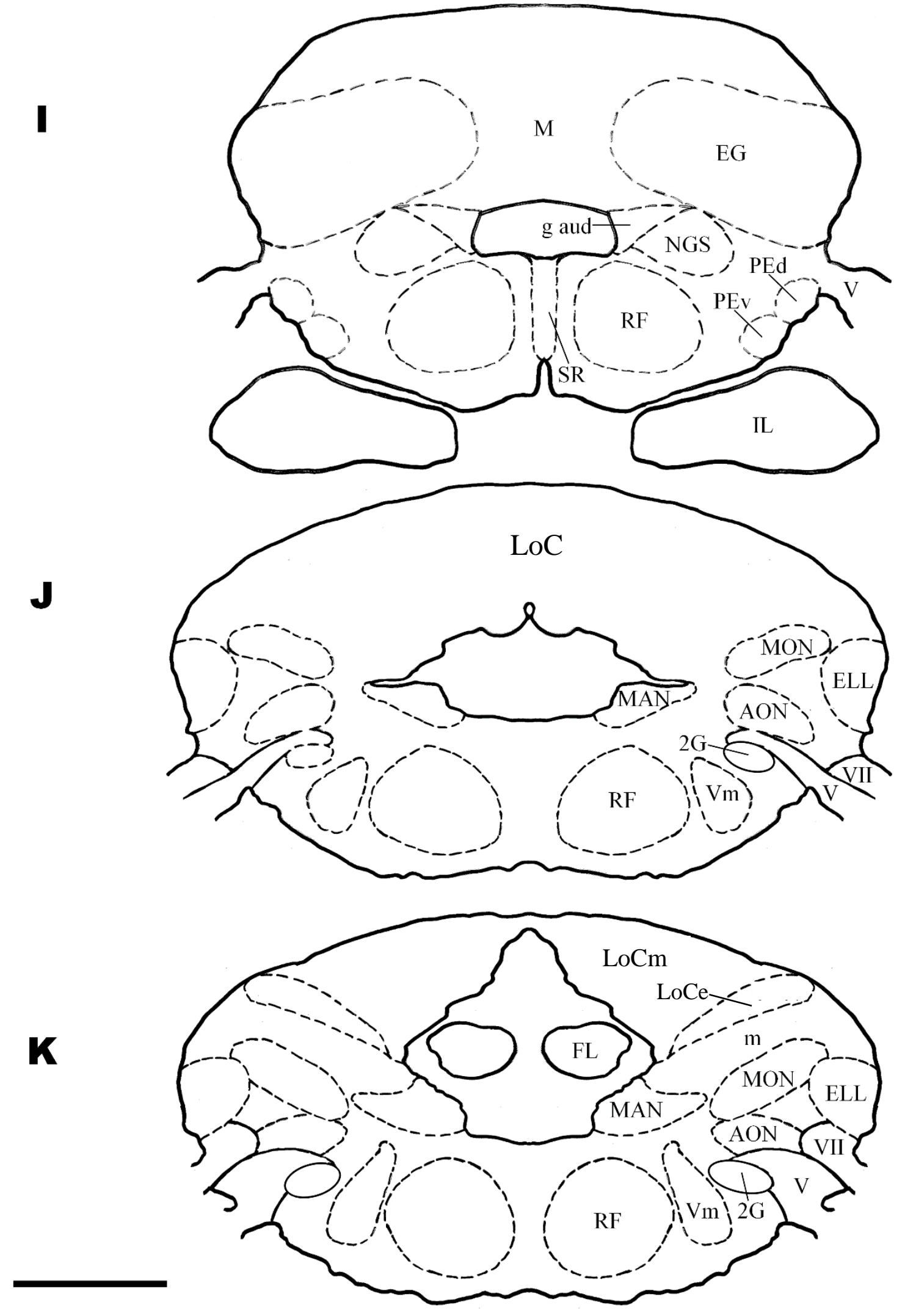

Scheme 21 


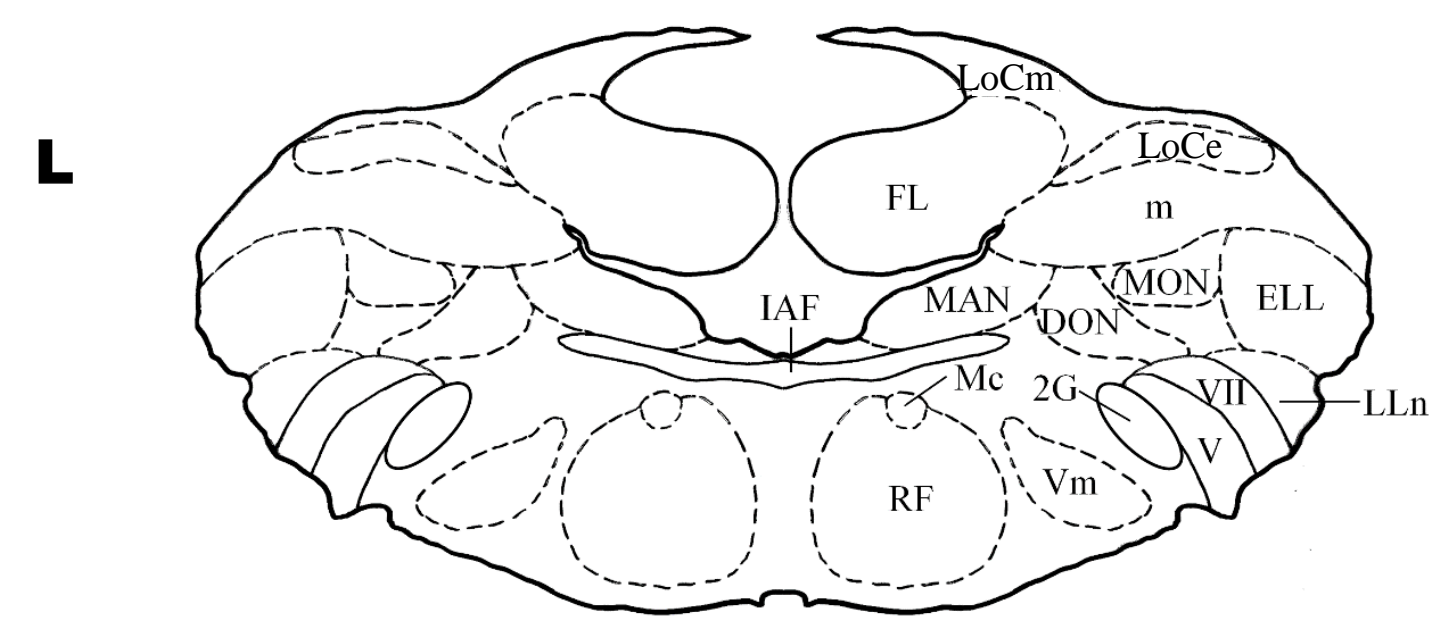

M
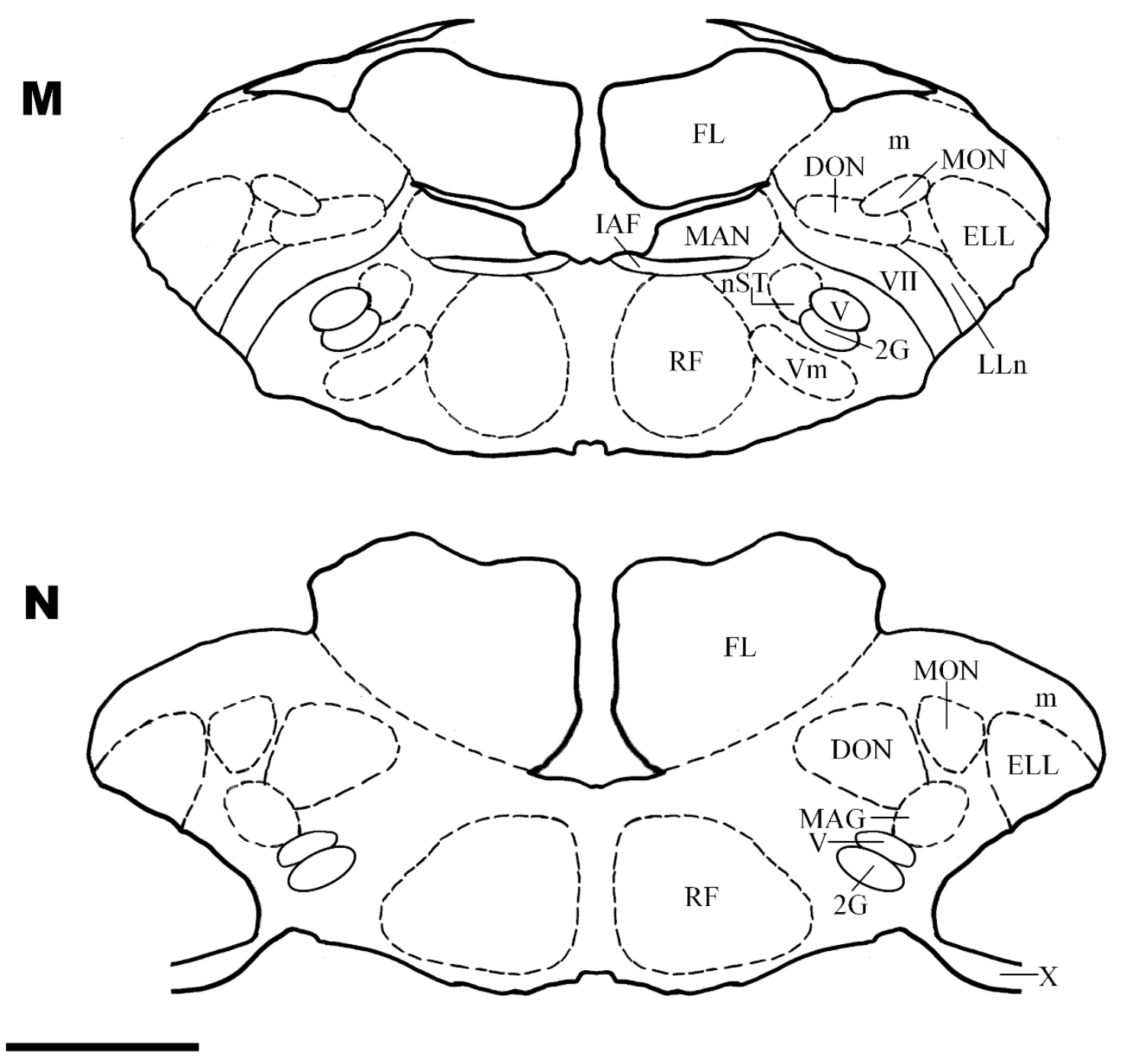

Scheme 22 
$\mathbf{0}$

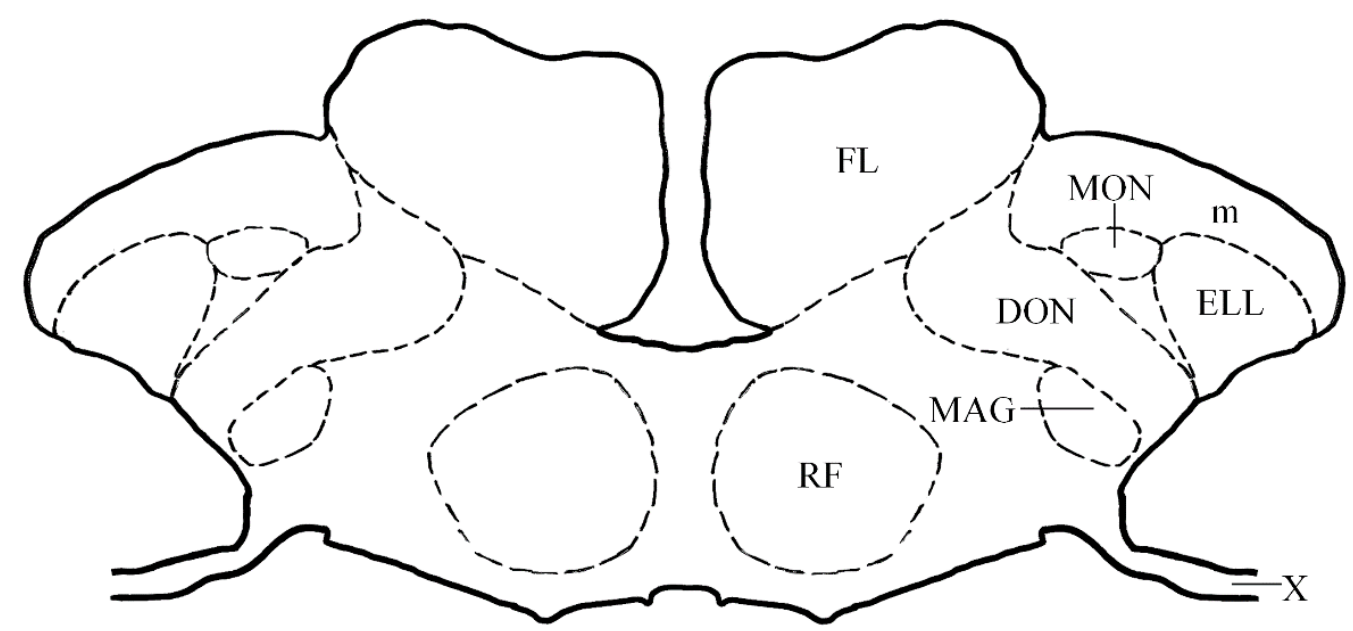

$\mathbf{P}$

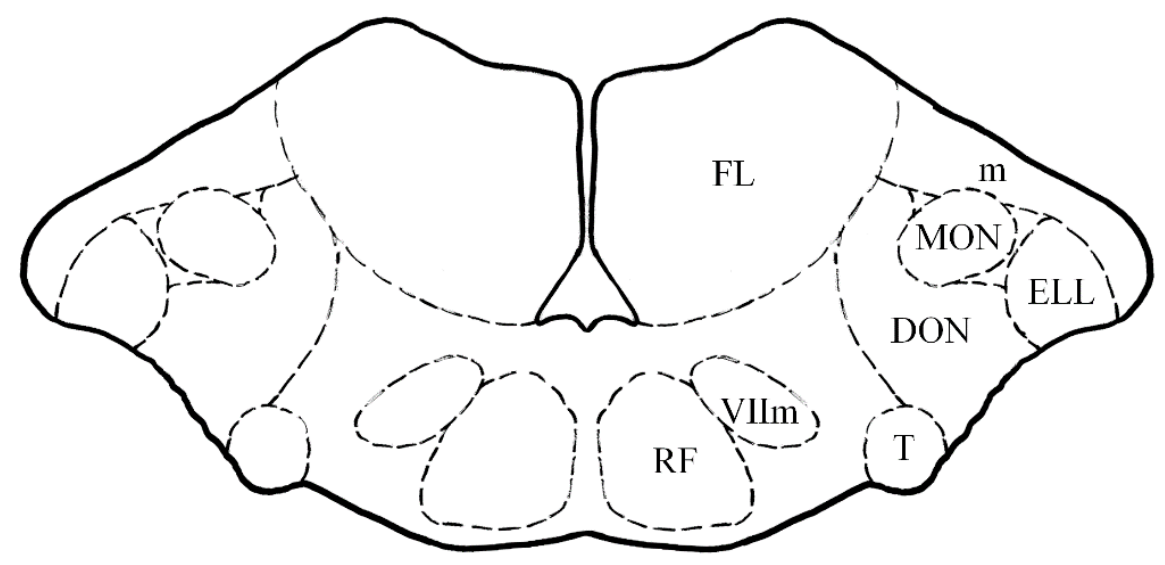

Q

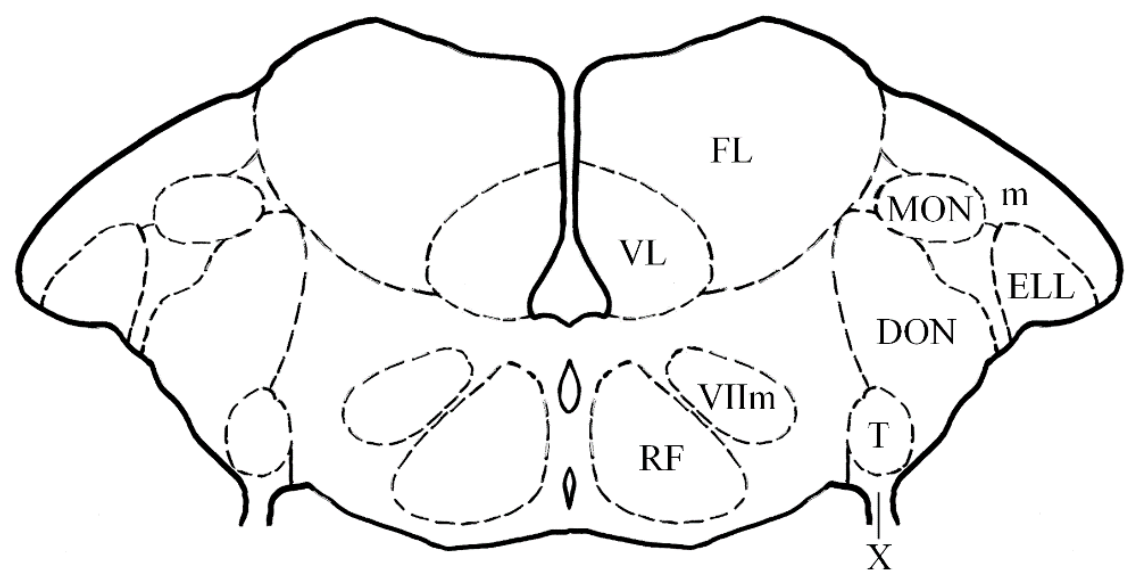

Scheme 22 
$\mathbf{R}$

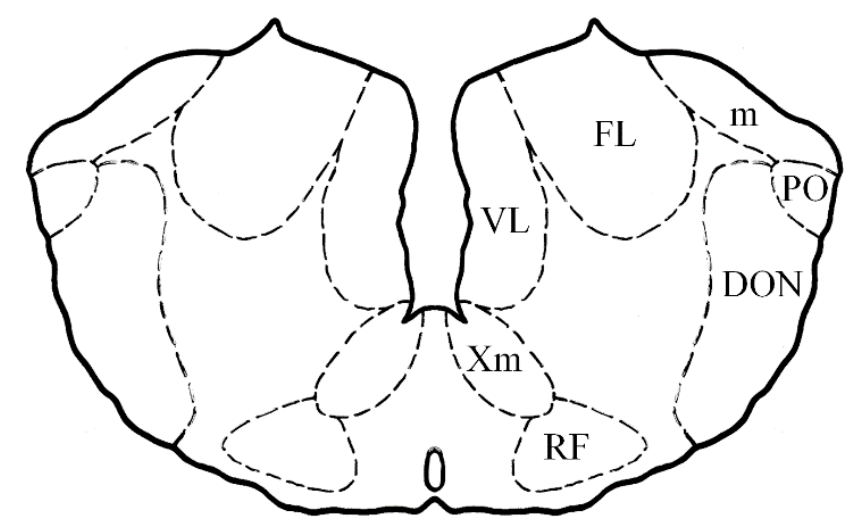

$\mathbf{S}$

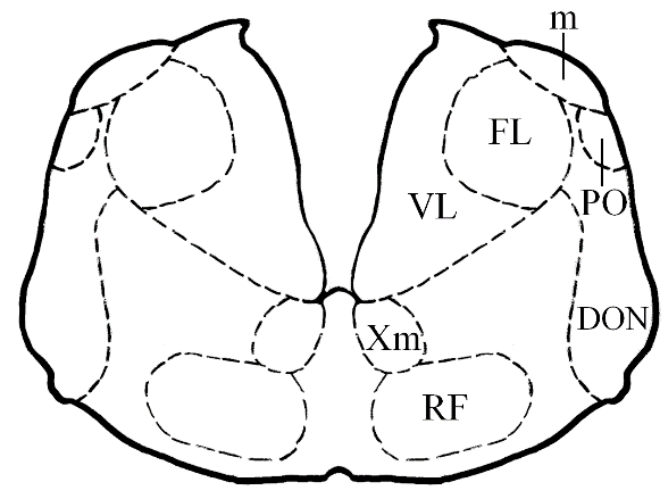

T

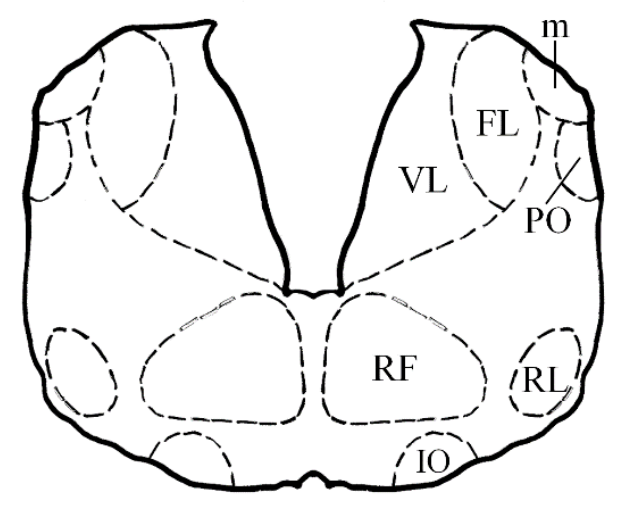

Scheme 23 
REFERENCES 
ATEMA, J., FAY, R. R., POPPER, A. N. TAVOLGA, W. N. 1988. Sensory biology of aquatic animals. New York, Berlin: Springer-Verlag. 936pp.

ANKEN, R. AND RAHMANN, H. (1994). Brain Atlas of the Adult Swordtail Fish Xiphophorus helleri and of Certain Developmental Stages. 88 pp. Gustav Fischer Verlag, Germany.

BABU, P. R \& PRASADA-RAO, P. D. 1988. Retinal projections in the catfish, Mystus Vitatus (Bloch) as revealed by tracer studies with horseradish peroxidase. Cell. Tissue Res. 253: 259-262.

BEHREND, K. AND DONICHT, M. 1990. Descending connections from the brainstem to the spinal cord in the electric fish Eigenmannia. Brain Behav. Evol. 35: 227-239.

BASS, A.H. 1981. Organization of the telencephalon in the channel catfish, Ictalurus punctatus. Journal of Morphology, 169: 71-90.

BAYLÉ, J. D, RAMADE, F, OLIVER, J. 1974. Stereotaxic topography of the brain of the quail, Coturnix coturnix japonica. J Physiol. (Paris). 68: 219-241.

BILlARD, R., PETER, R. E. 1982. A stereotaxic atlas and technique for nuclei of the diencephalon of rainbow trout (Salmo gardineri). Reprod. Nutr. Dev. 22: 1-25.

BRADFORD, Jr, M. R, NORTHCUTT, R. G. 1983. Organization of the diencephalon and pretectum of the rayned-fishes. In Northcutt, R. G. \& Davis, R. E. Eds Fish Neurobiology. 2: 117-163. University of Michigan Press, Ann Arbor.

BRAFORD, M.R., JR. 1986. Science 232,489-491.

BRANDSTÄTTER, R. AND KOTRSCHAL, K. (1989). Life history of roach, Rutilus rutilus (Cyprinidae, Teleostei). Brain, Behav. Evol. 34: 35-42.

BRANDSTATTER, R. AND KOTRSCHAL, K. (1990). Brain growth patterns in four European cyprinid fish species (Cyprinidae, Teleostei): roach (Rutilus rutilus), bream (Abramis brama), common carp (Cyprinus carpio) and sabre carp (Pelecus cultratus). Brain, Behav. Evolut. 35: 195-211.

BELL, C. C., FINGER, T. E. AND RUSSELL, C. J. 1981. Central connections of the posterior lateral line lobe in mormyrid fish. Exp. Brain Res. 42, 9-22.

BELL, C. C. AND SZABO, T. 1986. Central structures and pathways of the mormyrid electrosensory system. In Electroreception (ed. T. H. Bullock and W. Heiligenberg), pp. 375-421. New York: Wiley \& Sons. 
BURMEISTER, S. S, MUNSHI, R. G, FERNALD, R. D. 2009. Cytoarchitecture of a Cichlid Fish Telencephalon. Brain Behav Evol. 74:110-120

BURGUS, R., M. BUTCHER, N. LING, M. MONAHAN, J. RIVIER, R. FELLOWS, M. AMOSS, R. BLACKWELL, W. VALE, R. GUILLEMIN, 1971 Molecular structure of the hypothalamic factor (LRF) of ovine origin monitoring the secretion of pituitary gonadotropic hormone of luteinization (LH). C R Acad Sci Hebd Seances Acad Sci D 273: 1611-1613.

BUTLER, A. B., SAIDEL, W. M. 1991. Retinal projections in the freshwater butterfly fish, Pantodon buchholzi (Osteoglossoidae). I. Cytoarchitectonic analysis in primary visual pathways. Brain Behav Evol. 38: 127-153.

BUTLER, A. N., NORTHCUTT, R. G. 1993. The diencephalon of the pacific herring, Clupea harengus: cytoarchitectonic analyses. J Comp Neurol. 328: 527-546.

BUTLER, A. B. 2000. Nervous system: Microscopic functional anatomy. IN: Handbook of Laboratory Animals: Fish, ed. by Ostrander, G. K. Academic Press, San Diego, pp. 331355.

CANEPPELE, D, HONJI, R. M, HILSDORF, A. W. S, MOREIRA, R. G. 2009. Induced Spawn of the endangered neotropical species Steindachneridion parahybae (Siluriformes: Pimelodidae). Neotrop Ichthyol. 7(4): 759-762.

CARR, C. E, MALER, L, HEILINGENBERG, SAS, E. 1981. Laminar organization of the afferent and efferent systems of the torus semicircular of gymnotiform fish: morphological substrates for parallel processing in the electrosensory system. J. Comp. Neurol. 203: 649-670.

CERDÁ-REVERTER, J.M, ZANUY, S, MUÑOZ-CUETO, J. A. 2001a. Cytoarchtectonic study of the brain of a Perciform species, the sea bass (Dicentrarchus labrax): I. The telencephalon. J Morph. 247: 217-228.

CERDÁ-REVERTER, J. M, ZANUY, S, MUÑOZ-CUETO, J. A. 2001b. Cytoarchtectonic study of the brain of a Perciform species, the sea bass (Dicentrarchus labrax): II The Diencephalon. Journal of Morphology. 247: 229-251.

CERDÁ-REVERTER, J. M, MURIACH, B, ZANUY, S, MUÑOZ-CUETO, J. A. 2008. A cytoarchtectonic study of the brain of a Perciform species, the sea bass (Dicentrarchus labrax): the midbrain and hindbrain. Acta Histochemica, 110: 433-450.

CHÁVES-APONTE, E. O., GUERRERO, H. Y., CARDILLO, E., MARCANO, D., POLEO, G. A., FINOL, H. J., BELlO, B., VELASCO, E., MEJÍA, E. 2009. Anatomy, 


\section{CHAPTER I - A Atlas of the Catfish Brain - References}

Histology and Ultrastructure of Pineal Gland of the Sawing Catfish, Oxydoras sifontesi (Siluriformes: Doradidae): Some Morphofunctional Implications. Acta Microsc. 18(2): 67-75.

DAMJANOVI'C I, MAXIMOVA E, MAXIMOV V. 2009a. On the organization of receptive fields of orientation-selective units recorded in the fish tectum. J. Integr. Neurosci. 8: 323-344.

DAMJANOVI'C I, MAXIMOVA E, MAXIMOV V. 2009b. Receptive field sizes of direction-selective units in the fish tectum. J. Integr. Neurosci. 8: 77-93.

DONOVAN, B.T., AND G.W. HARRIS, 1954 Effect of pituitary stalk section light-induced oestrus in the ferret. Nature 174: 503-504.

DUBOIS, E. A, ZANDBERGEN, M. A, PEUTE, J, BORGERD, J, GOOS, H. J. T. 2001. Development of three distinct GnRH neuron populations expressing two different GnRH forms in the brain of the African Catfish (Clarias gariepinus). J Comp Neurol. 437: 308-320.

EASTMAN, J. T., LANNOO, M. J. 1995. Diversification of brain morphology in antarctic fish Notothenioid fishes: Basic descriptions and ecological considerations. J of Morph. 223: 47-83.

EBBESSON, S. O. E. \& O’DONNEL, D. 1980. Retinal projections in the electric catfish (Malapterurus eletricus). Cell Tissue Res. 213: 497-503

ECHTELER, S.M. 1984. Connections of the auditory midbrain in a teleost fish, Cyprinus carpio. J. Comp. Neurol., 230: 536-551.

FERNALD, R. D., SHELTON, L. C. 1985. The organization of the diencephalon and the pretectum in the cichlid fish, Haplochromis burtoni. J comp Neurol. 238: 202-217.

FINGER, T.E., 1978. Cerebellar afferents in teleost catfish (Ictaluridae). J. Comp. Neur., 181: 173-182.

FINGER, T.E. 1983a. Organization of the teleost cerebellum. In Northcutt, R.G. and Davis, R.E. Eds. Fish Neurobiology, Vol. 1, pp. 261-284. University of Michigan Press, Ann Arbor.

FINGER, T.E. 1983b. The gustatory system in teleost fish. In Northcutt, R.G. and Davis, R.E. Eds. Fish Neurobiology, Vol. 1, pp. 285-309. University of Michigan Press, Ann Arbor. 


\section{CHAPTER I - A Atlas of the Catfish Brain - References}

FINGER, T.E. AND TONG, S.-L. 1984. Central organization of eighth nerve and mechanosensory lateral line systems in the brainstem of ictalurid catfish. J. Comp. Neurol., 229: 129-151.

FINGER, T.E. 1986. In: Electroreception (eds T.H. Bullock and W. Heiligenberg), John Wiley \& Sons, New York, pp. 287-317.

FINGER, T. E., KANWAL, J. S. 1992. Ascending general visceral pathways to the valvula cerebelli in mormyrid fish. Exp. Brain Res. 42: 23-33.

FRALEY, S. M, \& SHARMA, S. C. 1986. Topography of retinodiencephalic projections in adult channel catfish. Brain Res. 385: 179-184.

GABE, M. 1968. Techiniques histoloques. Paris. Masson.

GOMEZ-SEGADE, P. AND ANADON, R. 1986. Ciliated neurons of the nucleus praeopticus magnocellularis and nucleus lateralis tuberis of an advanced teleost, Chelon labrosus (Risso, 1826). J. Hirnforsch 27:423-430.

GOMEZ-SEGADE, P. AND ANADON, R. 1988. Specialization in the diencephalon of advanced teleosts. J. Morphol. 197: 71-103.

HIECMAN, C.P., ROBERTS, L.S., LARSON, A. Princípios integrados de Zoologia. 11th. Ed. Guanabara Koogan, Rio de Janeiro, 2004.

HONJI, R.M, 2011. Controle do eixo hipotálamo-hipófise-gônadas do Surubim do Paraíba (Steindachneridion parahybae) (Siluriformes: Pimelodidae) em relação ao ciclo reprodutivo e à reprodução induzida em cativeiro. Tese (Doutorado), Instituto de Biociências da Universidade de São Paulo. Departament de Fisiologia. 300p.

ITO, H. AND KISHIDA, R. 1978. Afferent and efferent fiber connections of the carp torus longitudinalis. J. Comp. Neurol. 181: 465-476.

ITO, H., MURAKAMI, T. AND MORITA, Y., 1982. An indirect telencephalo-cerebellar pathway and its relay nucleus in teleosts. Brain Res., 249: 1-13.

ITO, H \& VENEGAS, H. 1983. Cytoarchitecture and ultra-structure of nucleus prethalamicus, with special reference to degenerating afferents from optic tectum and telencephalon, in a teleost (Holocentrus ascensionis). J. Comp. Neurol. 221: 401-415.

ITO, H., MURAKAMI, T., FUKUOKA, T. AND KISHIDA, R. 1986. Thalamic fiber connections in a teleost (Sebastiscus marmoratus): Visual, somatosensory, octavolateral and cerebellar relay region to the telencephalon. J. Comp. Neurol., 250: 215-227. 


\section{CHAPTER I - A Atlas of the Catfish Brain - References}

ITO, H. AND YOSHIMOTO, M., 1990. Cytoarchitecture and fiber connections of the nucleus lateralis valvulae in the carp (Cyprius carpio). J. Comp. Neurol., 298: 385-399.

ITO H., ISHIKAWA, Y., YOSHIMOTO, M., YAMAMOTO, N. 2007. Diversity of brain morphology in teleosts: brain and ecological niche. Brain, Behavior and Evolution, 69: 76-86.

ISHIKAWA Y, YOSHIMOTO M, YAMAMOTO N, ITO H. 1999. Different brain morphologies from different genotypes in a single teleost species, the medaka (Oryzias latipes). Brain Behav. Evol. 53: 2-9.

JACOBSON M, and GAZE R. 1964. Types of visual response from single units in the optic tectum and optic nerve of the goldfish. Exp. Physiol. 49: 199-209.

KANWAL, J. S, FINGER, T. E. and CAPRIO, J. 1988. Forebrain connections of the gustatory systems in the ictalurid catfishes. J. Comp. Neurol. 278: 353-376.

KANWAL, J. S, \& FINGER, T. E. 1997. Parallel medullary gustatospinal pathways in a catfish: possible neural substrates for taste-mediated food search. J. Neuroscience. 17(12): 4873-4885.

KELLER, C. H, MALER, L, HEILIGENBERG, W. 1990. Structural and functional organization of a diencephalic sensory-motor interface in the gymnotiform fish, Eigenmannia. J. Comp. Neurol. 293: 347-376.

KING, J.A., AND R.P. MILLAR, 1982a Structure of chicken hypothalamic luteinizing hormone-releasing hormone I. Structural determination on partially purified material. J Biol Chem 257: 10722-10728.

KING, J.A, AND R.P. MILLAR, 1982b Structure of chicken hypothalamic luteinizing hormone-releasing hormone II. Isolation and characterization. J Biol Chem 257:1072910732 .

KOTRSCHAL, K., VAN STAADEN, M, J., HUBER, R. 1998, Fish brains: evolution and environmental relationships. Reviews in Fish Biology and Fisheries. 8: 373-408.

KUENZEL, W. J, MASSON, M. 1988. A stereotaxic atlas of the brain of the chick (Gallus domesticus). John Hopkins University Press, Baltimore.

KNUDSEN, E. I. 1977. Distinct auditory and lateral line nuclei in the midbrain of catfishes. J. Comp. Neurol. 173: 417-431.

KNUDSEN, E. I. 1978. Functional organization of the electroreceptive midbrain of the catfish. J. Neurophysiol. 41: 350-364. 
LEVINE, R.L. AND DETHIER, S. 1985. The connections between the olfactory bulb and the brain in the goldfish. J. Comp. Neurol., 237: 427-444.

LONDOÑO, C., GIRALDO, H. H. 2010. Preliminary morphologic and morphometric study of the encephalon of the "tiburoncito" Ariopsis seemanni (Pisces: Ariidae). Universitas Scientarum, 15(2): 101-109.

MALER, L., SAS, E., JOHNSTON, S., ELLIS, W. 1991. An atlas of the brain of the electric fish Apteronotus leptorhynchus. J. Chem. Neuroanat.. 4: 1-38.

MATSUO, H., Y. BABA, R.M.G. NAIR, A. ARIMURA, AND A.V. SCHALLY 1971 Structure of the porcine LH- and FSH-releasing hormone. I. The proposed amino acid sequence. Biochem Biophys Res Comm 43: 1334-1339.

MAXIMOV V, MAXIMOVA E, MAXIMOV P. 2005. Direction selectivity in the goldfish tectum revisited. Ann NY Acad. Sci. 1048: 198-205.

MCCORMIC, C. A. 1982. The new organization of the octavolateralis area in actnopterigyan fishes: A new interpretation. J. Morphl. 171: 159-181.

MILLER, R. N. 1940. The diencephalic cell masses of the teleost, Corydoras paliatus. J. Comp. Neurol. 73: 345-378.

MUKUDA, T., ANDO, M. 2003. Brain atlas of the japanese eel: Comparison to other fishes. Mem. Fac. Integrad Arts and Sci. Hiroshima University. 4(29): 1-25.

MUÑOZ-CUETO, J. A., SARASQUETE, C., ZOHAR, Y., KAH, O. A atlas of the Brain on the giltheas seabream (Sparus aurata). Baltimore. Maryland Sea Grant. 2001.

MORITA, Y., FINGER, T. E. 1987. Area postrema of the goldifish, Carassius auratus: Ultrastructure, fiber connections, and immunocytochemistry. J. Comp. Neurol. 264: 231-249.

MURAKAMI, T., MORITA, Y. AND ITO, H. 1983. Extrinsic and intrinsic fiber connections of the telencephalon in a teleost, Sebastiscus marmoratus. J. Comp. Neurol., 216: 115131.

MURAKAMI, T., MORITA, Y. AND ITO, H. 1986a. Cytoarchitecture and fiber connections of the superficial pretectum in a teleost, Navodon modestus. Brain Res., 373: 213-221.

MURAKAMI, T., ITO, H. AND MORITA, Y. 1986b. Telencephalic afferent nuclei in the carp diencephalon, with special reference to fiber connections of the nucleus preglomerulosus pars lateralis. Brain Res. 382: 97-103. 


\section{CHAPTER I - A Atlas of the Catfish Brain - References}

MURAKAMI, T., FUKUOKA, T. AND ITO, H. 1986c. Telencephalic ascending acousticolateral system in a teleost (Sebastiscus marmoratus), with special reference to the fiber connections of the nucleus preglomerulosus. J. Comp. Neurol., 247: 383-397.

NELSON, J.S. Fishes of the world, 3 ed. John Wiley \& Sons, New York. 2006. 600p.

NIEUWENHUYS, R. 1982. An overview of the organization of the Brain of actinopterigyan fishes. Amer. Zool. 22: 287-310.

NIEUWENHUYS, R. AND OEY, P.L. 1983. Topological analysis of the brainstem of the reedfish, Erpetoichthys calabaricus. J. Comp. Neurol., 213: 220-232.

NIEUWENHUYS, R. AND POUWELS, E. 1983. In Fish Neurobiology, Vol. 1. Brain Stem and Sense Organs (eds R.G. Northcutt and R.E. Davis), pp. 25-87. University of Michigan Press, Ann Arbor.

NIEUWIENHUYS, R., TEN DONKELAAR, H. J., NICHOLSON, C. The central nervous system of vertebrates. Vol. 2. Ed. Springer-Verlag, Berling Heiderberg. 1998.

NORTHCUTT, R. G., BRAFORD, Jr, M. R. 1980. News pobservation on the organization and evolution of thetelencephalon of actinopterigyan fishes. In Ebbesson,S.O.E Ed Comparative Neurology of the Telencephalon, pp. 41-98. Plenum Press, New York.

NORTHCUTT, R. G., DAVIS., R. E. 1983. Telencephalic organization in ray-finned fishes. IN: DAVIS, R. E., NORTHCUTT, R. G., editors. Fish neurobiology, Vol 2. Ann Arbor: University of Michigan Press. p203-236.

NORTHCUTT, R.G. AND WULLIMANN, M.F. 1988. The visual system in teleost fishes: Morphological patterns and trends. In Atema, J., Fay, R.R., Popper, A.N. and Tavolga, W.N. (Eds.) Sensory Biology of Aquatic Animals, pp. 515-552. Springer-Verlag, New York.

NORTHCUTT, R.G. AND BUTLER, A.B. 1993. The diencephalon and optic tectum of the longnose gar, Lepisosteus osseus (L.): Cytoarchitectonics and distributions of acetylcholinesterase. Brain Behav. Evol., 41: 57-81.

NORTHCUTT R. G. (2006). Connections of the lateral and medial divisions of the goldfish telencephalic pallium. J. Comp. Neurol. 494, 903-943

NORTHCUTT, R. G. 2008. Forebrain evolution in bony fishes. Brain Research Bulletin. 75: 191-205. 


\section{CHAPTER I - A Atlas of the Catfish Brain - References}

NORTHMORE, D.P.M., WILLIAMS, B. AND VANEGAS, H. 1983. J. Comp. Physiol. 150: $39-50$.

OKA, Y., SATOU, M. AND UEDA, K., 1986. Descending pathways to the spinal cord in the him $\vartheta$ salmon (Landlocked red salmon, Oncorhynchus nerka). J. Comp. Neurol., 254: 91-103.

PETER, R.E. AND GILL, V.E. 1975. A stereotaxic atlas and technique for forebrain nuclei in the goldfish, Carassius auratus. J. Comp. Neurol., 159: 69-102.

PETER, R.E., MACEY, M.J. AND GILL, V.E. 1975. A stereotaxic atlas and technique for forebrain nuclei of the killifish, Fundulus heteroclitus. J. Comp. Neurol.,159: 103-128.

PETER, R.E., CRIM, L.W. AND BILLARD, R. 1991. A stereotaxic atlas and implantation technique for nuclei of the diencephalon of Atlantic salmon (Salmo salar) parr. Reprod. Nutr. Dev., 31: 167-186.

PRASADA RAO, P.D., JADHAO, A.G. AND SHARMA, S.C., 1987. Descending projection neurons to the spinal cord of the goldfish, Carassius auratus. J. Comp. Neurol., 265: 96-108.

PRASADA RAO, P.D., JADHAO, A.G. AND SHARMA, S.C., 1993. Topographic organization of descending projection neurons to the spinal cord of the goldfish, Carassius auratus. Brain Res., 620: 211-220.

PUELLES, L. AND RUBENSTEIN, J.L.R. 1993. Expression patterns of homeobox and other putative regulatory genes in the embryonic mouse forebrain suggest a neuromeric organization. Trends Neurosci., 16: 472-479.

RUPP, B., WULLIMANN, M. F., REICHERT, H. 1996. The zebrafish brain: a neuroanatomical comparison with the goldfish. Anat Embriol. 194:187-203.

RUPP, B., NORTHCUTT R. G. 1998. The diencephalon and pretectum of the white sturgeon (Acipenser transmontanus): a cytoarchitectonic study. Brain Behav. Evol. 51, 239-262

STRIEDTER, G.F. AND NORTHCUTT, R.G. 1989. Two distinct visual pathways through the superficial pretectum in a percomorph teleost. J. Comp. Neurol., 283: 342-354.

STRIEDTER, G. F. 1990a. The diencephalon of the channel catfish Ictalurus punctatus. I. Nuclear organization. Brain Behav. Evol. 36: 229-354. 


\section{CHAPTER I - A Atlas of the Catfish Brain - References}

STRIEDTER, G.F. 1990b. The diencephalon of the channel catfish, Ictalurus punctatus. II. Retinal, tectal, cerebellar and telencephalic connections. Brain Behav. Evol., 36: 355377.

SPRINGER, A. D, EASTER JR, AGRANOFF, B. W. 1977. The role of the optic tectum in various visually mediated behavior of goldfish. Brain Res.128: 393-404.

TRAJANO, E. 1994. Comparative study of the brain and olfactory organ of the troglobict catfish, Pimelodella kronei (Ribeiro, 1907), and its putative ancestor, P. transitoria (Ribeiro 1912) (Siluriformes Pimelodidae). Tropical Zoology. 7(1): 145-160.

VON BARTHELD, C.S., MEYER, D.L., FIEBIG, E. AND EBBESSON, S.O.E. 1984. Central connections of the olfactory bulb in the goldfish, Carassius auratus. Cell Tissue Res., 238: 475-487.

WULLIMANN, M.F. 1988. The tertiary gustatory center in sunfishes is not nucleus glomerulosus. Neurosci. Lett., 86: 6-10.

WULLIMANN, M. F, NORTHCUTT, R. G. 1988. Connections of the corpus of cerebelli in the two teleosts, the common goldfish and the Green sunfish. J. Comp. Neurol. 289: 554-567.

WULLIMANN, M.F. AND NORTHCUTT, R.G. 1989. Afferent connections of the valvula cerebelli in two teleosts, the common goldfish and the green sunfish. J. Comp. Neurol., 289: 554-567.

WULLIMANN, M.F. AND NORTHCUTT, R.G. 1990. Visual and electrosensory circuits of the diencephalon in mormyrids: An evolutionary perspective. J. Comp. Neurol., 297: 537-552.

WULLIMANN, M.F. AND ROTH, G. 1994. Descending telencephalic information reaches longitudinal torus and cerebellum via the dorsal preglomerular nucleus in the teleost fish, Pantodon buchholzi: A case of neural preadaptation? Brain Behav. Evol., 44: 338352.

WULLIMANN, M. F., RUPP, B., REICHERT, H. 1996. Neuroanatomy of the zebrafish brain: a topological atlas. Birkhauser Verlag, Switzerland.

ZOHAR, Y, MUÑOZ-CUETO, J. A, ELIZUR, A, KAH, O. 2010. Neuroendocrinology of the reproduction in teleosts fish. Gen Comp Endocr. 165(3): 438-55. 


$$
\text { CHAPTER II }
$$




\title{
FIRST INSIGHTS INTO THE LOCALIZATION OF GNRH-1
}

\section{NEURONS IN Steindachneridion parahybae JUVENILES}

\begin{abstract}
Studies related to the distribution, localization and roles of the different molecular forms of the Gonadotropin-Releasing Hormone $(\mathrm{GnRH})$ in the brain of fish, allow to the better understanding of the reproductive biology of the species. Thus, in this study, we have analyzed the distribution of the cells expressing catfish GnRH form in the brain of juveniles of a native catfish species - Steindachneridion parahybae-, using specific antibodies to the corresponding GnRH-associated peptide (GAP), by immunohistochemical techniques. The animal used were juveniles with up to 100 days post-hatching. We have described immunoreactive neurons in the external cell layer of the olfactory bulbs, with several fibers-ir distributed along all extension of the bulbs, in different layers. In the telencephalon few neurons-ir were recognized in the caudal part of the medial dorsal telencephalon (Dmc), while several fiber-ir can be observed distributed along the periventricular wall in the ventral and dorsal part. Interesting, some cells containing catfishGAP were target in the limit of DP (dorsal posterior nuclei of the telencephalon) and Dmc. About the diencephalon, the preoptic area present some neurons-ir, involved in several fiber-ir, which extends to medial and inferior zone of the hypothalamus, into to reach the pituitary gland. A significant number of fiber-ir were observed in the inferior lobe of the hypothalamus, around the lateral recess nucleus.
\end{abstract}

Key words: Fish brain; Endocrinology; GnRH; Teleost; Fish reproduction, Steindachneridion parahybae. 


\section{INTRODUCTION}

In teleost fish, the reproduction is modulated by external stimuli such as temperature, photoperiod, rainfall, electrical conductivity. As a result of the reception and transduction of environmental signals, endogenous factors act regulating fish reproduction. Acting at the top of the hormonal cascade responsible for the reproductive process, we highlight the hypothalamic neurohormone GnRH (gonadotropin-releasing hormone). This is a main neurohormone involved in the reproductive process of teleost fish, present in several brain regions and is the responsible for the stimulation of pituitary cells to synthesize and release gonadotropins (FSH - follicle-stimulating hormone and LH-luteinizing hormone), that act directly on gonadal development e maturation. This complex system involving different hormones that act in the whole reproductive process, is also called Brain-Pituitary-Gonads axis (Figure 1) (Yamamoto, 2003; Zohar et al., 2010; Miranda et al, 2013).

Although the number of neuroendocrine factors that have been related to the control of the reproductive process in fishes has been increasing progressively in the last two decades, in many cases detailed information does not exist describing when and how these effects are exerted, nor whether these effects can be generalized to all fish species. Initially it was considered that GnRH was released by one single population of hypophysiotrophic neurons that stimulated the secretion of pituitary gonadotropins, and that represented the principal factor setting off the hormonal cascade that controlled the reproductive axis. Since the pioneering studies of Bernard Breton and collaborators, who showed that GnRH stimulates the release of gonadotropins in the carp (Breton $\boldsymbol{e t}$ al., 1972), and the studies of Nancy Sherwood, who characterised the first form of GnRH in fishes, the salmon GnRH (Sherwood et al., 1983), researches on the GnRH systems in fishes has attracted considerable attention. This interest is due in part to the practical applications of GnRH in aquaculture (Zohar \& Mylonas, 2001), but also because teleosts are a phylogenetic group of great interest for understanding the evolution of genes and GnRH systems in vertebrates. As we shall see in the following sections, today we know that most vertebrates express two or three different forms of $\mathrm{GnRH}$ in different tissues; these forms can exert pleiotropic actions mediated by different types of receptors. Teleosts have played a crucial role in the establishment of these new concepts, which have enabled researchers to establish evolutionary models for how the functions of the different forms of GnRH have evolved (Gorbman \& Sower, 2003; Lethimonier et al., 2004; Guilgur et al., 2006; Kah et al., 2007). 
It is known that GnRH is a decapeptide, present in fish in two or three different molecular forms, with different functions, being one of these functions the stimulation of synthesis and release of GtHs by the anterior pituitary (Zohar et al., 2010), a function related with the location of these GnRH forms in the brain. Thus, the distribution of neurons that synthesize the three paralogous forms of GnRH (GNRH1, GnRH2 and GnRH3 - for review to see Fernald \& White, 1999) has been studied in different teleost species (Okubo \& Nagahama, 2008). The different forms of GnRH have specific names (Table I). In addition, among the different terms used when referring to $\mathrm{GnRH}$, traditionally it receives the name of the species in which $\mathrm{GnRH}$ was first isolated (e.g. $c f \mathrm{GnRH}$, catfish $\mathrm{GnRH}$, firstly isolated in a catfish). However, the current terminology and the one adopted in the present study is based on the location and function of this neurohormone in the brain (Fernald \& White, 1999).

Regarding the distribution of neurons that synthesize the three forms of GnRH GnRH1, GnRH2 and GnRH3 (Table II) -, they have been studied in different teleost species and the three forms have survived throughout evolution (Okubo \& Nagahama, 2008). In most teleosts, GnRH1 is mainly synthesized in the pre-optic area and almost exclusively released in the pituitary, while the GnRH2 and GnRH3 are produced in the mesencephalic tegumentum and the terminal nerve, respectively, and transported in many areas of the brain (Yamamoto et al., 1995).

With respect to the embryological origin of the GnRH system in teleost fish, the appearance of GnRH neurons during the ontogeny is different: the neurons of GNRH1 and GnRH3 in teleosts have common origin in the olfactory placode, as reported for another vertebrates (González-Martínez et al., 2002, 2004; Kah et al., 2007). Abraham and collaborators (2008) - studying zebrafish-, and Dubois et al (2001) - studying a catfish species -, suggest that the origin of the GNRH1 and GnRH3 occurs in the olfactory region, subsequently there is a migration of neurons through terminal nerve (TN) and ventral part of the telencephalon to the hypothalamic region. While $\mathrm{GnRH} 2$ has its origin in the synencephalon, migrating almost exclusively to the mesencephalic tegumentum (Yamamoto et al., 1995). 


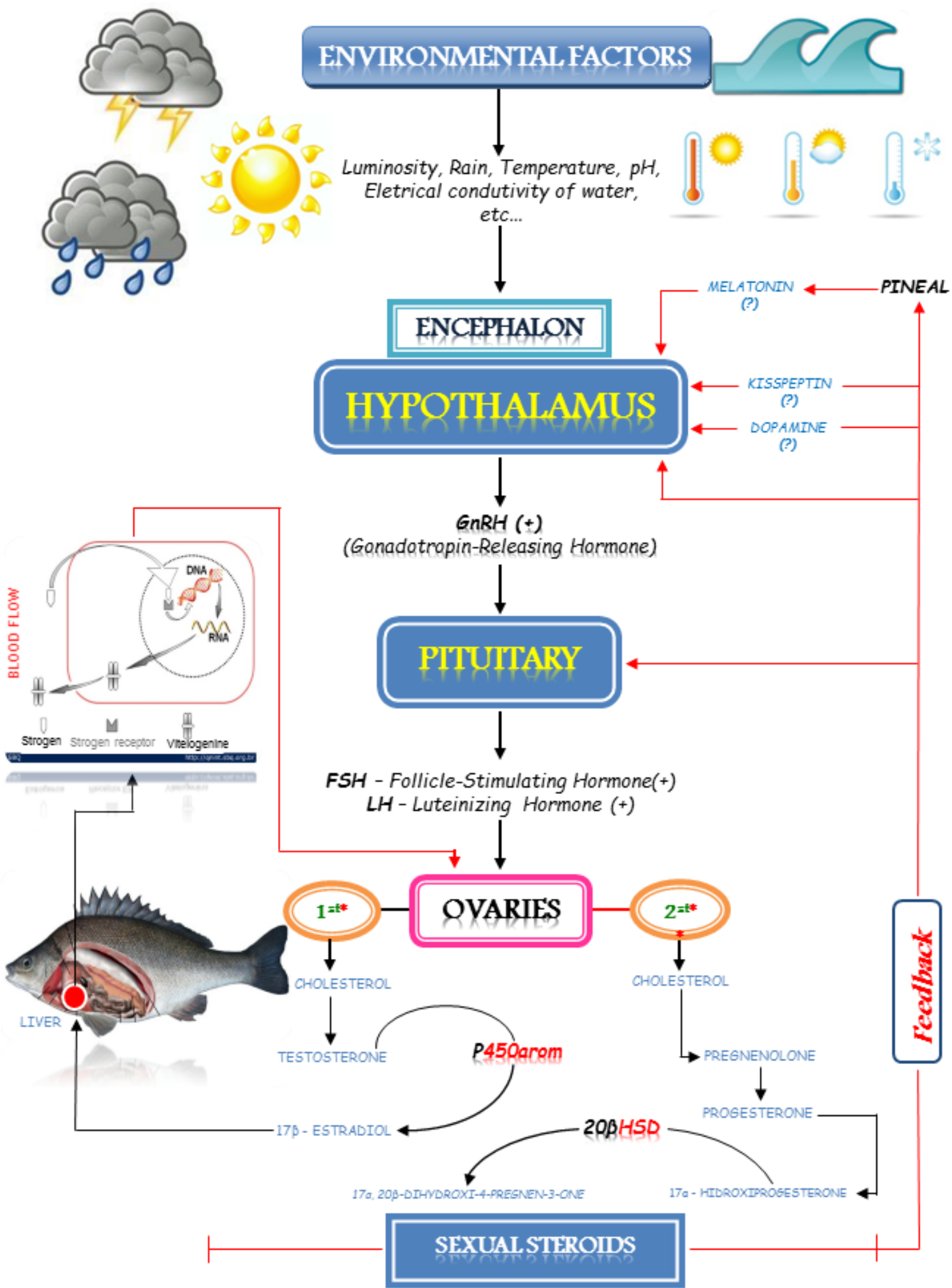

Figure 1. Scheme of Brain-Pituitary-Gonads axis in female teleosts fish - Main pathways of synthesis of the sexual steroids and vitellogenin. $(*)$ maturation of the ovaries, $(* *)$ final maturation

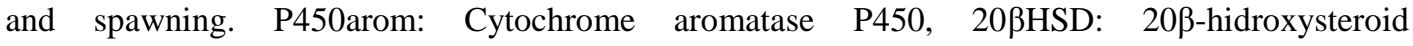
dehydrogenase. Adapted of Melamed \& Sherwood, 2005; Zohar et al., 2010. 
Table I. Amino acid sequences of vertebrates GnRH peptides. Different amino acids, compared with mammalian GnRH are showed with blue shading. In gray shading are showed the GnRH forms identified in fish (adapted from Honji, 2011).

\begin{tabular}{|c|c|c|c|c|c|c|c|c|c|c|c|c|}
\hline \multirow{2}{*}{ Animal } & \multicolumn{12}{|c|}{ Aminoácidos } \\
\hline & 1 & 2 & 3 & 4 & 5 & 6 & 7 & 8 & 9 & 10 & & \\
\hline Mammalian & pGlu & His & $\operatorname{Trp}$ & Ser & Tyr & Gly & Leu & Arg & Pro & Gly- $\mathrm{NH}_{2}$ & & \\
\hline Whitefish & pGlu & His & $\operatorname{Trp}$ & Ser & Tyr & Gly & Met & Asn & Pro & Gly- $\mathrm{NH}_{2}$ & & \\
\hline Salmon & pGlu & His & $\operatorname{Trp}$ & Ser & Tyr & Gly & Trp & Leu & Pro & Gly- $\mathrm{NH}_{2}$ & & \\
\hline Sea Bream & pGlu & His & $\operatorname{Trp}$ & Ser & Tyr & Gly & Leu & Ser & Pro & Gly- $\mathrm{NH}_{2}$ & & \\
\hline Pejerrey & pGlu & $\mathrm{His}$ & $\operatorname{Trp}$ & Ser & Phe & Gly & Leu & Ser & Pro & Gly- $\mathrm{NH}_{2}$ & & \\
\hline Herring & pGlu & His & Trp & Ser & His & Gly & Leu & Ser & Pro & Gly $-\mathrm{NH}_{2}$ & & \\
\hline Catfish & pGlu & His & $\operatorname{Trp}$ & Ser & His & Gly & Leu & Asn & Pro & Gly- $\mathrm{NH}_{2}$ & & \\
\hline Dogfish & pGlu & His & $\operatorname{Trp}$ & Ser & His & Gly & Trp & Leu & Pro & Gly- $-\mathrm{NH}_{2}$ & & \\
\hline Chicken-ll & pGlu & His & $\operatorname{Trp}$ & Ser & His & Gly & Trp & Tyr & Pro & Gly- $\mathrm{NH}_{2}$ & & \\
\hline Lamprey-III & pGlu & His & $\operatorname{Trp}$ & Ser & His & Asp & Trp & Lys & Pro & Gly- $-\mathrm{NH}_{2}$ & & \\
\hline Lamprey-I & pGlu & $\mathrm{His}$ & Tyr & Ser & Leu & Glu & Trp & Lys & Pro & Gly- $-\mathrm{NH}_{2}$ & & \\
\hline Guinea Pig & pGlu & Tyr & $\operatorname{Trp}$ & Ser & Tyr & Gly & Val & Arg & Pro & Gly- $-\mathrm{NH}_{2}$ & & \\
\hline Chicken-I & pGlu & His & $\operatorname{Trp}$ & Ser & Tyr & Gly & Leu & Gin & Pro & Gly- $-\mathrm{NH}_{2}$ & & \\
\hline Frog & pGlu & His & $\operatorname{Trp}$ & Ser & Tyr & Gly & Leu & $\operatorname{Trp}$ & Pro & $\mathrm{Gly}-\mathrm{NH}_{2}$ & & \\
\hline Tunicate-1 & pGlu & His & $\operatorname{Trp}$ & Ser & Asp & Tyr & Phe & Lys & Pro & Gly- $-\mathrm{NH}_{2}$ & & \\
\hline Tunicate-2 & pGlu & His & $\operatorname{Trp}$ & Ser & Leu & Cyr & His & Ala & Pro & Gly- $\mathrm{NH}_{2}$ & & \\
\hline Tunicate-3 & pGlu & His & $\operatorname{Trp}$ & Ser & Tyr & Glu & Phe & Met & Pro & Gly- $\mathrm{NH}_{2}$ & & \\
\hline Tunicate-4 & pGlu & His & $\operatorname{Trp}$ & Ser & Asn & Gln & Leu & Thr & Pro & Gly-NH $\mathrm{NH}_{2}$ & & \\
\hline Tunicate- 5 & pGlu & His & $\operatorname{Trp}$ & Ser & Tyr & Glu & Tyr & Met & Pro & Gly- $-\mathrm{NH}_{2}$ & & \\
\hline Tunicate- 6 & pGlu & His & $\operatorname{Trp}$ & Ser & Lys & Gly & Tyr & Ser & Pro & Gly-NH $\mathrm{NH}_{2}$ & & \\
\hline Tunicate-7 & pGlu & His & $\operatorname{Trp}$ & Ser & Tyr & Ala & Leu & Ser & Pro & Gly- $-\mathrm{NH}_{2}$ & & \\
\hline Tunicate- 8 & pGlu & His & $\operatorname{Trp}$ & Ser & Leu & Ala & Leu & Ser & Pro & Gly- $-\mathrm{NH}_{2}$ & & \\
\hline \multirow[t]{2}{*}{ Tunicate -9} & pGlu & $\mathrm{His}$ & $\operatorname{Trp}$ & Ser & Asn & Lys & Leu & Ala & Pro & $\mathrm{Gly}-\mathrm{NH}_{2}$ & & \\
\hline & 1 & 2 & 3 & 4 & 5 & 6 & 7 & 8 & 9 & 10 & 11 & 12 \\
\hline Octopus vulgaris & pGlu & Asn & Tyr & His & Phe & Ser & Asn & Gly & $\operatorname{Trp}$ & His & Pro & Gly- $\mathrm{NH}_{2}$ \\
\hline Aplysia californica & pGlu & Asn & Tyr & His & Phe & Ser & Asn & Gly & $\operatorname{Trp}$ & Tyr & Ala & Gly- $\mathrm{NH}_{2}$ \\
\hline
\end{tabular}

Asp: ácido aspártico; Glu: ácido glutâmico; Arg: arginina; Lys: lisina, His: histidina; Asn: asparagina; Gln: glutamina; Ser. serina; Thr: treonina; Ala: alanina; Gly: glisina; Val: valina; Leu: leucina; lle: isoleucina; Pro: prolina; Phe: phenilalanina; Met: metionina; Trp: triptofano; Cys: cisteína. 
Table II - Three molecular forms of GnRH and their possible functions in teleost fish.

\begin{tabular}{ll}
\hline GnRH1 & As the main form present in the pituitary, it seems clear that GNRH1 is responsible by regulation \\
(HyA) & of the reproductive endocrine system by act on anterior pituitary stimulating the synthesis and \\
& release of gonadotropins. \\
GnRH2 & Although its precise physiological role is somewhat unclear, the projection GnRH2 MB widespread \\
(TEG) & throughout the brain suggests its action as a neuromodulator as well as being heavily involved in \\
the regulation of reproductive behavior in teleosts, as in female goldfish to administration GnRH2 & also reinforce reproductive behavior. \\
GnRH3 & Present only in teleosts, is suggested as the GnRH3 also involved in reproductive behavior, in \\
(TN, VT) & addition to being involved in the transmission of sensory coordinates of the visual and olfactory. \\
& Besides GnRH3 act as neuromodulator, this has been reported as not participating in the process of \\
ovarian development and ovulation in goldfish. However, the presence of few containing fibers that \\
form in the pituitary gland of D. labrax suggests that the GnRH3 act as a factor hipofisiotrópico
\end{tabular}

Considering theses information about GnRH, specifically the GnRH1 and its importance in the reproductive process of fish, the present study aims to analyze how the GnRH1 neurons are distributed in the S. parahybae brain during its initial development, studying animals up to 100 days post hatching. It is important to stand that for the mentioned above, the prior knowledge of brain regions and different brain nuclei involved in each process is essential for accurately affirm the location of different neurohormones in the brain, as detailed in the Atlas of catfish brain (Chapter I). 


\section{MATERIAL AND METHODS}

\section{Animals}

The specimens used in this study were obtained from induced artificial reproduction (Caneppele, 2009) at the Hydrobiology and Aquaculture Station of the Energy Company of São Paulo (CESP). The animals were acclimated in rectangular tanks (72L, at a temperature of $29^{\circ} \mathrm{C}$ ) from hatching to the 100 day post-hatching (dph), it were desensitized with benzocaine (ethyl p-aminobenzoate) $\left(1 \mathrm{~g} / 10 \mathrm{~L} \mathrm{H}_{2} 0\right)$ and placed in a fixing solution (acetic Bouin) for 24 hours. It should be emphasized here that the procedures followed in this study were according to the protocol $\mathbf{0 7 2 / 2 0 0 8}$ of the Animal Ethics Committee from the Institute of Biosciences of the University of São Paulo.

\section{GnRH-Immunohistochemistry Analyses}

For immunohistochemistry analyses, three animals from forty-three and eighty-eight days after hatching $(d a h)$ were used. Obtained serial coronal sections ( $5 \mu \mathrm{m}$-thick) were deparaffinized in xylene, rehydrated in increasing dilutions of ethanol (from $70 \%$ to $100 \%$ ), and washed in PBS buffer (phosphate buffered saline, $\mathrm{pH}$ 7.4) for five minutes. Then the material was treated with hydrogen peroxide (10\%) diluted in PBS for twenty minutes to block the activity of the endogenous peroxidase. After this step, the sections were again washed in PBS for five minutes, and performed a nonspecific blocking with non-fat powdered milk (5\%) diluted in PBS for twenty minutes. Then the material was incubated overnight in a humid chamber $\left(-4^{\circ} \mathrm{C}\right)$ with the primary antibody for catfishGAP ( $c f$ GAP) (GAP: GnRHAssociated Peptide), diluted 1:500. After incubation, sections were washed in PBS for five minutes and incubated with biotinylated secondary antibody (DAKO kit ${ }^{\circledR}$ : System LSAB2 $H R P)$ for thirty minutes, then washed for five minutes with PBS and incubated for thirty minutes with streptavidin (Kit DAKO ${ }^{\circledR}: L S A B 2$ System, HRP). Finally, peroxidase activity was visualized with DAB Chromogenic solution (0.1\% - 3,3-diaminobenzidine). Additionally, to confirm the specificity of the immunohistochemical reactions, to avoid false positives, a control was performed by omitting the primary antibody, and replacing it by PBS solution. After processing, the material was counter-stained with Mayer hematoxylin for three minutes and the slides were dehydrated, mounted and analyzed. 


\section{RESULTS}

A few $c f$ GAP-immunoreactive neurons (ir) were found in the olfactory bulbs (OB) of $S$. parahybae between 43-88 $d p h$, lying in the external cell layer (ECL) of the OB. Moreover, a number of immunoreactive $c f \mathrm{GAP}$-fibers were found distributed through all layers of the $\mathrm{OB}$ (Figs. 2; 5A). $c f$ GAP were also found in Tel-fibers, from the dorsal (D) to ventral (V) parts of telencephalon (Fig. 3). The $c f$ GAP neurons were observed in dorsal regions of D (Figs. 3A $(\boldsymbol{c}))$, these neurons-ir occurred in regions such as Dmc and Dp. In addition, some fibers-ir were found mainly in Dmc, but in Dc2 also (Fig. 3A $(\boldsymbol{c})$. In these regions, there is a large number of fibers that are distributed throughout the telencephalon (Figs. 3; 5B, C). In the diencephalon, although less than in Tel, neurons-ir $c f \mathrm{GAP}$ were located in the preoptic area (Figs. 3a, b; 5C), anterior thalamic nucleus (A) (Figs. 3D; 5D), ventromedial thalamic nucleus (VM) (Figs. 3D; 5D) and throughout the hypothalamus, but presenting also a large amount of fibers-ir of $c f G A P$ in the supracommissural organ (SCO) (Figs. 3D; 5D) and distributed along the inferior lobe of the hypothalamus (IL) (Figs. 4G, H; 5E).

The mammillary body seems to be directly related to the pituitary gland in $S$. parahybae, once that showed strong staining of fiber-ir (Figs. 4A, B, E; 5F), which extends from the caudal part of the lateral tuberal nuclei (NLTc) (Figs. 4A; 5E), before starts the pituitary to its most posterior region. Since the most lateral NLT up along the pituitary stalk (Fig. 4 D), we can observe $c f$ GAP numerous fibers-ir to $c f$ GAP reaching the neurohypophysis (NH) (Fig. 4E), distributing for almost its entire length (Fig. 4F). In addition, beyond the fibers-ir we also observed neurons-ir $c f$ GAP along the NLT and CM wall, which are different from other neurons-ir in this study, showing a fusiform-shape, with a stronger immunoreactive marking (Figs. 4A-E). 

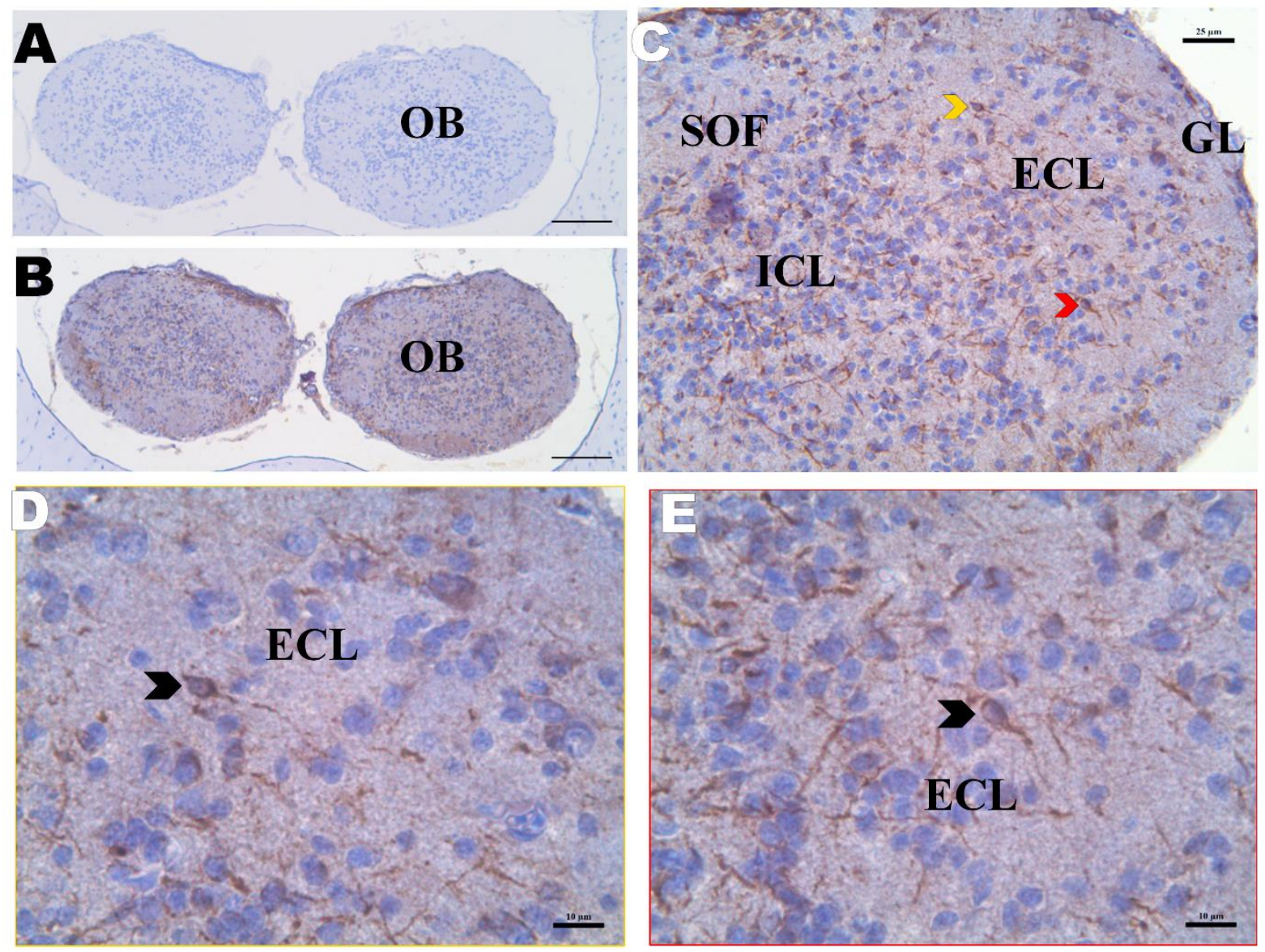

Fig. 2 - Neurons and fibers $c f$ GAP-immunoreactive (ir) in the olfactory bulbs $(\mathrm{OB})$ of juvenile Steindachneridion parahybae, between 43 and $88 \mathrm{dah}$. A and $\mathrm{B}$ show a pair of OB with not marking (control by omission of the primary anti-body) and a pair of OB showing neurons and fibers-ir to cfGAP, respectively; C) localization of the neurons-ir to $c f G A P$ in the ECL; D e E) represent the magnification of both, yellow and red arrows respectively in $\mathrm{C}$, indicating the cfGAP neurons-ir (black arrows). The abbreviations are in the Abbreviation List, in Chapter I. Scale Bar: $\mathbf{A}$ e $\mathbf{B}=100 \mu \mathrm{m}, \mathbf{C}=25 \mu \mathrm{m}, \mathbf{D}$ e $\mathbf{E}=$ $10 \mu \mathrm{m}$. 

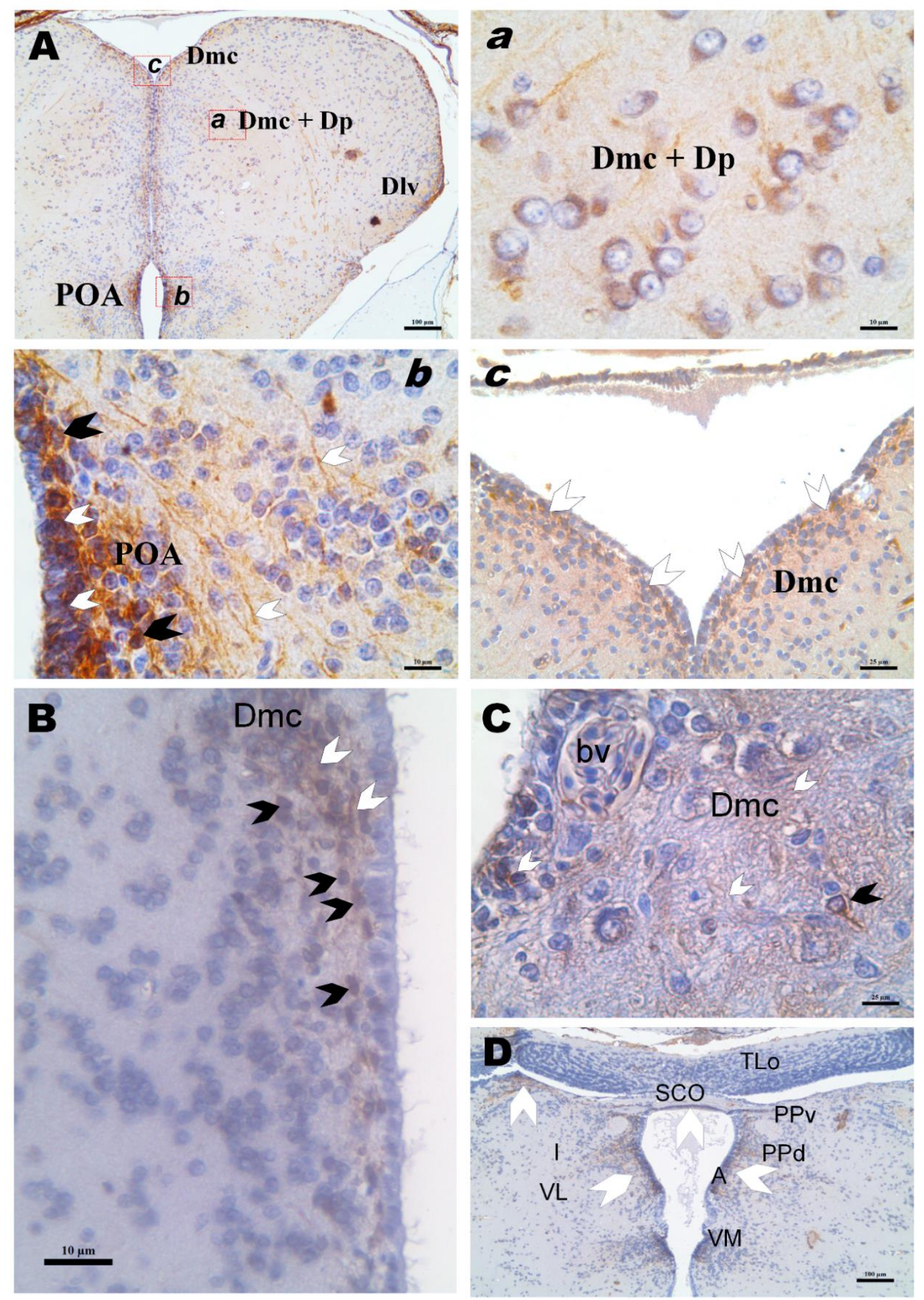

Fig. 3 - Neurons and fibers $c f$ GAP-immunoreactive (ir) present in both, telencephalic and thalamic area of juvenile Steindachneridion parahybae, between 22 and 43 dah. $a, b$ and $c$ shows the magnification of the areas inside of the red squares present in $\mathbf{A} ; \mathbf{B}$ and $\mathbf{C}$ ) neurons-ir and fiber-ir in the caudal part of the medial zone of the dorsal telencephalon; D) fibers-ir surround the areas of the thalamus. The black arrows indicate the presence of neurons of cfGAP-ir, while the white arrows indicate the fibers-ir. The abbreviations are in the Abbreviation List, in the Chapter I. Scale Bar: $\mathbf{A}=$ $100 \mu \mathrm{m}, \boldsymbol{a}$ and $\boldsymbol{b}=10 \mu \mathrm{m}, \boldsymbol{c}=25 \mu \mathrm{m}, \mathbf{B}=10 \mu \mathrm{m}, \mathbf{C}=25 \mu \mathrm{m}$ e $\mathbf{D}=100 \mu \mathrm{m}$. 

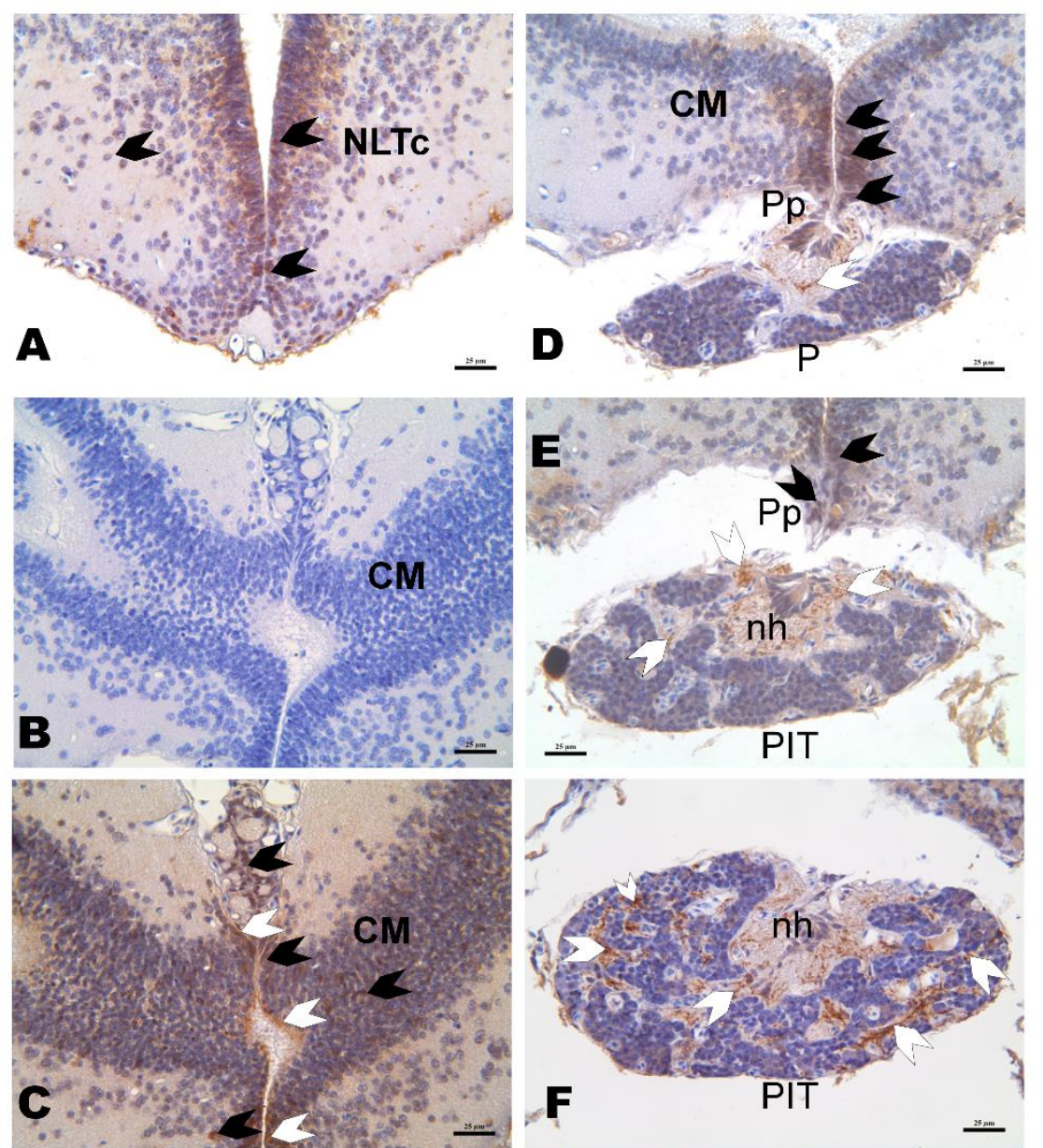

Fig. 4 - Neurons and fibers cfGAP-immunoreactive (ir) present in the hypothalamic area of the juvenile

\section{Steindachneridion}

parahybae, between 43 and

88 dah. A) caudal part of the lateral tuberal zone,

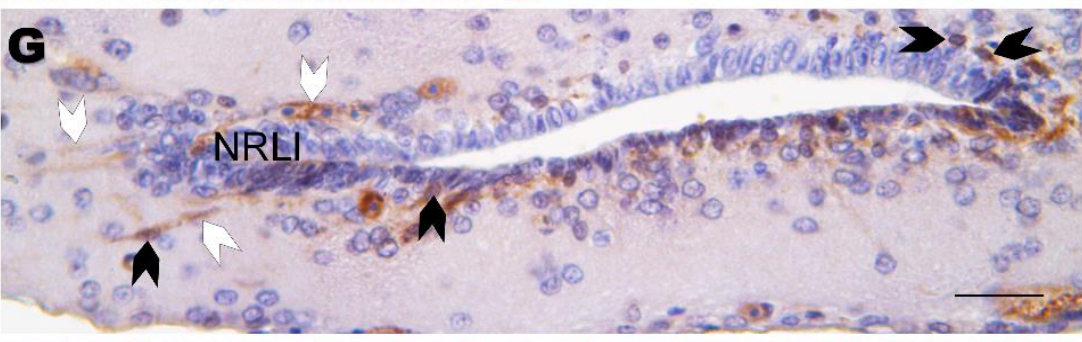

presenting neurons-ir to cfGAP as well as its fibers-ir; $\mathbf{B}$ and $\mathbf{C )}$ the mammillary body $(\mathrm{CM})$ with not marking (control by omission of the primary anti-body) and the $\mathrm{CM}$ showing neurons and fibers-ir to $c f$ GAP,

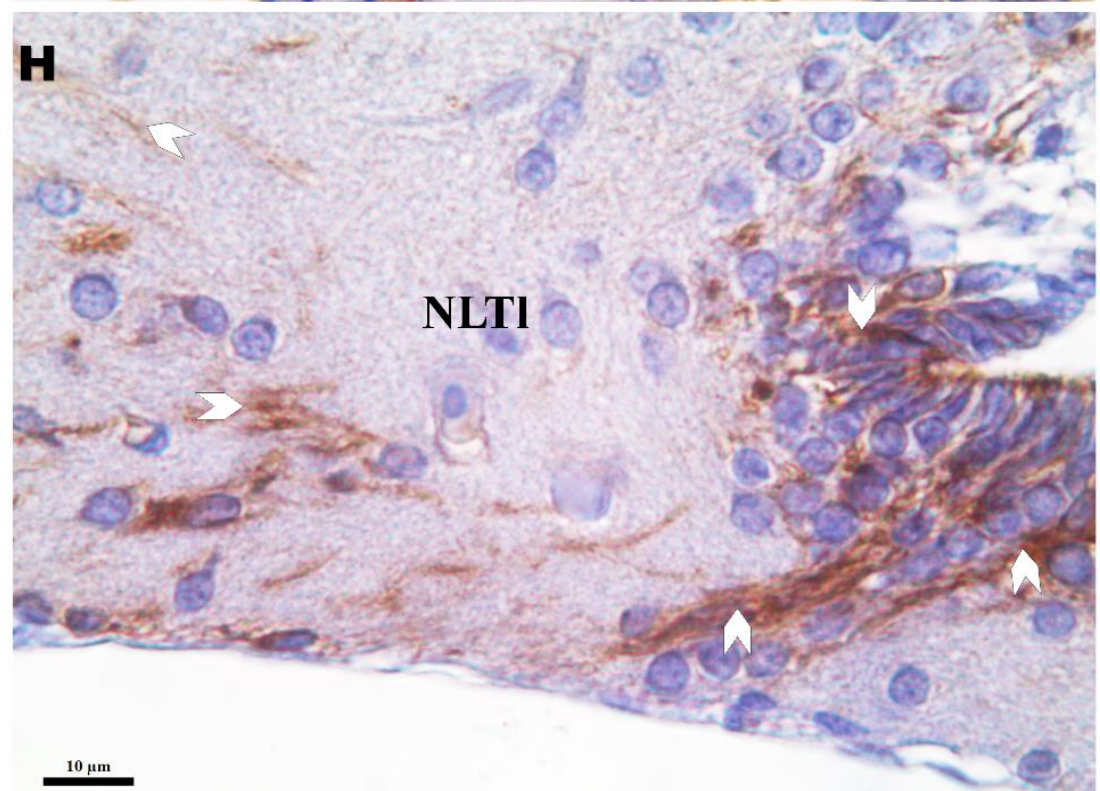
respectively. D e E) neuronsir and fibers-ir to $c f \mathrm{GAP}$ in the central wall of the $\mathrm{CM}$, reaching to pituitary through the pituitary stalk, showing a great amount of fibers-ir, also viewed $\mathbf{F}$; $\mathbf{G}$ and $\mathbf{H}$ ) presence of the fibers-ir in different regions of the inferior lobe of the hypothalamus. The black arrows indicate the neuronsir to $c f \mathrm{GAP}$, while the white arrows indicate the fibers-ir. The abbreviations are in the Abbreviation List, in the Chapter I. Scale Bar: A-G = $25 \mu \mathrm{m}, \mathbf{H}=10 \mu \mathrm{m}$. 
A

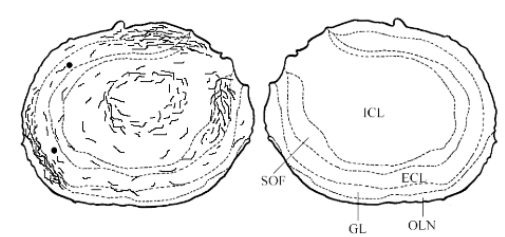

C

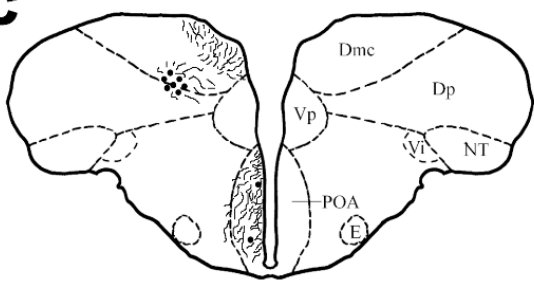

B
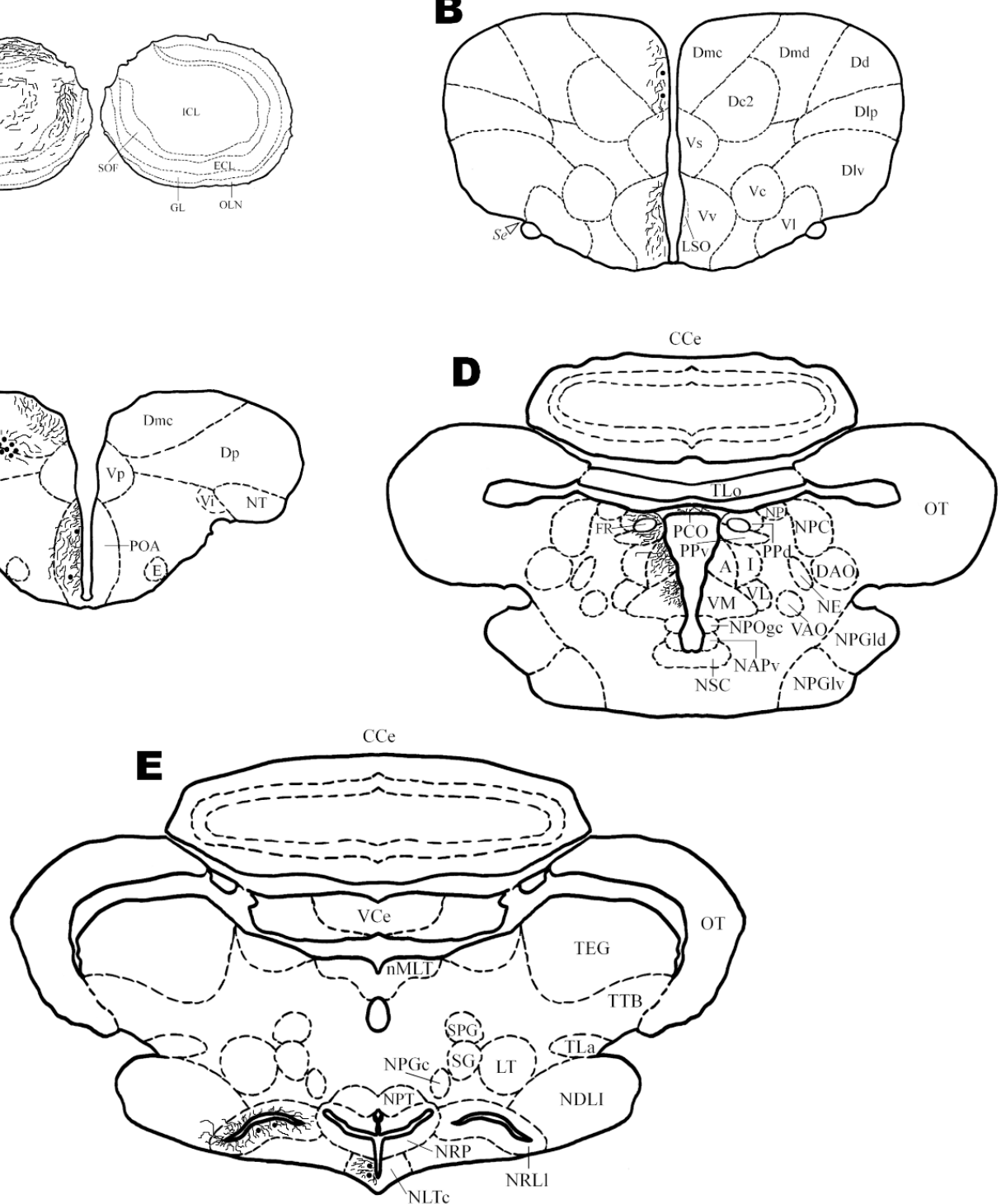

$\mathrm{CCe}$

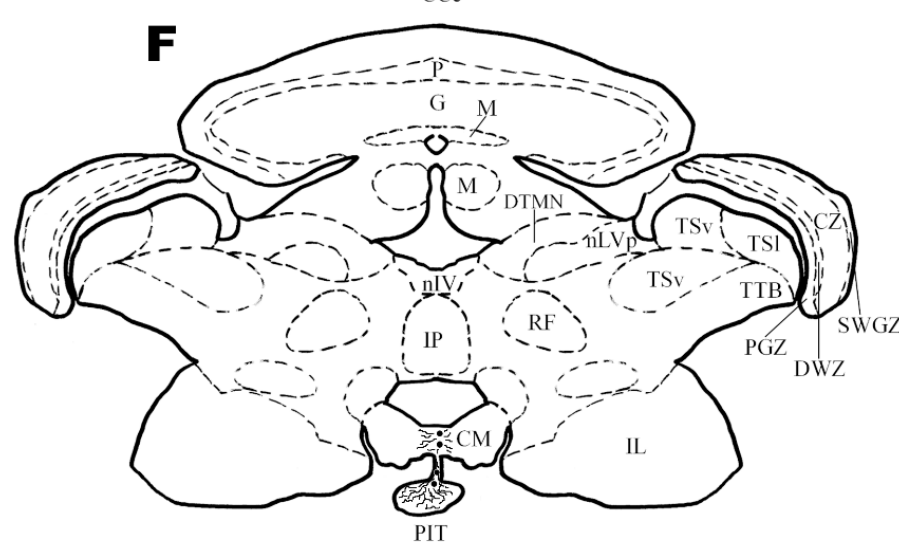

Fig. 5 - Schemes of cross-section to brain of Steindachneridion parahybae, representing neurons and fibers $c f$ GAP-immunoreactive (ir). Figures A, B, C, D, E and F correspond respectively to: Fig. 2C, Fig. 3B, Fig. 3a-c, Fig. 3D, 4G and Fig. 4F. The black circles indicate the neurons-ir to $c f$ GAP, while the irregular black lines indicate the fibers-ir. The abbreviations are in the Abbreviation List, in the Chapter I. Scale Bar $=550 \mu \mathrm{m}$. 


\section{DISCUSSION}

Although, in this study, neurons and fiber containing cfGAP have been observed in olfactory bulbs, besides dorsal and ventral telencephalon, we consider the hypothalamic regions as the most abundant in fibers of $c f$ GAP-ir. It is has been reported as one of the most important involved in the reproductive process, particularly regarding the innervation of pituitary and, in various species, it is reported as the main GnRH form in this region (Yamamoto et al., 1995; Fernald \& White, 1999; Okubo \& Nagahama, 2008;). In this context, supporting the literature, this study suggests that the hypothalamic region is heavily involved in the reproductive process since the initial development of catfish brain, being crucial to development of the GnRH-system (Zandbergen et al., 1995; Dubois et al., 2001; Dubois et al., 2002; Gonzalez-Martinez, 2004; Zohar et al., 2010; Honji, 2011; Gomes et al., 2013). Besides, distribution pattern of fiber-ir observed in this study is also reported as characteristic of GNRH1 neurons (Dubois et al., 2001; Sherwood \& Adams, 2005; Kah et al., 2007; Okubo \& Nagahama, 2008; Honji, 2011).

In the present study the antibody used, $c f \mathrm{GAP}$, unlike anti-cfGnRH, avoids unspecific markings among the different forms of $\mathrm{GnRH}$ in $S$. parahybae, since the similarity among them can cause this unspecificity. Besides that, it was observed that the cDNAs that encodes the GnRHs forms presenting associated peptides to each one GnRH, named GAP. Thus, GAPs are produced from the precursor molecules of $\mathrm{GnRH}$, and are co-localized in neurons that express it. These PCGs provide greater specificity than the GnRH itself, because they are larger and specific polypeptides for each molecular form of $\mathrm{GnRH}$, being a valuable tool in the identification and/or characterization of different GnRH molecular forms (Zohar et al, 2010; Pandolfi et al. 2005; Dubois et al, 2002, 2001).

The immunoreaction for neuron $c f \mathrm{GAP}$-ir in the ventral region of Tel and Die, observed in S. parahybae juveniles, have also been reported in other teleosts (Zandbergen et al., 1995; Pandolfi et al. 2005; Zohar et al., 2010), as well as catfish (Dubois et al., 2001) including adult S. parahybae (Honji, 2011). However, we have observed some neuros $c f G A P-i r$ in the limit between the Dmc and DC2, which were not described in adult S. parahybae (Honji, 2011). On the other hands, similarly to observed in this study, the presence of GnRH in the posterior region of the medial and dorsal part of the dorsal telencephalon was reported for Astyanax altiparanae, nevertheless, described only as GnRH (Gomes et al., 2013).

Additional studies are also necessary to elucidate the function of neurons-ir of $c f \mathrm{GnRH}$ in brain regions as Dmc and its fibers in the Dc of S. parahybae juveniles. In other catfish 
species the presence of the molecular form $c f \mathrm{GnRH}$ into two neuronal populations in the brain is known, being these populations found in the nerve terminal (TN) (Zandbergen et al., 1995; Dubois et al., 2001) and ventral telencephalon and diencephalon (Vv, POA, IL and PIT) (Honji, 2011; Dubois et al. 2001; Zandbergen et al., 1995). In S. parahybae adult females, neurons-ir cfGAP have been identified along the ventral region of the telencephalon and in important areas of the diencephalon, especially in the hypothalamus, including fiber-ir of $c f$ GAP in the pituitary (Honji, 2011). This author suggests that GNRH1 is responsible for the endocrine control of reproduction in S. parahybae, mainly in the release of GtHs in the pituitary, which can also be suggested in the present study by the presence of $c f G A P$ fibers-ir that reach the pituitary gland. These findings show the importance of certain brain regions or steps in the reproductive process, even during the initial stages of the life cycle, suggesting the significance of studies in this area.

We suggest that the GnRH system is set early in this species, considering that it was observed the presence of neurons-ir to cfGAP in animals between 23 and 43 dah. Clarias gariepinus (Siluriformes), as S. parahybae, has two different molecular forms of GnRH ( $c f \mathrm{GnRH}$ and $c \mathrm{GnRH}-\mathrm{II}$ ). In this species the population of $\mathrm{GnRH} 2$ arose in the second week after hatching (wah), as well as neurons and fibers that appeared respectively at GnRH1 ventral telencephalon and pituitary, also in the second week and subsequently in the preoptic area and ventral hypothalamus (between 4-6wah) (Dubois et al., 2001). Oncorhynchus nerka and O. keta, both Salmoniformes also have only two GnRH populations, GnRH2 and GnRH3, being the latter hypophysiotropic, and these forms were identified, respectively, at the 16 and 19daf (Chiba et al., 1994; Parhar et al., 1995). In this sense, it is clear that the GnRH systems can arise at different moments during the embryological development according to the fish species.

Thus, the data herein found allow to suggest that the nuclei identified here might be related to reproduction in $S$. parahybae, and the use of $c f$ GAP is a valuable tool for accurate analysis of brain regions, also offering a support to cytoarchitectonic studies in fish, strengthening the understanding of reproductive physiology in S. parahybae. Beside the studies about GnRH in $S$. parahybae adult females, the location of the different GnRH forms during the ontogeny of this species is important for further studies on the development, roles and functions of $\mathrm{GnRH}$ in catfish physiology. 


\section{ACKNOWLEDGMENTS}

The authors would like to thank CESP and its employees for providing the logistics and the animals; to Dr. Henk Goos (Utrecht University - Netherlands) for the kind donation of the cfGAP antibodies; and, finally, the São Paulo Research Foundation (FAPESP) (grant\# 2012/14115-1). 


\section{REFERENCES}


ABRAHAM, E, PALEVITCH, O, IJIRI, S. DU, S.J, GOTHILF, Y, ZOHAR, Y. 2008. Early development of forebrain gonadotropin release hormone $(\mathrm{GnRH})$ neurons and of $\mathrm{GnRH}$ as an autocrine migration factor. J Neuroendocrinol. 20: 394-405.

AMOSS, M, BURGUS, R, BLACKWELL, R, VALE, W, FELLOWS, R, GUILLEMIN, R. 1971. Purification, amino acid composition and N-terminus of the hypothalamic luteinizing hormone releasing factor (LRF) of ovine origin. Biochem Biophysiol Res Comm. 44: 205-210.

BRETON, B., C. WEIL, B. JALABERT, AND R. BILLARD, 1972. Activité réciproque des facteurs hypothalamiques de Bélier (Ovis aries) et des poissons téléostéens sur la sécrétion in vitro des hormones gonadotropes c-HG et $\mathrm{LH}$ respectivement par des hypophyses de carpe et de bélier. C R Acad Sci (Paris) Sér III 274: 2530-2533.

CANEPPELE, D, HONJI, R. M, HILSDORF, A. W. S, MOREIRA, R.G. 2009. Induced spawn of the endangered neotropical species Steindachneridion parahybae (Siluriformes: Pimelodidae). Neotrop Ichtyol 7(4): 759-762.

CHIBA, A, OKA, S, HONMA, Y. 1994. Ontogenetic development of gonadotropin-releasing hormone-like immunoreactive neurons in the brain of the chum salmon, Onchorhynchus keta. Neurosci Lett. 178: 51-54.

DUBOIS, E. A, ZANDBERGEN, M. A, PEUTE, J, BORGERD, J, GOOS, H. J. T. 2001. Development of three distinct GnRH neuron populations expressing two different GnRH forms in the brain of the African Catfish (Clarias gariepinus). J Comp Neurol. 437: 308-320.

DUBOIS, E. A, ZANDBERGEN, M. A, PEUTE, J, GOOS, H. J. T. 2002. Evolutionary development of three gonadotropin-releasing hormone $(\mathrm{GnRH})$ systems in vertebrate. Brain Res Bull. 57(3/4): 413-418.

FERNALD, R. D., SHELTON, L. C. 1985. The organization of the diencephalon and the pretectum in the cichlid fish, Haplochromis burtoni. J Comp Neurol. 238: 202-217.

FERNALD, R. D, WHITE, R. B. 1999. Gonadotropin-release hormone genes: phylogeny, structure, and functions. Frontiers in Neuroendocrin. 20: 224-240.

FRYER J, MALER, L. 1981. Hypophysiotrophic neurons in the goldfish pituitary demonstrated by the retrograde transport of horseradish peroxidase. Cell Tissue Res 218:93-102.

GONZALEZ-MARTÍNEZ, D, ZMORA, N, ZANUY, S, SARASQUETE, C, ELIZUR, A, KAH, O, MUÑOZ-CUETO, J. A. 2002. Development expression of three different 
prepo-GnRH (gonadotropin release-hormone) messengers in the brain of the European sea bass (Dicentrarchus labrax). J Chem Neuroanat. 23: 255-267.

GONZALEZ-MARTÍNEZ, D, ZMORA, N, SALIGAUT, D, ZANUY, S, ELIZUR, A, KAH, O, MUÑOZ-CUETO, J. A. 2004. New insights in developmental origins of different GnRH (gonadotropin-releasing hormone) systems in Perciform fish: an Immunohistochemical study in the European sea bass (Dicentrarchus labrax). J Chem Neuroanat. 28: 1-15.

GOMES, C. C., COSTA, F. G., BORELLA, M. I. 2013. Distribution of GnRH in the brain of the freshwater teleost Astyanax altiparanae (Garutti \& Britski, 2000). Micron. 52-53: 33-38.

GORBMAN, A., SOWER, S. A., 2003. Evolution of the role of GnRH in animal (Metazoan) biology. Gen. Comp. Endocrinol. 134: 207-213.

GUILGUR, L.G., N.P. MONCAUT, A.V. CANARIO, AND G.M. SOMOZA, 2006. Evolution of GnRH ligands and receptors in gnathostomata. Comp Biochem Physiol A Mol Integr Physiol 144: 272-283.

HONJI, R.M, 2011. Controle do eixo hipotálamo-hipófise-gônadas do Surubim do Paraíba (Steindachneridion parahybae) (Siluriformes: Pimelodidae) em relação ao ciclo reprodutivo e à reprodução induzida em cativeiro. Tese (Doutorado), Instituto de Biociências da Universidade de São Paulo. Programa de Fisiologia Geral. 300p.

KAH, O, LETHIMONIER, C, SOMOZA, G, GUILGUR, L. G, VAILLANT, C, LAREYRE, J. J. 2007. GnRH and GnRH receptors in metazoan: A historical, comparative, and evolutive perspective. Gen Comp Endocr. 153: 346-364.

LETHIMONIER, C., T. MADIGOU, J.A. MUÑOZ-CUETO, J.J. LAREYRE, AND O. KAH, 2004. Evolutionary aspects of GnRHs, GnRH neuronal systems and GnRH receptors in teleost fish. Gen. Comp. Endocrinol. 135: 1-16.

MELAMED, P, SHERWOOD, M. N. 2005. Gonadotropin-releasing hormone in fish: evolution, expression and regulation of the GnRH gene. In: Sherwood, M.N, Adams, A.B. Hormones and their receptors in fish reproduction: molecular aspects of fish and marine biology. 4: 3-39.

MIRANDA, L. A, CHALDE, T, ELISIO, M, STRÜSSMANN, C. A. 2013. Effects of global warming on fish reproductive endocrine axis, with special emphasis in pejerrey Odontesthes bonariensis. . Gen Comp Endocr. 192: 45-54.

MUNZ, H, STUMPF, W. E, JENNES, L. 1981. LHRH systems in the brain of platyfish. Brain Res. 221: 1-13. 
MYLONAS, C. C, ZOHAR, Y. 2001. Use of GnRHa - delivery system for the control of reproduction in fish. Rev Fish Biol Fisher. 10: 463-491.

OKUBO, K, NAGAHAMA, Y. 2008. Structural and functional evolution of gonadotropinreleasing hormone in vertebrates. Acta Physiol, 193: 3-15.

PARHAR, I. S, IWATA, M, PFAFF, D. W, FUKUDA, M. 1995. Embryonic development of gonadotropin-releasing hormone neurons in the sockeye salmon. J Comp Neurol. 362: 256-270.

PANDOLFI, M, MUÑOZ-CUETO, J. A, LO NOSTRO, F. L, DOWNS, J. L, PAZ, D. A, MAGGESE, M. C, URBANSKI, H. F. 2005. GnRH systems of Cichlasoma dimerus (Perciformes, Cichlidae) revisited: a localization study with antibodies and riboprobes to GnRH-associated peptides. Cell and Tissue Res. 321: 219-232.

SHERWOOD, N., L. EIDEN, M. BROWNSTEIN, J. SPIESS, J. RIVIER, AND W. VALE, 1983. Characterization of a teleost gonadotropin-releasing hormone. Proc. Natl. Acad. Sci. USA 80: 2794-2798.

SHERWOOD, N. M., ADAMS, B. A. 2005. Gonadrotopin-releasing hormone in fish: evolution, expression and regulation of the GnRH gene. In: SHERWOOD N. M., MELAMED, P. (Eds). Hormone and their receptor in fish reproduction. Mol. Aspec. Fish. Mar. Biol. Pp. 1-39.

YAMAMOTO, N, OKA, Y, AMANO, M, AINDA, K, HASEGAWA, Y, KAWASHIMA, S. 1995. Multiple gonadotropin-releasing hormone (GnRH)-imunoreactive system in the brain of the dwarf-gourami, Colisa lalia: Immunohistochemistry and radioimmunoassay. J Comp Neurol. 355:354-368.

YAMAMOTO, N. 2003. Three gonadotropin-releasing hormone neural groups with special reference to teleosts. Anat Sci Int. 78: 139-155.

ZANDBEGEN , M.A, KAH, O, BORGED, J, PEUTE, J, GOOS, H.J, 1995. Expression and distribution of two gonadotropin-release hormone in the catfish brain. Neuroendocrinol. 62: $571-578$.

ZOHAR, Y, MUÑOZ-CUETO, J. A, ELIZUR, A, KAH, O. 2010. Neuroendocrinology of the reproduction in teleosts fish. Gen Comp Endocr. 165(3): 438-55. 


\section{FINAL}

CONSIDERATIONS 
As was demonstrated in the Chapter I and Chapter II, several studies were carried out so far, trying to understand the numerous roles and integrative processes involving the different brain nuclei, besides to elucidate how these nuclei are involved in the general physiology and behavior of species. In this sense, the development of neuroendocrinology in fish has been strongly supported by studies of the functional anatomy, which has the main objective to identify various regions of the brain, potentially active in the neuroendocrine regulation of pituitary functions as well as the mapping of the neural systems participating in these processes. Summarizing, this study reveals that:

(i) the gross morphology of S. parahybae brain is so similar at observed to the Order of Siluriformes fishes, which present a long olfactory tract that distance the olfactory bulb to telencephalic hemispheres, and a big cerebellum, that cover a great part of brain;

(ii) although the animals used here were juveniles, the cytoarchitecture is very similar to observed in adults from the same species and adult of another catfish species;

(iii) it was possible to performing a complete Atlas of brain of catfish and even to test the results of this Atlas in a neuroendocrine experiment in this species, being able to mapping precisely the brain area studied;

(iv) besides to serve for the future studies in S. parahybae, mainly about its reproductive physiology and conservation, this Atlas serves as a valuable tool for different fields, as neuroendocrinology, neurophysiology and comparative neuroanatomy. 
ACKNOWLEDGEMENTS 
\ão menos importante que as demais subdivisões que compõem este trabalho, em meu ponto de vista, o item Agradecimentos representa uma parcela fundamental nesta dissertação. Antes, como já é notório, quero dizer que a presente dissertação foi compartimentalizada de modo a perder de vista seus itens e subitens porque, ou eu escolhi algo que fosse complexo, ou algo complexo me escolheu por saber que só um complexo entenderia o outro. Enfim, optei por compartimentalizar também os meus agradecimentos, decidindo fazê-los em duas etapas: $1^{a}$ ) Agradecimentos Formais $e 2^{a}$ ) Agradecimentos Informais. Porém, antes de iniciar qualquer subdivisão, agradeço ao meu Deus, toda e qualquer causa $e$ circunstância pela qual eu passei, e comigo a Sua presença. Presença que se manifestou, e manifesta-se, com as mais variadas combinações entre o possível e impossível, o pensar e agir, o querer e conseguir, além das conquistas em minha vida. Somente a Ele devo minhas prestações do chamado viver.

\section{AGRADECIMENTOS FORMAIS}

\section{Agradeço:}

- À Professora Dra. Andreia Maria Garrido dos Santos apresentar-me aos professores da Universidade de São Paulo;

- À Professora Dra. Renata Guimarães Moreira-Whitton aceitar-me em seu laboratório (LAMEROA - Laboratório de Metabolismo e Reprodução de Organismos Aquáticos), dando-me a oportunidade que, de fato, é impagável;

○ À Universidade de São Paulo permitir o meu ingresso ainda na graduação, para a realização da Iniciação Científica e, posteriormente, o presente Mestrado;

○ Ao Instituto de Biociências da Universidade de São Paulo e toda a sua qualificada Equipe de Funcionários, a qual pronta e eficientemente atenderam-me, sempre com sorrisos e providências;

○ À renomada e exigente Fundação de Amparo à Pesquisa do Estado de São Paulo (FAPESP) conceder-me as Bolsas de Estudos que, sem dúvida, viabilizaram este trabalho, cujos números e títulos dos processos oferecidos são: 
- Processo 2012/14115-1: Bolsa Regular no País: Atlas do cérebro do Catfish Steindachneridion parahybae: Um estudo citoarquitetônico detalhado das diferentes áreas e núcleos encefálicos como a base para ulteriores estudos morfológicos e funcionais.

- Processo 2013/25879-5: Bolsa de Estágio e Pesquisa no Exterior (Espanha): Atlas do cérebro do Catfish - Steindachneridion parahybae: Um estudo citoarquitetônico detalhado das diferentes áreas e núcleos encefálicos como a base para ulteriores estudos morfológicos e funcionais.

- Ao Dr. Renato Massaaki Honji introduzir-me às rotinas histológicas básicas de um laboratório, bem como a fascinante área de estudos do $\mathrm{GnRH}$;

○ À Companhia Energética de São Paulo (CESP) ceder os animais para o presente estudo;

○ À Universidad de Cádiz, na Espanha, aceitar a realização do trabalho em um de seus laboratórios;

- Ao Professor Catedrático Dr. José Antonio Muñoz-Cueto aceitar ser colaborador deste trabalho e pacientemente me ensinar tudo o que sei sobre atlas do cérebro de peixes.

- Finalmente, à Banca Avaliadora gentilmente aceitar o convite para participar do julgamento deste trabalho. 


\section{AGRADECIMENTOS INFORMAIS}

Sem as palavras adequadas, ou com expressividade suficiente - já que as mesmas não são facilmente encontradas - agradeço aos meus pais (Crispiniano Medrado e Marinalva Teles Medrado) o carinho, apoio e o entusiasmo demonstrado a mim durante o período do meu Mestrado, além, claro, durante toda a minha vida. Talvez, por ver o filho sempre saindo para fazer as chamadas coletas e até mesmo viagens mais longas, tenha sido motivo de orgulho e os fizeram pensar "como meu filho trabalha bastante!”. Mas certo é que, mesmo sem fazer ideia do que se tratava o meu trabalho, sempre me apoiaram; pelo menos nunca me fizeram aquela famosa pergunta "quando você procurará um emprego?". E isso é mais que uma boa razão para afirmar que realmente acreditavam em mim. Assim, considerando que a vida me ensinou algo, os meus Pais podem ser chamados, então, de excelentes professores.

Em continuação, agradeço à minha Família (grande família) o apoio, reconhecimento e otimismo demonstrados a mim, sempre. Mencionaria um por um, mas a família é grande mesmo! E, quando digo Família, estou considerando as famílias Medrado e Martins, todos muito especiais para mim, sem os quais certamente eu não seria quem sou, como sou e para que sou!

Professora Renata, o que dizer dessa mulher? No mínimo posso dizer que foi uma verdadeira conspiração iluminada do chamado destino que, para a minha sorte, rendeu uma ótima amizade, além de muito aprendizado. Agradeço-a todas as conversas e resolução de problemas. Sabe aquele momento quando você diz "_Rê, precisamos conversar, você tem 5 minutinhos?” e, então, ela responde “_tem que ser bem rápido, porque tenho uma reunião da CCP daqui a pouco... qual a bomba?"? Pois bem, nesses momentos as bombas nunca explodiram, pelo contrário, ela sempre conseguiu controlar todas as situações, até aquelas mais complicadas. Por isso e muito mais, Rê, deixo-lhe aqui duas recomendações (não que eu seja exemplo para isso): (i) nunca deixe de ser essa pessoa que transita entre os dois mundos - profissional e pessoal - sem levar vestígios de um para o outro; (ii) seja sempre uma orientadora em Potencial e uma Amiga verdadeira, características quais considero que você tem habilidade de sobra para possuí-las.

Agradeço aos colegas, amigos e Amigos que fiz no Instituto de Biociências da USP. E da mesma maneira categórica àqueles(as) do LAMEROA. Foram muitas risadas, trocas de informações, saídas de campo, confraternizações e experiências adquiridas ao longo da PósGraduação que, com certeza, fizeram toda a diferença na construção da minha carreira. 
Assim, quero deixar meus sinceros agradecimentos àqueles(as) que, independentemente do quadrante ocupado no plano cartesiano da vida e com ele seus sinais, participaram da minha jornada:

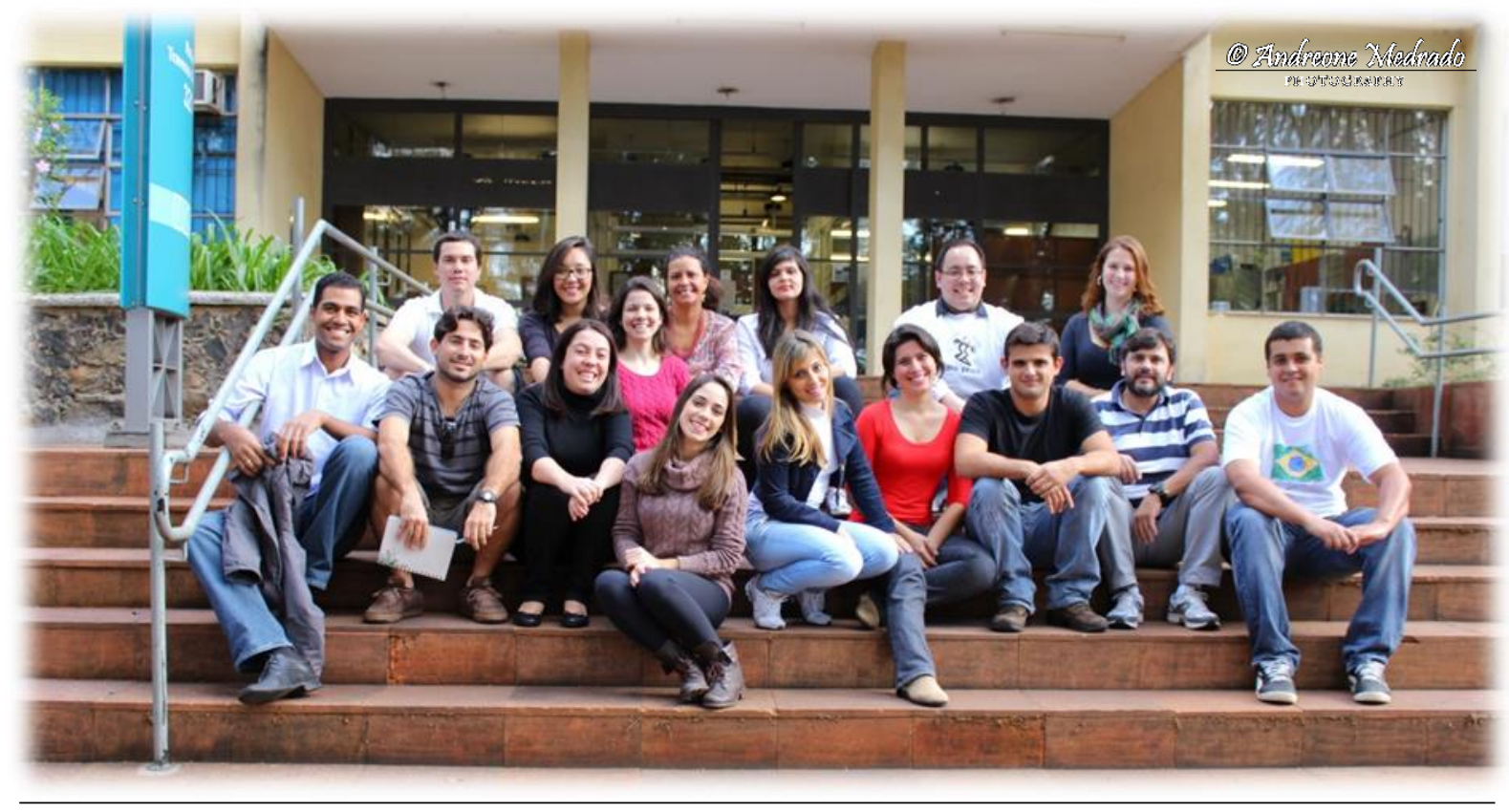

Equipe do LAMEROA (Laboratório de Metabolismo e Reprodução de Organismos Aquáticos) em frente ao Instituto de Biociência da Universidade de São Paulo - Junho de 2013. Da esquerda para a direita, na parte superior: Paulo (Jovial de Barretos), Bianca (Kidahora), Amanda ("você pode tudo"), Renata (Chefa), Walquíria (Walks), Renato Honji, Mariana (Mari). Da esquerda para a direita, na parte inferior: Eu, Jandyr (Jajá), Cristiéle (professora), Raísa (Paraguaçu), Gabriela (Gabi), Aline D'Olio (irmãzinha), Bruno (Brunão), Carlos E. Garcia (Tiboja,) e Carlos E. Tolussi (Kadu). Alguns não estão na foto: Roberta (Robs), Tiago Correia (Tiagão), Vanessa Oliveira (linhagem de Einstein), Vagner (Vagnêra ou Corintiano).

Walquíria Pedra Parreira, para começo de conversa あなたの計り知れない 貴重な友情いただきありがとうございます (muito obrigado pela sua imensa e valiosa amizade). Com certeza foi a pessoa que mais se destacou dentro da Pós-Graduação e que posso considerar uma Amiga para todas as horas. Agradeço-lhe as imensas e longas conversas sobre o famoso "ser ou não ser? Eis a questão" ... sem dizer dos momentos de devaneios filosóficos onde tentávamos buscar uma resposta para algumas questões que, por ocasião da vida, ou, talvez simplesmente por uma conspiração desvirtuada do acaso, nos fizeram provar do mesmo cálix. Um tanto amargo por sinal, mas que foi bebido como honra ao direito de viver, provando que a questão não é como os desafios se apresentam, mas como eles devem ser superados. Ademais, nada que uma boa diafanização não desse um jeito, afinal, o efeito constrangedor do xilol não é de todo um mal. Por fim, agradeço-lhe as tantas 
trocas de livros no famoso rodízio cultural, variando desde livros que exploram as várias dimensões do Universo, até àqueles narrados por uma criança de 5 anos. Valeu, Jovem!

Cintia Yamashita, minha irmã de OS, agradeço-lhe a amizade e as loooooongas conversas nos momentos de aquisição de cafeína diluída, que particularmente considero como momentos sagrados na vida de um ser humano. Além disso, agradeço-lhe as conversas sobre as fases críticas da minha dissertação, seja sobre histologia, formatação ou até mesmo sobre conduta e filosofia de vida dentro da pós-graduação. Obrigado, de coração!

Susy Mary, você leu sobre o que falei dos momentos sagrados, acima? Pois é, você é responsável por esses tais momentos. "Nem só de pão viverá o homem”; o "nem” me permite incluir o café como umas das coisas que o homem precisa para viver. Você pode não saber, mas as conversas na copa do Instituto de Biociências eram verdadeiras fugas da rotina na pós-graduação. Fuga que, na minha opinião, é fundamental para distrair a mente, além de reforçar os laços de amizade. Aproveitando, Roseli, Marcilene e Gisele, o que seria desse departamento sem vocês? Seria no mínimo chato e desorganizado. Agradeço-lhes a imensa boa vontade e agilidade em sempre me ajudar quando mais precisei. Algumas pessoas usam crachá para identificação, vocês optaram por usar, no lugar do tal, um contagiante sorriso. Que essa luz nunca se apague de vossos rostos, as pessoas precisam dela para iluminar seus caminhos. Certamente que a nossa querida Gisele não estará mais no departamento quando esses agradecimentos se tornarem públicos, mas sei que um dia eles a alcançarão, tecnologia é tudo!

Um tanto quanto difícil de fazê-lo, deixo meus agradecimentos à uma pessoa mais que especial, Luciene Di Santi. Por que difícil? Porque preciso controlar as palavras para apenas agradecê-la, do contrário, serias inúmeras linhas escritas, que em soma formariam um livro. A ela agradeço toda a compreensão dada a um estudante de pós-graduação que, como todos aqueles que passaram por isso, teve seus horários condenados à irregularidade, com os dias da semana transformados todos em apenas um, com os sábados, domingos e feriados transformados em prolongamentos das "-feiras", mas tudo isso, no meu caso, por uma justa causa: alimentar os filhotes de surubim! Observemos, aqui, que estou considerando a minha presença como algo importante para ela (se posso escolher no que acreditar, assim será). Um evento demonstrou o quanto fui sortudo em tê-la ao meu lado como uma verdadeira companheira e ajudadora e, ainda, ouso em dizer que poucas aceitariam essa situação da mesma forma. Refiro-me a uma viagem que fiz à Argentina, em 2013. Resumidamente, meu casamento ocorreu em 20 de Julho, no entanto, no dia seguinte eu estava embarcando em um avião com destino à Argentina, para participar de um curso da 
pós-graduação, com duração de 10 dias. Mas, o detalhe que a faz campeã no apoio e compreensão é que eu viajei sozinho. Não existem palavras para agradecê-la por todo o amor e carinho, por isso apenas digo: Obrigado por existir! Principalmente, por existir na minha vida!

\section{¡Ahora, en Español!}

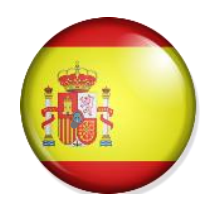

Gran José Antonio Muñoz-Cueto (Chiqui), te agradezco por recibirme en tu laboratorio como si fuéramos conocidos desde hace muchos años. Te estoy agradecido por enseñarme lo más complejo que hay y, a veces, poco comprendido en peces, el cerebro. Ahora sí que yo puedo decir algo sobre ese universo tan especial de estos animales. ¿Y qué decirte de todo el tiempo que te has quedado junto a mí en el microscopio? Seguro que no hemos mirado menos que 400 portas, y además, una seguida de la otra, como mínimo 50 veces... i¡iDios, qué pasada, qué pesado, pero que guay!!! (jajaja). Eres, sin duda, un profesor que tiene la preocupación de que el estudiante entienda de verdad lo que le estás enseñando. Dios, hasta ahora no sé explicar cómo alguien con tantas cosas que hacer puede haberse quedado tanto tiempo ayudándome en el microscopio... muchas veces hasta las $21 \mathrm{~h}$. Gracias por ser mi colaborador de la tesis y por su corrección, pues yo sé que es algo demasiado denso, y a veces pesado. ¡Claro!, no puedo olvidarme de agradecerte lo por las conversaciones en la cafetería. Por los consejos y por todo que me has ayudado en España. Por supuesto no lo considero sólo por profesor, sino también amigo. Siempre estaremos en contacto, hablando de algo. ¡Gracias por todo!

Quiero sin duda, dejar mis agradecimientos a las personas maravillosas del laboratorio de Chiqui: José Antonio (Tote, o Doctor House) - un verdadero investigador, muy inteligente, e muy amigo, pero deje de decir las palabrotas... jejeje; Patrícia Herrera (la Súper Madre) - eres una persona con mucho Brillo, que indudablemente has traído aún más brillo al mundo, ese brillo se llama Álvaro, la estrellita de Sanlúcar, mi sobrino guapísimo; 
Águeda Jimena (la enemiga del reloj) - independientemente del horario, a veces atrasada, siempre está lista para ayudar en todo que puede. Eres fantástica, muy amiga (aunque dices muchas veces la palabra “joder”... jajaja). Para ella, todos los días son de alegría, y las personas que están a su alrededor tienen la suerte de alegrarse también; Mairi - fue un verdadero placer conocerla, hemos hablado siempre de todo lo que se pueda pensar. Unas veces hablábamos en inglés, otras en español, pero la verdad es que siempre estábamos hablando. Hay una cosa en Mairi que algunas personas en el mundo actual no tienen, o, si lo tienen, esconden dentro de sí mismos: la sonrisa. De verdad, siempre, siempre y siempre, ella tenía una sonrisa para compartir con todos; Alba, mi hermana (hermanita)! ¡Una gran amiga y compi de piso! Fueron seis meses en su casa, donde aprendí muchas cosas en español que sin duda, me ayudaron en mi estancia allí. Además del español, aprendí muchas cosas con ella, pero la más terrible de todas fue el camino al Carrefour. Dios, nunca en mi vida olvidaré eso. ¡Allí es una pasada! ¡Alba eres fantástica, muchísimas gracias por su paciencia!!!

Dejo ahora un "molto forte abbraccio" a las chicas italianas más especiales: Contanza, Illaria, Sarah. Si alguna vez tengo que describir a la gente de Italia, y estas son mi referencia, he de decirquel@s italian@s son fantástic@s. Muchas gracias por haber conocido a cada una de mis sorellas!

Finalmente yo agradezco a las dos personas más especiales que conocí en España: Juan Juiz, siempre juntos nosotros bajábamos a la cafetería a desayunar (yo echo de menos a las napolitanas de jamón y queso), almorzar o a tomar un cafelito por la tarde. JU-ONE, es mi verdadero amigo en España, hasta hoy! ¿Quizás él pueda leer lo que escribo aquí! Y Maria, no tengo palabras para escribirte cuanto eres especial. En tu coche hemos conocido todo Cádiz, siempre yo, ella e Ju-One. ;Salimos muchas veces a tomar fotos, y siempre riendo mucho! Pero, también agradezco a Maria por las grandes ayudas en el laboratorio, al criostato e todo lo demás. ;Muchas gracias mi Súper Hermana!

Obrigado!

¡Gracias!

Thanks!, 
